NBSIR 77-1239

\title{
Workshop on Applications of Phase Diagrams in Metallurgy and Ceramics
}

L. H. Bennett and G. C. Carter

Institute for Materials Research

National Bureau of Standards

Washington, D.C. 20234

April, 1977

Summary Report

\section{Prepared for}

National Science Foundation

Defense Advanced Research Projects Agency

Office of Naval Research

National Aeronautics and Space Administration

- IV Research and Development Administration

QC Army Research Office

100

.U56

77-1239

1977 



\section{WORKSHOP ON APPLICATIONS OF PHASE DIAGRAMS IN METALLURGY AND CERAMICS}

L. H. Bennett and G. C. Carter

Institute for Materials Research National Bureau of Standards

Washington, D.C. 20234

April, 1977

Summary Report

Prepared for

National Science Foundation

Defense Advanced Research Projects Agency

Office of Naval Research

National Aeronautics and Space Administration

Energy Research and Development Administration

U.S. Army Research Office

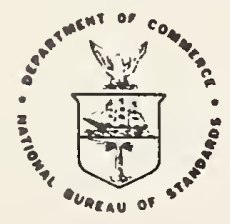

U.S. DEPARTMENT OF COMMERCE, Juanita M. Kreps, Secretary

Dr. Sidney Harman, Under Secretary

Jordan J. Baruch, Assistant Secretary for Science and Technology

NATIONAL BUREAU OF STANDARDS, Ernest Ambler, Acting Director 



\section{PLIASE DIAGRAMS IN METAILURGY AND CERAMICS}

\section{Table of Contents}

1. Overview of the Workshop

1.1 Introduction ..................... I

1.2 Goals ........................ I

1.3 Sumary of the Progran . . . . . . . . . . . . 2

1.4 Denonstrations and Films ............. 3

1.5 Proceedings ................... 4

2. Poster Board Design and Layout . . . . . . . . . . . . . 5

3. List of Registrants . . . . . . . . . . . . . . . 8

4. Workshop Contents . . . . . . . . . . . . . . . . 17

4.1 Program . . . . . . . . . . . . . . . . 18

4.2 Abstracts .................... 37

4.3 Index to Abstracts .................. 225

5. Informal Program for Phase Diagram Data Center

Representatives . . . . . . . . . . . . . . . . . 227

6. Organizing Comittee . . . . . . . . . . . . . . . . . 229 



\section{PHASE DIAGRAMS IN METALLURGY AND CERAMICS}

1. Overview of the Workshop

\subsection{Introduction}

A material's phase, depends on its temperature, composition, pressure, and other thermodynamic variables. This relation is most commonly presented graphically in phase diagrams, which have become indispensable to metallurgists, ceramists, geochemists, materials engineers and solid state chemists and physicists. Knowledge of the structure of materials is important in understanding several industrially significant phenomena and applications such as aging, hardness, occurrence of brittle intermetallic compounds, magnetic transition temperatures, high-temperature solubility of impurities, corrosion resistance, solid electrolytes and non-crystalline solids. The study of a phase diagram appropriate to a particular material can often provide information important to its scientific and technical application.

The list of the workshop registrants (section 3 ) exhibits wide participation from industry, government, and universities. International participation was particularly successful among the data evaluation groups including important presentations from the Soviet Union, Germany, France, the UK, Japan, and Canada. Other countries were represented; experimentalists and theorists determining phase diagrams were among the participants, as were a substantial fraction of phase diagram users from industry.

The workshop was organized by the Alloy Data Center and the group compiling "Phase Diagrams for Ceramists", and supported internally by the Institute for Materials Research and the Office of Standard Reference Data, National Bureau of Standards.

\subsection{Goals}

The workshop goals were:

1. to assess the current national and international status of phase diagram determinations and evaluations for alloys, ceramics and semiconductors. 
2. to determine the needs and priorities, especially technological, for phase diagram determinations and evaluations, and

3. to estimate the resources being used and potentially available for phase diagram evaluation.

Specific subjects of investigation were:

...to identify resources being expended that could be made more useful by appropriate coordination,

...to recognize unnecessarily overlapping efforts in determining phase diagrams,

...to suggest areas of international cooperation,

...to gauge the relative importance of depth of coverage and range of materials including factors such as a) high precision, b) metastable phases, c) binary and higher order systems, d) magnetic, metal nonmetal and other phase transitions, e) high pressure data, f) integration of collateral information, and $g$ ) the role of impurities or trace additions, ...to determine current awareness needs, ...to review the strengths and limitations of various experimental techniques for determining phase diagrams, ...to briefly survey the status and merits of various predictive methods (CAIPHAD, PHACOMP, psedupotential, etc.), ...to discuss diverse presentation methods, and ...to discuss effective and alternative means for dissemination of phase diagram data.

\subsection{Sumary of Program}

The workshop program (detailed in Section 4) was designed to stimulate interactions between (i) phase diagram data providers and users, (ii) metallurgists, geochemists, thermochemists, ceramists, solid state chemists, and physicists, and other experimentalists, (iii) representatives from industry, government, and the academia, (iv) phase diagram data centers from many countries (see section 5 for informal program held in addition for this latter group).

Plenary lectures introduced the subjects of present status of data availability from reference books, data centers and computerized files, the status of experimental data and theory of alloy phases. A panel on computation and prediction gave a more thorough introduction to that subject, and short reviews introduced the subjects of phase diagram representations and methods of distribution. Poster sessions followed these introductions, and extremely lively participation 
by all ensued. The success of these interactive poster sessions was the result of both the stimulating introductory sessions and a new design of poster board arrangement (section 2).

Four on-line demonstrations of computer-data handing systems related to phase diagrams were held in the poster session, while short instructional movies were shown in the neighboring auditorium (see section 1.4 for listing). Three panels addressed the subjects of user's needs for phase diagram data, with strong participation from the industrial sector. Discussion covered needs for multicomponent diagrams (up to 9 or 10 components) for industrial applications, as evident from the panel members, whereas voices from the audience enphasized needs for less complex systems, down to binary equilibrium diagrams, for various $R \& D$ programs.

\subsection{Demonstrations and Films}

Four demonstrations and a small film were held during the poster sessions in the same lounge with the posters. Two series of short films were shown in the auditorium, one during each poster session.

\section{Summary of Demonstrations and Films}

On-Line Computer Manipulations

J. Hilsenrath, B. B. Molino

Office of Standard Reference Data

National Bureau of Standards

Washington, D.C.

Alloy Data Center Graphical

Methods

R. A. Kirsch

Institute for Basic Standards

and

I. J. Swartzendurber

Institute for Materials Research

National Bureau of Standards

Washington, D.C.

MTDATA On-Line Thermochemical

Calculations

L. Kaufman

ManLabs, Inc.

Cambridge, MA

An On-Line Demonstration of a

Computerized Canadian Thermodynamic

Data Bank

A. D. Pelton

Dept. de Genie Metallurgique

Ecole Polytechnique

Universite de Montreal

Montreal, Canada

and (shown in conjunction with poster MPSI-7)

(shown in conjunction with poster MPSI-8)

(shown in conjunction with poster TPSI-11)

(shown in conjunction with poster TPSI-16) 
W. T. Thompson

Dept. of Metallurgical and Mining

Engineering

McGill University

Montreal, Canada

A Short Film Illustrating some Examples on the

Calculations of Phase Diagrams

I. Ansara

Thermochemical Data Center

Laboratoire de Thermodynamique

et Physico-Chimie Metallurgiques

Grenoble, France

Four Short Instructional Movies

Contributed by $\mathrm{H}$. Mckinstry

$$
\begin{aligned}
& \text { Materials Research Laboratory } \\
& \text { Pennsylvania State University } \\
& \text { University Park, PA }
\end{aligned}
$$

Produced at Pennsylvania State University; sponsored by NSF

Two Instructional Movies

Contributed by C.H.P. Lupis

Carnegie Mellon University

Produced at CMU, sponsored by NSF

\subsection{Proceedings}

A Proceedings of the workshop will be published as an NBS Special Publication. It will contain all. the full papers presented, plus a number of comments and a summary of the workshop. The requisite number of copies will be forwarded to the sponsoring organizations. Aditional copies will be available from the Superintendent of Documents, U.S. Government Printing Office, Washington, D.C. 20402, under the title Proceedings of the Workshop on Applications of Phase Diagrams in Metallurgy and Ceramics. 


\section{Poster Board Design and Layout}

Poster "tripod" stations were designed to allow some shielding from neighboring presentations. This basic idea was taken from poster sessions given at Uppsala, Sweden at the 1976 "Solid Compounds of Transition Elements" conference, and improved stations were designed at NBS (see Fig. 1), with large, high boards. This layout allows for three poster presentations, isolated from each other, per tripod center. Each such poster presentation can use two $4^{\prime} \times 5^{\prime}$ boards at an angle of $120^{\circ}$ from each other, allowing ample space for the presentations. A shelf was designed in front of the right panel, which hinges at the board and a loose wooden stik to support the shelf if the author wishes to use it. This shelf was designed somewhat higher than an ordinary table would be. This was useful to most, but maybe some would have preferred it a little lower.

The sessions were held in a carpeted lounge, which helped reduce noise levels. Participation was larger than anticipated, allowing for only few chair and table arrangements for additional discussions on the side. Several small coffee centers were set in the lounge, during the poster sessions, obviously adding to the liveliness of the sessions, and also helping to keep the group from wandering off. Fig. 2 shows the layout of the lounge for Tuesday afternoon's poster session.

After the first hour of each poster session we suggested that poster authors could take a break and see some of the other posters, or to switch coauthors at a poster where there are more than one author. This helps minimize the problem that poster authors are not mobile to see other posters in their own session. 


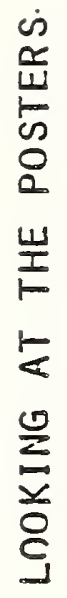

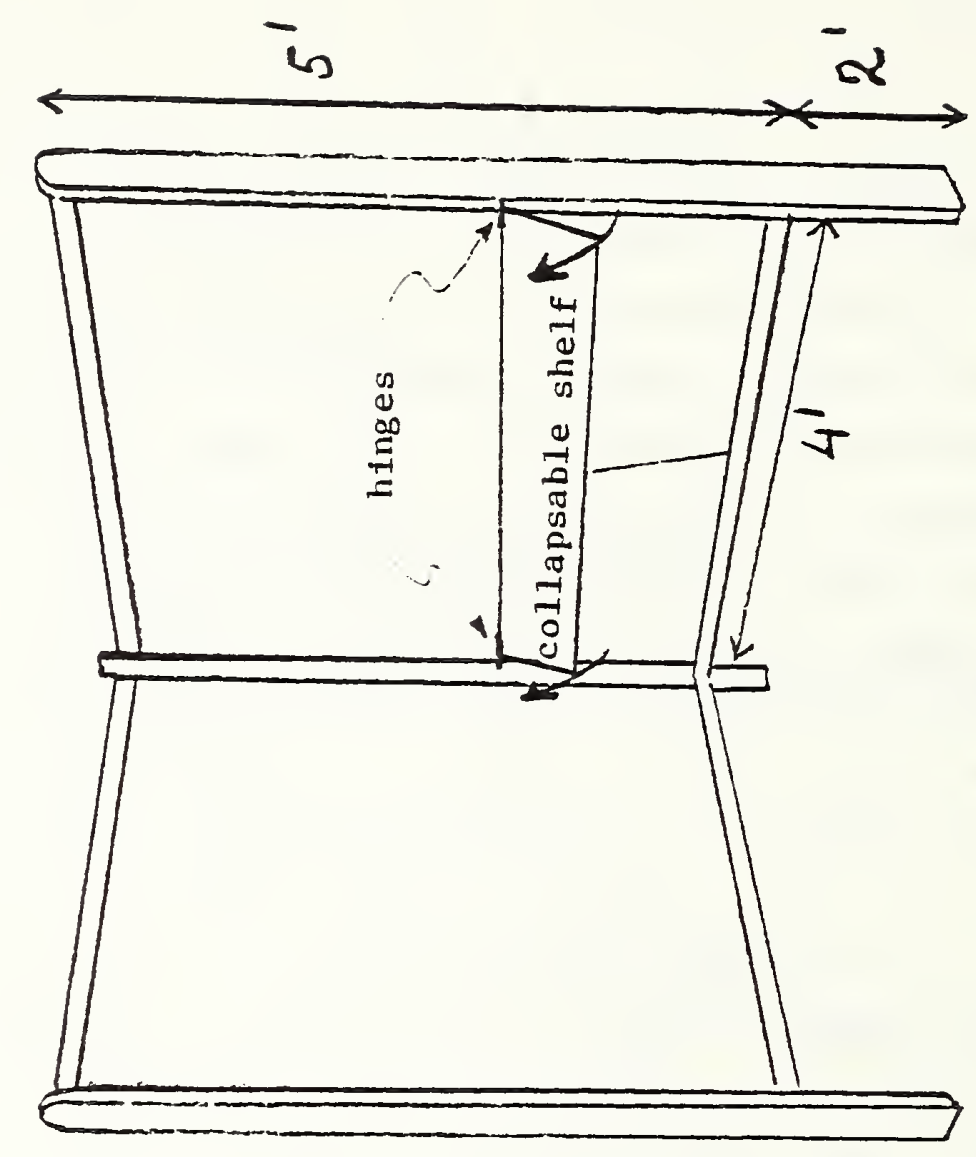

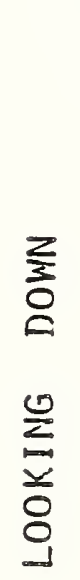

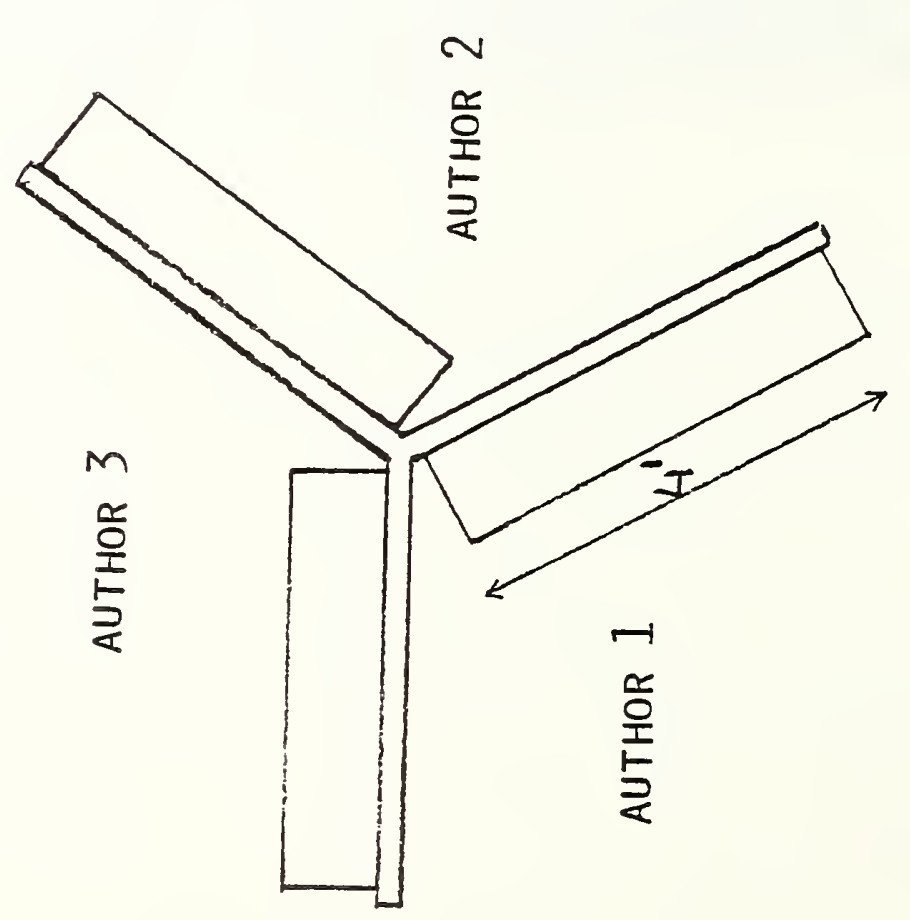

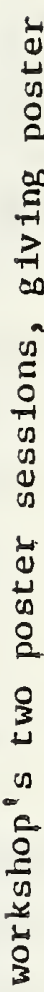

$\stackrel{4}{0}$

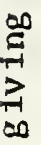

I 


\section{EMPLOYEES LOUNGE}

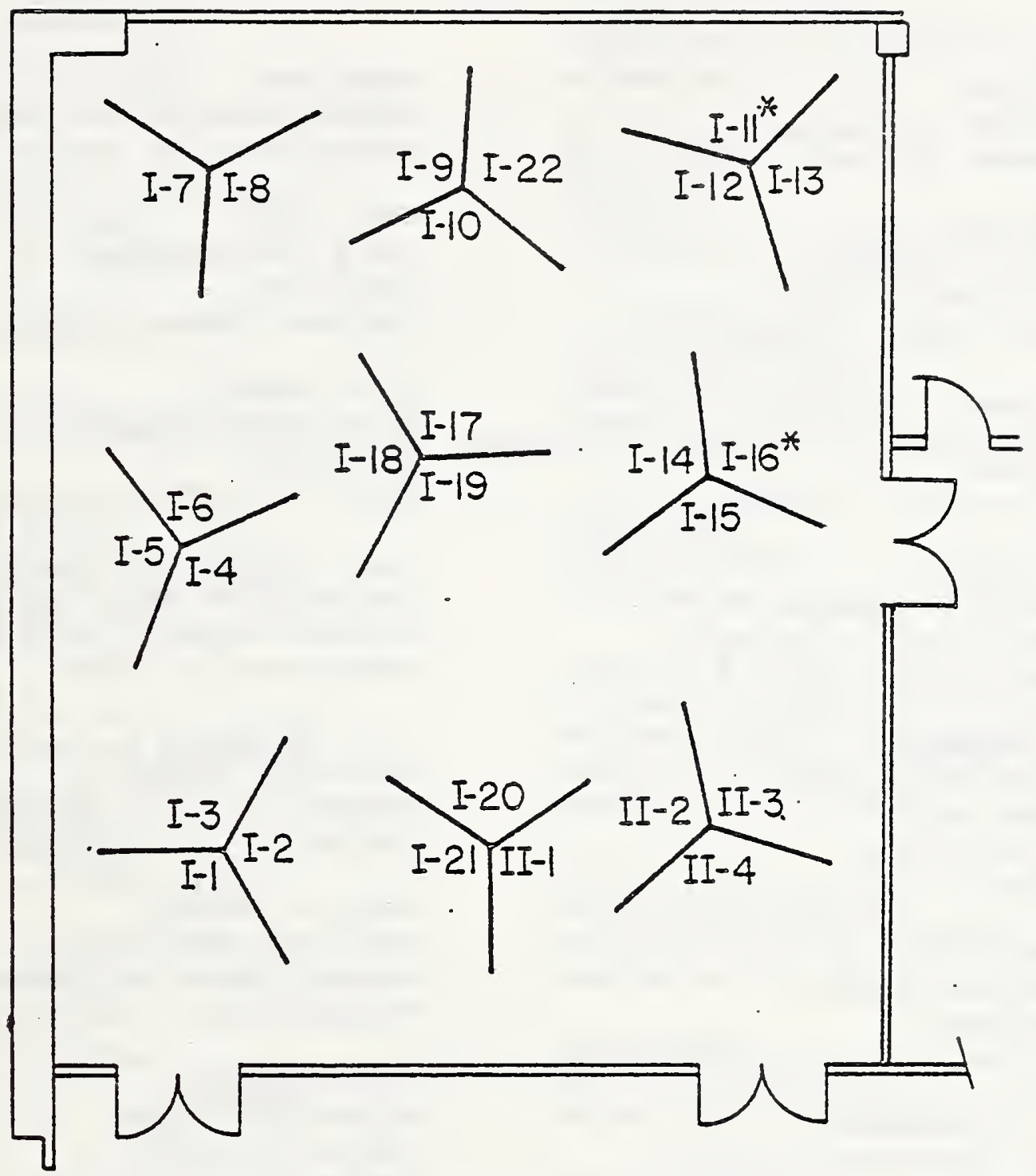

ENTRANCE

ENTRANCE

\section{POSTER SESSIONS \\ TUESDAY, JANUARY $\|, 1977$ \\ 3:30-6:00 p.m.}

\section{*DEMONSTRATION}

FIG. 2. Layout of the poster tripod stations for the Tuesday afternoan (1I Jan) poster session, indicating location of each poster paper. Small coffee stations were placed along the walls. 
3. List of Registrants

Nazir Ahmad

University of Birmingham

Birmingham, England

Frank Ajersch

Ecole Polytechnique

C.P. 6079 Succ. "A" .

Montreal, Quebec H2V-2W8

I. Aldinger

Max-Planck-Institut Fir Metallforschung

Busnauerstr. 175

D-7000 Stuttgart, W. Germany

Ernest Ambler

Office of the Director

National Bureau of Standards

Washington, DC 20234

Paul R. Ammann

Kennecott Copper Corp.

Ledgemont Lab

128 Spring Street

Lexington, MA 02173

I. Ansara

Domaine Universitaire

B.P. 44-38401

St. Martin-d'Heres, France

George T. Armstrong

Physical Chemistry Division

National Bureau of Standards

Washington, DC 20234

N. Ault

Norton Co.

Worcester, MA

Donald M. Bailey

Iowa State University

130 Metallurgy Bldg.

Ames, IA 50011
Hugh Baker

American Society for Metals

Metals Park, OH 44073

Chris Bale

Ecole Polytechnique

C.P. 6079

Montreal, Quebec H3C3A7

S. K. Banerji

Foote Mineral Company

Route 100

Exton, PA 19341

Ian R. Bartky

Institute for Materials Research

National Bureau of Standards

Washington, DC 20234

C. J. Bechtoldt

Metallurgy Division

National Bureau of Standards

Washington, DC 20234

Larry $\mathrm{H}$. Bennett

Metallurgy Division

National Bureau of Standards

Washington, DC 20234

Milton Blander

Argonne Nat'l Lab

9700 S. Cass Ave.

Argonne, IL 60439

John H. Blanks

Pennsylvania State University

271 Mat. Res. Lab.

University Park, PA 16802

Edward L. Brady

Office of Information Programs

National Bureau of Standards

Washington, DC 20234 
Robert F. Brebrick

Marquette University

1515 W. Wisconsin Ave.

Milwaukee, WI 53233

Leo Brewer

Lawrence Berkeley Laboratory

Univ. of California

Berkeley, CA 94720

Jesse J. Brown, Jr.

VPI \& SU

302 Holden Hall

Blacksburg, VA 24061

Daniel Butrymowicz

Metallurgy Division

National Bureau of Standards

Washington, DC 20234

J. W. Cahn

Metallurgy Division

National Bureau of Standards

Washington, DC 20234

Thomas B. Cameron

University of Connecticut

$\mathrm{U}-136$

Storrs, CT 06268

Cynthia Carter

Metallurgy Division

National Bureau of Standards

Washington, DC 20234

Forrest L. Carter

Naval Research Laboratory

Code 6132

Washington, DC 20034

Y. Austin Chang

College of Engineering

University of Wisconsin-Milwaukee

Milwaukee, WI 53201

James R. Chelikowsky

Bell Labs

600 Mountain Ave.

Murry Hill, NJ 07974
U. V. Choudary

College of Engineering

University of Wisconsin-M1lwaukee

Milwaukee, WI 53201

G. W. Cleek

Consultant

5512 N. 24th St.

Arlington, VA 22205

W. Dale Compton

Ford Motor Company

20000 Rotunda Drive

Dearborn, MI 48124

Bruce R. Conard

INCO, Ltd.

Sheridan Park

Mississauga, Ontario, Canada

Lawrence P. Cook

Inorganic Materials Division

National Bureau of Standards

Room B214, Materials Bullding

Washingeon, DC 20234

S. R. Coriell

Metallurgy Division

National Bureau of Standards

Washington, DC 20234.

Joseph Cox

Watervliet Arsenal

Watervliet, NY 12189

John R. Cuthill

Metallurgy Division

National Bureau of Standards

Washington, DC 20234

Amit DasGupta

Oak Ridge National Lab

Oak Ridge, TN 37830

Didier de Fontaine

University of California

6532 Boelter Hall

Los Angeles, CA 90024

Peter R. Debruyn

Industrial Liaison

National Bureau of Standards

Washington, DC 20234 
Joseph E. Davison

Univ. of Dayton

300 'College Park

Dayton, OH 45469

R. C. Devries

General Electric

General Electric R \& D Center $\mathrm{K}-1$

Schenectady, NY 12345

R. L. Dreshfield

Materials Processing and Joining Section NASA Lewis Research Center

Cleveland, $\mathrm{OH}$

\section{J. Elliott}

Department of Metallurgy \& Metals MIT

Cambridge, MA 02139

S. G. Epstein

Aluminum Association

New York, NY

Maria-Luise Fiedler

North Carolina State Unfversity

Raleigh, NC 27607

H. Alan Fine

University of Arizona

Dept. of Met. Eng.

Tucson, AZ 85721

Gerhard R. Fischer

Corning Glass Works

$\mathrm{SP}, \mathrm{FR} 1$

Corning, NY 14830

Julius Fister

Metals Research Laboratories

Olin Corp.

91 Shelton Ave.

New Haven, CT 06504

Sherman P. Fivozinsky

Office of Standard Reference Data

National Bureau of Standards

Washington, DC 20234

René Flukiger

Dept. Phys. Mat. Cond.

32, Bd. d'Yvoy

Geneva, Switzerland

Paul Fopiano

Watertown Arsenal

Arsenal Street

Watertown, MA 02172
Patrick K. Gallagher

Bell Laboratories

Rm. 6D - 311

Murray Hill, NJ 07974

B. C. Giessen

Department of Chemistry \&

Mechanical Engineering

Northwestern University

Boston, MA

F. P. Glasser

University of Aberdeen

old Aberdeen

Scotland, UK AB9 ZUE

Joseph I. Goldstein

Lehigh University

Bethlehem, PA 18015

J. Ronald Gonterman

Owens/Corning Fiberglas

Technical Center

Granville, OH 43023

Chuck Greskovich

General Electric Co. $\mathrm{K}-1$, 3C12, P.0. Box 8

Schenectady, NY 12301

K. A. Gschneidner, Jr.

Rare Earth Information Center

Iowa State University

Ames, IA

John L. Haas, Jr.

U.S. Geological Survey

National Center, Stop 959

Reston, VA 22092

David Hansen

Ballistics Research Laboratory

Aberdeen, MD 21005

Ernst-Theo Henig

Max-Planck-Institut für Werkstoffwissensch

Buesnauerstr. 175

D-7000 Stuttgart-80, Germany

Keith A. Hill

Carpenter Technology Corporation

P.0. Box 662

Reading, PA 19603 
J. Hilsenrath

National Bureau of Standards

Washington, DC 20234

Michael Hoch

University of Cincinnati

Location 12

Cincinnati, OH 45221

John D. Holder

Oak Ridge National Laboratory

Box X, 4500S S280

Oak Ridge, TN 37830

Emanuel Horowitz

Institute for Materials Research National Bureau of Standards

Washington, DC 20234

R. A. Howald

Chemistry Dept.

Montana State University

Bozeman, MT

Chen-Chao Hsu

Argonne National Laboratory

9700 S. Cass Ave.

Argonne, IL 60439

David Dew-Hughes

Brookhaven National Laboratory

Bullding 480

Upton, NY 11973

F. A. Hummel

Pennsylvania State University

Room 214 M.I. Bldg.

University Park, PA 16802

M. R. Jackson

General Electric Co.

CRD, K-1 223 Met

Schenectady, NY 12309

R. I. Jaffee

Electric Power Research Institute

Palo Alto, CA

Ronald B. Johnson

Institute for Materials Research

National Bureau of Standards

Washington, DC 20234
Daniel J. Kahan

Metallurgy Division

National Bureau of Standards

Washington, DC 20234

Larry Kaufman

Manlabs Inc.

21 Erie St.

Cambridge, MA 02146

B. H. Kear

Pratt and Whitney

Materials Engineering \&

Research Lab

E. Hartford, $\mathrm{CT}$

S. E. Khalafalla

Dept. of the Interior

P.0. Box 1660

Twin Cities, MN 55111

R. Kikuchi

Hughes Research Laboratories 3011 Malibu Canyon Road

Malibu, CA 90265

R. Kirsch

Applied Mathematics Division National Bureau of Standards Washington, DC 20234

0. J. Kleppa

The James Franck Institute

University of Chicago

Chicago, II

Michael J. Koczak

Drexel University

Dept. of Materials Englneering

Philadelphia, PA 19104

Tamara Kolesnikova

Academy of Sciences of the USSR

Baltijskaya ul., 14

Moscow, USSR

Ram Kossowsky

Westinghouse Research Laboratories 1310 Beulah Road

Pittsburgh, PA 15235 
John Krc, Jr.

Parke, Davis \& Company

Joseph Campau at the River

Detroit, MI 48232

Eric R. Kreidler

General Electric Co.

Nela Park

Cleveland, OH 44143

A. K. Kuriakose

Norton Research Corp. (Canada) Ltd. 8001 Daly St.

Niagara Falls, Ont., Canada

R. Laudise

Materials Research

Bell Telephone Labs

Murray Hill, NJ 07974

Y. E. Lee

Union Carbide Corp. Metals Div.

4625 Royal Ave.

Niagara Falls, NY 14302

David R. Lide, Jr.

Office of Standard Reference Data

National Bureau of Standards

Washington, DC 20234

James D. Livingston

General Electric Co.

Corp. Res. \& Dev.

Schenectady, NY 12308

C. H. P. Lupis

Institute Fur Eisenhuttenkunde

Aachen, Germany

Lottie T. McClendon

Institute for Materials Research

National Bureau of Standards

Washington, DC 20234

Scott McCormick

Illinois Institute of Technology

Dept. of Metallurgical and Matls. Eng.

Chicago, IL 60616

H. Mckinstry

Materials Research Lab

Pennsylvania State University

University Park, PA
R. McNally

Ceramic Research

Corning Glass Works

Corning, $\mathrm{NY}$

Michael McNeil

National Bureau of Standards Room Al29, Technology Building

Washington, DC 20234

H. F. McMurdie

Inorganic Materials Division

National Bureau of Standards

Washington, DC 20234

Richard Magin

Nat'l Institutes of Health

9000 Rockville Pike

Bethesda, MD 20795

A. I. Malausky

Tyco Laboratories

Waltham, PA

John R. Manning

Metallurgy Division

National Bureau of Standards

Washington, DC 20234

Vincent C. Marcotte.

IBM

$\mathrm{D} / 45 \mathrm{~K} \mathrm{~B} / 300-95$

Hopewell Jen, NY 12533

Dennis Marshall

Globe-Union, Inc.

5757 N. Greenbay Ave.

Milwaukee, WI 53201

Robert F. Martin

Institute for Materials Research

National Bureau of Standards

Washington, DC 20234 
Thadeus B. Massalski

Carnegie-Mellon University

Schenley Park

Pittsburgh, PA 15213

Leo Merrill

High Pressure Data Center

5093 HBLL, Brigham Young University

Provo, UT

Peter J. Meschter

Univ. of Tennessee

Dept. Chem. \& Met. Eng.

Knoxville, TN 37919

Alan D. Mighell

Inorganic Materials Division

National Bureau of Standards

Washington, DC 20234

D. B. Minor

Inorganic Materials Division

National Bureau of Standards

Washington, DC 20234

A. P. Miodownik

University of Surrey

Guildford, UK GU2 5XH

W. G. Moffatt

General Electric Co.

1 River Road P.O. Box 8

Schenectady, NY 12301

B. J. Molino

Office of Standard Reference Data

National Bureau of Standards

Washington, DC 20234

L. F. Mondolfo

Syracuse University

Syracuse, NY 13210

John E. Morral

University of Connecticut

U-136

Storrs, CT 06268

Arnulf Muan

Penn State Univ.

118 M. S. BIdg.

University Park, PA 16802
A. Navrotsky

Chemistry Division

National Science Foundation

Washington, DC

Taki Negas

Inorganic Materials Division

National Bureau of Standards

Washington, DC 20234

T. Nishizawa

Dept. of Metallurgy, Materials

Science \& Metal Processing

Tohoku University

Japan

E. F. Osborn

Carnegie Institution of Washington

2801 Upton St., NW

Washington, DC 20008

Robert L. Parker

Metallurgy Division

National Bureau of Standards

Washington, DC 20234

P. Parish

U.S. Army Research Office

Box 12211

Research Triangle Park, NC 27709

Elio Passaglia

Institute for Materials Research

National Bureau of Standards

Washington, DC 20234

David D. Pearson

United Technologies Research Center

Silver Lane

East Hartford, CT 06108

W. B. Pearson

Faculty of Science

University of Waterloo

Waterloo, Canada

Arthur Pelton

Ecole Polytechnique

C.P. 6079

Montreal, Quebec H3C3A7

Guenter Petzow

Met-Planck-Inst. Metallforschung

Buesnauerstr 175

7000 Stuttgart 80 , W. Germany 
Sri Prakash

Union Carbide Corporation

P.O. Box 5928

Greenville, SC 29606

Svante Prochazka

$G E C R \& D$

P.O. Box 8

Schenectady, NY 11301

Alan Prince

Hirst Research Centre

East Lane, Wembly

Middlesex HA9 7PP, England

Schrade F. Radtke

International Lead-Zinc Research Org. 292 Madison Ave.

New York, NY

Dennis Readey

Division of Physical Research

ERDA

Washington, DC 20545

Curt W. Reimann

Institute for Materials Research

National Bureau of Standards

Washington, DC 20234

R. C. Reno

Dept. of Physics

University of Maryland

Baltimore, MD

Robert J. Reynik

National Science Foundation

1800 G St., NW

Washington, DC 20550

Frederick N. Rhines

University of Florida

Dept. of Mat-Sci. \& Eng.

Gainesville, FL 32611

A. D. Romig

Lehigh University

Whitaker Lab. \# 5

Bethlehem, PA 18015

Barry H. Rosof

Technology Division, Cabot Corp. 1020 Park Avenue

Kokomo, IN 46901
W. Rostoker

University of Illinols

Chicago Circle, P.O. Box 4348

Chicago, IL 60680

Robert S. Roth

Inorganic Materials Division

Room B214, Materials Building

Washington, DC 20234

William Ruff

Metallurgy Division

National Bureau of Standards

Washington, DC 20234

M. I. Saboungi

Argonne National Lab

Chemical Engineering Div.

Argonne, IL 60439

Saed Safai

Materials Sci. Dept.

SUNY at Stony Brook

Stony Brook, L. I., NY 11794

E. Salkovitz

Office of Naval Research

Arlington, VA

Gary Sandrock

International Nickel Co,

Sterling Forest

Suffern, NY 10901

L. M. Schetky

International Copper Research Assoc.

825 Third Ave.

New York, NY 10022

Coulson M. Scheuermann

NASA Lewis Research Center

21000 Brookpark Road

Cleveland, $\mathrm{OH} \quad 44135$

Fred C. Schwerer

U. S. Steel Research, MS \#98

Monroeville, PA 15146

J. E. Selle

Metals and Ceramics Div.

Oak Ridge National Lab

Oak Ridge, TN 37830 
M. Semchyshen

Research Laboratory

Climax Molybdenum Corp.

1600 Huron Pkwy.

Ann Arbor, MI 48105

Charles E. Semler

Ohio State Univ.

Refractories Research Center

2041 College Rd.

Columbus, OH 43210

Gertrude B. Sherwood

Office of Standard Reference Data

National Bureau of Standards

Washington, DC 20234

John Shyne

NSF

1800 G St., NW

Washington, DC 20550

W. C. Simons

AFOSR

BIdg. 410

Bolling AFB, DC 20332

Satish P. Singhal

State University of New York

Materials Science Dept.

Stony Brook, NY 11794

P. Slick

Bell Telephone Laboratories

Murray Hill, NJ

J. F. Smith

Iowa State University

Ames, IA 50010

J. E. Smugeresky

Sandia Labs

Div. 8312

Livermore, CA 94550

Shigeyuki Sómiya

Tokyo Institute of Technology

Ookayama, Meguro, Tokyo, 152

Tokoyo, Japan

Charles A. Sorrell

Dept. of Ceranic Engineering

Univ. of Missouri

Rolla, MI 65401
Karl E. Spear

Pennsylvania State University

Materials Research Laboratory

University Park, PA 16802

G. R. Speich

U. S. Steel, Research Labs

Monroeville, PA

G. Springer

Falconbridge Nickel Mines Ltd. 8810 Yonge Street, P.O. Box 900

Thornhill, ontario

Judith K. Stalick

Inorganic Materials Division

National Bureau of Standards

Washington, DC 20234

Kurt H. Stern

Naval Research Laboratory

Code 6130

Washington, DC 20375

C. P. Stroble

Allegheny Ludlum Steel Corp.

Research Center

Brackenridge, PA 15065

Lydon J. Swartzendruber

Metallurgy Division

National Bureau of Standards

Washington, DC 20234

J. Swisher

Energy Research \& Development Admin. Washington, DC

R. E. Thoma

Union Carbide Corporation

P.O. Box X

Oak Ridge, TN 37830

Marshall K. Thomas, Jr.

Naval Air Devel. Center (30231)

Warminster, PA 18974

William Thompson

MCGill University

Montreal, Quebec

C. Thurmond

Bell Telephone Labs

Murray Hill, NJ 07974 
H. Van Olphen

Numerical Data Advisory Board

National Research Council

2101 Constitution Avenue

Washington, DC 20418

E. C. van Reuth

DARPA

1400 Wilson Blvd.

Arlington, VA 22209

Chester J. Van Tyne

Lehigh University

Whitaker Laboratory \#5

Bethlehem, PA 18015

Francis L. Ver Snyder

Pratt \& Whitney Aircraft Group

400 Main Street

East Hartford, CT 06108

Walter E. Wahnsiedler

Alcoa Laboratories

Alcoa Technical Center

Alcoa Center, PA 15069

J. Waldman

Frankford Arsenal

Bridge \& Tacony Streets

Philadelphia, PA 19137

Chang-E. Wan

Pennsylvania State University

271 Materials Res. Lab

University Park, PA 16802

Frederick E. Wang

NSWC

Silver Spring, MD

Richard M. Waterstrat

Polymers Division

National Bureau of Standards

Washington, DC 20234

R. E. Watson

Brookhaven National Laboratory

Upton, NY 11973

Alan Webb

Naval Research Laboratory

Code 6434

Washington, DC 20375
George Wei

ORNL

P. O. Box X

Oak Ridge, TN 37830

J. H. Westbrook

General Electric Co. BIdg. 5-327

1 River Road

Schenectady, NY 12345

Howard J. White, Jr.

National Bureau of Standards

Office of Standard Reference Data

Washington, DC 20234

William B. White

The Pennsylvania State University

Materials Research Laboratory

University Park, PA 16802

Calvin S. Williams

Union Carbide Corporation

P.O. Box 5928

Greenville, SC 29606

Ray Woodriff

Roberts Hall

Montana State University

Bozeman, MT 59715

L. Richard Woodyatt

Bethlehem Steel Corp.

Homer Research Labs

Bethlehem, PA 18015

Han-II Yoo

Inorganic Materials Division

Room B214, Materials BIdg.

Washington, DC 20234

William Vincent Youdelis

Dept. Engineering Materials

University of Windsor

Windsor, Ontario N9B 3P4 
MONDAY

January 10, 1977
TUESDAY

January 11, 1977
WEDNESDAY

January 12, 1977

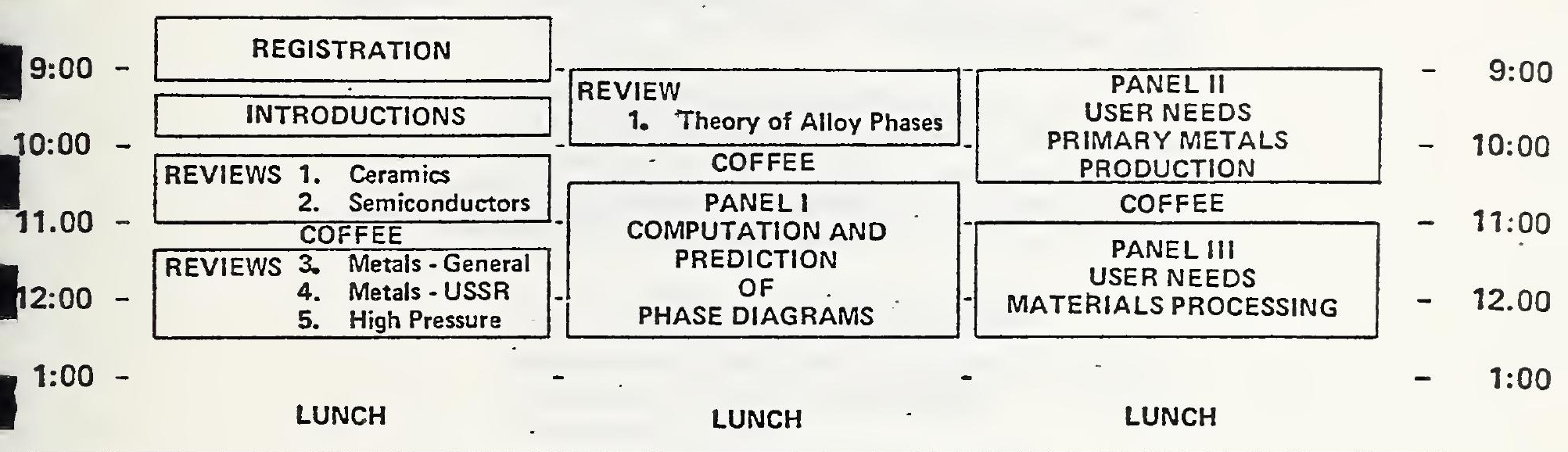

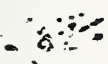

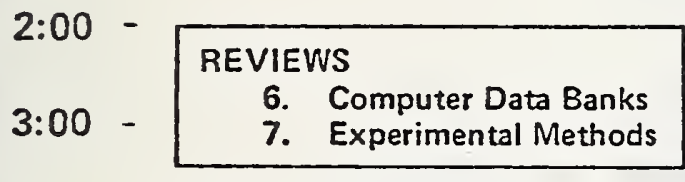

\begin{tabular}{|c|c|c|}
\hline $4: 00-$ & $\begin{array}{r}\text { COFFEE } \\
\text { POSTER S }\end{array}$ & $\begin{array}{l}\text { AND } \\
\text { ESSION }\end{array}$ \\
\hline$: 00-$ & $\begin{array}{l}\text { Phase Diagrams } \\
\text { Compilations } \\
\text { Activities }\end{array}$ & $\begin{array}{l}\text { Experimental } \\
\text { Techniques }\end{array}$ \\
\hline
\end{tabular}

$6: 00$

Buses leave NBS for Hotel

7:00 - 11:00 Informal Discussions at Hotel - Gallery Room
FORMATAND DISTRIBUTION 2. Representation of Phase Equil. 3. User's View

4. Distributor's View

5. Producer's View

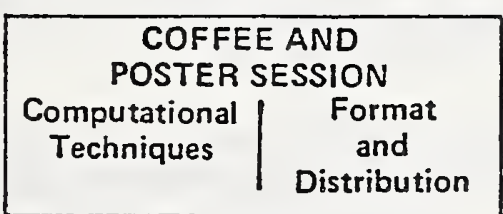

Buses leave NBS for Hotel

PANEL IV

USER NEEDS

PRODUCT APPLICATIONS

COFFEE

SUMMARY

Buses leave for Hotel, Airports

- 5:00

$-6: 00$

7:00-11:00

Reception at Hotel (7 PM)

Banquet at Hotel (8 PM) 


\subsection{Program}

The program includes surveys given by rapporteurs, and panel, tutorial, and poster presentations. There will be ample time for informal discussions among the workshop attendees.

All technical sessions will be held in the NBS Green Auditorium except the poster sessions, which will be conducted in the Employee's Lounge. Evening activities will be held at the Holiday Inn of Bethesda.

Sunday, January 9, 1977

7:00 p.m. Reception and Registration at the Holiday Inn

Monday, January 10, 1977

8:00 a.m. Buses leave hotel for NBS

$8: 30$ a.m. Registration

$9: 15 \mathrm{a} \cdot \mathrm{m}$. Welcome and Introduction (Green Auditorium)

E. Ambler, Acting Director National Bureau of Standards Washington, DC

D. R. Lide, Jr.

Office of Standard Reference Data

National Bureau of Standards Washington, DC

L. H. Bennett Alloy Physics Section Institute for Materials Research National Bureau of Standards Washington, DC

H. van 01phen Numerical Data Advisory Board National Academy of Sciences Washington, DC 
MONDAY, JANUARY 10, 1976

Morning Session (Continued)

$10: 00$ a.m. Present Status of Phase Diagrom
Compization Activities

Chairman T. B. Massalski

Dept. of Metallurgy and Materials Sciences

Carnegie-Mellon University

Pittsburgh, PA

10:00 a.m. $\frac{\text { Phase Diagram Compilation }}{\text { Activities in Ceramics }}$

R. S. Roth

Solid State Chemistry Section

Institute for Materials Research

National Bureau of Standards

Washington, DC

M-2 Semiconductor Phase Diagrams

10:30 a.m.

C. Thurmond

Bell Telephone Laboratories

Murray Hill, NJ

11:00 a.m. COFEEE

11:20 a.m. Present Status of Phase Diagram

Compilation Activities (Continued)

M-3 Phase Diagrams Compilations for

11:20 a.m. Metallic Systems - an Assessment

of Ongoing Activities

G. C. Carter

Alloy Data Center

Institute for Materials Research

National Bureau of Standards

Washington, DC

M-4 Organization of Phase Diagram

11:50 a.m. Information in the Soviet Union

N. V. Ageev, D. L. Ageeva, T. P. Kolesnikova, and L. A. Petrova

Baikov Institute of Metallurgy, and

Institute for Scientific Information

Academy of Sciences of the USSR

Moscow, USSR 
MONDAY, JANUARY 10, 1977

Afternoon Session (Continued)

M-5 Phase Diagrams of Materials at

12:10 p.m. High Pressure

L. Merrill

High Pressure Data Center

Brigham Young University

Provo, UT

12:30 p.m. LUNCE

2:00 p.m. Present Status of Phase Diagram

Compilation Activities (Continued)

Chairman K. A. Gschneidner, Jr.

Rare Earth Information Center

Iowa State University

Ames, IA

M-6 Phase Diagram Information

$2: 00$ p.m. from Computer Banks

I. Ansara

Laboratoire de Thermodynamique et Physico-Chimie Métallurgiques

Institut National Polytechnique

Grenoble, France

M-7 Experimental Techniques in

$2: 30$ p.m. Phase Diagram Determination - an overview -

F. N. Rhines

Dept. of Materials Science and Engineering

University of Florida

Gainesville, FL

3:30 p.m. POSTER SESSION

(Employee's Lounge)

Coffee will be availabe during

the session

Two topics will be addressed

in the session. 
MONDAY, JANUARY 10, 1977

Poster Session (Continued)

\section{Phase Diagram Compilation and Data Evaluation Activities}

MPI-1 Proposal for a Comprehensive Handbook on "Ternary Phase Diagrams of Metals"

E. Aldinger, E.-Th. Henig,

H. L. Lukas, and G. Petzow

Max Planck Inst. für Metallforschung Institut für Werkstoffurissenschaften Stuttgart, Germany

MPSI-2 $\mathrm{WO}_{3}$-Containing Binary Oxide Systems

I. Y. Chang

Department of Geology

Miami University

Oxford, $\mathrm{OH}$

MPS-3 RIC in Phase with Rare-Earth

Constitutional Diagrams

K. A. Gschneidner, Jr., M. E. Verkade, and R. L. Evans

Rare Earth Information Center

Iowa State University

Ames, IA

MPSI-4 Phase Diagrams and Thermodynamic Properties of Ternary Copper Alloy Systems

Y. A. Chang, Joachim P. Neuman, and U. V. Choudary

Materials Department

College of Engineering and Applied Science

University of Wisconsion - Milwaukee

Milwaukee, WI

MPI-5 Phase Equilibria in Variable Valence Oxide Systems

W. B. White

Materials Research Laboratory

Department of Geosciences

Pennsylvania State University

University Park, PA 
MONDAY, JANUARY 10, 1977

Poster Session (Continued)

MPSI-6 Phase Diagrams for Ceramists

I. P. Cook, R. S. Roth, T. Negas, and $G$. W. Cleek

Institute for Materials Research

National Bureau of Standards

Washington, D.C.

MPSI-7 NBS Crystal - Data Center

A. Mighell, H. Ondik, J. Stalick, and R. Boreni

Institute for Materials Research

National Bureau of Standards

Washington, D.C.

MPS-8 The NBS Alloy Data Center

G. C. Carter, D. J. Kahan, and $\mathrm{L}$. H. Bennett

Institute for Materials Research

National Bureau of Standards

Washington, D.C.

MPI-9 Phase Equilibria in Cryolite Systems

J. J. Brown, Jr.

Department of Materials Engineering

College of Engineering

Virginia Polytechnic Institute and State University

Blacksburg, VA

MPS-10 Methods of Compiling and Editing

"Handbook of Binary Metallic Systems"

A. E. Vol and E. K. Kagan

Leningrad, USSR

II. Experimental Techniques in

Phase Diagram Determinations

MPII-1 The Determination of Phase Diagrams

for Liquid Oxides and Metallurgical

Slags by Hot-Wire Microscopy

H. A. Fine

Dept of Metallurgical Engineering

University of Arizona

Tucson, AZ 
MONDAY, JANUARY 10, 1977

Poster Session (Continued)

MPSII-2

Experimental Techniques in Phase

Diagram Determinations of

Superconducting Compounds Con-

taining Volatile Components at

Temperature up to $2200^{\circ} \mathrm{C}$

R. Flükiger and J.-L. Jorda

Dépt. de Physique de la Matiere Condensée

University of Geneva

Geneva, Switzerland

MPSI-3 Experimental Techniques in Phase

Diagram Determinations: Applications

to Silicate Systems

F. P. GIasser

Dept. of Chemistry

University of Aberdeen

Aberdeen, Scotland

MPSI-4 Protective Coatings for Superalloys and the Use of Phase Diagrams

M. R. Jackson, J. R. Rairden

Research and Development Center

General Electric Co.

Schenectady, NY

MPSII-5 Application of the Scanning Electron Microscope (SEM) to the Study of High

Temperature Oxide Phase Equilibria

L. P. Cook and D. B. Minor

Institute for Materials Research

National Bureau of Standards

Washington, D.C.

MPSII-6 Nuclear Hyperfine Techniques

in the Determination of Phase

Diagrams

R. C. Reno

Dept. of Physics

University of Maryland, Baltimore

County

Baltimore, MD

and

L. J. Swartzendruber, G. C. Carter, and L. H. Bennett

Institute for Materials Research

National Bureau of Standards

Washington, D.C. 
MONDAY, JANUARY 10, 1977

Poster Session (Continued)

MPSI-7 $\frac{\text { Experimental Determination of Phase }}{\text { Diagrams with the Electron Micro- }}$

A. D. Romig, Jr., and J. I. Goldstein

Dept. of Metallurgy and Materials Science

Lehigh University

Bethlehem, PA

MPSI-8 Interrelations between Phase Diagrams and Hydriding Properties for Alloys based on the Intermetallic Compound FeTi

G. D. Sandrock

Paul D. Merica Research Laboratory

International Nickel Co., Inc.

Suffern, NY

and

J. J. Reilly, and J. R. Johnson

Dept. of Applied Science

Brookhaven National Laboratory

Upton, NY

MPSII-9 Phase Equilibria in the System

$\mathrm{MgO}-\mathrm{RCl}$ (R-Ii, Na, and K) Solution under Hydrothermal Conditions by Means of a Capsul Bursting Method

S. Sōmiya, K. Nakamura, S.-I. Hirano, and S. Saito

Research Laboratory of Engineering Materials

Tokyo Institute of Technology

Tokjo, Japan

MPSI-10 Use of High Energy Ion Beams in

Phase Diagram Determination

J. E. Smugeresky

Metallurgy and Electroplating Division

and

S. M. Myers

Ion-Solid Interactions Division

Sandia Laboratories

Livermore, CA 
MONDAY, JANUARY 10, 1977

Poster Session (Continued)

MPSI-11 Phase Equilibrium Diagrams in terms

of Electronic Structure

F. E. Wang

Materials Division

Naval Surface Weapons Center

White Oak, MD

MPSII-12 Use of Segregation Phenomena

in Solid Solutions as a Method for Determining Solidification Diagrams. Application to some $\mathrm{Sc}_{2} \mathrm{O}_{3}-\mathrm{Ln}_{2} \mathrm{O}_{3}$

Systems

T. M. Badie

Laboratoire des Ultra-Refractaires

Centre National de la Recherche

Scientifique

Odeillo, France

MPSI-13 Studies of the Fe-C-B Phase Diagram

by Autoradiography

T. B. Cameron and J. E. Morral

Dept. of Metallurgy and Inst. of

Materials Science

University of Connecticut

Storrs, CT

MPSI-14 Industrial Needs

P. J. Fopiano

Army Materials and Mechanics Research

Center

Watertown, MA

3:30 p.m. Demonstrations

(Employee's Lounge)

Demonstration Video Tape

I. Ansara

Thermochemical Data Center

Laboratoire de Thermodynamique et

Physico-Chimie Métallurgiques

Grenoble, France 
MONDAY, JAVUARY 10, 1977

Poster Session (Continued)

And Demonstrations In Coniunction iith

MPI-7 On-Iine Computer Manipulations

J. Hilsenrath, B. B. Molino

Office of Standard Reference Data

National Bureau of Standards

Washington, D.C

MPS-8 Allov Data Center Graphical Methods

R. A. Kirsch

Institute for Basic Standards

and

L. J. Swartzendruber

Institute for Materials Research

National Bureau of Standards

Washington, D.C.

Fizms

(Green Auditorium)

Eour Short Instructional Movies

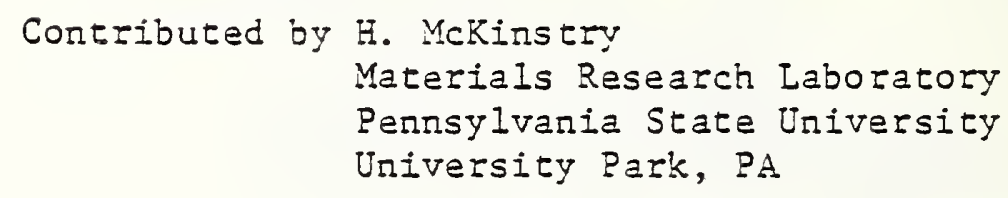

Contributed by H. Mckinstry

Materials Research Laboratory

Pennsylvania State University

University Park, PA

Produced at Pennsylvania State University

6:00 p.m. Buses leave NBS for hotel

7:00 p.m. Informal discussion at hotel

Tuesdav, January 11, 1977

8:15 a.m. Buses leave hotel for NBS

Methods of Phase Diagram Calculations

9:00 a.m. Theory of Allov Phases

R. E. Watson

Brookhaven National Laboratory

Upton, $N Y$

H. Ehrenreich

Harvard University

Cambridge, MA

$$
\text { and }
$$

L. H. Bennett

Institute for Materials Research

National Bureau of Standards

Washington, D.C. 
TUESDAY, JANUARY 11, 1977

Morning' Session (Continued)

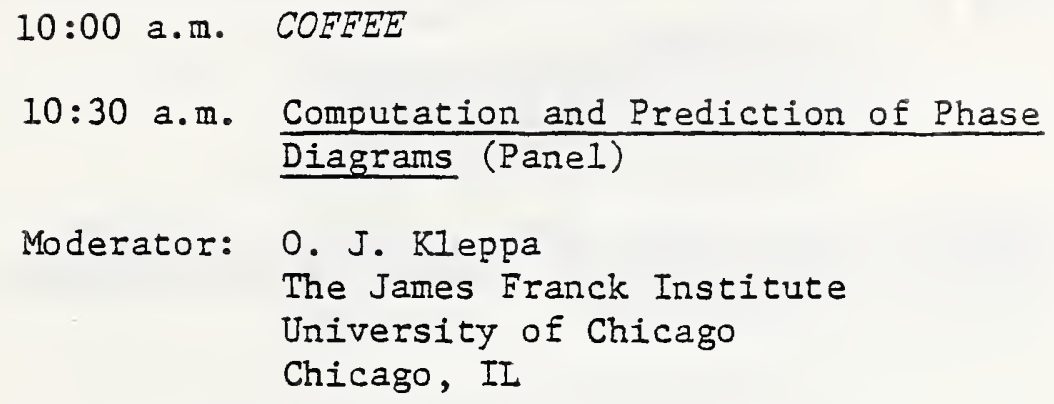

Panel Members: L. Brewer

Inorganic Materials Research Div.

Lawrence Berkeley Laboratories

University of California

Berkeley, CA

D. de Fontaine

Materials Department

University of California

Los Angeles, CA

R. L. Dreshfield

Materials Processing and Joining Section

NASA Lewis Research Centar

Cleveland, $\mathrm{OH}$

B. C. Giessen

Dept. of Chemistry and Mechanical Engineering

Northeastern University

Boston, MA

L. Kaufman

ManLabs, Inc.

Cambridge, MA

A. Navrotsky

Chemistry Department

Arizona State University

Tempe, AZ

12:30 p.m. LUNCH

2:00 p.m. Review of Phase Diacram Representations, Eormat, and Distribution

Chaiman: J. W. Cahn

Dept. of Materials Science \& Engineering

M.I.T.

Cambridge, MA 
TUESDAY, JANUARY 11, 1977

Afternoon Session (Continued)

T-2 The Representation of Phase Equilibria $2: 00 \mathrm{p} . \mathrm{m}$.

A. Prince

Hirst Research Centre

General Electric, Ltd.

Wembley, Middlesex England

T-3 Phase Diagram Format and Distribution -

$2: 45$ p.m. User's View

J. Livingston

Research and Development Center

General Electric, Ltd.

Schenectady, NY

T-4 Some Thoughts on the Distribution

3:05 p.m. of Reference Data

H. J. White, Jr.

Office of Standards Reference Data

National Bureau of Standards

Washington, D.C.

T-5 Remarks on Producing and Publishing

$3: 20$ p.m. Critically Evaluated Data

W. B. Pearson

Faculty of Science

University of Waterloo

Waterloo, Canada

3:30 p.m. POSTER SESSION

(Employee's Lounge)

Coffee will be available during the session.

Two topics will be addressed in this session.

I. Computational Techniques for Phase Diagran Constmetion

TPSI-1 Computerized Characterization of the Al-Cu-Ni and Al-Cu-Ag Ternary Phase Diagrams

M. L. Boyle, C. J. Van Tyne, and S. K. Tarby

Dept. of Metallurgy and Materials Science

Lehigh University

Bethlehem, PA 
TUESDAY, JANUARY 11, 1977

Poster Session (Continued)

$\begin{array}{ll}\text { TPSI-2 } & \frac{\text { Correlations and Predictions of }}{\text { Metal-Boron Phase Equilibria }} \\ & \text { K. Spear } \\ \text { Materials Research Laboratory } \\ \text { Pennsylvania State Unversity } \\ \text { University Park, PA } \\ \text { TPSI-3 A Valence Bond Test for the Validity } \\ \frac{\text { of Intermetallic and Semiconducting }}{\text { Structures }}\end{array}$

F. L. Carter

Chemistry Division

Naval Research Laboratory

Washington, D.C.

TPSI-4 Computatior of the Component Activities from Ternary Miscibility Gap Data:

$\mathrm{Cu}-\mathrm{Ag}-\mathrm{S}(\mathrm{Se})$

U. V. Choudary and Y. A. Chang

Materials Department

College of Engineering and Applied

Science

University of Wisconsin-Wilwaukee

Milwaukee, Wisconsin

TPSI-5 The Mathematical Representation of

Activity Data in Three Component

Systems and its Use for the Computation

of Multiphase Equilibria

I. Eliezer and R. A. Howald

Chemistry Department

Montana State University

Bozeman, MT

TPSI-6 A Program for Binary Phase Equilibria Using the Redlick-Kister Equations

E. Eliezer and R. A. Howald

Chemistry Department

Montana State University

Bozeman, MT 
TUESDAY, JANUARY 11, 1977

Poster Session (Continued)

TPSI-7 Polynomial Representation of the Excess Free Energy of Multicomponent Systems and Their Use in Phase Diagram Calculations

H. Gaye

IRSID - PCM 57

Maizières - les - Metz

France

and

C. H. P. Lupis

Department of Metallurgy and Materials Science

Carnegie - Mellon University

Schenley Park, Pittsburgh, PA

TPSI-8 Thermodynamic Data for the Fe-O System Evaluated Using a New Computer-Aided Strategy.

J. L. Haas, and J. R. Fisher

National Center for the Thermodynamic Data of Minerals

Geological Survey

Reston, VA

TPSI-9 Analysis and Synthesis of Phase Diagrams of $\mathrm{Fe}-\mathrm{Cr}-\mathrm{Ni}, \mathrm{Fe}-\mathrm{Cu}-\mathrm{Mn}$ and Fe-Cu-Ni Systems

M. Hasebe and T. Nishizawa

Department of Materials Science

Faculty of Engineering

Tohoku University, Sendai, Japan

TPSI-10 Optimization of Phase Diagrams by

a Least Squares Method Using

Simultaneously Different Data

E.-Th. Henig, H. L. Lukas, and B. Petzow Max Planck Institute für Metallforschung Institut für Werkstoffwissenschaften Stuttgart, Germany

TPSI-11 Application of Data Bank Methods to Calculation of the Thermochemistry and Phase Diagram of Metal and Ceramic Systems

L. Kaufman

ManLabs, Inc.

Cambridge, MA 
TUESDAY, JANUARY 11, 1977

Poster Session (Continued)

TPSI -12

a. Theoretical Calculation of Phase

Diagrams Using the Cluster Variation

(CV) Method

b. Fundamental Caluclations of Coherent

Phase Diagrams

R. Kikuchi and D. de Fontaine

Dept. of Engineering and Applied

Science

University of California

Los Angeles, CA

TPSI-13 Evaluation of Free Energy Functions for

the Prediction of Phase Equilibria in

Multicomponent Sustems: The Fe-Cu

System as an Example

0. Kubaschewski

Institute für Kermbrenstoffe und

Theoretische Huttenkunde

Technische Hochschule

Aachen, Germany

and

J. F. Smith and D. M. Bailey

Ames Laboratory USERDA

Iowa State University

Ames, Iowa

TPSI-14 Characteristics and Calculation of

Stability Diagrams

S. McCormick and Y. Bilimoria

Illinois Institute of Technology

Chicago, IL

TPSI-15 Effect of Irradiation on Phase

Stability

P. A. Miodownik

Metallurgy and Materials Technology

Department

University of Surrey, U.K. 
TUESDAY, JANUARY 11, 1977

Poster Session (Continued)

TPSI-16 Facility for the Analysis of Chemical Thermodynamics - (A computerized Canadian Thermodynamic Data Bank)

A. D. Pelton, and C. W. Bale Dépt. de Génie Métallurgique, École Polytechnique Université de Montréal

Montréal, Canada and

W. T. Thompson

McGill University

Dept. of Metallurgical and Mineral Engineering Montreal, Canada

TPSI-17 The Calculation of Pourbaix Diagrams Using a Modified Linear Programming Technique

B. H. Rosof

Technology Division

Cabot Corporation

Kokomo, Indiana

TPSI-18 Theoretical Concepts Useful in the Calculation or Storage of Phase Diagrams of Ionic Systems

M. -L. Saboungi, and M. Blander

Chemical Engineering Division Argonne National Laboratory Argonne, IL

TPSI-19 Estimation of Isothermal Sections of Ternary Phase Diagrams of Lithium Containing Systems: The Li-Al-Mg System

M. L. Saboungi, and C. C. Hsu Chemical Engineering Division Argonne National Laboratory Argonne, IL 
TUESDAY, JANUARY 11, 1977

Poster Session (Continued)

TPSI-20 Cybernetic Prediction of the Formation of Chemical Compounds in Uninvestigated Systems

E. M. Savitsky, V. B. Gribulya, and N. N. Kiseleva

Baikov Institute of Metallurgy Academy of Sciences of the USSR Moscow, USSR

TPSI-21 The Determination and Representation of Metastable Phase Diagram Features and Some Kinetic Characteristics of

Alloys

G. C. Giessen

Institute of Chemical Analysis, Applications and Forensic Science, and Department of Chemistry Northeastern University Boston, Mass. 
TUESDAY, JANUARY 11, 1977

Poster Session (Continued)

II. Format and Distribution of Phase Diagram Data

TPSII-1 Tables of Contents and Cumulative Subject Index for "Phase Diagrams of Metallic Systems", N. V. Ageev editor, Volumes 1-19

C. M. Scheuermann Alloys Section NASA Lewis Research Center Cleveland, $\mathrm{OH}$

TPSII-2 Graphical Summary of Binary Diagrams

J. E. Selle

Metals and Ceramics Division

Oak Ridge National Laboratory

Oak Ridge, TN

TPSII-3 Standards for Publication of Phase Equilibrium Data

E. R. Kreidler

Lamp Business Division

Lamp Materials Research Lab 非1361

General Electric Co.

Cleveland, $\mathrm{OH}$

TPSII-4 Formatting and Distributing Evaluated

Reference Data by the Office of

Standard Reference Data at the

National Bureau of Standards

S. P. Fivozinsky and G. B. Sherwood

Office of Standard Reference Data

National Bureau of Standards

Washington, D.C.

3:30 p.m. Demonstrations

(Employee's Lounge)

Demonstrations in Conjunction with

TPSI-11 MTDATA On-Line Thermochemical

Calculations

L. Kaufman

Manlabs, Inc.

Cambridge, MA 
TUESDAY, JANUARY 11,1977

Demonstrations (Continued)

TPSI-16 An On-Line Demonstration of a Computerized Canadian Thermodynamic Data Bank

A. D. Pelton

Dépt. de Génie Métallurgique

École Polytechnique

Université de Montréal

Montréal Canada

6:00 p.m. Buses leave NBS for hotel

7:00 p.m. Reception at hotel

8:00 p.m. Banquet at hotel

Keynote Speaker:

W. Dale Compton

Vice President, Scientific Research

Ford Motor Company

Dearborn, MI

Wednesday, January 12, 1977

$8: 15$ a.m. Buses leave hotel for NBS

User Needs for Phase Diagram

Information

9:00 a.m. Primary Production

(Pane1)

Moderator: J. F. Elliott

Dept. of Materials Science and Engineering

M.I.T.

Cambridge, MA

Panel Members: P. Amman

Ledgemont Laboratory

Kennecott Copper Corporation

Lexington, MA

H. Larson

American Smelting and Refining Company

Plainfield, NJ 
WEDNESDAY, JANUARY 12, 1977

Moming Session (Continued)

\author{
R. D. Pehlke \\ Metallurgy Division \\ University of Michigan \\ Ann Arbor, MI \\ 10:40 a.m. COFEEE \\ 11:00 a.m. Materials Processing \\ (fabricating, machinging, heat \\ treating, etc.) \\ (Panel) \\ Moderator: W. Rostoker \\ Dept. of Materials \\ Engineering \\ University of Illinois \\ Chicago, IL
}

Panel Members: E. R. Kreidler

Lamp Business Division

General Electric Co.

Cleveland, $\mathrm{OH}$

R. McNaliy

Ceramics Research

Coming Glass Works

Corning, NY

L. Mondolfo

Consultant

Clinton, $\mathrm{NY}$

S. Prochazka

Ceramics Branch

Physical Chemistry Laboratory

General Electric Co.

Schenectady, NY

G. R. Speich

Research Laboratories

United States SteeI

Monroeville, PA

12:30 p.m. IUNCH

2:00 p.m. Product Applications

(Pane1)

Moderator: F. L. VerSnyder

Materials Engineering and Research

Pratt and Whitney Aircraft, U.T.C.

E. Hartford, CT 
WEDNESDAY, JANUARY 12, 1977

\author{
Panel Members: C. Greskovich \\ Research and Development Center \\ General Electric Co. \\ Schenectady, NY \\ R. I. Jaffee \\ Fossil Fuel \& Advance Systems \\ Division \\ Electric Power Research Institute \\ Palo Alto, CA \\ B. H. Kear \\ Materials Engineering and \\ Research Laboratory \\ Pratt and Whitney Aircraft, U.T.C. \\ Middletown, CT \\ A. I. Mlavsky \\ Sr. Vice President of Technology \\ Tyco Laboratories, Inc. \\ Waltham, MA \\ P. SIick \\ Bell Telephone Laboratories \\ Allentown, PA
}

3:30 p.m. COFEEE

4:00 p.m. Sumary

J. Elliott

Dept. of Materials Science and Engineering

M.I.T.

Cambridge, MA

5:00 p.m. Buses leave NBS for hotel, airports 


\title{
4.2 Abstracts
}

\author{
MONDAY, 10 JANUARY, 1977 \\ $10: 00 \mathrm{AM}-12: 30 \mathrm{PM}$
}

\section{REVIEWS OF THE PRESENT \\ STATUS OF}

FHASE DIAGRAM COMPILATION ACTIVITIES 


\title{
PHASE DIAGRAM COMPILATION ACTIVITIES IN CERAMICS
}

R.S. Roth, I.P. Cook, T. Negas, G.W. Cleek, and J.B. Wachtman

National Bureau of Standards

Washington, D.C. 20234

\begin{abstract}
Phase diagrams play an important role in the development of ceramic materials. Phase equilibria data are essential in meeting the expanding needs for refractories, electronic components, non-crystalline solids, and various other applications of interest to ceramic scientists and engineers. Compilation of ceramic phase diagrams began in 1933, when the American Ceramic Society published 178 diagrams, compiled by Hall and Insley. The effort has been continued through the years by compilers at the National Bureau of Standards. In 1964, a revised edition of "Phase Diagrams for Ceramists" was published containing 2066 diagrams. This was followed in 1969 by a supplement containing an additional 2183 diagrams. A third supplement, published in 1975, contains another 850 diagrams - this latest supplement includes a discussion of the methods, data and interpretations made in the construction of each diagram. Since the death of E.M. Levin in 1974, this effort is being continued by a team of scientists actively engaged in phase equilibria studies in ceramic research centers around the country and abroad. This group is led by researchers at NBS who are assuming the responsibility for collecting data from the literature, distributing it among the group for evaluation, and coordinating preparation of the publication, as well as preparing evaluations of systems in their own area of expertise. This effort is being supported in part by the office of Standard Reference Data.

There are some duplications of compilation activity in the ceramic sciences. This is largely an international problem: the principal compilations in addition to "Phase Diagrams for Ceramists" are Russian. Such duplication is not necessarily wasteful, since any publication would have to be made available in both languages. Also, the two groups of publications, which are partly independent, can be cross-checked for inclusion of otherwise missed obscure references. A more complete review of other partial compilations in this field will be presented.
\end{abstract}

A questionnaire was distributed by the American Ceramic Society in July 1976 to purchasers of the 1975 supplement requesting information from users of this service. A $40 \%$ response allows a determination of user needs in phase equilibria with a reasonably statistical probability of success. The major categories covered in the questionnaire include a description of the respondent, his uses of phase equilibria data and principles, evaluation of "Phase Diagrams for Ceramists" as a publication of the American Ceramic Society and the users needs for experimental and/or theoretical work not now being done. The statistical results of this questionnaire will be presented along with specific examples illustrating user oriented problems. 
SEMICONDUCTOR PHASE DIAGRAMS

by

C. D. Thurmond

BeIl Iaboratories

Murray Hill, New Jersey 07974

- The largest group of semiconductors for which

extensive phase studies have been made are the tetrahedrally coordinated semiconductors with 4 valence electrons per atom. The prototypes are the group IV diamond structure elemental semiconductors $\mathrm{C}$ (diamond), Si and Ge. The binary zincblende semiconductors, III-V and II-VI compounds, are members of this class as are the ternary chalcopyrite semiconductors, $I I-I V-V_{2}$ and $I-I I I-V_{2}$.

The range of properties of these semiconductors is greatly extended by the occurrence of solid solutions of wide composition range. For example, III-V compound solid solutions

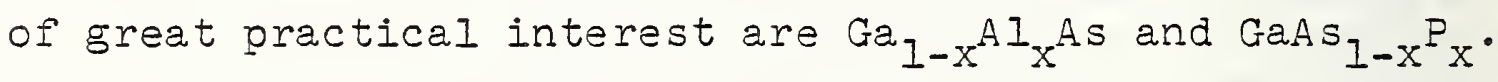
Many other pseudobinary semiconductor solid solutions have been studied as have the associated ternaries.

The interest in this class of semiconductors lies in the ability to alter their electrical and optical properties with the addition of small amounts of donors or acceptors. The donor (acceptor) - semiconductor phase diagrams represent a large portion of the phase equilibria of interest. 
The principal sources of reviews of evaluated phase diagrams of the tetrahedrally coordinated semiconductors are the following:

The Fansen, Elliot and Shunk volumes( $I$ ) which contain many $T-X$ binary diagrams for which Si or Ge is cne of the components. A number of III-V and II-TI binary diagrams are also given. F. A. Kröger (2) who has inciuded the phase diagrams of a number of semiconauctcrs in his bock. Particular emphasis is given by Kröger to the Brouwer diagram. M. B. Panish and M. Ilegems (3) who have critically evaluated and presented a number of important ternary III-V systems. $J$. I. Shay and J. F. Wernick ${ }^{(4)}$ who have included a critical evaluation of a large number of chalcopyrites, I-III-VI-2 and II-IV-V $V_{2}$ compounds, and solid solutions. N. Ilegems and $G$. I. Pearson (5) who have reviewed phase equilibria in III-V, II-VI and IV-VI compound semiconductor alloy systems. other sources of information will also be considered.

Of broader interest are electronic materials of which semiconductors are a part. Some comments will be made about phase diagrams of other electronic materials. 
1. M. Hansen, Constitution of Binary Alloys, 2nd Ed., prepared in cooperation with $\mathrm{K}$. Anderko, McGraw HilI, 1958; R. P. Elliott, First Supplement, 1965; F. A. Shunk, Second Supplement, 1969.

2. F. A. Kröger, The Chemistry of Imperfect Crystals, Vol. 1, Preparation, Purification, Crystal Growth and Phase Theory, and Vol. 2, Imperfection Chemistry of Crystalline solids, and revised edition, 1974.

3. M. B. Panish and M. Ilegems, Phase Equilibria in Ternary III-V Systems, in progress in Solid state Chemistry, eds., H. Reiss and J. O. McCaldin (Pergamon Press, New York) 1972, VOI. 7, . $39-83$.

4. J. I. Shay and J.H. Wernick, Ternary Chalcopyrite Semiconductors; Growth, Electronic Properties and Applications Pergamon Press, 1975.

5. M. Ilegems and G. I. Pearson, Phase Studies in III-V, II-VI and IV-VI Compound Semiconductor Alloy Systems, Annual Review of Material Science, Vol. 5, 1975, p. 345-371. 
Phase Diagram Compilations for Metallic Systems - an Assessment of Ongoing Activities

\author{
G. C. Carter, L. H. Bennett, and D. J. Kahan \\ Alloy Data Center \\ Metallurgy Division \\ Institute for Materials Research \\ National Bureau of Standards, Washington, D.C. 20234
}

Alloy phase diagrams provide a basis for solving many industrial problems. It is therefore not surprising to find critical phase diagram data compilation activities generally concentrated in the more industrialized countries. Among these are extensive compilation projects in Germany (1), France (2), and the USSR $^{(3)}$, all three well-established, outstanding centers. Numerous smaller projects, also of reputable quality, exist in England and other western European countries, the USA Japan, and elsewhere.

Methods of preparing critical phase diagram compilations have undergone substantial changes since large products such as the USA's "Hansen" series (4) was produced. The reason is that in the past there existed an ample, though not excessive, amount of classical metallurgical data on the one hand, while, on the other hand, theoretical models and computerized methods to obtain phase diagrams from thermodynamic data were not yet adequate.

At the present time, the available phase diagram data have become so diverse and numerous that a single, concise condensation for all binary alloys has become impracticable for a single evaluation project to be carried out. This problem becomes amplified for ternaries and other multicomponent alloys. The alternate route, which applies improved computer facilities and increasingly sophisticated models has therefore received greatly increased attention in recent vears. These methods either integrate existing experimental data with evaluated thermodynamic data, from which equilibrium diagrams can be calculated, or simply use the thermodynamic data to predict equilibrium diagrams. This latter method becomes invaluable for alloys for which classical phase diagram determination experiments are cumbersome, difficult, and lengthy (and often expensive). This is often the 
case for multicomponent alloys utilized in industrial applications. Especially for these alloys, specific groups of phase diagrams only in certain ranges of composition need to be evaluated, and comprehensive phase diagram compilations are not always a desired product for such specific needs. For instance, the PHACOMP method was developed to determine phase diagrams of quatemary and other Ni-based alloys in which certain hard intermetallic phases tend to precipitate after solidification ${ }^{(5)}$.

As a result of these computational developments, a large number of small projects are now underway in various countries. Several of these projects collaborate with each other, forming larger groups such as CALPHAD ${ }^{(6)}$.

The ADC will have available at the workshop, a comprehensive list of all existing phase diagram compilations (7), a comprehensive list of currently on-going phase diagram compilation centers ${ }^{(8)}$, and a list of the related phase diagram calculation and evaluation projects briefly described above. Availability of phase diagram data from these compilations, calculations, automated data banks, and translations, will be reviewed, as well as programs of the other data centers.

(1) A major center is under 0. Kubaschewski, P. J. Spencer, and collaborators, Inst. fur Theoretische Huttenkunde, R. -W. Technische Hochschule, Aachen.

(2) I. Ansara, C. Bamard, and collaborators, Laboratoire de Thermodynamique et Physico-Chimie Metallurgique, Domaine Universitaire de Grenoble.

(3) N. V. Ageev, O. S. Ivanov, and collaborators, Institute of Metallurgy, Baikov Institute, Moscow.

(4) "Constitution of Binary Alloys", M. Hansen and K. Anderko, McGraw-Hill (1958); Supplement I, R. P. Elliott (1965); Supplement II, F. A. Shunk (1969).

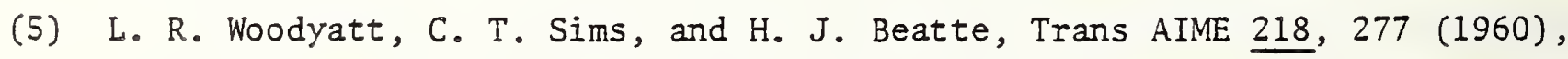
and W. J. Boesch and J. S. Slaney, Met. Prog. 86, 109 (1964).

(6) CALPHAD - an international group on "Calculations of Phase Diagrams" meetings are held about once a year to discuss progress and problems in calculations and predictions of phase diagrams from thermodynamic data. 
(7) This will be an update of the compilation in "Alloy Phase Diagram Data", L. H. Bennett, D. J. Kahan, and G. C. Carter, Mat. Sci. and Eng. 24, 1 (1976).

(8) In addition to the three major data centers in refs. (1) to (3), there are a large number of other centers, which will be reviewed at the Workshop. These are compiled in Appendix A (CALPHAD members) and Appendix B (other data centers) of Reference 9, which will be updated for the workshop. An abbreviated, ammended list, selecting some more prominent centers of appendix $B$ not listed above:

- I. Brewer et al., Inorganic Materials Research Div. University of California, Berkeley, CA 94720

(prediction of high-temperature multi component alloy equilibria presented in two-dimensional Brewer projection diagrams: review of Mo binary alloy phase diagrams in preparation).

- Y. A. Chang et al., Materials Department

University of Wisconsin, Milwaukee, WI 53211

(ternary copper alloy phase diagrams are being critically evaluated).

- K. Gschneidner, Rare Earth Information Center

Iowa State University, Ames IA 50010

(the Center's bibliographic files include phase equilibria, crystallographic and thermodynamic data of rare earth alloys; phase diagram evaluations published).

- I. Kaufman, ManLabs, Inc., Cambridge, Mass, 02139

(Manlabs-National Physical Laboratory (U.K.) Data Bank- a computer-stored numerical data file of thermodynamic data made available commercially).

- L. Merrill, High Pressure Data Center

Brigham Young University, Provo, UT 84602

(the Center's bibliographic files include phase transformations under pressure).

- W. Moffatt, Metallurgy and Ceramics Laboratory

General Electric Research \& Development Lab., Schenectady, NY 12301

(compilations of unevaluated binary phase diagrams. for diagrams not encountered in "Hansen"-Elliott-Shunk series. (ref. 4))

- G. Petzow et al., Max-Planck-Institut für Metallfor schung

Institut für Werkstoffwissenschaften, Stuttgart-80, Busnauerstr. 175, Germany

(handbook on ternary phase diagrams: bibliography completed; comprehensive handbook of data proposed). 
- A. Prince, Hirst Research Centre. General Electric Co. Ltd. East Lane, Wembley, Middlesex, HA9 7PP, England

(critical evaluation of phase diagram data on Au-based alloys is in progress).

- G. Raynor, Dept, of Physical Metallurgy and Science of Materials University of Birming ham, Birmingham. BI5 2TT, England

(in progress: critical evaluation of ternary phase diagram data on Au-based allol compilation of a bibliography on multicomponent alloy constitution)

- E. Rudy, Materials Science Department, Oregon Graduate Center, Beaverton, OR 977 (evaluated phase diagrams of refractory carbide and boride systems).

- K. E. Spear, Materials Research Laboratory, Pennsylvania State University, University Park, PA 16802

(Evaluation of metal-boron phase equilibria; predictions of undiscovered phases using electronic structure considerations).

(9) L. H. Bennett, G. C. Carter, and D. J. Kahan, CODATA Conference, Boulder, Colo., June 1976. 
A paragraph taken from the submitted paper.

ORGANISATION OF PHASE DIAGRAM INFORMATION IN THE

\section{SOVIET UNION}

N. V. Ageev, D. I. Ageeva, T. P. Kolesnikova, and I. A. Petrova

Baikov Institute of Metallurgy

USSR Academy of Sciences

Institute of Scientific Information

Moscow

A eritical orervier of the phase diagram information in the Soviet Union suggests that:

(1) information on phase diagrems corers not just binary, bat also ternary and nore complex systems;

(2) bandbooks reproduce phase diagress from original publications without any modification;

(3) regular published iaformation on phase diagrans o: metal and oxide systems is produced;

(4) primary publications dealing wit studies of piase diagrams are not concentreted in anj single source, but scattered over several jourals and sertals;

(5) times spent on bringing information to user's notice are: through VIIITI' abstract journaI - for Soviet publications, 3 to 5 months; for foreifn publications, 4 to 8 montis; throudh VIilTI's handbooks, three years;

(6) no rorks on critical review of experimental data, such as the handbook of ir. Hansen et al., are available;

(7) those handbooks that are bejng puolished are sold ou: too soon; ard

(8) despite definite phase diagrar description forass sanctioned by practice, there are strict standard require=e=is, so that publications opten lack essential data for a judgerent about reliability and quality of the passe diagrems. 
From data covered by handbooks, one can concinde (see Pigure) that the Soviet Jnion holda a major place in siudies of metal systems' phase diagrams.
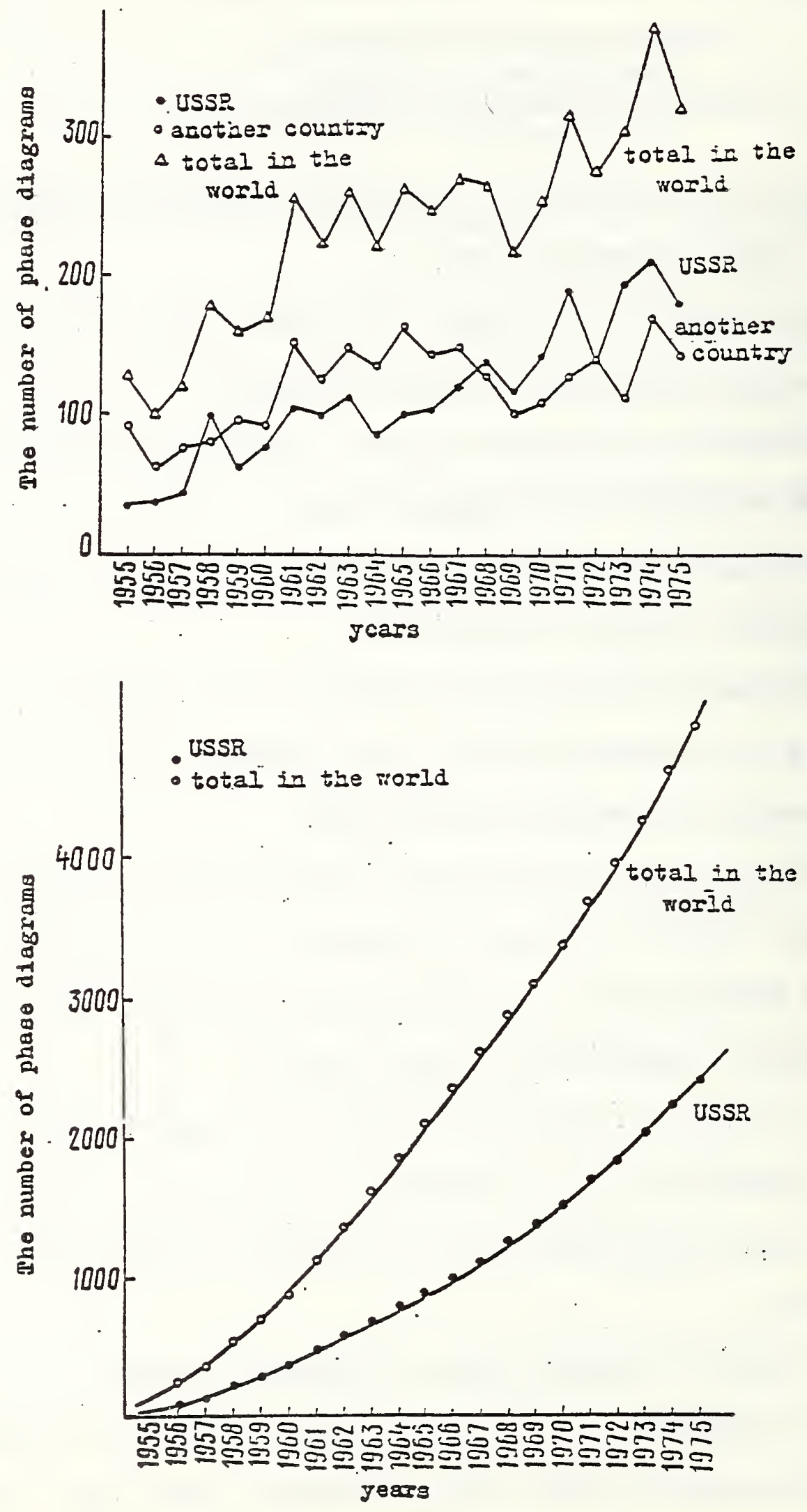
Phase Diagrams of Materials at High Pressure

Leo Merrill

High Pressure Data Center

Brigham Young University

Provo, Utah 84601

A survey of polymorphic phase diagrams as a function of temperature and pressure is presented for the elements and simple inorganic compounds. All materials included in this survey are those for which crystallographic data are available. Phase studies of materials include the following formula types: elements (69), $\mathrm{AB}$ (87), $\mathrm{AB}_{2}(78), \mathrm{AB}_{3}(8), \mathrm{ABO}_{2}$ (11), $\mathrm{A}_{2} \mathrm{~B}_{3}(67)$, $\mathrm{ABO}_{4}$ (54), and miscellaneous types (58) mainly of mineral systems or mineral analogs. The number in parentheses is the number of materials which have been tabulated in each formula type.

The preparation of high pressure phases falls into two principal categories; (1) pressure and temperature induced structural transformations, and (2) inorganic synthesis in which the product can be recovered either stably or metastably. In general, in the case of pressure induced polymorphic transformations, materials proceed to structures with higher densities and higher cation coordination. The characteristic measurements are the determinations of pressure and temperature behavior of the liquid-solid and solid-solid phase boundaries. Occasionally some of these phases may be retained metastably at atmospheric pressure. Many new compounds and polymorphs have been prepared by inorganic synthesis. In a class of compounds it is often observed that a certain structural type is found to exist up to a certain empirical radius ratio. Beyond this region, the particular structure can not be prepared under normal synthesis procedures. Due to the differential compressibilities of the component elements of the compound, it has been shown that the range of a particular structure type can be extended by high pressure synthesis. This has been repeatedly demonstrated with compounds of the rare-earth series. 
The study of high pressure phases has played an important role in the basic understanding of solids. If one expands the free energy as a function of temperature and volume, it can be shown to a first approximation that the total energy of a system can be altered by the heat term which changes the population of the energy levels, or by the work term which relates a change in volume to a shift in the energy levels. The significance of pressure, then, is that it serves as a convenient method to study the volume dependence of physical properties. Pressure also has been a most important parameter in the search for new materials, notably, synthetic diamond and cubic boron nitride. The study of phases of geologic minerals with their associated physical properties have made significant contributions to the understanding of the structure of the earth's interior. Tables of crystallographic data for many of the high pressure phases are also presented. 


\author{
MONDAY, 10 JANUARY, 1977 \\ $2: 00 P M-3: 30$ PM
}

\begin{abstract}
REVIEWS OF THE PRESENT STATUS OF PHASE
DIAGRAM COMPILATION ACTIVITIES (CONTINUED)

AND
\end{abstract}

REVIEN OF EXPERIMENTAL PHASE DIAGRAM

DETERMINATION METHODS 
PHASE OIAGRAM INFORMATION FROM COMPUTER BANKS

$=$ ニニニ $=$ = $=$ = $=$ =

I. ANSARA

LABORATOIRE DE THERMODYNAMIQUE ET PHYSICO-CHIMIE METALLURGIQUES (L.A. 29) - E.N.S.E.E.G. B.P. $\mathbb{N}^{\circ} 44$ - Domaine Universitaire - 38401 - SAINT MARTIN D'HERES - (FRANCE).

The need to develop computer techniques for phase diagram calculation and storage purposes arises from a number of major pratical considerations. Firstly, since the volume of information is extremely great, whether phase diagrams or the thermodynamic properties of materials are concerned, computers provide a simple means of handing the data. Secondy, modern technology requires that information be provided rapidly on the equilibrium phase stability of the materials that it uses. The computer enables such data to be calculated for the operating conditions of interest. Thirdly, the problem of achieving consistency of all the available information for a particular system often requires tedious calculation procedures.

For these reasons, a certain number of data centres have already established computer programs for the storage, retrieval, and application of phase diagram information The centres currently involved in such work and their pacticular areas of interest will be briefly mentioned. The basic differences in these data banks lie in the manner in which the phase diagram is reproduced. The phase boundaries themselves may be mathematically described or they may be calculated from stored thermodynamic values, Examples of both techniques applied to binary systems will be given as well as the structure of the data file. The thermodynamic approach to the calculation of phase diagrams of multicomponen systems is mainly carried out using the properties of the limiting binary systems. The numerical aspects will be discussed and illustrated for two ternary systems. 


\section{Experimental Techniques in Phase Diagram Determination - An overview - \\ E. N. Rhines \\ Department of Materials Science and Engineering University of Elorida \\ Gainsville, Fla. 32611}

In his book, "Phase Diagrams in Metallurgy" (1) . Professor Rhines introduces his chapter "Determination of Phase Diagrams" with the following paragraph:

"The modest collection of phase diagrams of metal systems that is now arailable to us is the product of the painstaking labor of a very large number of skillful investigators working in all parts of the world during the past three-quarters of a century. It is a constantly growing body of literature, improving both in the extent of its coverage and in the precision of its content. Few, if any, diagrams may be considered complete and final. Repeated investigation, with refinements in apparatus and techniques, leads to their frequent revision. Much of this refinement has been achieved through the modification and adaptation of a few basic research methods to fit the special requirements of specific alloy systems. It is not feasible, therefore, to present a collection of the "best" methods of investigation (no method is "best" for all systems), nor is it feasible to give a standardized procedure for any one method. It is possible, however, to outline the basic methods from which most of the specialized techniques are derived and to state those principies of investigation which are common to all cases. ${ }^{1}$ For detailed guidance the investigator must, of necessity, turn to the research literature, because the specialized problems met in constitutional studies are almost as numerous as are the alloy systems themselves. "

${ }^{1}$ A detailed outline of experimen:al procedures is given by W. Hume-Rothery, J. W. Christian, and W. B. Pearson, "Metallurgical Equilibrium Diagrams," The Institute of Physics, London, 1952. Some helpful experimental techniques are also described by A. U. Seybolt and J. E. Burke, "Experimental Metallurgy," John Wiley \& Sons, Inc., New York, 1953.

Professor Rhines will review the basic classical methods and several refinements, as well as some new approaches to experimental phase diagram determinations in his tutorial talk.

(1) F.N. Rhines, "Phase Diagrmas in Metallurgy, Their Development and Application" Metallurgy and Metallurgical Engineering Series. R.F. Mehl ed. . McGraw-Hill. N.Y., P. $290(1956)$. 
MONDAY, 10 JANUARY, 1977

$3: 30 P M-6: 00$ PM

PAPERS GIVEN BY POSTER

TOPIC I

PHASE DIAGRAM COMPILATION ACTIVITIES 
Proposal for a Comprehensive Handbook on "Ternary Phase Diagrams of Metals"

\author{
F. Aldinger, E.-Th. Henig, H.L. Lukas and G. Petzow, \\ Max-Planck-Institut für Metallforschung, \\ Institut für Werkstoffwissenschaften, \\ D7-Stuttgart-80, Büsnauerstr. 175
}

Today, constitutional data of ternary systems are available on a large scale, but they are scattered over a large number of different reports, journals and books. In order to use this enormous amount of knowledge more extensively, our Institute together with the Gmelin Institute has proposed to publish a comprehensive handbook on ternary phase diagrams.

For a proposal on this subject we prepared a literature survey covering constitutional work carried out before 1974. This preliminary index comprises about 4000 references on about 1500 ternary systems of metals.

A rough estimate shows that about 400 systems are fully investigated, and about 600 are covered fairly well. Of the remaining 500 systems constitutional data are available only on a rather limited scale. According to our concept the book will extend to about 6000 pages!

We are not going into details of organization and costs of this project, but we will. discuss the content of the handbook as well as the kind of presentation of the systems and diverse nomenclatures. The content of the handbook includes a brief presentation of fundamentals of the heterogeneous phase equilibria together with a proper nomenclature, enabling to "read" the ternary phase diagrams which will be presented in the alphabetical order of the chemical symbols. In addition to this the binaries which provide the basis for the ternary diagrams should be listed in an appendix. For this appendix a critical evaluation of the available data is necessary to derive definite diagrams. That means mainly to summarize data of the well-known books of Hansen and Anderko as well as of the two supplements of Elliott and Shunk. 
In order to discuss the format of presentation of the ternaries we prepared three examples each representing one of the three classes of systems mentioned above. The list of contents includes:

1. A brief critical review of the work which has been published in the Iiterature

2. Ternary intermetallic phases

3. Invarient equilibria

4. Iiquid surface

5. Isothermal sections

6. Solid solutions

7. Miscellaneous (e.g. ordering, isopleths, etc.).

For this comprehensive work we wish to solicitate the cooperation of other institutes and organizations with experience in special groups of alloys. These institutions should contribute to the publication by critically reviewing special phase diagram data. 
MPS - 2

$\mathrm{WO}_{3}$-Containing Binary Oxide systems

Iuke I. $Y$. Chang

Department of Geology, Miami University, oxford, ohio

The purpose of this review is to summarize phase relations in $\mathrm{WO}_{3}$-containing systems and to present the compilation of phase diagrams according to the types of chemical compounds. Fourteen tungstate groups are selected for discussion and their phase relations are presented.

For the alkali tungstates, in addition to the $1: 1$ and $1: 2$ (oxide/ $\mathrm{WO}_{3}$ ratio) compounds, which are common to all systems, $I: 3$ and $1: 6$ compounds exist in the systems of $K, R b$, and $C s$, and the $1: 4$ compound is stable in the systems of $I i$, $\mathrm{Na}$, and $\mathrm{K}$. There is a tendency in their crystal structures for the polyhedral $\mathrm{WO}_{6} / \mathrm{WO}_{4}$ ratio to increase from $1: 1$ to $1: 6$ compounds. In the alkaline earth oxide - Wo 3 systems, the number of tungstates formed increases with the increase in the size of the divalent cation. The Be system is a simple eutectic, the Mg system has a $1: 1$ compound with the wolframite-type structure, and $\mathrm{Ca}, \mathrm{Sr}$, and $\mathrm{Ba}$ systems have both $1: 1$ and $1: 3$ compounds with, respectively, the scheelite-type and (NH4) $3 F e F 6^{-}$ type structures.

All rare earth oxide systems have 1:1 and 1:3. tungstates. In the systems of large rare earths ( $\mathrm{Ia}$ - Sm), tungstates of other ratios also exist. The $1: 3$ compounds have crystal structures closely related to the scheelite-type. The actinide oxide - WO$_{3}$ systems are represented by the formation of a $1: 2$ compound in the Th system and a $1: 1$ compound in the U system.

A $1: 2$ compound characterizes both $\mathrm{ZrO}_{2}-\mathrm{WO}_{3}$ and $\mathrm{HfO}_{2}-$ $\mathrm{WO}_{3}$ systems, and its crystal structure is related to the woliramite-type. No titanium tungstates have been reported.

In the $\mathrm{V}_{2} \mathrm{O}_{5}-\mathrm{WO}_{3}$ system, only a $1: 1$ compound has been reported, but a great number of compounds are known in the systems of $\mathrm{Nb}_{2} \mathrm{O}_{5}$ and $\mathrm{Ta}_{2} \mathrm{O}_{5}$. These are $30: 1,6: 1,7: 3,8: 5,9: 8$, $4: 9,2: 7,6: 11,1: 11,1: 15$ in the $\mathrm{Nb}$ system, and $41: 4,15: 2$, $41: 8,67: 14,89: 22,37: 10,59: 18,81: 26,11: 4,1: 1$ in the Ta system.

The formation of a $1: 1$ compound has been reported in the $\mathrm{MOO}_{3}-\mathrm{WO}_{3}$ system, but its existence is definitely in question. No study has been made for the system $\mathrm{CrO}_{3}-\mathrm{WO}_{3}$, but a 
I:I compound forms between $\mathrm{Cr}_{2} \mathrm{O}_{3}$ and $\mathrm{WO}_{3}$ and has a tri-rutile structure.

Phase relations of WO 3 with FeO, MnO, NiO, and COO are characterized by the formation of the wolframite-type (1:1) compound. In addition, a $1: 1$ compound is also present in the $\mathrm{Fe}_{2} \mathrm{O}_{3}-\mathrm{WO}_{3}$ system. In the CuO-WO 3 system, two compounds, $1: 1$ and $1: 3$, have been reported, and a $2: 1$ compound was produced in the oxidation of WC on copper plate at temperatures below $610^{\circ} \mathrm{C}$. CuWO 4 has a distorted wolframite-type structure.

Tungstates of the Group IIB elements form 1:1 wolframite-type compounds, although all but $\mathrm{ZnWO}_{4}$ show distortion.

The formation of a number of boron tungstates such as $3: 1,1: 1$, and $1: 3$, has been reported, but their stabilities have not been confirmed. In both $\mathrm{Al}_{2} \mathrm{O}_{3}-\mathrm{WO}_{3}$ and In $\mathrm{O}_{3}-\mathrm{WO}_{3}$ systems, the 1:3 compounds are known, and they are isostructural with $\mathrm{Sc}_{2} \mathrm{~W}_{3} \mathrm{O}_{12}$. No gallium tungstate has been reported.

Tungstates of Group IVA elements are known only in the systems of tin and lead oxides where the cations are in their divalent state. $\mathrm{SnWO}_{4}$ is dimoprhic with an orthorhombic low-temperature form and a cubic high-temperature form. Two lead compounds, $1: 1$ and $1: 2$, have been reported. The $1: 1$ compound has the scheelite structure.

A $1: 1$ compound is known in the $\mathrm{P}_{2} \mathrm{O}_{5}-\mathrm{WO}_{3}$ system, and no arsenic tungstate has been reported. Other members of the Group $V A$ elements, $S b$ and $B i$, show a trivalent state in their tungstate formation. The $\mathrm{Bi}_{2} \mathrm{O}_{3}-\mathrm{WO}_{3}$ system has four compounds, $7: 1,7: 2,1: 1$, and $1: 2$, and the $\mathrm{Sb}_{2} \mathrm{O}_{3}-\mathrm{WO}_{3}$ system has a $1: 1$ compound.

Phase relations in the system $\mathrm{TeO}_{2}-\mathrm{WO}_{3}$ have been studied, but no compound has been reported. 
RIC IN PHASE WITH RARE-EARTH CONSTITUTIONAL DIAGRAMS

K. A. Gschneidner, Jr., M. E. Verkade and B. L. Evans

Rare-Earth Information Center (RIC)

Energy and Mineral Resources Research Institute

Iowa State University

Ames, Iowa 50010

\section{Background}

The Rare-Earth Information Center (RIC) was established at the Ames Laboratory by the U.S. Atomic Energy Commission's Division of Technical Information in 1966 and transferred to Iowa State University's Energy and Mineral Resources Research Institute (formerly Institute for Atomic Research) in 1968 with funding provided through grants from world-wide rare earth industries. The Center serves the scientific and technical community by collecting, storing, evaluating and disseminating rare earth information with particular emphasis on the physical metallurgy and solid state physics of the rare earth metals and their alloys.

Data Base

All available resources including books, journals, reports, conference proceedings, etc. are canvassed by the Center's technically trained staff of three ( 1 full time and 2 part time). Rapid and flexible retrieval of stored information is provided via a computerized system utilizing over 7000 keyword descriptors plus author indexing. Keyword descriptors are assigned following an examination of the original document rather than relying on only the title or abstract as do some indexing systems. Conversion of the information base from manually sorted punched cards to computer-read magnetic tape, begun in 1973 , is about three-fourths completed and includes most of the approximately 12,000 journal articles held by the Center.

Publications

Utilizing this extensive information base, the Center engages in various publishing activities in addition to providing specialized literature searches on request. The RIC News, a quarterly newsletter containing items of current interest in science and technology of the rare earths, is distributed free to over 3550 subscribers in the U.S. and abroad. State-of-the-art reviews, bibliographies and data compilations, prepared and published by RIC, have included a survey of rare earth metals in steel (IS-RIC-4), compilations of thermochemical data for rare earth compounds (IS-RIC-5 and IS-RIC-6), and a critical review of selected cerium binary phase diagrams (IS-RIC-7). These reports are currently available free from the Center or the sponsoring industry, Molycorp, Inc., which 
funded the study. Distribution of the reports is aided by publication announcements placed in appropriate scientific and trade journals, periodic notices in the RIC News and inclusion in abstracting journals. Evaluation of Constitutional Diagrams

The staff of RIC has been involved over the past fifteen years with critical evaluation of phase equilibria, crystallographic and thermodynamic data on rare earth materials. The major effort has been primarily concerned with metallic systems. The evaluations on consitutional diagrams and crystal structures have been published as books, review articles or reports.

Rare Earth Alloys, K. A. Gschneidner, Jr., D. Van Nostrand Company, Inc., New York (1961) $449+$ xiii pp.

"Rare Earth Intermetallic Compounds" by O. D. McMasters and K. A. Gschneidner, Jr., Nuclear Metallurgy 10, $93-158$ (1964).

IS-RIC-7 "Selected Cerium Phase Diagrams" by K. A. Gschneidner, Jr. and M. E. Verkade (September 1974) 50 pp.

"Inorganic Compounds" by K. A. Gschneidner, Jr., and "Alloys and Intermetallic Compounds" by K. A. Gschneidner, Jr., Chapters 8 and 9 (pp. $152-251$ and 252-323, respectively) of Scandium, Its Occurrence, Chemistry, Physics, Metallurgy, Biology and Technology, C. T. Horovitz, K. A. Gschneidner, Jr., G. A. Melson, D. H. Youngblood and H. H. Schock, Academic Press, New York (1975).

In addition to the above efforts the staff has also been involved in evaluating and estimating the rmodynamic data for rare earth materials which are of special interest to the preparation and utilization of common metals, such as steel, ductile iron, superalloys, etc. These data compilations include:

IS-RIC-5 "Thermochemistry of the Rare Earth Carbides, Nitrides and Sulfides for Steelmaking" by Karl A. Gschneidner, Jr. and Nancy Kippenhan (August 1971) 27 pp.

IS-RIC-6 "Thermochemistry of the Rare Earths. Part 1. Rare Earth Oxides, Part 2. Rare Earth Oxysulfides, Part 3. Rare Earth Compounds with B, Sn, Pb, P, As, Sb, Bi, Cu, and Ag'l by Karl A. Gschneidner, Jr., Nancy Kippenhan and O. Dale McMasters, (August 1973) 67 pp.

"Thermodynamic Stability and Physical Properties of Metallic Sulfides and Oxysulfides", by Karl A. Gschneidner, Jr., pp. 159-77 in SULFIDE INCLUSIONS IN STEEL, J. J. DeBarbadillo and E. Snape, eds., American Society for Metals, Metals Park, Ohio (1975). 
MPSI - 4

\title{
Phase Diagrams and Thermodynamic Properties
}

of Ternary Copper Alloy Systems

by

\author{
Y. Austin Chang \\ Joachim P. Neumann \\ U. V. Choudary \\ Materials Department \\ College of Engineering and Applied Science \\ University of Wisconsin-Milwaukee \\ Milwaukee, Wisconsin 53201
}

Phase diagram and thermodynamic data for copper alloy systems are of considerable fundamental and practical interest in many aspects of extractive, chemical, and physical metallurgy. These data have been reported for binary copper alloy systems in a critical evaluation by Hultgren and Desai [1], which forms one of the monographs in the series, "The Metallurgy of Copper", sponsored by the International Copper Research Association (INCRA). Since commercial alloys usually consist of more than two components, it is imperative to extend the work of Hultgren and Desai [1] to ternary copper alloy systems. At the suggestion of Dr. L. McDonald Schetky of INCRA, a project to compile and evaluate phase diagrams and thermodynamic properties of ternary copper alloy systems was initiated in 1972 at the University of Wisconsin-Milwaukee. A total of 38 elements in addition to copper was considered for evaluation. These 38 elements are $\mathrm{Ag}, \mathrm{Al}, \mathrm{As}, \mathrm{Au}, \mathrm{B}, \mathrm{Be}, \mathrm{Bi}, \mathrm{C}, \mathrm{Ca}, \mathrm{Cd}, \mathrm{Co}, \mathrm{Cr}, \mathrm{Fe}, \mathrm{Ge}, \mathrm{Hg}$, In, $\mathrm{Mg}, \mathrm{Mn}, \mathrm{Mo}, \mathrm{Nb}, \mathrm{Ni}, \mathrm{O}, \mathrm{P}, \mathrm{Pb}, \mathrm{Pd}, \mathrm{Pt}, \mathrm{Re}, \mathrm{S}, \mathrm{Sb}, \mathrm{Se}, \mathrm{Si}, \mathrm{Sn}, \mathrm{Ta}, \mathrm{Te}, \mathrm{Ti}, \mathrm{V}, \mathrm{W}$, and $\mathrm{Zn}$. The non-metallic elements $O$ and $S$ are included because of the technological importance of ternary systems containing one of these two elements. A simple calculation shows that all combinations of these 38 elements yields a 
total of 703 temary copper alloy systems. A literature search mainly based on Chemical Abstracts through June 1973 indicated that data were available for roughly 300 ternary copper alloy systems. In view of the rather large number of systems and in view of the fact that some of these systems are of less commercial interest, the total number of systems for inclusion in this project was reduced to 181. As of October, 1976, a total of 85 ternary copper alloy systems has been completed. These 85 systems are:

(1) $20 \mathrm{Cu}-\mathrm{Ag}-\mathrm{X}$ systems where $\mathrm{X}$ represents $\mathrm{Al}, \mathrm{Au}, \mathrm{Cd}, \mathrm{Fe}, \mathrm{Ge}$, In, $\mathrm{Mg}$, $\mathrm{Mn}, \mathrm{Ni}, \mathrm{P}, \mathrm{Pb}, \mathrm{Pd}, \mathrm{Re}, \mathrm{S}, \mathrm{Sb}, \mathrm{Se}, \mathrm{Sn}, \mathrm{Te}, \mathrm{Ti}$, or $\mathrm{Zn}$;

(2) $17 \mathrm{Cu}-\mathrm{Al}-\mathrm{X}$ systems where $\mathrm{X}$ represents $\mathrm{Be}, \mathrm{Bi}, \mathrm{Cd}, \mathrm{Ce}, \mathrm{Co}, \mathrm{Cr}, \mathrm{Fe}$, $\mathrm{Ge}, \mathrm{In}, \mathrm{Nb}, \mathrm{Ni}, \mathrm{Pb}, \mathrm{Pd}, \mathrm{S}, \mathrm{Si}, \mathrm{Ta}$, or $\mathrm{V}$;

(3) $7 \mathrm{Cu}-\mathrm{Au}-\mathrm{X}$ systems where $\mathrm{X}$ represents $\mathrm{Co}, \mathrm{Fe}, \mathrm{Ni}, \mathrm{Pb}, \mathrm{Pd}, \mathrm{Sn}$, or $\mathrm{Zn}$;

(4) 2 Cu-B-X systems with $X$ being either $\mathrm{Ni}$ or $\mathrm{S}$;

(5) $8 \mathrm{Cu}-\mathrm{Be}-\mathrm{X}$ systems where $\mathrm{X}$ represents $\mathrm{Co}, \mathrm{Mg}, \mathrm{Mn}, \mathrm{Ni}, \mathrm{Si}, \mathrm{Sn}, \mathrm{Ta}$, or Ti;

(6) $3 \mathrm{Cu}-\mathrm{Ca}-\mathrm{X}$ systems with $\mathrm{X}$ being $\mathrm{Ge}, \mathrm{Mg}$, or $\mathrm{Si}$;

(7) 1 Cu-Cd-S System;

(8) $8 \mathrm{Cu}$-Co-X systems where $\mathrm{X}$ represents $\mathrm{Cr}, \mathrm{Fe}, \mathrm{Mn}, \mathrm{Ni}, \mathrm{Pd}, \mathrm{Si}, \mathrm{Sn}$, or Zn;

(9) $7 \mathrm{Cu}-\mathrm{Cr}-\mathrm{X}$ systems where $\mathrm{X}$ represents $\mathrm{Fe}, \mathrm{Mn}, \mathrm{Nb}, \mathrm{Ni}, \mathrm{Pd}, \mathrm{Ta}$ or $\mathrm{Ti}$;

(10) I Cu-Ga-S system;

(11) $1 \mathrm{Cu}-\mathrm{Ge}-\mathrm{S}$ system;

(12) I Cu-Mn-S system;

(13) $1 \mathrm{Cu}-\mathrm{Mo}-\mathrm{S}$ system;

(14) $1 \mathrm{Cu}-\mathrm{Nb}-\mathrm{S}$ system;

(15) 1 Cu-Pd-Pt system;

(I6) I Cu-Re-S system;

(I7) 4 Cu-S-X systems with $X$ being $\mathrm{Si}$, Ta, Ti or $\mathrm{V}$; 
and (18) 1 Cu-Ta-V system.

They contain a total of 166 diagrams (liquidus projections, isothermal sections, isopleths and thermodynamic properties) and a total of 16 general references and 360 specific references.

Reference

[1] Hultgren, R., and Desai, P. D., INCRA Monograph I, Selected Thermodynamic Values and Phase Diagrams for Copper and Some of Its Binary Alloys, The International Copper Research Association, Inc., New York, 1971. 
PHASE EQUILIBRIA IN VARIABLE VALENCE OXIDE SYSTEMS

\author{
William B. White \\ Materials Research Laboratory and \\ Dept. of Geosciences \\ The Pennsylvania State University \\ University Park, PA 16802
}

Some 40 elements react with oxygen to form a series of compounds in which the element appears in more than one valence state. These include most of the transition elements, a group loosely referred to as the Rydberg elements, in which one of the stable valence states is formed by the creation of a nonbonding lonepair electron system, a few of the lanthanide elements, and most of the actinide elements. The objectives are to compile a complete set of phase diagrams for all variable valence element-oxygen systems. This is accomplished by assembling the usually fragmentary diagrams from the literature into a single internally consistent (which does not necessarily mean "accurate") diagram and by using thermochemical calculations where possible to estimate missing parts of the phase diagram.

The systems under study are tabulated in the table. Three types of systems can be distinguished: (i) those in which the solid phases are refractory and in which the oxygen fugacity in the vapor phase is low, so that equilibria can be represented by mapping solid-vapor equilibria as fugacity lines on the T-X diagram that shows the SS and SL equilibria; (ii) systems in which the oxygen vapor pressure is large, so that the effect of pressure on SS and SL equilibria must be considered, and (iii) systems in which one or more oxides is volatile becomes an important constituent of the vapor phase in some temperature-pressure regime. Systems of type (i) are listed as "f-T-X" and of types (ii) and (iii) as "P-T-X" diagrams in the table. For those systems whose status is "H" enough data are available to prepare nearly complete diagrams including melting relations, solidvapor equilibria, and compositions of nonstoichiometric compounds as a function of oxygen activity. Systems listed as " + " are less complete and for systems listed "+" there are only fragmentary data. 
Status of Variable Valence Element-Oxygen

Binary Phase Diagrams

\begin{tabular}{|c|c|c|c|c|c|}
\hline System & $\begin{array}{c}\text { Type of } \\
\text { Representation }\end{array}$ & Status & System & $\begin{array}{l}\text { Type of } \\
\text { esentation }\end{array}$ & Status \\
\hline \multicolumn{3}{|c|}{ Transition Element Systems } & Pt -0 & $P-T-X$ & + \\
\hline Ti-O & $f-T-X$ & + & $A u-0$ & $P-T-X$ & + \\
\hline $\mathrm{V}-\mathrm{O}$ & $f-T-X$ & H & \multicolumn{2}{|c|}{ Rydberg Systems } & \\
\hline $\mathrm{Cr}-\mathrm{O}$ & $P-T-X$ & $H$ & As -0 & $P-T-X$ & + \\
\hline$M n-0$ & $\begin{array}{l}f-T-X \\
P-T-X\end{array}$ & + & $S n-0$ & $f-T-X$ & $t+$ \\
\hline $\mathrm{Ee}-\mathrm{O}$ & $f-T-X$ & +4 & $S b-0$ & $P-T-X$ & + \\
\hline $\mathrm{Co}-\mathrm{O}$ & $\begin{array}{l}f-T-X \\
P-T-X\end{array}$ & $H$ & $\mathrm{~T} 1-0$ & $f-T-X$ & + \\
\hline $\mathrm{Ni}-\mathrm{O}$ & $P-T-X$ & + & $\mathrm{Pb}-\mathrm{O}$ & $P-T-X$ & +4 \\
\hline $\mathrm{Cu}-\mathrm{O}$ & $f-T-X$ & + & $\mathrm{Bi}-0$ & $P-T-X$ & + \\
\hline $\mathrm{Nb}-\mathrm{O}$ & $f-T-X$ & + & \multicolumn{3}{|c|}{ Lanthanide Systems } \\
\hline Mo-O & $f-T-X$ & $H$ & $\mathrm{Ce}-\mathrm{O}$ & $P-T-X$ & $H+$ \\
\hline$T c-0$ & $P-T-X$ & + & $\operatorname{Pr}-0$ & $\begin{array}{l}P-T-X \\
f-T-X\end{array}$ & ++ \\
\hline $\mathrm{Ru}-\mathrm{O}$ & $P-T-X$ & + & $\mathrm{Eu}-0$ & $E-T-X$ & $H$ \\
\hline $\mathrm{Rh}-\mathrm{O}$ & $P-T-X$ & $H$ & $\mathrm{~Tb}-0$ & $\begin{array}{l}P-T-X \\
f-T-X\end{array}$ & ++ \\
\hline$P d-0$ & $\mathrm{P}-\mathrm{T}-\mathrm{X}$ & + & \multicolumn{2}{|c|}{ Actinide Systems } & \\
\hline Ag-0 & $P-T-X$ & + & $\mathrm{U}-\mathrm{O}$ & $f-T-X$ & ++ \\
\hline $\mathrm{Ta}-0$ & $f-T-X$ & $+H$ & $\mathrm{~Np}-\mathrm{O}$ & $f-T-X$ & + \\
\hline$W-0$ & $f-T-X$ & $H$ & $\mathrm{Pu}-0$ & $f-T-X$ & + \\
\hline $\operatorname{Re}-0$ & $P-T-X$ & + & $A m-0$ & $f-T-X$ & + \\
\hline $0 s-0$ & $P-T-X$ & + & Cm -0 & $f-T-X$ & + \\
\hline Ir -0 & $P-T-X$ & + & $B k-0$ & $f-I-X$ & + \\
\hline
\end{tabular}


L.P. Cook, R.S. Roth, T. Negas and G.W. Cleek

Institute for Materials Research

National Bureau of Standards

Washington, D.C. 20234

Compilation of phase equilibria data of interest to ceramists is continuing, in accordance with the pattern established by the 1975 supplement to "Phase Diagrams for Ceramists". This latest supplement includes critical comentaries discussing preparation of starting materials, experimental methods, characterization of products, accuracy and precision of data and of diagram. The following experts in various fields are serving as Contributing Editors for the 1978 Supplement:

- J. J. Brown, Virginia Polytechnic Inst. Fluoride containing systems

- L. L. Y. Chang, Miami Univ. Tungstates, molybdates, carbonates

- R. C. DeVries, General Electric Co. High pressure studies

- F. P. Glasser, Univ. Aberdeen Alkali oxide containing systems

- F. A. Humel, Pennsylvania State Univ. Sulfides, phosphates

- K. A. Jack, Univ. Newcastle Upon Tyne Nitrides, oxynitrides

- A. Muan, Pennsylvania State Univ. First row transition metal oxide containing systems

- C. Semlar, Ohio State Univ. Anhydrous silicate - oxide systems

- C. A. Sorrell, Univ. Missouri-Rolla Aqueous salt systems

- K. Stern, Naval Research Laboratory Binary systems with halides only

- R. Thoma, Oak Ridge National Laboratory Fused salts

- D. R. Wilder and M. Berard, Iowa State Univ. R.E. oxide bearing systems

- H. S. Yoder, Jr., Carnegie Inst. Washington Hydrous silicate systems, high pressure silicate studies 
Scientists at NBS (Cook, Roth and Negas) with the help of the American Ceramic Society (Cleek, Smith and others) are assuming much of the responsibility for gathering the data from the literature and coordinating the preparation of evaluations and final editing of diagrams.

Coverage according to chemical system for the various editions is as follows:

\begin{tabular}{|c|c|c|c|c|}
\hline & 1964 & 1969 & 1975 & 1978 \\
\hline Metal-oxygen systems & 146 & 202 & 104 & $\sim 205$ \\
\hline Metal oxide systems & 855 & 408 & 401 & $\sim 655$ \\
\hline $\begin{array}{l}\text { Systems with oxygen containing } \\
\text { radicals }\end{array}$ & 172 & 228 & 68 & 2120 \\
\hline Systems with halides only & 483 & 718 & 145 & $\sim 365$ \\
\hline $\begin{array}{l}\text { Systems containing halides } \\
\text { with other substances }\end{array}$ & 214 & 273 & 72 & $\sim 160$ \\
\hline $\begin{array}{l}\text { Systems containing cyanides, } \\
\text { sulfides, etc. }\end{array}$ & 43 & 82 & 20 & $\sim 140$ \\
\hline Systems containing water & 151 & 131 & 40 & $\sim 250$ \\
\hline
\end{tabular}

Results of a questionnaire are being analyzed to determine user interest as a function of chemical system and user opinion regarding the critical commentaries, in order to guide the preparation of future editions. 
NBS CRYSTAL-DATA CENTER

\author{
A. Mighell, H. Ondik, J. Stalick, R. Boreni \\ Institute for Materials Research \\ National Bureau of Standards \\ Washington, D.C. 20234
}

The NBS Crystal-Data Center abstracts and critically evaluates crystallographic data. For a substance to be included in the crystaldata file, cell parameters must be reported for the material. These parameters are determined primarily by powder and single-crystal x-ray diffraction. Crystallographic data results from a variety of disciplines and, consequently, is taken from over 300 scientific journals. The total number of crystalline compounds now in the file is over 40,000 .

The output of the project includes:

1. Crystal Data Determinative Tables: Used to identify crystalline materials via the ratios of the cell parameters. The most recent volume published is the third edition. I A supplement to the third edition will be issued in 1977.

2. Crystal Data Space-Group Tables: Materials are arranged by space group. These tables can be used to identify materials of any given space group or symmetry, and to identify isostructural materials. These tables will be consonant with the third.edition of Crystal Data. They will be published in the Journal of Physical and Chemical Reference Data in the Spring of 1977.

3. NBS Magnetic Tape $\# 9:^{2}$ This tape is an abbreviated version of the third edition of Crystal Data and contains cell, space group, density, formula, and determinative ratios. As supplements to the third edition are published the tape will be updated.

4. Component of CIS (Chemical Information System) which is being set up by NIH/EPA: The crystal-data file will be in the CIS system along with the powder-data file, the Cambridge structural file, the mass spectroscopy file and other scientific data bases. These files are to be used primarily in the identification of unknown crystalline materials.

A principal use of the cell and chemical data is the identification of unknown crystalline materials. Several recent developments give great promise for the identification of unknown materials via singlecrystal work. They include the growth of the data base, advances in lattice theory, and automation of the single-crystal x-ray diffractometer. To identify an unknown, one can start with a single crystal, mount it on a diffractometer, determine a refined primitive cell, reduce the cell, and check against a file of known reduced cells. The entire procedure can be automated. As a result, the single-crystal x-ray diffraction method can now complement the powder method for the routine analysis of crystalline materials. 
A major objective of the NBS Crystal-Data Center is to establish close ties with other data efforts with common interests and to coordinate our data evaluation with these centers (e.g. Joint Committee on Powder Diffraction Standards, Cambridge Crystallographic Data Centre, The Chemical Information System).

1 J.D.H. Donnay and Helen M. Ondik, "Crystal Data Determinative Tables," Third Edition, Vol. 1 and 2, U.S. Department of Commerce, National Bureau of Standards, and the Joint Committee on Powder Diffraction Standards (1972, 1973).

2 For information about the tape and its lease, contact the National Technical Information Service (NTIS), Department of Comerce, 5285 Port Royal Road, Springfield, VA 22151.

DEMONSTRATION: The NBS magnetic tope \#9 described under item 3 of this abstract wizl be accessed in an accompanying demonstration of "On-Iine Data Retrieval and Analysis Systems Such as OMNIDATA", by B. B. Molino and $J$. Hilsenrath, NBS. 
The NBS Alloy Data Center

\author{
G. C. Carter, D. J. Kahan, and L. H. Bennett \\ Metallurgy Division \\ Institute for Materials Research \\ National Bureau of Standards \\ Washington, D.C. 20234
}

Knowledge of the structure of materials is important in understanding several industrially significant phenomena and applications such as aging, hardness, occurrence of brittle intermetallic compounds, magnetic transition temperatures, high-temperature solubility of impurities, corrosion resistance, solid electrolytes and non-crystalline solids, as well as many other physical properties. The study of a phase diagram appropriate to a particular material can often provide information important to its scientific and technical applications. In recent years it has become increasingly clear that the need for reliable phase diagrams far exceeds the availability, and the Alloy Data Center is now addressing this problem in some detail.

As a result of this need, our present workshop has been organized, with as goals: to assess the current national and international status of phase diagram determinations and evaluations for alloys, ceramics and semiconductors; to determine the needs and priorities for phase diagram determinations and evaluations; and to estimate the resources being used and potentially available for phase diagram evaluation.

Currently, several data centers thoughout the world are engaged in collecting, critically evaluating, and disseminating phase diagram data. The Alloy Data Center plans to interact with these groups and hopes to coordinate some of their activities in order to help avoid costly and time consuming duplication of efforts, as well as to identify areas of greatest needs and recommending programs in these areas. In order to achieve these objectives, the Center has already prepared a compendium of existing phase diagram compilations and other reference material (1) and a list of existing phase diagram evaluation groups (both data 
enters and groups involved in CALPHAD-type computational techniques (2)). Updated ists with this information will be available at the workshop, as well as some results from a study on phase diagram data activities and data needs conducted via questionnaire sent out to participants in this workshop.

The Alloy Data Center plans to critically evaluate phase diagrams in specific areas, and has started with metal-hydrogen systems applied to a hydrogen storage. Assistance in phase diagram evaluations carried out by other groups-is planned through creating a central computerized bibliographic file with on-line lapabilities; development of an on-line system using graphical methods for the numerical phase diagram data is also planned for user accessibility.

In general, the Alloy Data Center maintains an awareness of about 150 physical properties in metals and alloys, evaluating only those properties for which a special need exists and for which qualified researchers are employed in the Alloy Physics Section, in which the Alloy Data Center is located. In the past, critical compilations in soft $x$-ray spectroscopy ${ }^{(3)}$ and nuclear magnetic resonance ${ }^{(4)}$ were prepared (the latter including some 800 binary phase diagrams). Consequently, our current bibliographic files ${ }^{(5)}$, which contain nearly all papers on the first two subjects published up to recent years are not being kept up-to-date, while papers on phase diagrams are being annotated and entered at an increased rate for production of a comprehensive bibliographic file. This file is expected to become quite large and warrants modifications of our current computerized system to an on-line system which can be queried from terminals located at user sites. The above-mentioned development of graphical methods for numerical phase diagram data handling is a separate goal in numerical data dissemination.

At the poster session, an exhibit of several of the phase diagram reference books, of the current annotated indexing system, and of some preliminary graphical techniques for phase diagram display will be presented.

(1) L. H. Bennett, D. J. Kahan, and G. C. Carter, MatIs. Sci. Eng. 24, 1 (1976).

(2) L. H. Bennett, "Alloy Phase Diagram Activities of the Alloy Data Center", 5th International CODATA Conference, Boulder, Co., June 28-July 1, 1976. 
(3) Soft X-ray Emission Spectra of Metallic Solids: Critical Review of Selected Systems and Annotated Spectral Index, J. R. Cuthill, A. J. McAlister, R. C. Dobbyn, and M. L. Williams, NBS Special Publication No. 369 (1974).

(4) "Metallic Shifts in NMR", G. C. Carter, L. H. Bennett, and D. J. Kahan, Progress in Materials Science 20, 1-2260, Pergamon Press (1977).

(5) File, described in NBS Technical Note 464, by G. C. Carter et al. (1968); the file holdings up to 1970 published in "The NBS Alloy Data Center: Permuted Materials Index", by G. C. Carter et al. (1971); the file holdings through 1972 made available in NBS Magnetic Tape 3, Alloy Data Center Tape and Docummentation Parce1, Nat1. Tech. Info. Ser., Springfield, VA. 22151.

DEMONSTRATION: A demonstration "AZZoy Data Center Graphical Methods" by $R$. A. Kirsch and L.J. Swartzendmber, NBS, will be carmied on during the poster session. 


\author{
Phase Equilibria in Cryolite Systems \\ Jesse J. Brown, Jr. \\ Department of Materials Engineering \\ College of Engineering \\ Virginia Polytechnic Institute and State University \\ Blacksburg, Virginia 24061
}

The electrolyte used in the Hall process for producing aluminum metal consists basically of a fused mixture of alumina $\left(\mathrm{Al}_{2} \mathrm{O}_{3}\right.$ ) and cryolite $\left(\mathrm{Na}_{3} \mathrm{AlF}_{6}\right)$. Other ingredients including $\mathrm{AlF}_{3}$, LiF, and $\mathrm{CaF}$ are added to modify properties such as bath density, electrical conductivity, and freezing temperature. The electrolyte composition now used was determined largely by trial and error because of the incompleteness of available phase equilibria data.

For the past five years, a research program jointly sponsored by the Alcoa Foundation and the VPI\&SU Research Division has been underway in the Materials Engineering Department at VPI\&SU. This program was designed to critically review the existing phase equilibria data on systems involving cryolite and to expand upon this body of knowledge by determining the liquidus-solidus phase relationships in a portion of the $\mathrm{LiF}-\mathrm{CaF}{ }_{2}-\mathrm{AlF}_{3}-\mathrm{NaF}-\mathrm{AI}_{2} \mathrm{O}_{3}$ system.

Historically a variety of experimental techniques have been employed to determine the phase diagrams of systems important to the Hall process. Many of the early experiments were conducted using open containers. This practice resulted in the publication of some inaccurate phase diagrams because of the decomposition of many of the fluoride compounds at high temperatures. In more recent years, it has become standard procedure to encapsulate all samples in sealed platinum containers. Quenching and Differential Thermal Analysis (DTA) experiments 
using samples sealed in the platinum containers have been used to revise some of the early phase diagrams and to investigate new systems.

In this paper, the phase diagrams that are known in the $\mathrm{LiF}-\mathrm{CaF}_{2}-$ $\mathrm{AIF}_{3}-\mathrm{NaF}-\mathrm{Al}_{2} \mathrm{O}_{3}$ system are reviewed in a systematic manner and the diagrams that have been determined at this University over the past five years are included. The result is a current review of the phase equilibria knowledge of cryolite containing oxy-fluoride systems of importance to the aluminum industry. 


\section{Краткие сведения}

- содерғании третьего, четвертого и пятого томов труда

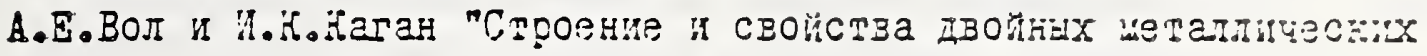

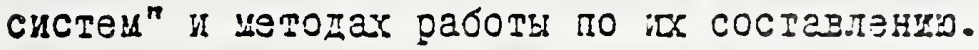

Во всех томах принят единвй прицип располовения материета, а именео, кан металлы, тан и осразузше ими двойные системи располагартся з алфавитном порядие по их паименованиям на русском

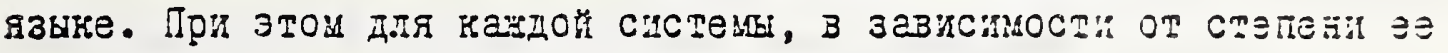
изученности, приводлтся следуошие дениве:

I. Диагра:ща состокния и кристаллиесная структура;

2. Физическле и механические свойства (тернодианически,

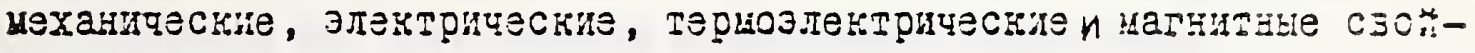
ства, поверхностное Еатязение и вязиость, упругость даров, полт-

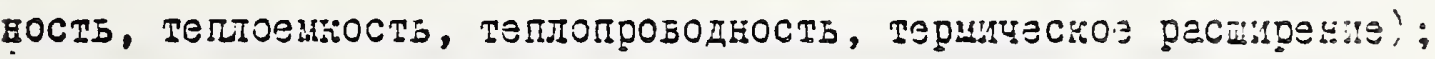

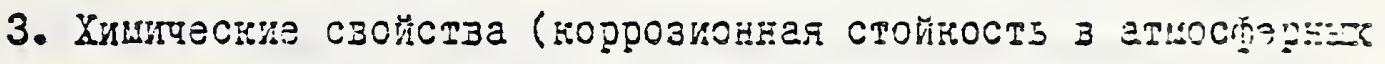
условияк, а танғе в различных агрессивнх средах и з газах, стойкость против окисления при высоких тенперагурах);

4. Список использованной литературн.

Авторы уделярт отень большое внинание вопросу болея пол:его

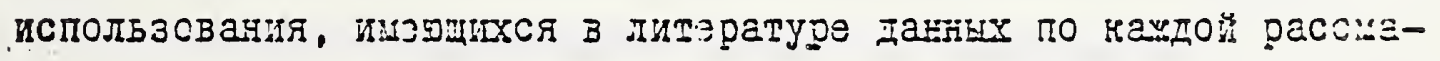
триваеной спстене. При написании третьего тома, в ко'орьй вогли системы золота, индия, иридия, иттербия и иттрия, били использованы данные, опубликованцые по I970-7І гІ включительно. При полготовке матеріталоз для 4-Го тока, в которни войдут систезы кадиия, калия и кальция, используются данше, опублиованнце по I973-74 ГГ. включительно. Для составления 5-Го тома, в которьй воидут систены кислорода, кобадьта и нремия, будут использозаны дитературные даннье, опубликованные по I975-7.6 ГГ. видриительво.

В третьеу томе (объек $\sim 70$ печатных листов), вщход котосого из пэчати одидается в ноябре-декабре I976 Г., приводятся данние 
по 288 двойпи систонам, в точ числе для II6 систем приведень диатрами состояния во всей области нонцентрания и сделан под-

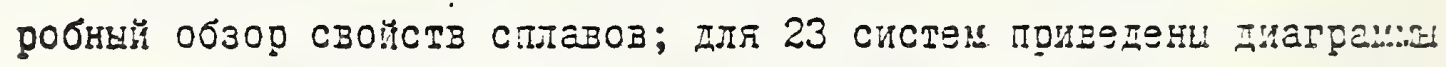
состолния не во всей области нонцентраций й менее подробное оп::-

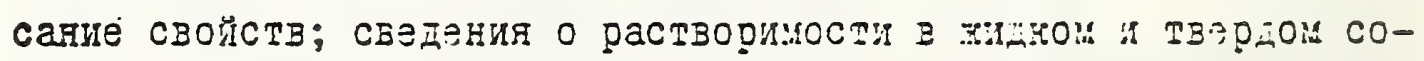
стояниях, составе промезуточних баз.с описантен з ряде случаез отдельних своиств, призедены для I49 двойнх систәи.

При построени диаграми состояния предпочтение -отпаватось данны, полученним при псследовании наиболее чистих сплазов С

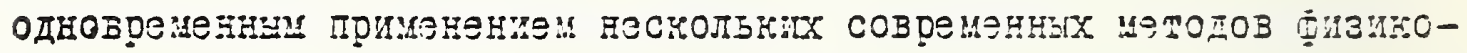
химического анализа. В тех случаях, когда имоникя а расторя:звии авторов даннех было недостаточно для одтознатуого рөшения, в нниту помещали два зарианта одной и той те диаграмин ссстоя-

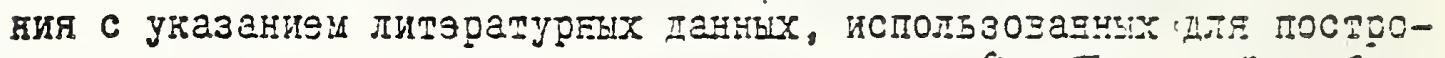

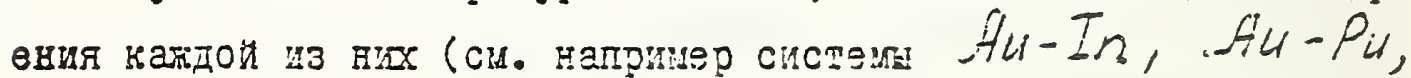
$\left.I_{n}-M g, I_{n}-N_{2}, I_{n}-T \hat{l}, I_{2}-T i\right)$.

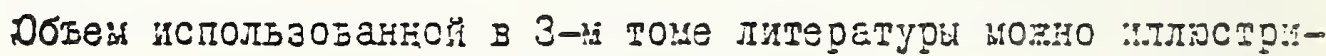

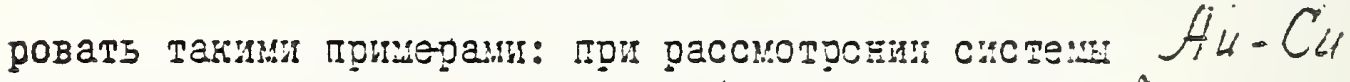

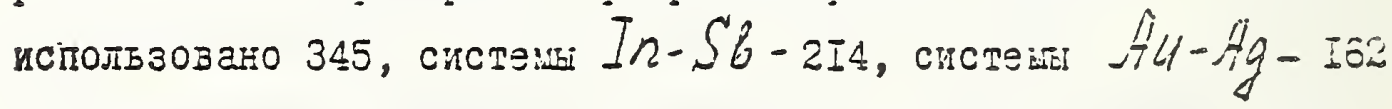
литературенх источниа. Тани образом, только тля этих трех спстен использовано более 700 литературних источниов.

В 4-х томе (обвец окола 50 печатныг листов) рассиотрено I63. систен. В этон тоне для 54 систем понедены диаграни состояния во всей области составов ил стелан подробный обзор свойств сплавов. Iля остальних I09 систен приведены сведения о взаинной раствориноси номпонентов системы й (илI) состазе образуемпх пми пронетутонных фаз с описанием в ряде случаед свойств сптазов.

объеу 5-то тома предполагается $\sim 60$ печятних листов c. pассмотрением около I40 систем.

В капестве основних материалов для ваплсани паречисленных 


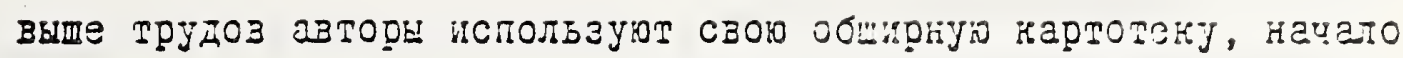

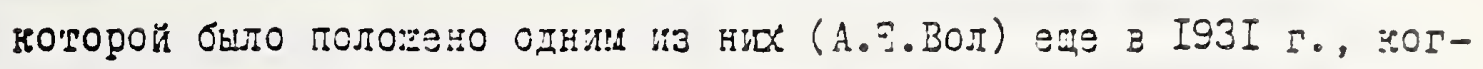

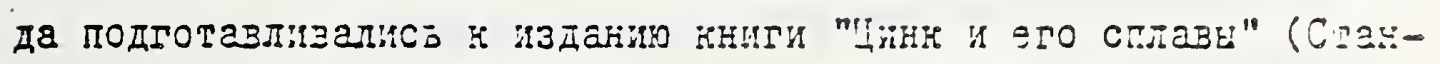
дартгиз, І9з3 г.), "Никель и его сплази" ("ветиетиздат, ІЯзаг.)

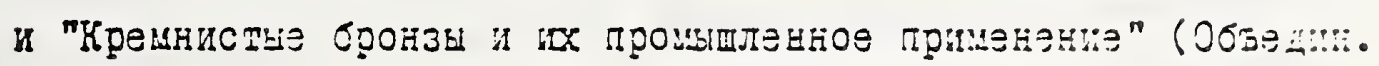

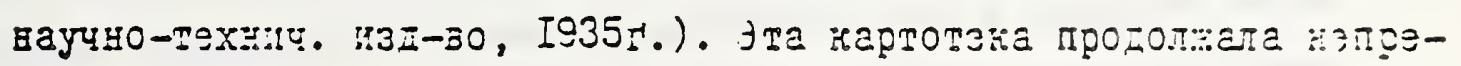

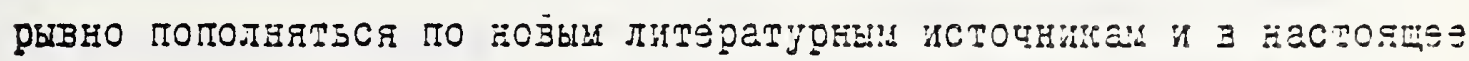

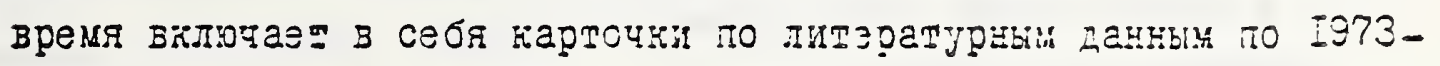

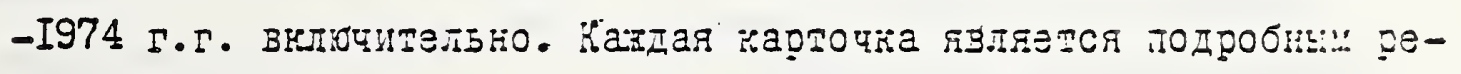
Фератом с притовевиех граџ̆иов и таблиц оригинальиого истот:на

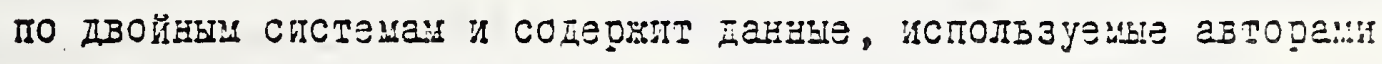

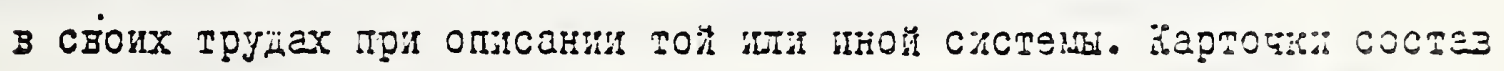

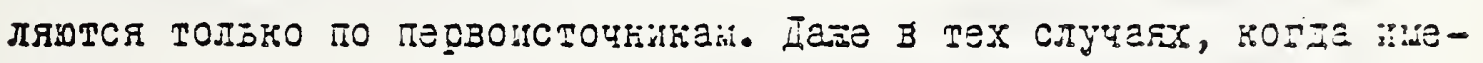

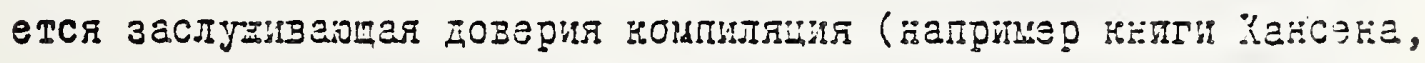

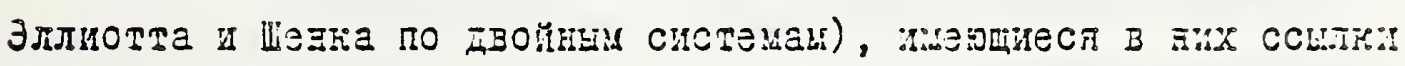

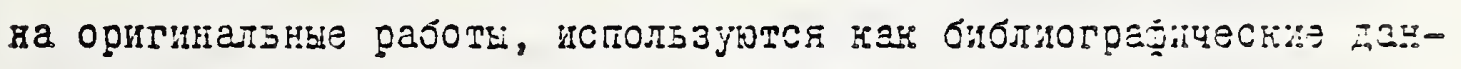

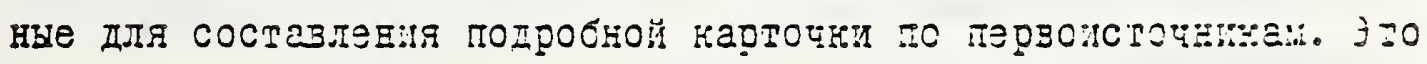

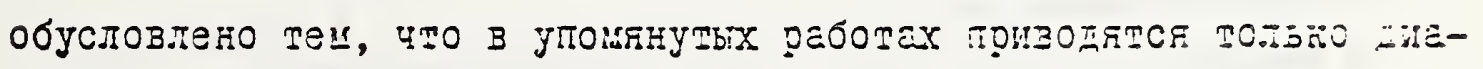

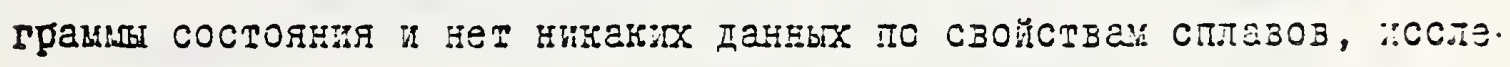

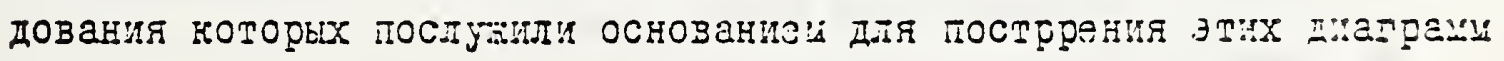
В случае невозиовности ознакомления с первоисточниами - испол-

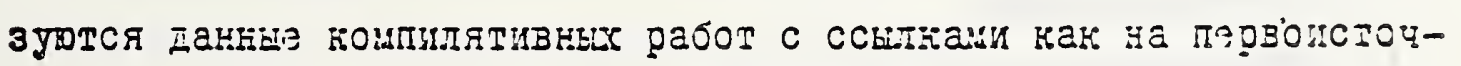
ник, так и на компилятпвиур работу.

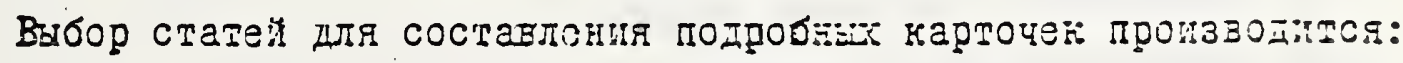

I. путем систематического просмотра целого ряда пурнатов, изда-

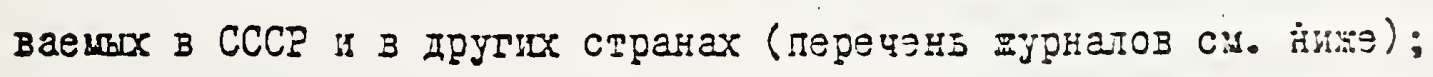

2. путем систейтического просиотра litaliureical Abstracts 10 Journal Institute of Metals (Iordon);

3. путен систенатического просиотре ређеративй пурнатов "Металлургия" и "Химия", издаваемих в ССС?. 
Классификация иарточеи в картотеке полностью отзэчазт привятой для издания трудов. Кавдошу эләщзнту периодической систе-

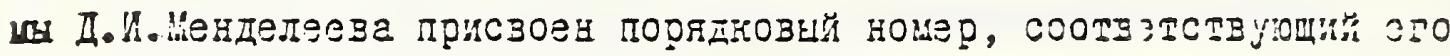

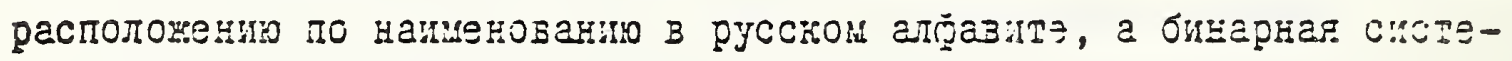

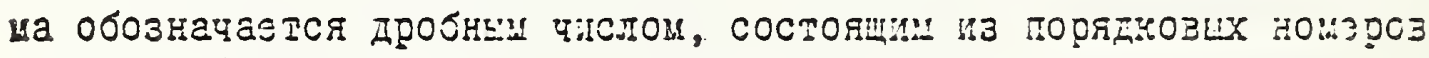

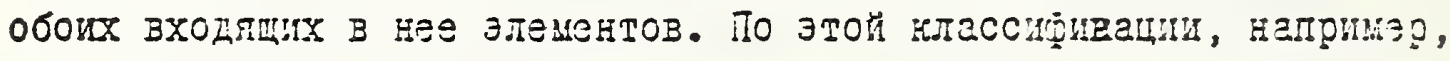

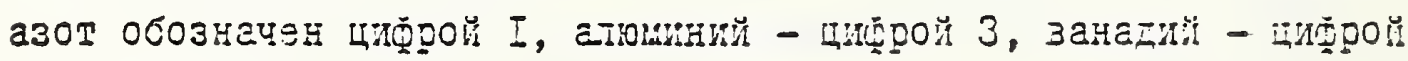

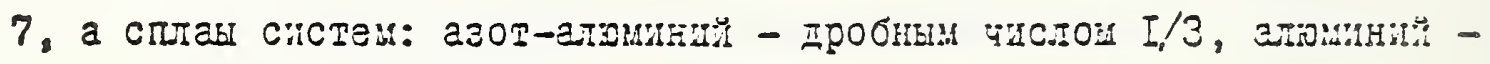

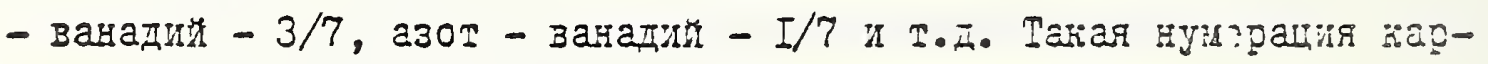

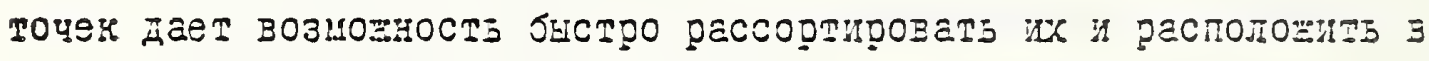

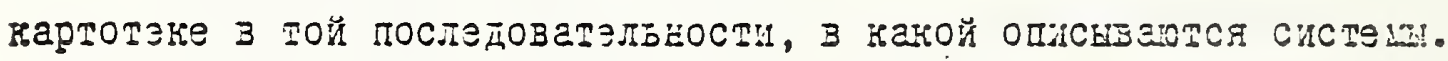

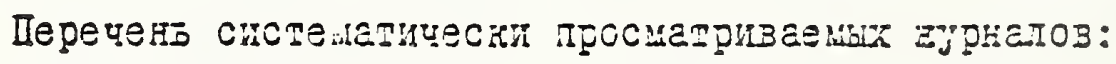

I. Атомная энергия,

2. Iоклады Arazewn haуr CCCP,

3. журнал неортанической химй,

4. Мурнал прикладной кимни,

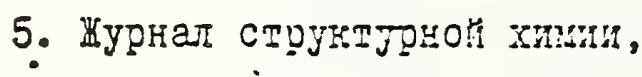

6. щурнат Физичеспой химия,

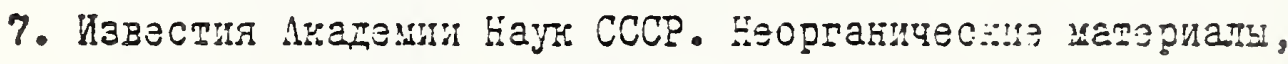

8. Известия Авадении Наун СССР. цетатлы,

9. Известия Высших учебних зазздәнй. Пветнал иеталлургия, I0. Кристаллогратия,

II. Металловедение й термическея обработка метаптов,

I2. Унраннский хинический шурнал,

I3. Физика мзэллов и металловедение,

I4. Acta Crystallographica,

I5. Acta Netallurgica,

I6. Comptes rendus Acad. Sci., Paris,

17. Joura. Iess-Common Hetals,

I8. Journ. Institute of Metals, 
I9. Transactions ASi:

20. Transactions AIIIZ (Trans. Petaliurg. Soc. AIIJ),

2I. letallurgical Transactions

(1970.

22. Zeitschrift fur anorganische chesie,

23. Zeitschrift fll ëristallographie,

24. Zeitschrift fur "etallaunde.

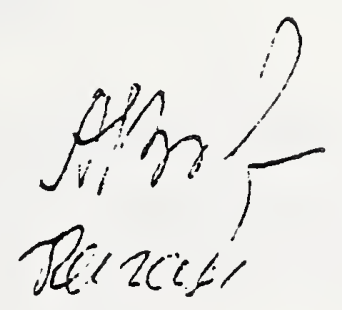

\section{Brief Summary}

The $3 r$, 4th, and 5th volumes of the "Handbook of Binary Metaliic Systems" and the Methods of compilation Q editing.

by A. E. Vol \& E. K. Kagan

Leningrad, USSR 
An English translation of MPSI-10 prepared by G. Marinenko, Analytical Chemistmy Division, Institute for Materials Research, NBS.

Brfef Information on the Content of the Third, Fourth, and Fifth Volumes of the Colievtion "Structure and Properties of Binary Metallic Systems" by A. E. Vol and I. R. Ragan, As Well As Presentation of The Methods of The Work In Compllation of These Volumes

\section{A. E. VoI and I. K. Kagan}

Leningrad, IJSSR

In all of the volumes a single principle of organizing the material was adhered to; namely, both metals, as well as the hinary systoms which these metals form, were arranged in alphbetical order in acco:-dance with thefr chemical symols In the Russian language. At the same time for eich system, dependiag on the degree to which the system was studied, the following Aita were cited:

(1). Phase Eiagram and Crystal Structures;

(2). Physical and Mechanical Properties (Thermodynamic, Mechanical, Electrical, Thermoelectric and Magnetic Properties, Surface Tension and Viscosity, Vapor Pressure, Density, Heat Capacity, Thermoconductivity, and Thermal expansion);

(3). Mechanj cal Properties (Corrosion Stab.ility under atmospheric conditicas, - as wel: as in various other corrosive media and gasses, Oxidation Stabil: ty at elevated temperatures);

(4). Enumer: tion of bibllography which was used.

The authors devote extremely great attention to the question of fuller utilization of data which are available in the literature on each of the considered systems. In writing the third volume, which contained systens of Au, In, Ir, Yb, and $Y$, data were ut1lized which wera published until 1970-1971 inclusively. In preparation of the materials for the Fourth volume which included $C d, K$, and $C a$ systems, data were utilized which were published unt1 1973-1974 inclusively. In compilation of the fifth volume, which contains 0 , Co, and Si systems, litarature data published unt11 1975-1976 inclusively were utilized. 
The third volume (amounting to approxdmately 70 printed pages), publication of which is expected to be in Nov.-Dec. $1976^{*}$ the data are cited on 288 b1nary systems, Including phase diagrams over the entire composition range and detailed studies of the properties for 116 systems; for 23 systems phase diagrams are provided, but not orer the entire composition range and the descrlptions of the properties are less detalled; information on the solubility in liquid and solid states, composition of the intermediate phases with the description in a number of cases of individual properties are given for 149 binary systems.

In constructing the phase diagrams the preference was given for data which were obtained with the study of the purest alloys witl. simultaneous use of several modem methods of physico-chemlcal analysis. In thos' cases where the data avallable to the authors were insufficlent for a single-valued decision, two varlations were lacluded in the book for the same phase diagram indicating the 11terature data which were utilized for the construction of each of these (see for example the following systems: Au-In, Au-Pu, In-Mg, In-Na, In-TI, Ir-I1).

The scope of literature utilized in the third volume can be 11lustrated with the following example: In considering the Au-Cu system, 345 11terature sources were used, for In-Sb system 214 siurces were used, while for Au-Ag system, 162 sources were ut1l1zed. Thus, for these three sytems only, more thin 700 I1terature sources were utilized.

In the fourth volime (approximated 50 printed fages) 163 systems are considered. Phase diagrams are pro-Ided over the whole compositfo:! range and a detalled review of the properties of 5, alloy systems is made. For tre remaining 109 systems, information is given $m$. the mutual solubility of the somponents of the systems and/or composition of the intermediate phases which are formud by the component metals along with a description of the propertles of the allcys in a number of cases.

The fifth volume is expected to be approximately 50 printed pages and to contain approximately 140 systems.

"Translator's note: has been published by "Nauka", Moscow, 1976. 
The basic materials which were used for compilation of the above cited work were the extensive card file of the authors, which was initiated by one of the authors (A. E. Vol) back in 1931, when the books "Zinc and Its Alloys" ("Standartgiz" Publishing Bouse, 1933), "Nickel and Its Alloys" ("Tsvetmetizdat" Publishing House, 1932) and "Silicon Bronzes and Their Industrial Aplications" ("Ob'Yedin. Nauchno-Tkhnich." Publishing House, 1935) were being prepared for publication. This card file was continuously updated from new literature sources and at present includes Iiterature data up to 1973-1974 inclusively. Each card is a detailed reference with the attached graph and tables of the original source on the binary systems and contains data which are utilized by authors in their work in describing these various systems. The cards are compiled only from the original sources. Only in those cases, when reliable compilations are available (for example., the books by Hansen, Elliott, and Shunk on binary systems), the references contaired in those books to the original works were utilized as bibliographic data for the compllation of a detailed card file on primary sources. This results from the fact tirt in the above works only phase diagrams are given and there are no data on the propertics of alloys, the studies of which served as the basis for the construction of these phase. diagrams. In a case when it is not possible to becore familiar with the primary source, the data of compiled works are ut1lized with references both to the primary source as well as to the compilation utilized.

Cholce of ar:icles for compllation of the cetalled card file is performed is follows:

1. By systenatic review of the whole series of journals which are published in the USSR and other countries (for a list of jcurnals, see below);

2. By systelatic review of the Metallurgical Abstracts in the Journal of Institute of Metals (London);

3. By systematic search of the reference journals ("Referativni Zhurnal") "Metallurgiya" and "Khimiya", published in the USSR.

The classification of cards in the card file corresponds completely to the format used in publishing the work. An ordinal number is given to each of the elements of the peroldic system of elements of D. I. Mendeleev, which corresponds to its alphabetical position in a list of chemical symbols in the Russian language, and binary systems are denoted by fractional numbers, which consist of both ordinal numbers of the elements which comprise the system. In accordance with this classification, for example, nitrogen 
is designated by 1, Aluminum by 3, Vanadium by 7, and the alloys of the systems: nitrogen-aluminum by $1 / 3$, aluminum-vanadium by $3 / 7$, nitrogen-vanadium by $1 / 7$, etc. Such numberlng of cards enables one to quickly sort them and place them lato the card file 1n the sequence which corresponds to the description of the system.

The 11st of foumals which are systematically searched:

1. Atomaya Energiya (Atomic Energy),

2. Doklady Akademil Nauk SSSR (Ieports of the Acadeny of Sclences of the USSR),

3. Zhumal Neorganicheskoy Khimil (Joumal of Inorganic Chemistry),

4. Zhumal Prikladni.y Khimil (Journal of Applied Chemistry),

5. Thurnal Strukturioy Khimil (Joumal of Structural Chemistry),

6. Zhumal Fizfcheskoy Khimil (Journal of Physical Chemistry),

7. Izvestiya Akademi1 Nauk SSR. Neorganicheskiye Materialy (News of the Academy of Sciences of the USSR, Inorganic Materials),

8. Izvestiya Akademil Nauk SSSR. Metally (News of the Academy of Sclences of the USSR, Metals),

9. Izvestiya Vysshikh Uchebnykh Zavedeniy. Isvetnaya Metallurgiya (News of the Institutions of iligher Learning. Nonferrous Metallurgy),

10. Kristallografiyc (Crystallography),

11. Metallovedeniya : Termicheskaya Obrabotka Metallov (Metal Science and the Thermal Treatment of Metals),

12. Ukralnskiy Khimicheskiy Zhumal (Ukrainian Chemi cal Journal),

13. Fizika Metallov : Metallovedeniya (Physics of Metals and Metal Science),

14. Acta Crystallographica,

15. Acta Metallurgic $\exists$,

16. Comptes rendus Ar:ad. Sc1., Paris,

17. Journ. Less-Comin Metals,

18. Journ. Institute of Metals,

19. Transactions A.SM,

20. Transactions ADME (Trans. Metallurg. Soc. AIME),

21. Metallurgical Transactions c1970,

22. Zeitschrift fur anorganische Chemle,

23. Zeltschrift fur Kristallographie,

24. Zeitschrift fur Metallkunde. 
MONDAY, IO JANUARY, 1977

$$
3: 30 \text { PM - 6:00 PM }
$$

PAPERS GIVEN BY POSTEP

$$
\text { TOPIC II }
$$

EXPERIMENTAL TECHNIQUES IN PHASE

DIAGRAM DETERMINATIONS 
The Determination of Phase Diagrams for Liquid

Oxides and Metallurgical Slags by

Hot-Wire Microscopy

by

H. Alan Fine

Dept. of Metallurgical Eng.

University of Arizona

Tucson, AZ 85718

Hot-wire microscopy has been used successfully to determine the liquidus surfaces for many oxide systems. The technique, which lends itself to measurements in all temperature ranges, can be used to determine liquidus surfaces for transparent or semi-transparent melts under reducing, neutral or oxidizing atmospheric conditions.

A review of the previous work using hot-wire microscopy is presented and the limitations and the experimental idiosyncrasies of the technique are discussed. The speciai equipment necessary for atmosphere control within the hot-wire microscope are discribed and the application of this equipment to measurements on metallurgical slags is discussed. 
EXPERIMENTAL TECHNIQUES IN PHASE DIAGRAM

DETERMINATIONS OF SUPERCONDUCTING COMPOUNDS CONTAINING

VOLATILE COMPONENTS AT. TEMPERATURE UP TO $2200^{\circ} \mathrm{C}$

by

R. Flükiger and $\mathrm{J},-\mathrm{L}$. Jorda

Département de physique de la Matière Condensée

32 , bd d'Yvoy

1211 - Geneva

SWITZERLAND

If one analyses all the work which have been published on superconductors during the last 15 years, it is astonishing that the phase diagrams of the highest Ic superconductors, such as $\mathrm{Nb}$ - Ge, $\mathrm{Nb}$ - $\mathrm{Al}$ and $\mathrm{Nb}$ - Ga are far from being really known at the formation temperature of the superconducting A 15 phase, i.e., in the range $1750<T<2200^{\circ} \mathrm{C}$. The main reason is the lack of direct observations at these temperatures, which are particularly difficult if one of the components, as $\mathrm{Ga}, \mathrm{Al}, \mathrm{Sb}, \ldots$ has a high vapor pressure at these temperatures. It is

evident that the contamination problem becomes more and more important, thus limiting the choice in crucible materials.

We have developed facilities for measuring precisely the high-temperature part of such diagrams, which consists in a combination of

1) HIGH-TEMPERATURE DTA up to $2200^{\circ} \mathrm{C}$ under an Argon pressure of 1 - 10 at.

2) SIMULTANEOUS STEPWISE HEATING of 10 samples of different compositions up to $2200^{\circ} \mathrm{C}$ under an Argon pressure of 1 - 10 at.

After each step, the samples are cooled down to room temperature and are analyzed microscopically. This technique is used for checking the DTA thermal arrests, with steps of 5 or $10^{\circ} \mathrm{C}$.

3) High-rate quenching techniques.

The work on these materials can only be judged on the basis of different information on the same thermal arrest. Thus 1 ) and 2) are complementary, and their combination is necessary.

It is clear that the temperature has to be measured simultaneously by different methods and that different crucible materials have to be tested, in order to exclude a possible influence on the thermal arrests. 
The analysis of the samples is done by microscopic observation, chemical analysis and microprobe measurements.

The problem of suitable standards is very important, and has been solved by melting of a single-phased alloy having a composition close to that of the investigated samples, but melted under pressures of 100 and more atmospheres, in order to minimize the weight losses and thus the uncertainty in composition. In some cases, the standards would have to be formed even at higher pressures leading to weight losses smaller than $0.5 \%$.

The combination of all these techniques allowed us to determine the phase diagrams of the systems $\mathrm{Nb}-\mathrm{Ga}$ and $\mathrm{Nb}$ - Ge with a precision of $\pm 15^{\circ} \mathrm{C}$ in temperature at $2000^{\circ} \mathrm{C}$ and 0.5 to 1 at. \% in composition. These systems are presented in detail. It is seen that the proximity of the A 15 phase regions to the stoichiometric compositions $\mathrm{Nb}_{3} \mathrm{Ga}$, and $\mathrm{Nb}_{3} \mathrm{Ge}$ respectively (both systems are of the type shown in fig. 1), can only be determined by the combination of 1) and 2).

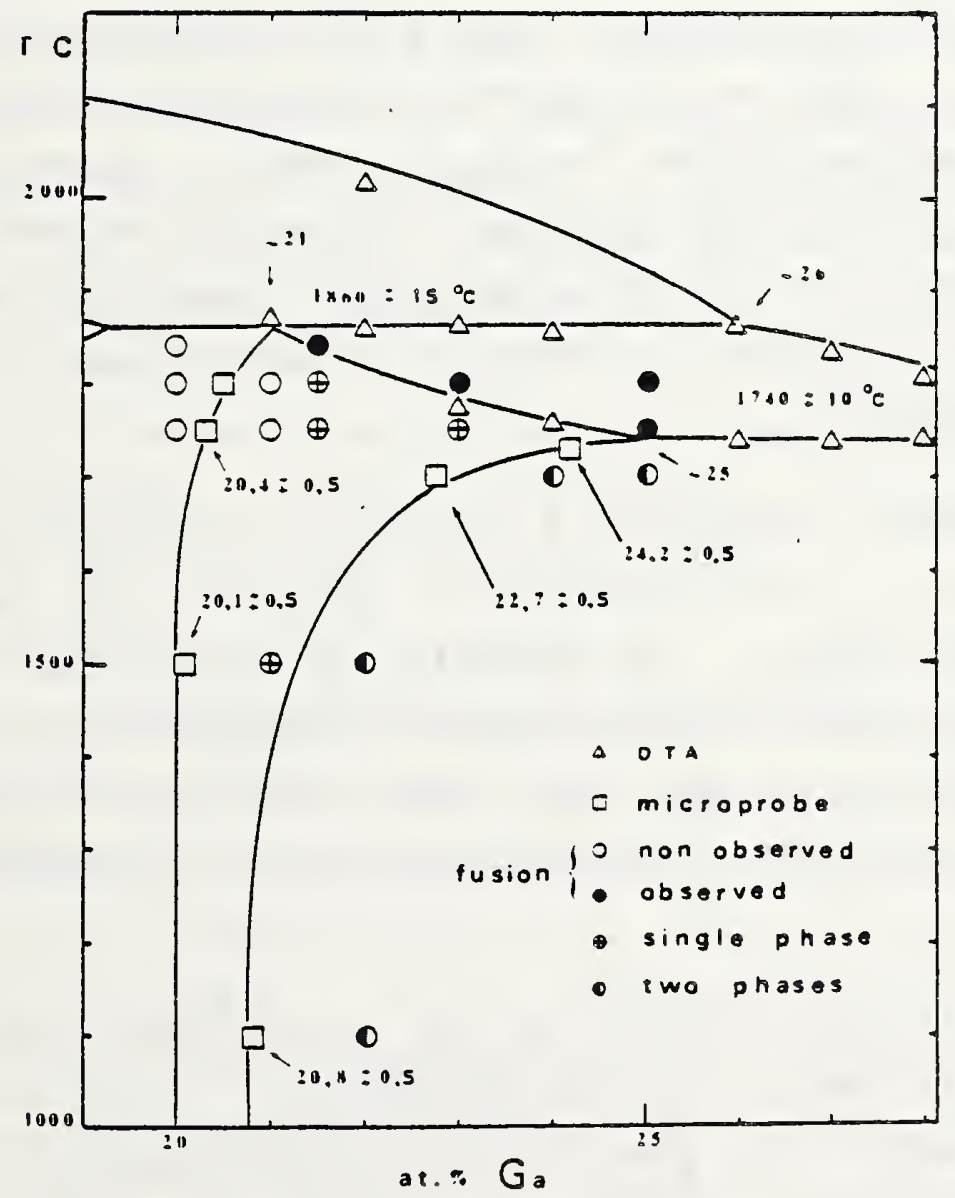


Exporinontal Tochriquos In Rhase Diafram Daterminatjons : Applications to Silicate Systems.

F.P. GIasser

Department of Chemistry

University of Aberdeen

Meston Walk, Old Aberdeen

Aberdeen $A B 9$ 2UE, Scotland.

Many silicate systems relevant to oxide technology which have been studied in previous decades require restudy using improved phase-sensitive techniques. A number of examples of the applications of specific techniques and the results obtained by their application to specific systems will be preserted.

Re-examination of the $\mathrm{Na}_{2} \mathrm{O}-\mathrm{CaO}-\mathrm{SiO}_{2}$ system has disclosed the presence of two incongruently-melting compounds, $\mathrm{Na}_{6} \mathrm{Si}_{8}{ }^{0} 19$ and $\mathrm{Na}_{2} \mathrm{CaSi}_{5} \mathrm{O}_{12}$. The former closely resembles $\mathrm{Na}_{2} \mathrm{Si}_{2} \mathrm{O}_{5}$ both in its optical properties and $\mathrm{X}$-ray powder pattern. Sincle-crystal studies and density determinations were nacessary to characterize $\mathrm{Na}_{6} \mathrm{Si}_{8} \mathrm{O}_{19}$ and to prove its formula. The range of solid solution shown to exist on the $\mathrm{Na}_{2} \mathrm{SiO}_{3}-\mathrm{CaSiO}_{3}$ join were characterized by density and unit cell determinations, combined with classical methods of determining the single-phase Iimit of homogenity.

It is almost essential to be able to apply X-ray crystallographic metriods if the formulae of phases with complex chemistry are to je elucidated. An example is the characterization of the quaternary phase which occurs in systems of the type $\mathrm{BaO}-\mathrm{CaO}-\mathrm{MO}-\mathrm{SiO}_{2} \quad\left(\mathrm{M}=\mathrm{Mg}\right.$, Co, $\left.\mathrm{Zn}, \mathrm{Fe}{ }^{2+}\right)$, the quaternary phase was shown to be $\mathrm{Ba}_{2} \mathrm{CaM}_{2} \mathrm{Si}_{6}{ }_{17}$ and is isostructural with pellyite.

A thorough exploration of the subsolidus phase relations in silicate systems is often neglected. It is, nevertheless, an essential part of a phase equilibrium diagram. Compounds may have a minimum temperature of thermal stability as well as a maximum. The systems $\mathrm{PbO}_{-\mathrm{SiO}_{2}}$ and $\mathrm{Na}_{2} \mathrm{SiO}_{3}-\mathrm{CaSiO}_{3}-\mathrm{S}_{2} \mathrm{SiO}_{3}$ will be used as illustrations. Experiments of relatively 
Iong duration are usually required to detexmine these subsolidus equilibria: trief experiments, especially those in which it has not been demonstrated that reactions are reversible, are unreliable to define the equilibrilum state. In systems wilere a phase is stable to liquidus temperatures it may coexist with liquid over only a small range of compositions and its existence is unlikely to be revealed except by very detailed study of the liquidus. However, X-ray examination of the products of subsolidus reactions will usually reveal the presence of a new phase or phases. The history of the $Q$ phase in the $\mathrm{CaO}-\mathrm{MgO}_{\mathrm{H}} \mathrm{A}_{2} \mathrm{O}_{3}-\mathrm{SiO}_{2}$ system and the discovery of a second quaternary phase (designated $R$ ) in this system are examples. Another important type of subsolicius phase change occurs when solid-phase combinations present at liquidus invariant points become less stable at lower temperature with respect to some other permutation of tre pluases occurring in the system. In the systom MgO-At. $\mathrm{O}_{3}-\mathrm{SiO}_{2}$ cordierite and corundum are not compatible phases either at liquidus temperature or at the solidus, whereas below $\sim 1360^{\circ}$, they become a stable assemblage. Subsolidus equilibria in this system meet the criteria of being fully reversible, although experiments of several month:s duration are required to prove this.

Results of siudies undertaken by the writer show that definitive phase equilibrium diagram exist for oniy a few silicate systems. In the future, the application of predictive methods will be handicapped if systematic efforts are not made to both reassess and also check experimentally the quality of these data. It is considered likely that for the forseeable future, experimental and predictive methods for the determination of phase equilibria will be used in conjunction with each other rather than in competition. 


\section{PROTECTIVE COATINGS FOR \\ SUPERALLOYS AND THE USE OF PHASE DIAGRAMS}

M.R. Jackson and J.R. Rairden

General Electric Company

Corporate Research \& Development

Schenectady, New York

Compositional modifications to increase the strength of superalloys have produced parallel decreases in environmental resistance, both for oxidation limited jet engine applications and hot corrosion limited gas turbine applications. Coupled with the economic impetus for longer and higher temperature service, this has resulted in increased emphasis on high-temperature protective coatings. Initially simple aluminide coatings were formed by pack aluminization. With greater demands on oxidation resistance, MCrAI ( $Y$ ) coatings have come into use ( $M$ is $\mathrm{Ni}, \mathrm{Co}$ and/or $\mathrm{Fe}$ ), and duplex coatings have been formed by aluminizing the MCrAl( $Y$ ) coatings. Other elements are also of interest as additions to coatings, either homogeneously. distributed throughout the coating or localized as an inner or outer layer of the coating.

Phase equilibria in ternary and higher order systems can be extremely useful in correlating coating/substrate compositions, microstructures and behavior. For example, the formation of coatings 
on superalloy surfaces can be understood in terms of multi-element diffusion between the elements added and the elements in the substrate. The coating degradation that results from interdiffusion between coating and substrate in service is also a problem of multielement diffusion. For many superalloys, such as IN-738, IN-100 and René 80 , the compositions are primarily $\mathrm{Ni}, \mathrm{Al}$ and $\mathrm{Cr}$, and can be described approximately in terms of ternary or quaternary phase diagrams. Both coating formation and coating degradation for the superalloys have been mapped in terms of diffusion paths through the ternary or quaternary diagrams. These paths are important in pointing the way to modifications which may further improve the stability of present coating compositions.

Unfortunately, the availability of complete information on phase equilibria for the $\mathrm{Ni} / \mathrm{Al} / \mathrm{Cr}$ ternary system and pertinent higher order systems is limited. Examination of coating/substrate systems in terms of microstructure and microanalysis of the chemistries allows reasonably accurate description of the phase diagrams. These diagrams can serve as working hypotheses for understanding coating formation and degradation. Thus, the phase diagrams are important in understanding how to produce a particular environmentally resistant phase at the surface and how to maintain that against diffusional interactions with the substrate. The concept of graded or layered coatings involves an outer resistant region of the coating and an inner region to maintain adhesion 
to the substrate and/or prevent diffusional interactions with the substrate. Again, phase diagrams can be used to characterize the requirements for a stable coating/substrate system.

Specific examples of the application of phase diagrams to the understanding of coating formation and degradation will be presented: aluminization of superalloys, duplex aluminized coatings, the effects of Co on NiCrAl coatings, aluminization of platinide coatings on superalloys, and the influence of Si additions on NiCrAl coatings. 


\section{ESTIMATION OF ISOTHERMAL SECTIONS OF TERNARY PHASE DIAGRAMS OF LITHIUM-CONTAINING SYSTEMS: THE LI-A1-Mg SYSTEM \\ M. L. Saboungi and C. C. Hsu Chemical Engineering Division Argonne National Laboratory Argonne, IIIinois 60439}

In the development of high-temperature batteries, lithium and its alloys are primary candidates for the negative electrode. The Li-Al electrode has promising features which led to an intensive study of the thermodynamic and electrochemical properties of this binary system. ${ }^{1}$ Despite the performance of cells with this alloy electrode, problems were encountered which gave rise to a loss of capacity with repeated cycling. Addition of a third element is being considered in an effort to overcome these limitations. Knowledge of the ternary phase diagrams and especially of the phases stable at the temperatures of operation of the battery (648 $\mathrm{K}$ to $773 \mathrm{~K}$ ) is vital in this effort.

We report on computer-generated isothermal sections of a candidate system, Li-Al-Mg, at four temperatures: $I=648,673,723$ and $773 \mathrm{~K}$. A computer program developed by Kaufman and Nesor ${ }^{2}$ has been used. To sumarize the method, the solutions (binary or ternary) are treated as simple solutions. Available thermodynamic data on the binaries are properly incorporated into the Koehler equations to calculate boundary curves for each interaction occurring in the ternary system. In the present case, thermodynamic properties of the Ii-Al system were calculated using emf measurements ${ }^{3,4}$ and the recent phase diagram ${ }^{5}$; emf measurements ${ }^{6}$ and the binary phase diagram ${ }^{7}$ were also used to deduce necessary thermodynamic coefficients for the Li-Mg system. Finally, the data selected by Hultgren et al. ${ }^{\top}$ were used for the AI-Mg binary. 
gaps in a number of ternary systems; ${ }^{6-8}$ the agreement has generally been very good. An empirical extension of the theory to a broader range of systems, in which a pair of cations or anions have different charges, has shown to lead to a good representation of the phase diagrams. 9

The success of these calculations indicates their usefulness in evalwating the self-consistency of measurements and in the extrapolation of data into unmeasured regions. The equations should also prove useful for the storage of phase diagrams. The accuracy of such stored information can be improved by treating the coefficients $a, b, c, \Delta G^{\circ}$ and $Z$ as somewhat adjustable parameters and by adding more terms to eqs. (1) and (2) [e.g., one can add third order terms to eq. (1)]. Such procedures, when fuIly developed, should permit the storage of complex ternary phase diagrams with a minimum number of parameters.

\section{References}

1. H. Reiss, J. Katz and O. J. Kleppa, J. Chem. Phys. 36, 144 (1962).

2. M. Blander and S. J. Yosim, J. Chem. Phys. 39, 2610 (1963).

3. M. I. Saboungi and M. BIander, J. Chem. Phys. 63(1), 212 (1975).

4. M. I. Saboungi and P. Cerisier, J. Electrochem. Soc. 121, 1258 (1974).

5. M. Blander and M. L. Saboungi, "Fundamental Aspects of Molten Salt Solutions and Their Applications in Techrology," in Proceedings of the International Symposium on Molten Salts, edited by Pemsler et al., The Electrochemical Society, Princeton, N. J. (1976) pp. 93-110.

6. M. Blander and L. E. Topol, Inorg. Chem. 5, 1641 (1966).

7. M. L. Saboungi and M. Blander, High Temp. Sc1. 6,37 (1974).

8. M. L. Saboungi, H. Schnyders, M. Foster and M. Blander, J. Phys. Chem. 78 , 1091 (1974).

9. M. L. Saboungi and M. Blander, J. Am. Ceram. Soc. 58, 1 (1975). 


\section{THEORETICAL CONCEPTS USEFUL IN THE CALCULATION OR STORAGE OF PHASE DIAGRAMS OF IONIC SYSTEMS \\ Marle-Louise Saboungi and Milton Blander Chemical Engineering Division \\ Argonne National Laboratory \\ Argonne, Illinois 60439}

Equations for the a priori calculation or for the storage of phase diagrams and thermodynamic properties of molten termary ionic systems can be derived from a variety of models. We have focused on the conformal ionic solution (CIS) theory which rigorously takes into account the ionic nature of the melts. ${ }^{1-3}$ Thermodynamic functions for ternary fonic systems have been derived for cases in which all the cations have the same charge and all the anions have the same charge. ${ }^{1-5}$ For reciprocal systems, e.g., $\mathrm{A}^{+}, \mathrm{B}^{+} / \mathrm{X}^{-}, Y^{-}$, defined by the three components $A Y, B X$ and $B Y$, the excess free 2 energy of mixing, $\Delta G^{E}$, up to second order reads as:

$$
\Delta G^{E}=X_{A} X_{X} \Delta G^{0}+a_{A} X_{X} X_{Y}+a_{B} X_{X} X_{Y}+a_{X} X_{A} X_{B}+a_{Y} X_{A} X_{B}-X_{A} X_{B} X_{X} X_{Y} \frac{\left(\Delta G^{\circ}\right)^{2}}{2 Z R T}
$$

where the $X^{\prime} s$ are ion fractions, $\Delta G^{\circ}$ is the free energy change for the metathetical reaction $A X+B Y=A Y+B X, a^{\prime}$ s are coefficients deduced from the four subsidiary binaries, and $\mathrm{Z}$ is a parameter taken to be 6 .

For additive systems, e.g., $\mathrm{A}^{+} \mathrm{B}^{+}, \mathrm{C}^{+} / \mathrm{X}^{-}$, the excess free energy. of mixing, $\Delta G^{E}$, up to third order reads as:

$$
\Delta G^{E}=\sum \sum a_{i j} x_{i} x_{j}+\sum \sum b_{i j} x_{i}^{2} x_{j}+c x_{A} x_{B} x_{C}
$$

where the coefficients $b_{i j}$ are derived from the three subsidiary binaries and $c$ is directiy related to the $b_{i j}$ 's.

Using eqs. (1) or (2) and classical thermodynamic relations, one can calculate phase diagrams of the two classes of ternary systems a priorf from data on the lower order systems. Comparisons of such calculations with experimental data have been made for liquidus phase diagrams and miscibility 
A basic feasible solution corresponds to one corner of the polygon delimiting the region of stability. The corner where $\mathrm{Cu}, \mathrm{Cu}_{2} \mathrm{~S}$ and $\mathrm{Cu}_{2} \mathrm{O}$ coexist (Fig. I) is a basic feasible solution for $\mathrm{Cu}_{2} \mathrm{O}^{2}$ The object in ${ }^{2}$ Phase 2 is to find all basic feasible solutions.

The algorithm for selecting the vector to enter the base in Phase 2 is modified as follows: The two vectors not in the base are labeled $A$ and $B$. Vector $A$ is chosen to enter the base, Vector B becomes Vector $A$, and the vector leaving the base becomes Vector B. The vector leaving the base is chosen in the standard fashion so that the new solution is also a basic feasible soluiton. This procedure is repeated until the original basic feasible solution is obtained, yielding all corners of the polygón.

A new species is then chosen as the subject species and the entire procedure repeated to yield the polygon delimiting its region of stability. This procedure is continued until the region of stability is found for all metal bearing species to yield the complete diagram.

Electrochemical as well as high temperature systems can be treated. Additional non-metal bearing chemical species can be included at fixed activities. For example, the $\mathrm{Cu}-\mathrm{O}_{2}-\mathrm{SO}_{2}$ diagram changes markedly if chipine is introduced into the system at a fixed partial pressure of $10^{-10} \mathrm{~atm}$.

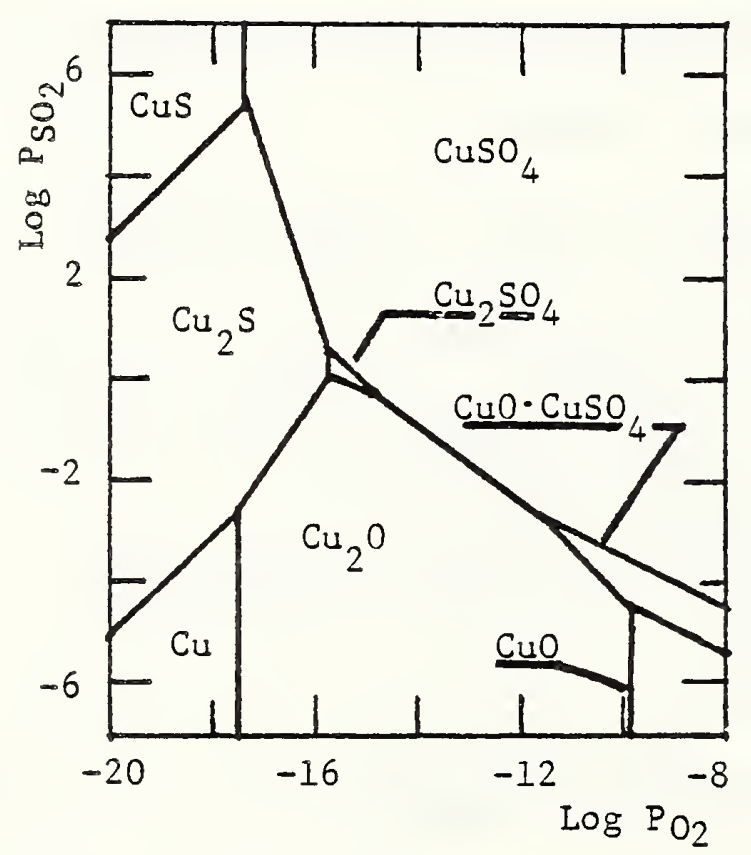

Fig. $1 \mathrm{Cu}-\mathrm{O}_{2}-\mathrm{SO}_{2}$ System $\mathrm{T}=700^{\circ} \mathrm{K}$.

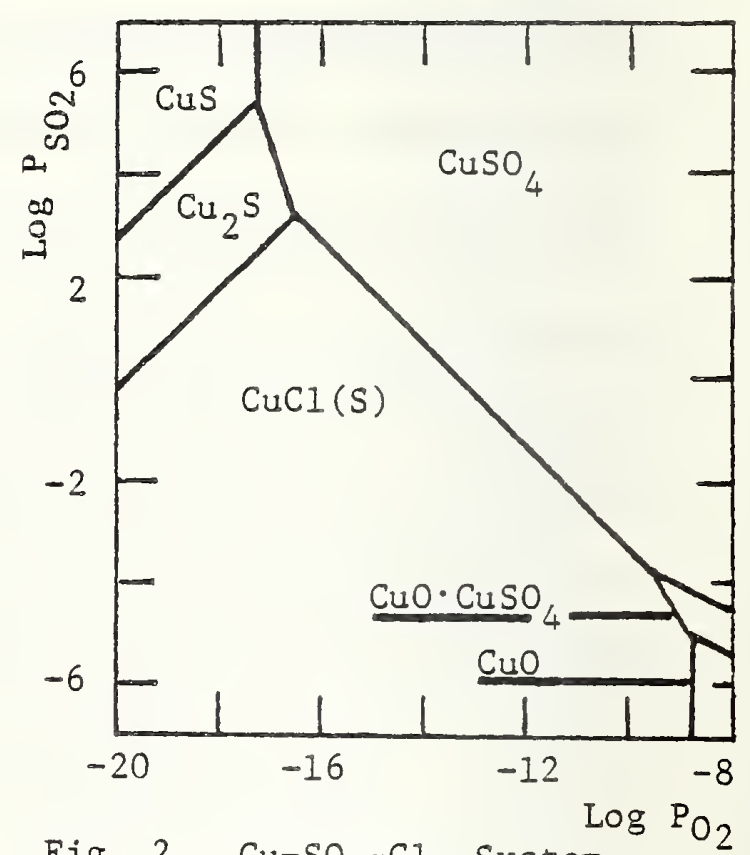

Fig. 2. $\mathrm{Cu}-\mathrm{SO}_{2}-\mathrm{Cl}$, system $\mathrm{I}=700^{\circ} \mathrm{K}^{2} \mathrm{P}_{\mathrm{Cl}_{2}}=10^{-10}$ atm $\mathrm{P}_{\mathrm{CuCI}(\mathrm{g})}<10^{-2}$ atm. ${ }^{\mathrm{P}} \mathrm{Cu}_{3} \mathrm{Cl}_{3}(\mathrm{~g})<10^{-2}$ atm. 
THE CALCULATION OF POURBAIX DIAGRAMS

USING A MODIFIED LINEAR PROGRAIMING TECHNIQUE

\author{
Barry H. Rosof \\ Technology Division, Cabot Corporation, Kokomo, Indiana 46901
}

An algorithm for calculating Pourbaix Diagrams (both partial pressure diagrams and potential $\mathrm{pH}$ diagrams) that is particularly suitable for use on a digital computor is presented. The algorithm consists of two principal parts. In the first part, the thermodynamic conditions under which a given phase is stable with respect to all other phases is formulated as a set of linear inequalities. In the second part, the set of linear inequalities is solved by a modified linear programming technique to yield the region in which the subject phase is the stable phase.

Any chemical reaction can be written as

e.g.

$$
\begin{aligned}
& 0=\sum v_{i} A_{i}, \\
& 0=\frac{3}{2} 0_{2}(\mathrm{~g})+2 \mathrm{SO}_{2}(\mathrm{~g})+\mathrm{Cu}_{2} \mathrm{O}-2 \mathrm{CuSO}_{4}(\mathrm{~s}) .
\end{aligned}
$$

By convention Species 3 and 4 are taken as the metal bearing species. The condition that Species 3 is stable wrt Species $4\left(\Delta G_{r} \leqslant 0\right)$ can be written after rearranging and after fixing the activities of all species except Species 1 and 2 as

$$
a_{1} \xi_{1}+a_{2} \xi_{2} \leqslant B
$$

where

$$
\begin{aligned}
& -B=\Delta G_{r}^{\circ}+\sum_{i=3}^{n} v_{i} R T \xi_{i}, \\
& \xi_{i}=\operatorname{lna} a_{i} \text { or } \ln P_{i} \\
& a_{i}=v_{i} R T .
\end{aligned}
$$

In the present case

$$
\frac{3}{2} \mathrm{RT} \text { ln } \mathrm{P}_{2}+2 \mathrm{RT} \text { ln } \mathrm{P}_{\mathrm{SO}_{2}} \leqslant \Delta \mathrm{G}_{\mathrm{R}}^{\circ} \text {, }
$$

where the activities of the solid phases have been set equal to unity.

For Species 3 to be stable it must not only be stable wrt Species 4 but also stable wrt all other possible metal bearing species, e.g. $\mathrm{Cu}_{2} \mathrm{O}^{4}$ must be stable wrt $\mathrm{CuS}, \mathrm{Cu}_{2} \mathrm{~S}$, $\mathrm{Cu}$, Cuo, etc., as well as wrt CuSO, II
there are $\mathrm{n}$ metal bearing species there are $\mathrm{n}-1$ stability conditions, each of the form given in Equation 3. The $n-1$ stability conditions, or constraints, define the region where species $3\left(\mathrm{Cu}_{2} \mathrm{O}\right)$ is stable as a function of $\xi_{1}$ and $\xi_{2}\left(\ln \mathrm{P}_{\mathrm{O}_{2}}\right.$ and $\left.\ln \mathrm{P}_{\mathrm{SO}_{2}}\right)$. The constraints delimit a polygon in $\xi_{1}-\xi_{2}$ space.

The problem of finding the region (of stability) that satisfies the n-l constraints can be solved by a modified version of the linear programming technique known as the two phase simplex process.

In Phase 1 the standard tableau is set up, but the cost row is omitted. (The "cost" row for Phase 1 is retained.) The conventional Phase 1 algorithm is executed leading to a basic feasible solution. 


\section{STSTEA $A-B-Y$}

FE-CR 0

TEMP - GONSTANT = Fe

LOStO(PY2) $\mathrm{Fe}$ 0.10 0.20 0.30 0.40 $X B /(X A+X B) \rightarrow$

$-1.0 \rightarrow-1.000$

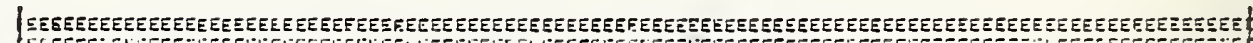

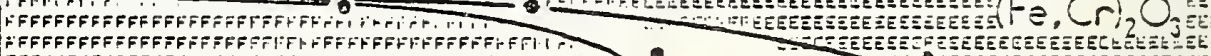

-4.500
-5.000

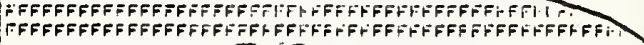
FFFFFFFFFFFFFFFF(

-5.000
-5.500

$-\$ .500$
-0.000

$-9.300$

-7.000
-7.500

$-6.000$

$-8.500$

$-9.000$

$-10.000$

$-10.500$

$-11.000$

-11.500
-12.000

-12.000
-12.200

$-13.000$

$-13.500$

$-14.000$

$-14.000$

$-15.000$

$-16.000$

$-17.0 \rightarrow-87.000$

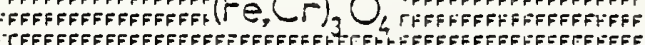

IFFFFFFFFFFFFFFFFFFFFFFFFFFFFFFFIFFFFFFFFFFFFF=FFFFFFF

FFHFFFFFFFFFFFFFFFFFFFFFFFFFFFFFFFHFFFFFFFFFFFFFFFFFFFFF

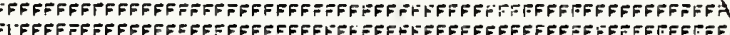

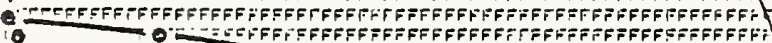

: $(F E, \mathrm{Cr}) \mathrm{O}$ O

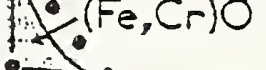

CEFFFFFFFFFFFFFFFFFFFF

OEFFFEFFFFFFFTFFFFF

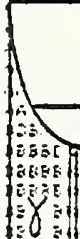

EEs:

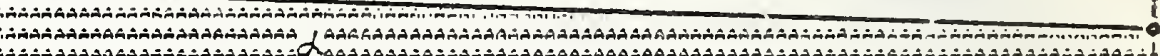
Fi๊. 2

STSTEM A-Q-P

EE-NIT-S-O

TEMP = CONSTANT $=1: 73.15 \mathrm{~K}$

$\mathrm{Fe}$

$\mathrm{Fe}-\mathrm{Ni}-\mathrm{S}-\mathrm{O}$

$T=1173 \mathrm{~K}$

$\log P_{\mathrm{SO}_{2}}=-2 \mathrm{O}_{\mathrm{Ni}}$

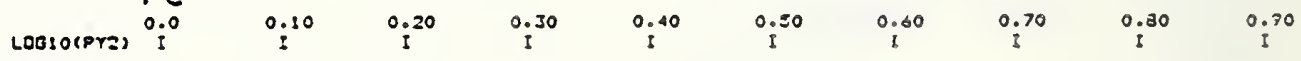

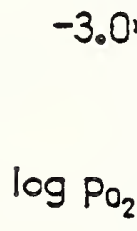

3.000

-3.200
-3.400

$-3.400$

$-3.800$

$=4.000$

$-4.400$

$\leftarrow \mathrm{Fe}_{2} \mathrm{O}_{3}$

-4.600
-4.300

$-5.000$

$-5.200$

A $\quad-5.400$

-5.600
-5.800

$-6.000$

$-6.200$

$-6.400$

-6.600
-6.800

$-7.000$

$-7.200$

$-7.400$

$-7.8000$

$-\theta .000$

$-8.200$

$-8.400$

$-9.600$

$-9.800$

$-9.000$

$-9.200$

$-9.400$

$-9.600$

-9.800
-10.000

10.200

10.400

$-10.600$

-11.000

$-11.200$

$-11.400$

$-11.000$

$-11.800$

$-11.800$

-12.000
-12.200

$-12.400$

$-12.600$

$-13.0 \rightarrow-13.000$

$-\$ 3.200$

$-\$ 3.400$
$-\$ 3.600$

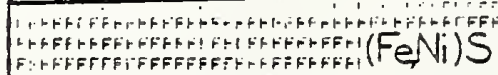

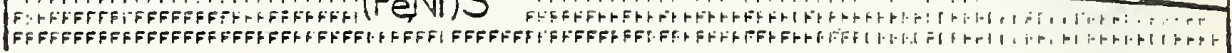

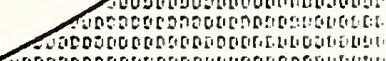

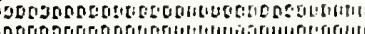

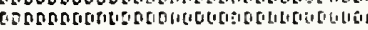

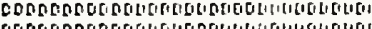

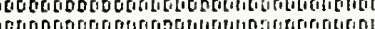

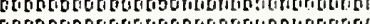

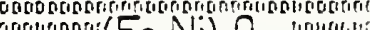

a

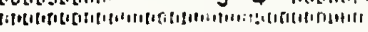

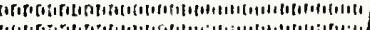

(1)

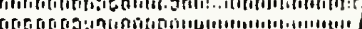

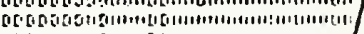

(1)

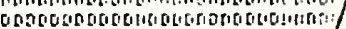

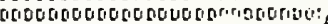

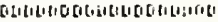

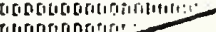

ativi.

sulfide

\section{Fig. 3}

Demonstration. It is hoped that an actual demonstration of the syste via direct hookup to Montreal will be carried on during the poster sessiur 


\section{- (A computerized Canadian thermodymanic data banis)}

A.D. Pelton, C.H. Bale (Dépt. de génie métallurgique, Ecole Polytechnique, Université de Montréal, Montréal) and V.T. Thompson (MicGill University, Dept of Metallurgical and Mineral Ingineering, Montreal, Canada)

An interactive computer system for the treatment of thermodynamic data (including phase diagram calculations) is being developed. The system will eventually contain an extensive data base. However, the facility will be much more than a data bank. Rather, the system will be capable of performing sophisticated calculations using eitiner stored or user-supplied data. AIl input and output will be in conversational mode from remote terminals from which users will contact the system via telephone. The software has already been developed for a number of types of calculation.

One program is concerned with the calculation of generalized "predoninance area diagrans". A sample output is shown in Figo 1. The user has specified the system $\left(\mathrm{Cu}-\mathrm{S}-\mathrm{O}\right.$ ), the axes (partial pressures of $\mathrm{SO}_{2}$ and of $\mathrm{O}_{2}$ ), the limits of the axes, and

the constant temperature. The computer has calculated the diagram using stored data. Any thermodymamically possible diagram can be calculated for systems of up to 5 components containing $S, O, F, C, C l$, etc. Axes and constants can be $T, 1 / T, l_{0}(Y)$, In $(\bar{Y})$, or $R T I n(Y)$ where $Y$ is a partial pressure, an activity, or a ratio of partial pressures or activities such as $\mathrm{P}_{\mathrm{CO}} / \mathrm{P}_{\mathrm{CO}_{2}}{ }^{\circ}$

A second program involves the calculation of binary and ternary phase diagrams. In Fig. 2 is an output of $\mathrm{log} \mathrm{P}_{2}$ versus metal ratio in the temary Fe-Gr-O systen at constant $\mathrm{T}=1573 \mathrm{~K}$. Plots of composition versus $\mathrm{T}$ at constant $\mathrm{P}_{2}$ as well as at constant $\mathrm{p}_{\mathrm{CO}} / \mathrm{p}_{\mathrm{CO}_{2}}$, etc. are also possible. Clearly, the same program can also be used to calculate binary phase diagrans. A calculated quatemary diagram for the Fe-ili-S -0 system is shown in Fig. 3.

A third program is concerned with calculations involving chemical reactions. Nearly any possible thermochemical calculation can be made for isothermal, adiabatic, isentropic. etc. paths.

Other sortware routines are under development. FACT should be operational on-line by the end of 1977. In the meantime, those interested in the analysis of specific systems with FACT should contact the authors.

SYSTEM CU-S -O

TEMFEFATUFE =

$Y=F(S * 02)$

$10(Y)=$

$10(Y)=$

$10(Y)=$

$10(Y)=$

$10(Y)=$

$10(Y)=$

$10(Y)=$

$10(Y)=$

$10(Y)=$

$10(Y)=$

$10(Y)=$

$10(Y)=$

$10(Y)=$

$10(Y)=$

$10(Y)=$

$10(Y)=$

$10(Y)=$

$10\langle Y\rangle=$

$10(Y)=$

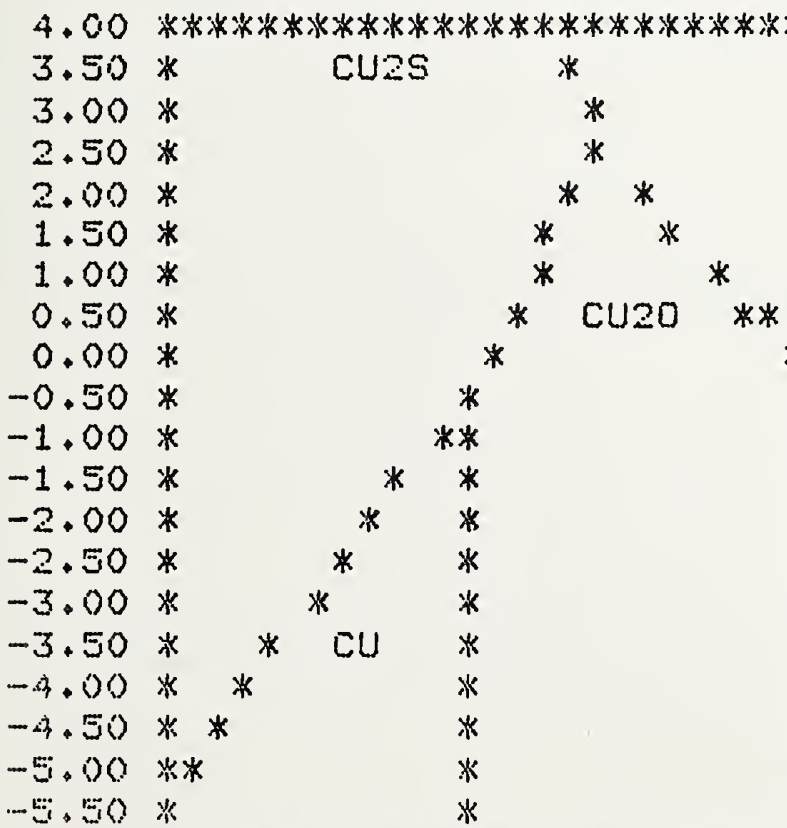

\subsection{KKELUIN}

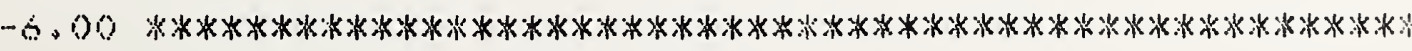

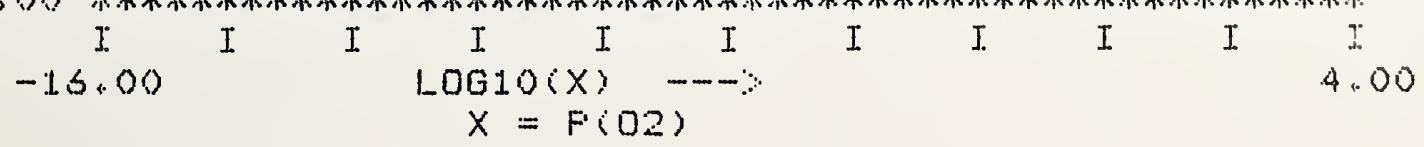


Effect of Irradiation on Phase Stability

P. A. Miodownik

Metallurgy and Materials Technology Department

University of Surrew, $U$. $K$.

The workshop has received notice that Dr. Miodoumik, together with I. Kaufman (Manlabs) and G. Inden (Max Planck Inst.), in conjunction uith J. S. Watkins (British Atomic Energy Authoritu) are cooperatively investigating the effect of irradiation on phase stability, particularly in stainless steels. Some interesting recent advances will be discussed by Dr. Miodownik, in part, in relation to some work on W-Re alloys performed by R. Williams (Oak Ridge). (I)

With the current interest in reactor progroms, the problem should receive an airing as a major field of specialized activity, which particularly raises the problem of phase equilibrium at temperatures where normal diffusion rates are very slou and it is difficult to obtain the necessary data by direct experiment.

(1) F. K. Williams, "Irradiation Effect in W-Re AlZoys" - $6^{\text {th }}$ Annual Spring Meeting of the AIME, Pittsburgh (1974).

(Text for this post-deadline paper prepared by the ADC). 
The ${ }^{\circ} G{ }_{M}^{\eta}$ terms are the molar free energies of component $M$ in $\eta$-phase standard states at fixed temperature and non-metal activity. The $a_{M}^{\eta}$ terms are the metal activities in solution with respect to the ${ }^{\circ} G_{M}^{\eta}$ standard states. To calculate the free energy curves, the thermodynamics of each stable solid or liquid solution must be known.

The Fe-Cr-O system will be used to illustrate these principles. 


\section{CHARACTERISTICS AND CALCULATION OF STABILITY DIAGRAMS}

by Scott McCormick and Yaz Bilimoria

Illinois Institute of Technology, Chicago, ILL. 60616

Stability diagrams are equilibrium diagrams that map phase equilibria in systems containing both metallic and non-metallic components as a function of temperature, non-metal chemical potential or activity, and $X_{M^{\prime}}$ the ratio of $M$ atoms to metal atoms. They offer an alternative perspective on phase equilibria and reaction paths in these systems. The characteristics and calculation of two forms of stability diagrams for systems containing one non-metallic and two metallic components will be discussed. In these two types of diagrams phase equilibria are mapped as a function of (1) non-metal activity and $X_{M}$ at constant temperature, and (2) temperature and $X_{M}$ at constant or continuously varying non-metal activity.

These diagrams are similar in form to conventional temperature-composition diagrams with horizontal tie lines and eutectic and perifectic-like features. The lever law can be used to calculate the distribution of metal atoms between phases in equilibrium. Non-metal activity- $X_{M}$ plots are ideal for carrying out ternary Gibbs-Duhem integrations with Schuhmann's method.

These types of diagrams can be calculated from plots of Gibbs free energy versus $X_{M}$ at constant temperature and non-metal activity. One mole of metal is chosen as the basis for the calculation. The two free energy ordinates are the molar free energies of the two metals. Temperature and non-metal activity are fixed, so that the condensed phases, stable and unstable, have the same non-metal chemical potential. The free energy of the system is therefore minimized when the combined free energies of the two metals are at a minimum. The curves are of the form

$$
G^{\eta}=X_{A}{ }^{\circ} G_{A}^{\eta}+X_{B}{ }^{\circ} G_{B}^{\eta}+R T\left(X_{A} \ln \sigma_{A}^{\eta}+X_{B} \ln a_{B}^{\eta}\right)
$$


composition indicated correctly that the fcc phase at intermediate alloy compositions tended to decompose to the $\varepsilon$-phase and the $\gamma$-phase which are respectively the $\mathrm{Cu}$-rich and $\mathrm{Fe}$-rich terminal fcc solid solutions in the system. In addition at $1367 \mathrm{~K}$, which is indicated in the phase diagram to be the temperature at which the $\mathcal{E}$-phase decomposes peritectically into liquid plus $\gamma$-phase, graphical comparison of the free energies of formation of the liquid and fcc phases indicated equilibrium compositions for the liquid and $\gamma$-phase in close accord with experimental values. However, the free energy of formation of the $\mathcal{E}$-phase was much too negative which prompted modification of the excess entropy term. This modification plus refinement of numerical coefficients predicted compositions for the phase boundaries associated with the Liq- $\varepsilon$, $\varepsilon-\gamma$, and Liq- $\gamma$ equilibria in close accord with the published phase diagram. An expression was then developed for the free energy of formation of the $a$ and $\delta$ phases which are respectively the low-temperature and high-temperature bcc terminal solutions on the Fe-rich side of the system. This expression is based on the approach of Hillert et al. ${ }^{2}$ and incorporates data for pure Fe. Adjustable parameters were fixed on the bases of the peritectic reaction at $1751 \mathrm{~K}$ and the eutectoid reaction at $1123 \mathrm{~K}$.

The final free energy expressions for the liquid, fcc-phases, and bccphases reproduce the experimental phase boundaries of the temperaturecomposition diagram generally to a fraction of an atom per cent and no instance worse than $\sim 2$ at. \%. These final free energy functions are expressed in terms of mole fraction and temperature and, in the sense of consistency with the observed temperature-composition diagram, adequately take into account the Fe-Cu interaction parameters. Since the importance of interaction parameters tends to decrease with the order of the interaction from binary to ternary to quaternary, etc., the free energy functions for the binary system may be combined with similar functions for other binary systems to give a reasonable first order prediction of multicomponent equilibria.

* Institut fưr Kernbrenstoffe und Theoretische Hüttenkunde, Technische Hochschule, 5100 Aachen, B.R.D.

t Ames Laboratory USERDA, Iowa State University, Ames, Iowa 500II, U. S. A.

1. J. F. Counsell, E. B. Lees, and P. J. Spencer in Metallurgical Chemistry Symposium 1971 (HMSO, London, 1972) p. 451.

2. M. Hillert, T. Wada, and H. Wada, J. Iron Steel Inst. 205, 539 (1967). 
EVAIUATION OF FREE ENERGY FUNCTIONS FOR THE PREDICTION OF PHASE EQUILIBRIA IN MULTICOMPONENT SYSTEMS: THE Fe-CU SYSTEM AS AN EXAMPLE

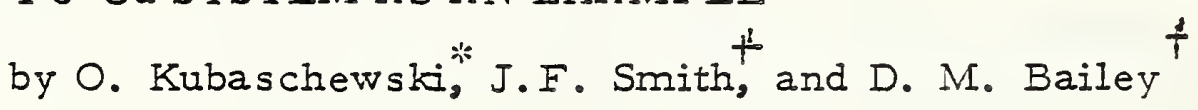

An estimation of the phase equilibria in a multicomponent system can be made if free energy functions are available for describing the formation of the competitive phasesinthe system. Such functions can be generated by combination of functions which describe the free energies of formation of the phases in the contributory binary systems. The generation of such free energy functions for the $\mathrm{Fe}-\mathrm{Cu}$ binary system is here used as an illustration of a general procedure for developing self-consistent free energy functions. The basic procedure consists in utilizing any reliable thermodynamic data which are available and then developing additional expressions and adjusting parameters on the basis of experimental data for the phase boundaries in the binary temperature-composition diagram.

In the $\mathrm{Fe}-\mathrm{Cu}$ system extensive thermodynamic data were available only for liquid alloys. These data result from a number of independent investigations of both the enthalpy and free energy of alloy formation and in composite represent an extensive composition range at temperatures in the vicinity of $1800 \mathrm{~K}$. This temperature is sufficiently high that kinetic inhibition to equilibrium is unlikely so that the reproducibility of the data indicates reliability. The data were then used to generate an analytical expression for the free energy of formation of liquid $\mathrm{Fe}-\mathrm{Cu}$ alloys as a function of temperature and composition. Subsequent refinements to the numerical coefficients in this free energy function were constrained to keep values within the range of scatter of the input experimental data.

Experimental data for solid alloys in the binary Fe-Cu system are lacking. However, Counsell, Lees, and Spencer ${ }^{l}$ had made some calorimetric measurements of the enthalpies of formation of a few fcc alloys in the Fe-Cu-Ni ternary system. Through combination of these enthalpy values with data for the $\mathrm{Fe}-\mathrm{Ni}$ and $\mathrm{Ni}-\mathrm{Cu}$ alloys plus some knowledge of the phase equilibria in sections of the $\mathrm{Fe}-\mathrm{Cu}-\mathrm{Ni}$ system, they developed a set of functions for the thermodynamics of formation of the fcc phase in the ternary system. In the present work these functions were extrapolated to the binary limit by setting the mole fraction of Ni to zero. Graphical representations of the resultant free energy function vs. 


\section{References}

1. D. de Fontaine, Acta Met. 23, 553 (1975).

2. R. Kikuchi, Phys. Rev. 81, 988 (1951).

3. W. Shockley, J. Chem. Phys. $\underline{6}, 130$ (1938).

4. J. Appl. Cryst., Special issue on Jülich meeting, 8 , part 2, April 1975.

5. R. Kikuchi and H. Sato, Acta Met., 22, 1099 (1974).

6. R. Kikucht, D. de Fontaine, (to be published).

7. C.M. Van Baal, Physica 64, 571 (1973).

8. R. Xikuchi, D. de Fontaine, M. Murakami and T. Nakamura, Acta Met. (in press). 
regular solution or Bragg-Williams entropy which in many cases can be $100 \%$ in error, or lead to phase diagrams which are not even topologically correct. (3)

In the CV method, the entropy contains no adjustable parameters so that the excess configurational entropy is calculated completely from first principles. The vibrational entropy change on ordering is assumed negligible by comparison. The enthalpy is expressed as a sum of pair, tetrahedra,... interactiors and, since the entropy can be obtained to a high degree of accuracy, i fit of the theory to experimentally known coherent transition temperatur ss yields very reliable values of the basic energy parameters. These, in turn, can be used to check or fit pair and many-body interactions obtained from appropriate band structure calculations from which, in principle, ail physical properties of alloys can be reduced. Furthermore, the CV method also gives short-range order parameters, at arbitrary temperature and concentration, in the form of pair and higher cluster frequencies, this information being of fundamental importance in $x$-ray and neutron diffraction studies 0 local atomic arrangements.

Thus, complete coherent phase diagramscontaining several intermediate phisses can be conputed from a single free energy function with a minimum number of adjustable interaction energy parameters, the physical meaning of which is completely unambiguous. Hence the $\mathrm{CV}$ method can be regarded as providing a bridge beiween experimental phase diagram determination and basic solidstate physics theories.

These ideas will be illustrated in the case of the (coherent) Cu-Au system, for which an excellent fit to the phase diagram has recently been obtained, $(6)$ following the ideas of Van Baal. (7) Additional applications include terrary (8) systems which exhibit both ordering and phase separation. 


\title{
FUNDAMENTAL CALCULATIONS OF COHERENT PHASE DIAGRAMS
}

\author{
Didier deFontaine and Ryoichi Kikuchi* \\ Department of Engineering and Applied Science \\ University of California, Los Angeles
}

By "coherent phase diagram" is meant a temiper.1ture-concentration diagram indicating thermodynamic relationships betwea' ordered and disordered solid phases which can all be derived from the same parent lattice. Often, the coherent ordered phases are metastable with respect to the incoherent ones which are described in experimentally determined phase diagrams; thus the coherent $\mathrm{DO}_{22}$ ordered phase is metastable with respect to the equilibrium incoherent $\mathrm{Ni}_{3}$ Mo intermetallic, for example, al though the former can actually be obtained by appropriate heat ireatments. The usefulness of coherent (metas talbe) phase diagrams for the analysis of microstructure has been pointed ol $t$. (I)

Incoherent phass diagrams cannot, at present, be computed from first principles, but they can be determined experimentally. By contrast, many coherent phase diagrams cannot be readily constructed experimentally, hence a reliable theoretical model yielding useful ;rototype phase diagrams is highly desirable. Such a model is provided by the Cluster Variation method first developed by Kikuchi in 1951. (2) In this method, the configurational entropy is treated in a very accurate manner, in contrast to the

* Permanent Address: Hughes Research Labs, Malibu, CA 
(NI) method. Different from the Newton-Raphson iteration technique, the NI method almost always converges, and at each iteration stage the grand potential decreases step by step $[2,6]$.

These methods are illustrated using the tetrahedron approximation for fcc ternary alloys as examples. Both the clustering phase diagrams and the order - disorder diagrams are shown [7].

*Permanent Address: Hughes Research Labs, Malibu, California 90265

1. R. Kikuchi and S. G. Brush, J. Chem. Phys. 47, 195 (1967).

2. R. Kikuchi, J. Chem. Phys., Dec. 1976.

3. R. Kikuchi, Phys. Rev. 81, 988 (1951).

4. R. Kikuchi, Acta Met. (in press).

5. R. Kikuchi and D. de Fontaine, Scripta Met., Nov. 1976.

6. R. Kikuchi, J. Chem. Phys. 60, 1071 (1974).

7. R. Kikuchi, D. de Fontaine, M. Murakami and T. Nakamura, Acta Met. (in press). 


\section{THEORETICAL CALCULATION OF PHASE DIAGRAMS USING THE CLUSTER VARIATION (CV) METHOD \\ Ryoichi Kikuchi* and Didier de Fontaine \\ Department of Engineering and Applied Science \\ University of California, Los Angeles}

The $\mathrm{CV}$ method is a hierarchy of approximate methods which are improvements of the Bragg-Williams approximation. Each CV method is formulated on a certain cluster of lattice points, called the basic cluster $[1,2]$. When a tetrahedron is chosen as the basic cluster, for example, the probability that a configuration $(i, j, k, 1)$ of the tetrahedron appears in the system is written as $w_{i j k l}$, and all the $w_{i j k l}$ 's for different configurations constitute the set of basic variables to be determined for the equilibrium state. The primary claim of the CV method is its unique way of writing the entropy expression in terms of $w_{i j k i}$ 's [3].

For diagram calculations, the $\mathrm{CV}$ method writes the grand potential $G=F-\left[\mu_{i} N_{i} \text { (rather than the free energy } F \text { ) in terms of } w_{i j k}\right]^{\prime} s$, and then minimizes $G$ with respect to $W_{i j k l}$ 's keeping $T$ and the chemical potentials $\mu_{i}$ 's fixed (rather than the compositions fixed). A phase boundary is determined as the point at which two $G-\mu$ curves (for the two phases) cross $[4,5]$.

In the process of minimizing $G$ with respect to $w_{i j k l}$ 's, a set of algebraic equations (of high order) results. These equations are solved using a special iteration technique called the Natural Iteration 
of sigma phase stability, eutectic formation and the location of melting point minima in complex systems. The system operates on data supplied by the user so that other inorganic, ceramic and metallic combinations can be considered. At present, extension of the system and data base to oxide, nitride, sulphide and fused salt systems is being explored. The Manlabs-NPL MATERIALS DATABANK is accessible via TSO (time sharing option) through standard teletye terminals which can be connected into the main computer by telephone anywhere in the U.S. and Canada. Users can employ almost any commercial teminal to gain access to the system and interact with the DATABANK. There are presently some fifteen client organizations on the DATABANK and an overview of some of the problem areas which have been considered will be presented.

\section{REFERENCES}

1. T. G. Chart, J. F. Counse11, G. P. Jones, W. Slough, and P. J. Spencer International Metallurgical Revievs 20, 57 (1975).

2. L. Kaufman and H. Nesor, Metallurgical Transactions 5, 1617 (1974), 5, 1623 (1974), 6A, 2115 (1975) and 6A, 2123 (1975).

3. L. Kaufman and H. Nesor, Canadian Metallurgical Quarterly, 14, 221, (1975).

4. L. Kaufmar and H. Nesor, "Proceedings of the Sacond Conferences on In-Situ Composites," Lake George, New York, September 1975. Edited by M. R. Jackson, J. L. Walter, F. D. Lemkey and R. W. Hertzberg (1976) pp 11-26 Kerox

- Individualized Publishing, Lexington, Mass. 02173.

5. L. Kaufman and $A$. Nesor, Second International Conference on Rapidly Quenched Metals, Massachusetts Institute of Trehnology, November 1975. Edited by. N. J. Grant and B. C. Giessen. Else ier Sequora, S. A. Lausanne. Reprinted from laterials Science and Enginee: $n g$ (Volume 2j, issue 2/j), pp $119-125$.

6. L. Kaufman and H. Nesor, "Computer Simulation for Materials Applications", Nuclear Metallurgy Volume 20, Part 1, Edited by R. J. Arsenalt, J. R. Beeler and J. A. Simmons. Library of Congress, No. 76-13801, ISBN No. 0-9501010, pp 63-74.

DEMONSTRATION. A demonstratior. of on-Zine use of the DATA BANR wizl be carried on aring the poster session. 
Application of Data Bank Methods to Calculation of the Thermochemistry and Phase Diagram of Metal and Ceramic Systems.

\section{Larry Kaufman \\ Manlabs, Inc.}

Cambridge, Massachusetts 02139

The system developed by National Physical Laboratory and Manlabs have been coupled to provide a Metallurgical Thermochemical Data Bank for storage and retrieval of data and calculation of binary and ternary phase diagrams. Approximately two thousand data sets for pure elements and compounds are stored providing thermodynamic functicss and differences for specific reactions in numerical form. Vapor pressure data for gaseous products and solubility data for gases in metals and dilute alloys sovering the Henrian range can be retrieved. Similar data for dilute solutions of metals in pure metals and binary alloys is also accessible. The system can also be used to compute all of the forty-five binary systems composed of the metals iron, chromium, nickel, cobalt, aluminum, niobium, molybdenum, titanium, carbun, and tungsten. This facilit; is available through explicit descriptions of solution and compound phases generated in terms of lattice stabiliti, solution and cumpound phase parameters which are employed to calculate the stible and metastable phase diagrams and thermochemical properties of the binary sy;tems. The system can be used for calculation of the one hundred twenty possible ternary systems composed of these metals over a wide range of temperature. Addition of manganese, siljcon, copper and boron to the data base is currently in progress. When completed, this expansion will raise the total of binary systems to ninety one and ternary systems to three hundred sixty four. A representative sample of thirty ternary systems covering many of the important superalloys has been computed and found to agree favorably with those cases where some phase diagram data arc available. The level of agreement attained between calculated and observed diagrams shows that the method provides an important tool for prediction 
Optimization of Phase Diagrams by a Least Squares Method Using Simultaneously Different Data

\author{
E.-Th. Henig, H.L. Lukas, B. Zimmermann, \\ Max-Planck-Institut für Metallforschung, \\ Institut für Werkstoffwissenschaften, \\ Büsnauer Strabe 175, D-7 Stuttgart 80
}

To optimize phase diagrams, thermodynamic and all other data should by used simultaneously. Normally optimization is done by trial and error methods. In this paper a least squares optimization method is described. The equations of error are constructed using two main ideas. If a measurement is described by $p$ variables and has $q$ degrees of freedom, there - are $p-q$ corresponding equations of error. These equations have to be constructed to be strongly dependent on one of the dependent variables and weakly dependent on the p-q-1 other dependent variables. The weight-function of the individual equations of error is given by the reciprocal of the accuracy of the value taking into account also the accuracies of the variables temperature and concentration.

This method is used to optimize binary diagrams and in a similar way to correct extrapolated ternary diagrams. As an example the results of the systems $\mathrm{Ag}-\mathrm{Bi}, \mathrm{Ag}-\mathrm{Pb}$ and $\mathrm{Bi}-\mathrm{Pb}$ and the resulting ternary $\mathrm{Ag}-\mathrm{Bi}-\mathrm{Pb}$ will be presented. 


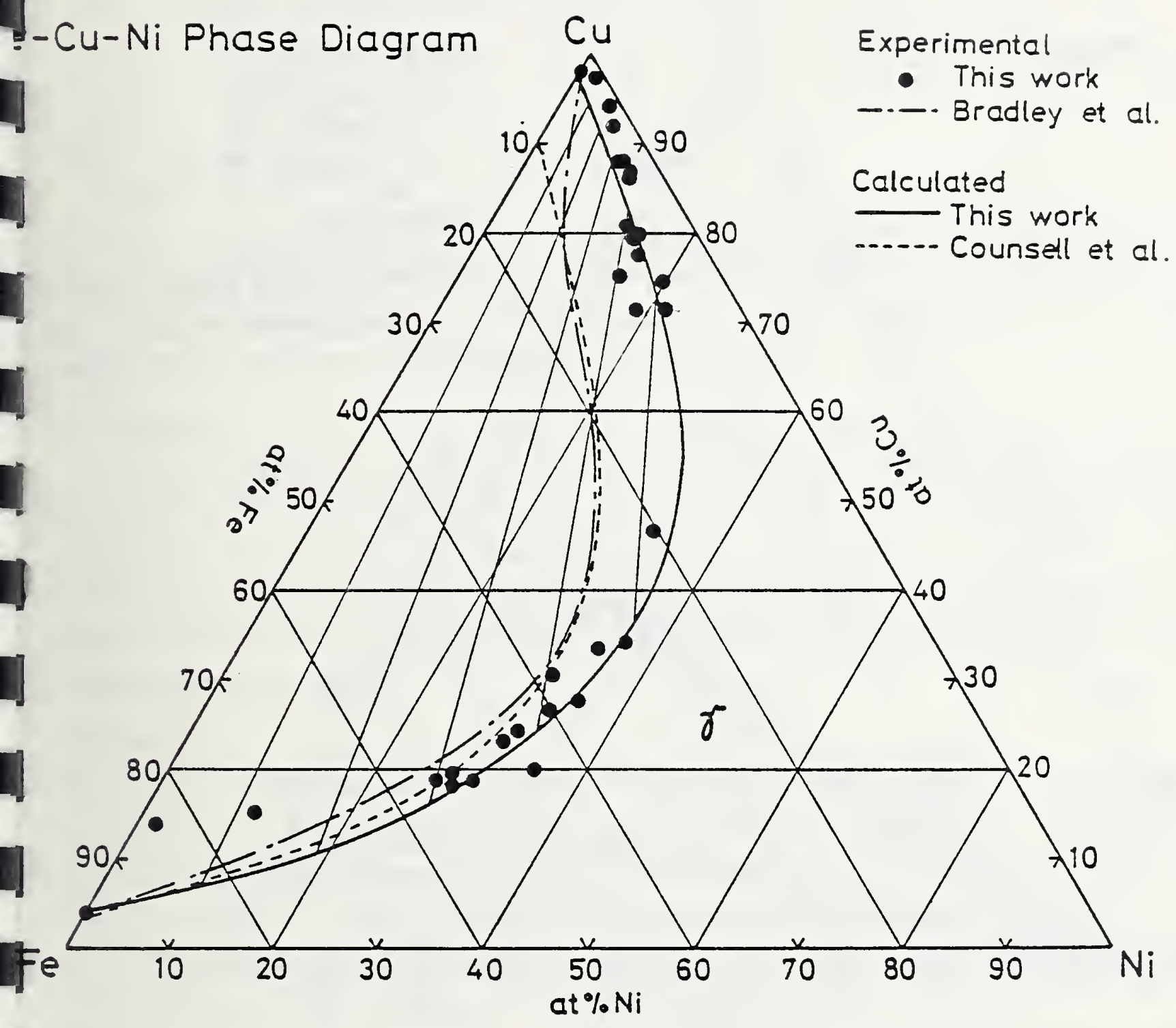

Fiฮ̃. 2 Iso-thermal section diagram of Fe-Cu-Ni system at $1223 \mathrm{Z}$. 
$\mathrm{Fe}-\mathrm{Cr}-\mathrm{Ni}$ Phase Diagram

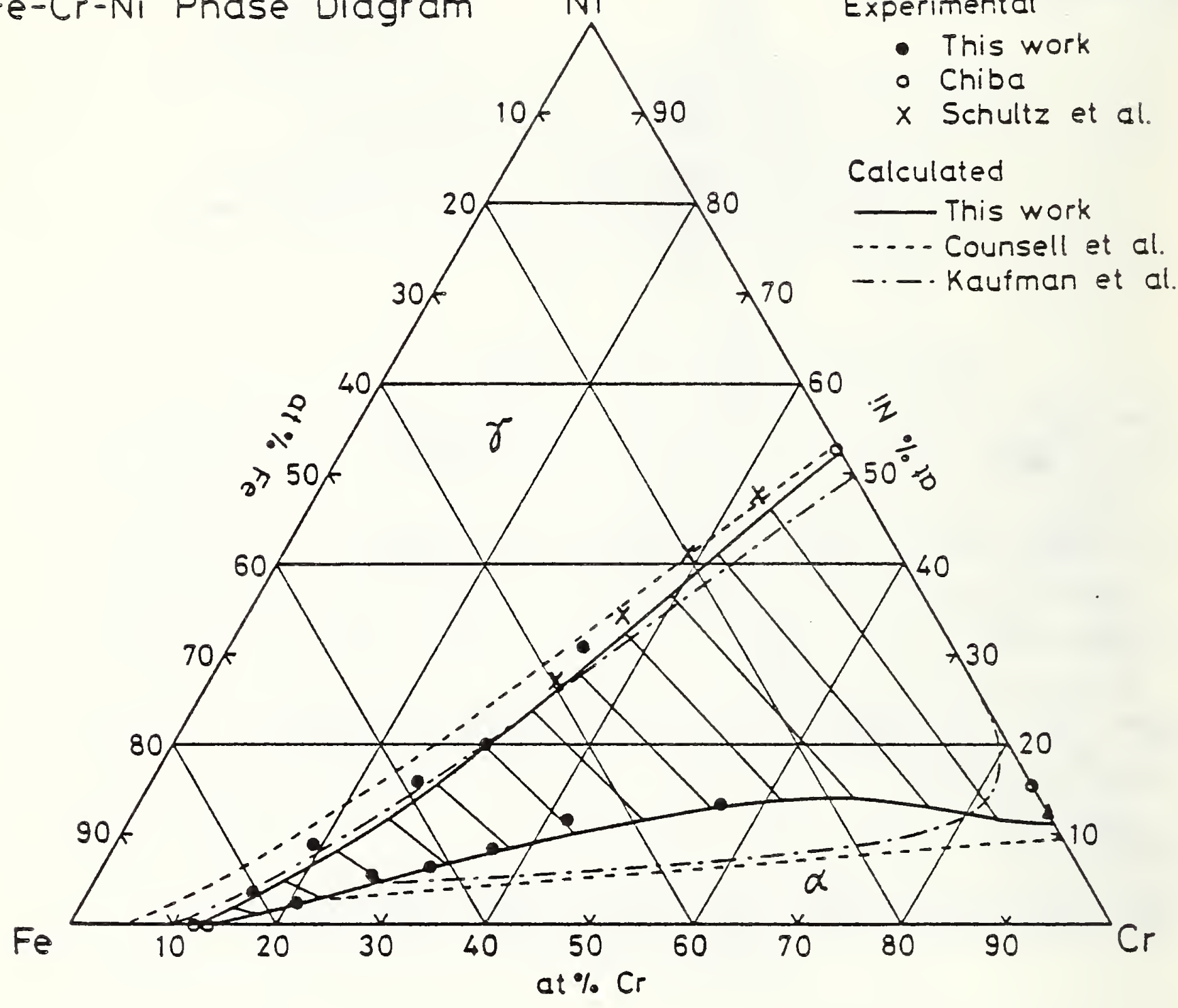


$i-j$ system and the ternary $i-j-k$ system, respectively.

These parameters were considered to depend on both concentration and temperature as follows :

$$
\begin{aligned}
& \Omega_{i j}=\Omega_{i j}^{0}+\Omega_{i j}^{I}\left(x_{j}-x_{i}\right)^{l}+\Omega_{i j}^{2}\left(x_{j}-x_{i}\right)^{2}+\ldots . . \\
& \Omega_{i j k}=\Omega_{i j k}^{i} x_{i}+\Omega_{i j k}^{j} x_{j}+\Omega_{i j k}^{k} x_{k} \\
& \Omega_{i j}^{n}=A_{i j}^{n}+B_{i j}^{n} T+C_{i j}^{n} T \text { In } T \\
& \Omega_{i j k}^{i}=A_{i j k}^{i}+B_{i j k}^{i} T+C_{i j k}^{i} T \text { In } T
\end{aligned}
$$

The coefficients in the above equations were evaluated by Iinear programming using the binary data together with the experimental results on the ternary systems. The values for the free energy ${ }^{\circ} \mathrm{G}$ in eq.(I) were taken from the literature values $(3) \sim(5)$.

IV. Results

The isothermal section diagrams computed for Fe-Cr-Ni at $1373 \mathrm{~K}$, and Fe-Cu-Ni at I223K are shown in Figs. I and 2. These diagrams are different in part from those of Kaufman and Nesor (4), Counsell et al. (6) and Bradley et al( (), which were synthesized by computation using binary data only $(4)(6)$ or constructed on the basis of experimental results in a conventional way $(7)$

References

(1) A.D.Pelton and W.T.Thomson : Prog. Solid State Chem., 10(1975), 119.

(2) International Symposium on Metallurgical Chemistry, England, (1971) ; International Symposium on Thermodynamics of Alloys, Munster, (1972).

(3) L.Kaufman : Phase Stability in Metals and Alloys, Ed. by P.S.Rudman, J.Stringer and R.I.Jaffee, McGraw-Hill, New York, (1967), 125.

(4) L.Kaufman and H.Nesor : Z. Metallk., 64(1973), 249.

(5) R.J.Orr and J.Chipman : Trans. Met. Soc. AIME, 239(1967), 630.

(6) J.F.Counsell, E.B.Lees and J.Spencer : Metallurgical Chemistry, Ed. by O.Kubaschewski, HSMO, London, (1972), 451.

(7) A.J.Bradley, W.F.Cox and H.J.Goldschmidt : J. Inst. Metals, 67(1941), 189. 
Analysis and Synthesis of Phase Diagrams of

$\mathrm{Fe}-\mathrm{Cr}-\mathrm{Ni}, \mathrm{Fe}-\mathrm{Cu}-\mathrm{Mn}$ and $\mathrm{Fe}-\mathrm{Cu}-\mathrm{Ni}$ Systems.

Mitsuhiro Hasebe and Taiji Nishizawa

Department of Materials Science,

Faculty of Engineering,

Tohoku University, Sendai, Japan

I. Introduction

In recent years remarkable progress for the analysis and synthesis of phase diagrams has been achieved by means of computer calculations combined with thermodynamic studies $(1)(2)$. Following these Iines of approach, we have also done extensive work to establish the phase diagrams of alloy systems composed of iron and its horizontal neighbors in the periodic table. In this paper, the phase diagrams of Fe-Cr-Ni, Fe-Cu-Mn and Fe-Cu-Ni systems are reported. Since the phase diagrams of these systems presently available involve a great deal of uncertainty, these should be reexamined experimentally and thermodynamically.

\section{Experimental}

Ternary diffusion couples were employed to obtain equilibrium data over a wide composition range. The ternary couples were prepared by joining a third metal piece onto one side of the binary couples of a first and a second component, which had been fully annealed for moderat ing the concentration gradients.

After equilibration at a fixed temperature between 1123 and $1523 \mathrm{~K}$, the ternary couples were examined by microscopy and micro-probe analysis, and the concentration profiles across the interphase boundaries were obtained. The equilibrium compositions were determined by extrapolating the concentration profiles to the position of the interphase boundar III. Thermodynamical

The free energy of a $\mathrm{N}$-component solution was expressed by an extended regular solution approximation as follows:

$$
G=\sum_{i=1}^{N} x_{i}\left({ }^{\circ} G_{i}+R T \text { In } x_{i}\right)+\sum_{i=1}^{N-1} \sum_{j=i+1}^{N} x_{i} x_{j} \Omega_{i j}+\sum_{i=1}^{N-2} \sum_{j=i+1}^{N-1} \sum_{k=j+1}^{N} x_{i} x_{j} x_{k} \Omega_{i j k}
$$

where $x_{i}$ is the atomic fraction, and ${ }^{\circ} G_{i}$ is the free energy of the ith component at $T K ! \quad \Omega_{i j}$ and $\Omega_{i j k}$ are interaction parameters in the binar 
The results show that the thermodynamic tables for wustite cannot be significantly irr-proved except by better data for the reported second-order composition- and temperature-dependent structural effects within the solid solution. The thermodynamic tables for hematite can be improved by better data on the solid solution limits for both bematite and magnetite as well as the effect of composition on the activity of the $\mathrm{Fe}_{2} \mathrm{O}_{3}$ and $\mathrm{Fe}_{3} \mathrm{O}_{4}$ components in the solid solutions. The thermodynamics of magnetite below $1000 \mathrm{~K}$ cannot be significantly improved through existing experimental techniques. There are no indications that magnetite and hematite have a residual entropy at the zero of absolute terrperature due to internal disorder. 
Thermodynamic Data for the Fe-0 System

Evaluated Using a New Computer-Aided Strategy

John L. Haas, Jr. and James R. Fisher

National Center for the Thermodynamic Data of Minerals

U. S. Geological Survey

National Center, Stop 959

Reston, Virginia 22092

This paper will describe the computational techniques employed in evaluating the excmple given in this abstract

Tables of therrodynamic properties and their confideace lir.its from 0 to $1800 \mathrm{~K}$ at one atm were obtained for the oxides wustite $\mathrm{Fe}_{0.947} \mathrm{O}$, magnetite $\mathrm{Fe}_{3} \mathrm{O}_{4}$, and hematite $\mathrm{Fe}_{2} \mathrm{O}_{3}$. In addition to reflecting the calorimietry accurately, the set is in bettez agreement with the known phase equilibria than previous sets. We eraluated the published experimental data for the phases and their interactions using the program PHAS20. PHAS20 is a weighted multiple regression routine which combines an empirical equation for the heat capacity with the functional relations among heat capacity, entropy, enthalpy, free energy, equilibrium coastants, and electrocherrical potentials for a group of chemically related phases. Confidence limits for tine tabulated data were obtained from the program RECKON, using the same relations, the refined constants, the variances, and covariances, and statistical theory. 
The Elexibility of polynomials has also been useful in the compilation and exploitation of the phase diagrams of oxide systems. Because many of the solid phases are stoichiometric, a relatively good picture of the diagrams can be derived from the knowledge of the liquidus surfaces. Representing them as polynomials:

$$
T_{\text {liq }}=P(\text { composition })
$$

allows simple interpolations and extrapolations and the calculation of crystallization paths. The example of blast furnace slags (in the system $\left.\mathrm{CaO}-\mathrm{SiO}_{2}-\mathrm{Al}_{2} \mathrm{O}_{3}-\mathrm{MgO}\right)$ will be presented. 
Polynomial Representation of the Excess Eree Energy of Multicomponent Systems and their Use in Phase Diagram Calculations

\author{
H. Gaye \\ IRSID - PCM 57 \\ Maizières - Les - Metz
}

France

and

C. H. P. Lupis

Department of Metallurgy and Materials Science

Carnegie - Mellon University

Schenley Park, Pittsburgh, Pa. 15213

Various polynomial formalisms can be proposed for the representation of the excess free energy of multicomponent solutions:

- for the partial molar properties, the "interaction coefficients" approach provides polynomials in terms of solute mole fractions;

- For the integral excess free energy, symmetric expressions in terms of all mole fractions can be used.

An advantage of polynomial formalisms is that the coefficients can be mapped into one-dimensional arrays, so that the number of compd nents and the order of the polynomials can easily remain unrestricted.

Several applications of these formalisms to the integration of the Gibbs-Duhem equation will be presented. To that effect, a new method of integration was derived. It is based upon the expressions:

$$
\begin{aligned}
& \ln \gamma_{1}=\frac{G^{E}}{R T}-\sum_{j=2}^{m} x_{j} \frac{\partial\left(G^{E} / R T\right)}{\partial X_{j}} \\
& \left.\ln \gamma_{i}=\ln \gamma_{1}+\frac{\partial\left(G^{E} / R T\right)}{\partial X_{i}} \quad \text { (for } i=2,3, \ldots m\right)
\end{aligned}
$$


series expansion of the excess free energy of mixing in the variable $(-1+2 x)$. Other advantages and disadvantages of the three polynomial forms are discussed, along with the conversion matrices used to convert from one polynomial form to another. It is suggested that both Redlich-Kister and Bale-Pelton coefficients should be reported when experimental data are fitted.

The capabitities of our program are described in terms of the subroutines currently available. Applications to a variety of multiphase binary systems of engineering importance are shown, including examples of calculated phase diagrams.

\section{References}

1. e.g. F. E. Spencer, Jr., J. C. Hendrie, Jr. and D. Bienstock, 6th Internat. Conf. MHD Elec. Power Generation, Vol. II, P. 181 (1975); T. G. Chart, J. F. Counsel1, G. P. Jones, W. Slough and P. J. Spencer, Internat. Metal. Rev. 20, 57 (1975)

2. C. W. Bale and A. D. Pelton, Metal. Trans. 5, 2323 (1974)

3. 0. Rediich, A. T. Kister and C. E. Turnquist, Chem. Eng. Progr., Symposium Series, 48,49 (1952) 
A PROGRAM FOR BINARY PHASE EQUILIBRIA USING THE REDLICH-KISTER EQUATIONS

Isaac Eliezer and Reed A. Howald Chemistry Department, Montana State University

Bozeman, Montana, 59715

A variety of mathematical forms have been proposed and used to describe the relationship between thermodynamic properties and composition in binary systems. The subject has been reviewed periodically since the early 1900's without any consensus being reached on what are the best mathematical forms, primarily because there is a basic conflict between the requirement of convenience and the requirement of satisfying the Gibbs-Duhem relationship. The subject is currently of special importance because the availability of large high speed computers permits the application of the equations to a wide range of materials problems encountered in many engineering applications.

Power series in mole fraction are well adapted to the general representation of data and to computer calculation of phase diagrams. At least three different power series in mole fraction have now been programmed for computers: a simple power series, ${ }^{1}$ the modified Legendre polynomials of Bale and Pelton, ${ }^{2}$ and the Redlich-Kister ${ }^{3}$ equations (the present work).

We have chosen to program the Redlich-Kister equations

$$
\begin{aligned}
& \log \gamma_{1}=(1-X)^{2}\left[A+B(-1+4 X)+C(-1+6 x)(-1+2 X)+D(-1+8 X)(-1+2 X)^{2}+\cdots\right] \\
& \log \gamma_{2}=X^{2}\left[A+B(-3+4 X)+C(-5+6 X)(-1+2 X)+D(-7+8 X)(-1+2 X)^{2}+\cdots\right]
\end{aligned}
$$

(where $X$ is the mole fraction of component $l$ and $\gamma$ is the activity coefficient) primarily because the same set of coefficients appears in the equation for both components. These coefficients are the coefficients in a simple power 
and

$$
x_{1}^{2}+x_{2}^{2}+x_{3}^{2}-\frac{1}{2}
$$

There are very few three component systems for which sufficient data are available to evaluate more than six of these terms.

The equations and programming have been checked by application to the solid and liquid phases in the iron-nickel-carbon system. Parameters are shown for several three component systems, and calculations of phase equilibria in three component systems are described and compared to the original experimental data. The additional work required to extend the calculations to four and five component systems is outlined. Such systems composed of selected oxides will be suitable models for the slags encountered in metallurgy, magnetohydrodynamics and other advanced technologies. 
THE MATHEMATICAL REPRESENTATION OF ACTIVITY DATA IN THREE COMPONENT SYSTEMS AND ITS USE FOR THE COMPUTATION OF MULTIPHASE EQUILIBRIA

Isaac Eliezer anis Reed A. Howald

Chemistry Department, Montana State University
Bozeman, Montana, 59715

The activity coefficient of each species in a three component system (and other thermodynamic properties as well) can be expressed as a Redlich - Kister expansion in the sum of the other two mole fractions, $T=X_{j}+X_{k}$.

$\log \gamma_{i}=T^{2}\left[A_{i}+B_{i}(-3+4 T)+C_{j}(-5+6 T)(-1+2 T)+D_{i}(-7+8 T)(-1+2 T)^{2}+\cdots\right]$

The coefficients in this equation are functions of $S$ defined as $x_{j} /\left(x_{j}+x_{k}\right)$, the Redlich - Kister coefficients for the three binary subsystems, and an additional set of parameters describing interactions of all three components at once $\left(B_{123}, C_{312}, C_{321}\right.$, etc.):

Typical equations for the calculation of the coefficients $A_{i}$ through $H_{i}$ are shown. We have derived these equations, and programmed them for computer calculation. The operation of our computer program is described. By transforming the parameter matrix, activity coefficients and activities can be calculated and printed for each of the three components.

The terms which are required beyond those for the binary systems, $B_{123}$, etc., can be evaluated making use of a set of two dimensional orthogonal functions for the excess free energy of mixing divided by $x_{1} x_{2} x_{3}$. The first four functions in this set are

1

$$
\begin{aligned}
& \left(x_{1}-x_{2}\right) \\
& \left(1-3 x_{3}\right)
\end{aligned}
$$




\section{References:}

1. U. V. Choudary and Y. A. Chang, A Thermodynamic Method for Determining the Activities from Ternary Miscibility Gap Data: the Cu-Pb-O System, Met.

Trans. 7B, Dec. issue (1976).

2. U. V. Choudary, Y. E. Lee and Y. A. Chang, A Thermodynamic Analysis of the Copper-Lead-Sulfur System at $1473 \mathrm{~K}$, Met. Trans., in review (1976).

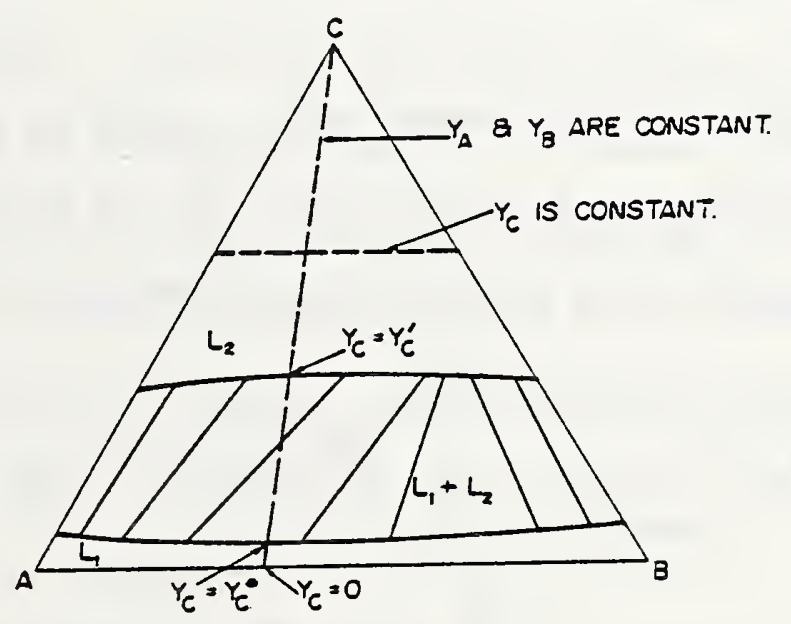

$$
y_{i}=\frac{n_{i}}{n_{A}+n_{B}}
$$

$n_{i}$ - No. of atoms of the ith component

$1 * 1$ - Denotes the value at the metal-rich boundary

$\cdots$ - Denotes the value at the metal-poor boundary

Fig. I A schematic of an isothermal section showing a miscibility gap in a ternary system $A-B-C$. 
been determined and are difficult to determine experimentally. Yet, these values are of practical interest. This method has been successfully applied to the systems $\mathrm{Cu}-\mathrm{Pb}-\mathrm{O}$ and $\mathrm{Cu}-\mathrm{Pb}-\mathrm{S}[1,2]$. In the $\mathrm{Cu}-\mathrm{Pb}-\mathrm{S}$ system, the experimentally determined activity values along the miscibility gap are in excellent agreement with the predicted values. For the $\mathrm{Cu}-\mathrm{Pb}-\mathrm{O}$ system, no experimental data of the activities are available. Since the proposed method was developed from classical thermodynamics, the thermodynamic values predicted should be exact if the phase equilibria data are correct.

In the present study, the method is used to predict the chemical potentials of $\mathrm{Cu}, \mathrm{Ag}$ and $\mathrm{S}$ (or $\mathrm{Se}$ ) for the ternary systems Cu-Ag-S (or Se) along the miscibility gap.

Since the development of the thermodynamic method is given in Ref. [1], only the relevant relations for the calculation of the activities along the miscibility gap boundary for the $\mathrm{Cu}-\mathrm{Ag}-\mathrm{S}(\mathrm{Se})$ system are given below:

$$
\begin{aligned}
& {\left[\begin{array}{ll}
l n & a_{S}
\end{array}\right]_{y_{A g}^{*}}=\left[\begin{array}{ll}
\ln & a_{S}
\end{array}\right]_{y_{A g}^{*}=0}+\int_{0}^{y_{A g}^{*}} \frac{y_{A g}^{*}-y_{A g}^{\prime}}{y_{S}^{\prime}-y_{S}^{*}} d\left[\ln \frac{{ }_{A g}}{{ }^{a}{ }_{C u}}\right]_{y_{A g}^{*}}}
\end{aligned}
$$

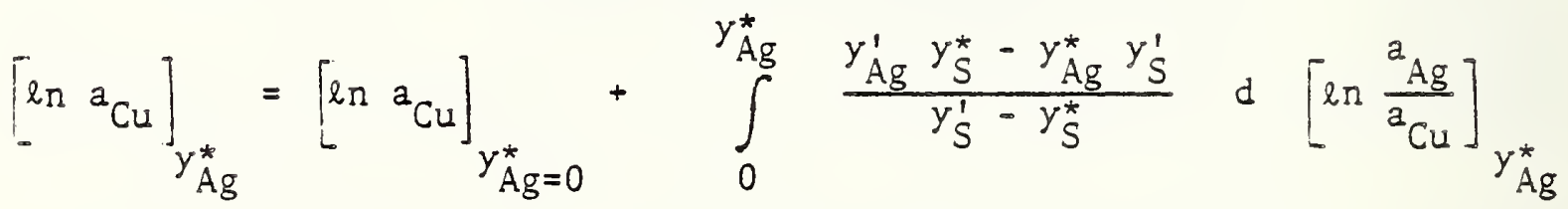

where the ratio of the activities of silver to copper along the miscibility gap boundary may be obtained from the relation:

$$
\begin{aligned}
& {\left[\ln \frac{{ }^{a} \mathrm{Ag}}{{ }^{a_{C u}}}\right]_{y_{A g}}=\left[\ln \frac{\gamma_{A g}}{\gamma_{C u}}\right]_{y_{A g}}+\left[\ln \frac{y_{A g}}{y_{C u}}\right]+y_{S}^{*}\left\{\frac{\ln \gamma_{S(A g)}^{\circ}}{\gamma_{S(C u)}^{0}}+\frac{2}{R T}\left[\frac{\Delta H-\Delta \bar{H}_{A g}}{1-y_{A g}}\right]\right\}} \\
& y_{S}=y_{S}^{*} \quad y_{S}=0
\end{aligned}
$$

The terms $\gamma, \Delta \mathrm{H}$ and $\Delta \overline{\mathrm{H}}_{\mathrm{Ag}}$ in the above relation represent the activity coefficient, inte and partial molar enthalpies in the binary Cu-Ag solutions. Also, the sulfur (selenium) potentials are estimated along the pseudo-binary $\mathrm{Cu}_{2} \mathrm{~S}(\mathrm{Se})-\mathrm{Ag}_{2} \mathrm{~S}(\mathrm{Se})$. 


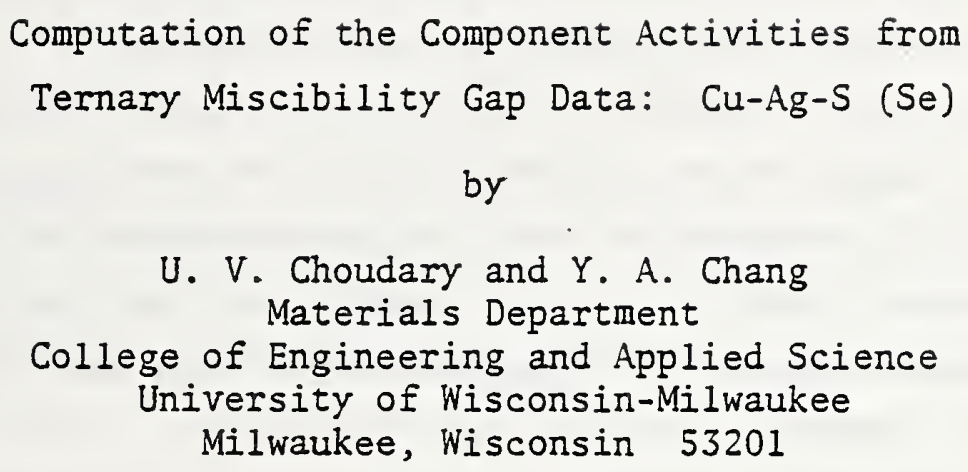

Phase equilibria and thermodynamic properties of alloy systems are closely interrelated. For instance, if we know the Gibbs energies of all the competing phases in any binary or ternary system as a function of composition and temperature, we may compute the phase diagram of this system. Conversely, from the experimentally determined phase diagrams we can often extract useful thermodynamic data of the alloy phases. This approach becomes extremely useful when it is experimentally difficult if not impossible to determine the appropriate thermodynamic properties.

Recently Choudary and Chang [1] developed a thermodynamic method to calculate the thermodynamic activities (or the chemical potentials) of the component elements A, B, C from a knowledge of the miscibility gap and the thermodynamic properties of C in A, B (see Fig. 1). This method is particularly applicable to ternary systems where the third component C (see Fig. 1) is a non-metal such as $0, \mathrm{~S}, \mathrm{Se}$, etc. Many of these systems are of extractive metallurgical interest, and are characterized by a ternary miscibility gap in the melt with one of the boundaries lying close to the $A-B$ boundary binary. For many of these systems, the tie-line distributions within the miscibility gap have been determined experimentally. But the chemical potentials of the components $A, B$ and $C$ have not 
Other possibilities include suggestions (c) that the compositional data are probably at fault as in $\mathrm{RuB}_{2}, \mathrm{OSB}_{2}$ and $\mathrm{AgB}_{2}(6)$, or finally (d) that the structure simply does not exist as reported, examples $A u B_{2}(6), W_{2} B_{5}$, and $R_{2} B_{5}(3)$. All the above suggestions and predictions have been supported by independent evidence.

While the current use of pauling's metallic radii can indicate problem areas in phase determinations, it cannot prove a phase is either correctly characterized or the most stable of several possible structures. Current plans include modifying the computer program to ultimately estimate heats of formation and make possible the selection of the most stable of known alternatives.

References

1. I. Pauling, "Nature of the Chemical Bond," 3 rd ed. (Cornell University Press, Ithaca, New York, 1960), p. 400 ff.

2. F. I. Carter and R. Mazelsky, J. Phys. Chem. Solids, 25, 571 (1964).

3. F. L. Carter, J. Less-Common Metals, 47, 157 (1976).

4. F. L. Carter, "A Mechanism for the High Temperature Transformation and the Resultant premartensitic TiNi(II)," Symposium on TiNi and Associated Compounds, Ed. F. E. Wang, 20 Feb 1968, NOITR 68-16.

5. F. I. Carter, "Valence Bond Formation in the Rare Earth Compounds having the CaCu 5 Structure," Proceedings of the Ninth Rare Earth Research Conference, Virginia Polytechnic Institute and State University, October 10-14, 1971, Vol. II, P. 617. 
A VALENCE BOND TEST FOR THE VALIDITY OF INTERMETALIIC AND SEMICONDUCTING STRUCTURES

\author{
Forrest I. Carter \\ Naval Research Laboratory \\ Washington, D.C. 20375
}

In the course of studying chemical bonding in transition metal intermetaliic compounds and semiconductors, we routinely apply the metallic radii approach of pauling(1). Starting with known composition and $x$-ray structure, the application of pauling's metallic radii provides one with an estimate of atomic valences, charges, bond orders, and bond hybridization. With experience, we have leamed that if the semiempirical approach of pauling cannot be self-consistently applied within certain Iimits (to be discussed), then either the structure or composition is seriously in error. In short, for a very wide selection of compounds one has a test for the correctness of a phase description provided the $\mathrm{x}$-ray data is available.

The basic equations for Pauling's metallic radii treatment are quite simple. An atom's valence $V_{i}$ may be calculated as $V_{i}=\Sigma n_{i j}$ where the bond orders $n_{i j}$ are calculated from the observed distances to its $j$ neighbors by the equation

$$
a_{i j}=R_{i}+R_{j}-0.600 \log n_{i j}
$$

The single bond radii $R_{i}$ and $R_{j}$ are given by a simple empirical formula for each row of the periodic table but are a function of effective charge, the valence, and the $d$ and $p$ hybridization of the bonds. Generally these equations must be combined with equations involved with the appropriate bookkeeping of orbitals and electrons. It is our observation that the validity of reported structural and compositional data may be questioned (a) when charge transfer is excessive, i.e. $|\Delta Q|>1.5$, or (b) when valences are abnormally high or low, or (c) when excessive d or f character must be used to achieve selfconsistent calculations. The range of results varies considerably, starting with the suggestion that either (a) further structural refinement is desirable as in the cases of $\mathrm{ZnSb}(2), \mathrm{Ta}_{3} \mathrm{~B}_{4}$ and $\operatorname{Ru}_{11} \mathrm{~B}_{8}(3)$, or (b) that the structure is unstable at ambient temperatures as in the cases of TiNi (Cscl structure) (4) and SmCo (5). 
The relatively smooth trends outlined above have been very useful in predicting the formation of undiscovered phases in binary metal-boron systems, and in predicting unstudied melting behavior and unmeasured melting temperatures. These trends along with published lower limits on melting temperatures and reasoning based upon phase relationships have been used to make such predictions, particularly for the rare-earth boride systems. The predictions and available data have been used in constructing temperature - composition phase diagrams.

* Research supported by the National Science Foundation, grants No. DMR-72-03133 and DMR $-76-14448$.

(1) Karl E. Spear, Phase Behavior and Related Properties of Rare-Earth Borides. Chapter II in Phase Diagrams, Materials Science and Technology, Vol. IV (A. M. Alper, Ed.) Academic Press, New York (1976), pp, 91-159.

(2) Karl E. Spear, Chemical Bonding in $\mathrm{AlB}_{2}$-Type Borides. J. Less-Common Metals 47, 195-201 (1976). 


\title{
CORRELATIONS AND PREDICTIONS OF METAL-BORON PHASE EQUILIBRIA*
}

\author{
Karl E. Spear \\ Materials Research Laboratory \\ Material Sciences Department \\ The Pennsylvania State University \\ University Park, Pennsylvania 16802
}

Attempts have been made to find correlations relating the phase equilibria of metal boride systems with the positions of the metals in the periodic chart. Both the group number (valency) and period number (size) significantly influence which phases form in a particular system, and the relative stability of each phase type. Particular emphasis was initially placed on the rare-earth boride systems (1), but the correlations have been extended to include transition metal and actinide metal borides as well as what little information is available on the borides of metais from groups IA, IIA, IIIA.

Metals with unfilled $d$-shells and larger sizes favor the formation of the more boron-rich phases such as $M_{6}, M B_{12}$, and $M_{66}$. Smaller metals with a significant number of d-electrons tend to form $\mathrm{H}_{3} B, M_{2} B, M_{3} B 2$, and $M B$ type phases. The metal boride with the highest melting temperature in a given $M-B$ system tends to follow similar compositional trends with size and number of d-electrons. For example, the larger rare-earths have $M_{6}$ phases with the highest melting temperatures. This shifts to the $\mathrm{MB}_{4}$ phase for the smaller rare-earths, then to the $\mathrm{MB}_{2}$ diborides for the titanium and vanadium group metals, and then to the MB monoborides for metals like iron.

The diboride phase with the $A T B_{2}$-type structure is the most common metal boride phase. The metals forming the diboride possess a wide range of sizes and electronic configurations. The reason for this appears related to the ability of metals to deform from a spherical shape in this structure (2). This also helps to explain its relatively high stability. 
the temary mixing equation proposed by Kohler ${ }^{2}$ to predict free energies, activities, and phase equilibria in temary systems.

The ternary miscibility gap for the $\mathrm{Au}-\mathrm{Cu}-\mathrm{Ni}$ system has been calculated at several temperatures and compares favorably with the experimentally determined phase diagram. Calculations of the phase equilibria for several isotherms in the $\mathrm{Au}-\mathrm{Cu}-\mathrm{Ag}$ system have been made. These are presented along with the optimization technique used for the phase equilibria determinations.

References:

1. M.I. Boyle, C. J. Van Tyne, and S.K. Tarby, "Computer Synthesis and Analysis of Phase Diagrams and Solution Thermodynamics" in Computer Simulation for Materials Application, edited by R. J. Acenaul, J. R. Beeler, and J.A. Simmons in Nuclear Metallurgy, 20, (1976), ‥ 187-197.

2. F. Kohler, "Zur Berechnung der thermodynamischen Daten eines ternären Systems aus den zugehörigen binären systemen," Monatshefte für Chemie, 91, (1960), P. 738-740.

3. J. I. White, "The Thermodynamics of the Liquidus-Solidus Gap in Binary Alloys: The Silver-Gold Systems," Transactions TMS-AIME, 215, (1959), p. 178-181.

* M. L. Boyle, C. J. Van Tyne, and S.K. Tarby are former graduate student, gradiate student, and professor respectively in the Metallurgy and Materials Science Department at Lehigh University, Bethlehem, Pa., 18015. 
COMPUTERIZED CHARACTERIZATION OF THE Au-Cu-ivi

AND Au-Cu-Ag TERNARY PHASE DIAGRAMS

by

M. I. Boyle, C. J. Van Tyne, and S. K. Tarby*

Information synthesized for binary systems by a computer method ${ }^{1}$ has been used in conjunction with Kohler's ${ }^{2}$ equation for mixing in ternary systems to characterize the $\mathrm{Au}-\mathrm{Cu}-\mathrm{Ni}$ and $\mathrm{Au}-\mathrm{Cu}-\mathrm{Ag}$ systems .

A computer program employing a least squares technique has been developed to analyze concurrently activity data, integral heat of mixing data, and phase diagram data in order to generate a set of $\alpha$-parameters for binary systems. The $\alpha$-parameter is defined as

$$
\alpha_{12}=\ln \gamma_{1} /\left(1-x_{1}\right)^{2}
$$

where $\gamma_{I}$ is the Raoultian activity coefficient and $x_{1}$ is the atom fraction of component 1 . These $\alpha$-parameters were given a composition and inverse temperature dependence of the form

$$
\alpha_{12}=\sum_{i=0}^{n}\left(A_{2 i+1}+A_{2 i+2} / T\right) \cdot x_{2}^{i}
$$

where $\mathrm{n}$ is the order of the $\alpha$-parameter representation, the $\mathrm{A}_{j}$ 's are constants detemined by the least squares analysis, and $T$ is absolute temperature. Each $\alpha$-parameter characterizes a single phase region in a binary system. The integral and partial molar solution thermodynamic quantities as well as the activities of each component can be calculated from the $\alpha$-parameter for any given temperature and composition in a one phase region. A pair of $\alpha$-parameters for two different phases can be used to predict two phase equilibria in a binary system.

The $\alpha$-parameters of the liquid and solid phases for the $\mathrm{Au}-\mathrm{Cu}, \mathrm{Cu}-\mathrm{Ni}$, $\mathrm{Au}-\mathrm{Ni}$, and $\mathrm{Ag}-\mathrm{Cu}$ binary systems have been detemined by this computer technique. The solid and liquid phase $\alpha$-parameters for the Ag-Au system were obtained from white ${ }^{3}$. These binary $\alpha$-parameters were then used with 
TUESDAY, I I JANUARY, 1977

$3: 30$ PM - 6:00 PM

PAPERS GIVEN BY POSTER

TOPIC I

COMPUTATIONAL TECHNIQUES FOR

PHASE DIAGRAM CONSTRUCTION 


\section{References}

1. Vanadium and its Alloys. J. Iron and Steel Inst., 1950, Vol. 164, pp. 149-159.

2. Lattice spacings and structures of metals and alloys. Pergamon Press, London, 1958, Pp. 1044.

3. Lattice spacings and structures of metals and alloys. Vol. 2, Pergamon Press, Oxford, 1967, pp. 1446.

4. Structure Reports. Intemational Union of Crystallography, Oosthoek, Utrecht. Volumes $17,18,19,20,21,22,23,24,25,26,27,28,29,30 \mathrm{~A}, 30 \mathrm{~B}, 31 \mathrm{~A}, 31 \mathrm{~B}$, $32 \mathrm{~A}, 32 \mathrm{~B}, 33 \mathrm{~A}, 33 \mathrm{~B}, 34 \mathrm{~A}, 34 \mathrm{~B}, 35 \mathrm{~A}, 35 \mathrm{~B}$.

5. The Crystal Chemistry and Physics of Metals and Alloys, Wiley \& Sons, New York, 1972, Pp. 806. 
assembled and sent to the publisher for photomoffset printing. It so happened that this process tumed out to be very much more rapid than the original one where the ms. was sent to the publisher who then went through it marking it for the printer, who set it in print. Thereafter the general and section editors went through up to four proofs to ensure correctness of the data. From this, one may conclude that unless a continuous data-bank operation is to be established at the same time as the production of ms., hand-typing operations may stll be cheaper and as rapid as computer-based operations, unless these are fully funded to provide day workers necessary for the operation. These observations are very cogent to the production of volumes of critically assessed data on phase equilibria, since computer handing of sucin operations is likely to require the development and successful operation of special programmes.

Finally a remark of two on comparative costs may be interesting. When I first became general editor of Structure Reports producing volumes in the early 1960s, a consumer buying the volumes obtained an average of 7 pages per Dutch florin ( $D$ I) spent, whereas critically evaluated data on a similar subject produced by a commercial company ran at one page only per $D$ fl., if my recollection is correct. Nevertheless, the production of Structure Reports was unsubsidized, and over the years they were self-financing and made a modest profit. In more recent years the costs of typesetting volumes of Structure Reports began to increase alarmingly: so that the price per page doubled. However, the changeover from typesetting to photo-offset printing of hand-typed ms. pages again halved the cost of a printed page. A certain loss of elegance results from the change from typeset pages with unjustified lines, but as far as I am aware this has not produced adverse comments, the users finding that any moves to reduce costs are welcome. 
As a general editor of Structure Reports for some 15 years (4), I have further experience of organizing numerous co-editors. Structure Reports is a series of annial volumes, which report in critical fashion all crystal structure determinations published in the year to which the volume is attributed. It is divided into three sections: Metals, Inorganic and Organic, each having its own co-editor assigned for the year in question. The work of a section co-editor thus comprises reading the appropriate literature, checking data and producing critical reports thereon which, when appropriately combined and edited, constitute the ms. The general editor is responsible for producing lists of structural papers to be read and for general coordination and checking of the different ms., reading proofs, etc. The trouble with this organization, where each editor takes on the work out of a sense of goodwill to the crystallographic community and in exchange for a relatively small honorarium, was that due to accidents or personal problems, one section of a volume frequently delayed the publication of the whole for several years. At one point the situation was so bad that Structure Reports volumes were only being published some 10 years after the year whose work was critically reported. Recently this back-log has been eliminated and Structure Reports now are appearing in the shortest possible time; only 2-3 years after the work that they report is published. Thus all volumes and up to and including 1973 were published by the end of 1975 .

An interesting reason for the rapid publication transpired to be a switch to direct photo-offset printing of typed ms. instead of having printers set the ms. in monotype, as was the earlier practice. This change was adopted primarily because the cost of typesetting the volumes was making them too expensive for individuals to purchase. At the time of the change, using any typing service to produce pages with justified lines was as expensive as setting the ms. in monotype, so "moonlignting" typists were engaged to type the pages of ms. in a standard format. The general editor then read the pages in proof and had corrections done before the ms. was 
Remarks on Producing and Publishing Critically Evaluated Data

W. B. Pearson

Faculty of Science, University of Waterloo

Waterloo, Ontario, Canada

Selected paragrophs of a full paper to copear in the formal proceedings

As somebody who has been concerned for nearly thirty years with critical compilations of phase equilibria and structural data on metals and alloys in particular (1-5), I offer some thoughts on "how to get the job done".

Iy general conclusions are as follows: a fully computer-based operation, is by far the most elegant, since with appropriate programing it can lead to books printed directly from magnetic tapes, but such a system requires very considerable financial backing, even if it goes no further than data handing and storage and does not proceed to the ultimate step of book production direct from the data files. Although computer programmes can be readily used to calculate and check data, the use of computers in no way obviates the need for experts to find the data in the literature and to critically evaluate it. In contrast to computer-based operations, a system of data handling by hand, using part-time typists as required, although far less elegant, is still workable and gives the final product at less cost.

Secondly, in order to get a critical data compilation prepared (unless there is sufficient money available to employ as many full-time assessors as is necessary), it is much better to support a single person (or possibly ewo) fulltime for the two or three years that may be required for the project, than to organize a team of many people on a "moonlighting" basis for nominal honoraria, each of whom is expected to complete a portion of the compilation. In the latter case the work is likely to become indefinitely delayed due to some memers of the "ream", for various reasons, not completing their assignments. 
Some Thoughts on the Distribution of Reference Data

\author{
Dr. Howard J. White, Jr. \\ Office of Standard Reference Data \\ National Bureau of Standards \\ Washington, D.C. 20234
}

Some of the characteristics of the existing methods of distributing reference data will be discussed. Strengths and weaknesses of the various methods wi11 be pointed out. There does not appear to be one superior method, but rather various methods or combinations of methods are indicated for individual cases. The problem of distributing reference data on phase diagrams will be considered specifically. 
Phase-Diagram Format and Distribution - Users' View

J. D. Livingston, General

Electric Co., Schenectady, N. Y.

Various aspects of users' needs for phase-diagram information will be introduced for discussion. User needs vary in their breadth and depth, and access to computer data bases will probably play an increasing role for in-depth needs. However, for the imediate future, most materials scientists and engineers will probably prefer phase-diagram compilations in book form. Presently, metallurgical phasediagram compilations in English are in an unsatisfactory state. The Constitution of Binary Alloys series is already 12 years out-of-date, and no satisfactory compilation of ternary and higher-order phase diagrams exists. An up-to-date compi1 ation of such data is sorely needed, perhaps similar in format to Phase Diagrams for Ceramists. Completeness, currency, and easy accessibility should bave higher priority than critical evaluations. If updating is achieved through annual volumes (like the Russian series), a cumulative index is necessary, preferably indexed by all components. Another possible approach to updating is the issuing of frequent supplements in looseleaf form, to allow incorporation in alphabetical order. If the lag between publication and compilation remains 1ong, a current-awareness journal on phase-diagram information may be uegful. 
The Representation of Phase Equilibria

by

\author{
A. Prince \\ Hirst Research Centre \\ General Electric, Itd. \\ United Kingdom
}

Phase diagrams are graphical presentations of the phase relationships in heterogeneous systems. A phase diagram consists of a coordinate framework enclosing geometrical elements representing the phase relationships (the phase complex). The coordinate framework is based on a coordinate simplex, which is equated to the concentration (composition) diagram of the system, combined with other geometrical elements representing the externally variable parameters such as temperature and pressure. The representation of compositions in $n-c o m p o n e n t$ systems is considered using the Kurnakov simplex generalisations. Consideration is given to secondary methods for representing compositions in which the concepts of electron concentrations, electron-vacancy numbers and average group numbers are introduced.

The representation of phase relationships in binary and multicomponent systems is considered from the point of view of models, their projections and sections. The handling of systems with variable valency of a component is included as is the case of reciprocal systems.

Phase relationships can be represented analytically. Topological relationships between the geometrical elements of a phase diagram and its sections are useful for generalising the basic rules of construction for simple systems $(n=2$ or 3 ) to more complex systems. 
(6) J. C. Phillips, Phys. Rev. Lett. 271197 (1971)

(7) A. Navrotsky and A. Muan, J. Inorg. Nucl. Chem. 33 35(1971)

(8) A. Navrotsky, J. Solid State Chem. II 10(1974)

A. Navrotsk 
Of special interest to this symposium might be a comparison of the state of the art in oxide systems versus metallic systems. Oxide phase diagrams are often dominated by rather stable stoichiometric ternary and quaternary compounds; thus calculations must correctly include and predict these stabilities. In metallic systems, compounds usually (but not always) have relatively low stability and more extensive homogeneity ranges, leading to a greater emphasis, in calculations, on solid solutior thermodynamics and defect chemistry. For geologic applications, the effect of high pressure on phase stability is very important, and the thermodynamic aspects of $P$ - $T$ stability relations have been more fully explored for silicates than for alloys. In oxide systems "tnereoretical" predictions of phase stability have been based largely on considerations of size and charge. This has led to good qualitative understanding but has been of little help in quantitative prediction of phase diagrams. The ionicity scale proposed by Phillips (6) has been used for analyzing semicc nductor phase diagrams. The theory of metal and alloy phase stability is somewhate more advanced than for oxide s!'stems. Further developments in both fields would benefit from greater interaction and awareness of problems common to metals, ceramics and minerals.

\section{References}

(1) H. C. Helgeson, in preparation.

(2) H. L. Haas and J. R. Fisher, Amer. Jour. Sci. 276 525(1976)

(3) D. M. Kerrick and J. Slaughter, Amer. Jour. Sci. 276883 (1976)

(4) A. Muan, Proc. Brit. Ceram. Soc. 8, 103(1967)

(5) B. J. Wood, Amer. Mineral, 61 599(1976) 
PHASE DIAGRAM CALCULATIONS

IN CERAMIC AND MINERAL SYSTEMS

\section{A. Narrotsky \\ Chemistry Department \\ Arizona State University \\ Tempe, AZ}

Emphasis in this area has been more on the calculation of thermodynamic parameters from measured phase equilibria rather than on the calculation of phase diacrams from stored numerical data. Major efforts have been made (a) to sxtract thermochemical data for minerals from $P$ - T stability curves $: 1,2,3)$, (b) to calculate activity - composition relations in ternary oxide and silicate solid solutions from subsolidus phase relations $(4,5,9)$ and (c) to obtain thermodynamic parameters for phase transitions for series of structurally and chemically related materials, e.g. the wurtzite - rocksalt transition in oxides and chalcogenides $(6,7)$ and the olivine - spinel transition in silicates and germanatss (8). Questions to be discussed include the following. (a) What is the inherent accuracy and precision of the thermochemical data derived from phase diagrams for silicate systems? (b) What efforts exist, or ari? needed, for compiling, evaluating, and updating such data? (c) What are the most useful and/or most correct equations to use to fit the data? Pirticularly, what power series for heat capacity and what formalism ( $r$ gular solution, subregular, or other) for activities? What accuracy can be expected in fitting activity data to phase diagrams? (d) What "theoretical" developments can we expect for these largely ionic systems - lattice energy calculations, structure-properties correlations, ionic vs covalent bonding, stabilities of special structures, etc.? 
ENERGETICS OF NONEQUILIBRIUM ALLOY PHASES - AN ABBREVIATED ABSTRACT.

A more detailed abstract is given in TPSI-21, pp 131-134, of the Abstract Booklet.

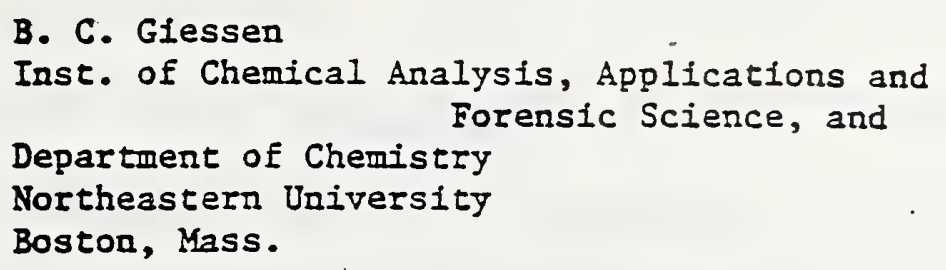

Interest will be focussed on the energetics of nonequilibrium alloy phases; i.e., metastable and unstable metallic phases, and their role in extended phase diagrams. Specific examples include amorphous metals, metastable disordered normal (s-p eiectrori) metal alloy phases, and metastable ordered alloy phases. Examples for vapor quenched, melt quenched, and electrodeposited phases and their phase diagrain representation will be discussed.

\section{REFERENCES:}

1. A. K. Sinha, B. C. Giessen and D. E. Polk, Metastable Phases Formed by Rapid Quenching from the Liquid and Vapor Phase, in Treatise on Solid State Chemistry, N. B Hannay, Ed., Vol. III, Plenum Press, New York, p. 1., 1976.

2. B. C. Giessen, Grystal Chemistry of Rapidiy Que uched (Splat.Cooled) Metastable B Metal Alloy Phases, Adv. in X-Ray Analysis, C. S. Barrett, G. R. Mallett, end J. B. Newkirk, Eds., Plenum Press, N. Y., Vol. 12, P. 23 (1969).

3. B. C. Giessen, Classification and Crystal Chemistry of Ordered Metastable Alloy Phases, Proc. Second Internat. Conf. on Rapidiy Quenched Metals, M.I.T., 1975, Section I, N.J. Grant and B. C. Giessen, Eds., M.I.T. Press, Cambridge, Mass. 1976, 119. 
can be applied to two phase alloys in general and possibly may be extended to other multiphase regions of multicomponent alloys.

\section{REFERENCES}

1. Boesch, W. J., and Slaney, J. S.: Met. Progress, Vol. 86, No. 11 , July 1964, pp. 109-111.

2. Woodyat:, L. R.; Sims, C. T.; and BeaHie, H. J., Jr.: Prediction of Sigma-Type Phase Occurrence from Compositions in Austenitic Superalloys. Trans-AlME, Vol. 236, No. 4, April 1966, pp. 519-527.

3. Kriege, O. H., and Sullivan, C. P.: The Separation of Gamma Prime from ldimet 700. Trans. ASH, Vol. 61, No. 2, June 1968, pp. 278-282.

4. Mihalisin, J.R.; and Pasquine, D. L.: Phase Transformations in Nickel-Base Superalloys. AlME International Symposium on Structural S:ability in Superalloys, Seven Springs, PA, September 4-6, 1968, FP. $134-171$.

5. Dreshfi:sld, R. L.: Estimation of Gamma Phase Composition in Nickel-3ase Superall loys. Met. Trans., Vol. 2, May 1971, pp. 13411346.

6. Dreshfirld, R. L., and Wallace, J. F.: The Gamma-Gamma Prime Region of the $\mathrm{Ni}-\mathrm{Al}-\mathrm{Cr}-\mathrm{Ti}-\mathrm{W}-\mathrm{Mo}$ System at $850^{\circ} \mathrm{C}$. Met. Trans., Vol. 5, January 1974, pp. 71-78. 
While PHACOMP served well to control the composition of alloys at the melt shop to prevent detrimental phases such as sigma, experimentally determined phase compositions indicated that the assumption of gamma prime stoichiometry was inaccurate. $3,4^{\circ}$ Also, no single calculation method or critical average electron vacancy number could be identified which would work well on a broad range of alloy compositions.

In an effort to avoid assigning an arbitrary stoichiometry to gamma prime; the Ni-Al-Cr-Ti diagram was analyzed using analytical geometry to determine the gamma composition, civen the alloy's composition: - The problem was treated by first icentifying the tie line on which the allcy-lay, then finding the inter section of that tie line and the gamma solvus.

To better describe the superal Toys" constitution, this study was conducted to model the gamina-gamma prime regicn of the $\mathrm{Ni}-\mathrm{Al}-\mathrm{Cr}-\mathrm{W}-\mathrm{Mo}$ system at $850^{\circ} \mathrm{C} .^{€}$ Analytical geometry principles were again used to allow the estima:ion of both the gamma and ganma prime composition, given the alloy composition."-lt was al so observed that the formation of additional phases could be predicted from tireè parameters: the $\mathrm{Ni}$ content of the alloy, the rate of charge of "Al with respect to $\mathrm{Cr}^{\circ} \mathrm{A}$ along the tie tiine, and function of the $\mathrm{Cr}$, Mo, and $w$ content in the gamna phase:

The eomputational: procedure was shown to be applicable to com-

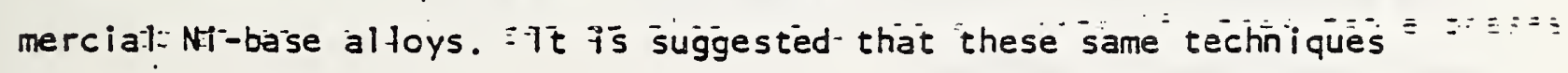




\title{
ESTIMATION OF CONJUGATE PHASE COMPOSITIONS IN \\ MULTICOMPONENT SYSTEMS \\ by Robert L. Dreshfield \\ NASA-Lewis Research Center \\ Cleveland, Ohio
}

\begin{abstract}
Recent advances in gas turbine technology have resulted in ap-
\end{abstract} plying a group of complex multicomponent $\mathrm{Ni}$-base alloys known as "superalloys" at temperatures and for times which may cause precipitation of phases which can significantly reduce their load bearing life. To allow melters to control their melt compositions to avoid these phases, a computational method called "PHACOMp" was developed."? This method was in effect an effort to determine if the desired composition was in the two phase field (gamn!a and gamma prime) of a phase diagram based on the $\mathrm{Ni}-\mathrm{Cr}-\mathrm{Al}-\mathrm{X}$ system. To determine if the alloy was stable, the melt composition was user to estimate the "residual matrix" ( $\gamma$ ) composition. This was accomplished by reducing the melt composition by the amount of alloy elements thought to precipitate either during solidification or processing. The precipitates were assumed to have nearly fixed stoichiometries. The average electron vacancy concentration was then calculated for the $y$ phase and compared to an empirically set critical value to estimate if undesirable phases might precipitate in service. 


\title{
COMPUTATION AND PREDICTION OF PHASE DIAGRAMS
}

\author{
Moderator: \\ 0. J. Rleppa \\ The James Franck Institute \\ University of Chicago \\ Chicago, II \\ Panel Members: \\ L. Brewer \\ Inorganic Materials Research Div. \\ Lawrence Berkeley Laboratories \\ University of California \\ Berkeley, CA \\ D. de Fontaine \\ Materials Department \\ University of California \\ Los Angeles, CA \\ R. L. Dreshfield \\ Materials Processing and \\ Joining Section \\ NASA Lewis Research Center \\ Cleveland, $\mathrm{OH}$ \\ B. C. Giessen \\ Dept. of Chemistry and \\ Mechanical Engineering \\ Northeastern University \\ Boston, MA \\ L. Kaufman \\ ManLabs, Inc. \\ Cambridge, MA
}
A. Navrotsky
Chemistry Division
Arizona State University
Tempe, AZ

Some of the panelists will give additional details with a poster or demonstration during poster session TPSI, in the Tuesday afternoon program. 
TUESDAY, II JANUARY, 1977

$2: 00 P M-3: 30 P M$

REVIEW OF PHASE DIAGRAM

REPRESENTATIONS,

FORMAT

AND

DISTRIBUTION 
Theory of Alloy Phases

\author{
R. E. Watson \\ Brookhaven National Laboratory \\ Upton, NY 11973 \\ H. Ehrenreich \\ Harvard University \\ Cambridge, Mass. 02138 \\ and \\ L. H. Bennett \\ National Bureau of Standards \\ Washington, D.C. 20234
}

We will survey theoretical approaches to phase stability in alloys ranging from model calculations (in the manner of Stringfellow, Engel-Brewer, Miedema, etc.) through pseudopotential approaches to efforts which endeavor to solve the Schrödinger Wave Equation. Topics to be considered will include phase stabilities of elemental metals, and of ordered compounds, and problems taking disorder into account.

We will discuss the predictive abilities of various approaches and especially the insight which the more rigorous methods provide in parameters entering model calculations. 
TUESDAY, II JANUARY, 1977

$9: 00$ AM - 12:30 PM

REVIEW OF

THEORY OF ALLOY PHASES

AND

PANEL ON

COMPUTATION AND PREDICTION

OF PHASE DIAGRAMS 


\section{In ThE EMPLOYEE'S LOUNGE}

DEMONSTRATION VIDEO TAPE

Thermochemical Data Center

I. Ansara

Laboratoire De Thermodynamique Et Physico-Chimie Metallurgiques

Domaine Universitaire

38401 Saint Martin D'Heres

France

TWO DEMONSTRATIONS IN CONJUNCTION WITH

MPSI-7 On-Line Computer Manipulations

J. Eilsenrath, B. B. Molino

Office of Standard Reference Data

National Bureau of Standards

Washington, DC 20234

MPSI-8 Alloy Data Center Graphical Methods

R. A. Kirsch, L. J. Swartzendruber National Bureau of Standards Washington, DC 20234

In THE GREEN AUDITORIUM

FOUR INSTRUCTIONAL MOVIES

Contributed by H. McKinstry

Materials Research Laboratory Pennsylvania State University University Park, PA 16802

Produced at Pennsylvania State University 
MONDAY, 10 JANUARY, 1977

$$
3: 30 P M-6: 00 \quad P M
$$

DEMONSTRATIONS DURING THE POSTER SESSION 
The author of this abstract is unable to attend the workshop. A full paper will be published in the workshop proceedings.

Phase - Diagram of a Metal - Gas System.

\author{
V.K. Sinha \\ Department of Materials Science \\ National Institute of Foundry \\ and Forge Technologg \\ Hatia, Ranchi-834003, India.
}

Phage diagram is an Indizpensable means for representing physicochemical state of a sjstem in terms of the state variables, pressure(P), Composition (C), and temerature(T). For metallic or other systems where none or the components is gas, the phase diagram is conventionalif represented in the form of $T-C$ diagrams at fixed pressure of 1 atm. A similar representation is, however, inadequate for metal-gas systems because of tile pronounced effect of gas partial pressure in sixing the physico-chemical state. The anthor, thurefore, recommends that in latter cases the TC diagram must be surllemented either with the isothermal P-C diagrams or the P - T isocho:es. Tae P - C - I data contained therein will then provide sot only a better understanding of the existence of equilibrium phases in terms of the state variables but also an easy means for comuting the vaidous thermo-dynamic functions.

The present paper demonstrates a better way of repregenting the phase diagram of a metal-gas system, with particular referesce to the binary Ir - $\mathrm{H}_{2}$ system. The method of determining the various tbermo-drnamic functions from the phase diegram is also discussed. 
Pase Diagram of a Socimen at High Termeratures under external tengile or Shear stress or both.

\author{
K.M Whanna \\ Materials Science Dept \\ National Institute of Foundry \\ and Forge Technology \\ Hatia, Ranchi-834003, India.
}

Fhase diagrams are graphs that give relationships between rarious phases in a system as a function of temperature, pressure and crmposition. To my mind, phase changes at higit temperatures under tensile or shear stress or both have not been studied so far. Similarly the corresponiing phase diagrams have also not been studied. It will be interesting to plot the phase diagram of a specimen under external tensile or shear stress or both, keeping pressive conatant and varying the temerature. Having done so we can hrve a better ingight tnto the control of micro-structure. We car have an idea of the life time of a specimen that works at high temperatures under external tensile and shear stress. Exper:mental studies can be made by ploviding a tensometer type attacbment to the dilatometer. 


\title{
DEMONSTRATIONS
}

Monday 10 Jan., 1977, 3:30 PM - 6:00 PM

VIDEO TAPE REPLACED WITH NEW FILM

demonstration VIDEO TAPE listed in the program, to be shown during the Monday poster session in the Employee's Lounge by I. Ansara of the Thermochenical Data Center, Grenoble, France, is being replaced with a FILM 1llustrating some mples on the calculations of phase diagrams.

\author{
Tuesday 11 Jan., 1977, 3:30 PM - 6:00 PM \\ ADDED FIM (Green Auditorium)
}

\begin{abstract}
"Generation of Phase Diagrams from Free Energy Curves" contributed by C. H. P. Lupis, Carnegie Mellon University, A 22 minute instructional color film sponsored by. NSF.
\end{abstract}


INDUSTRLAL NIIINS

by

Paul J. Fopiano

Army Materials \& Mechanics Research Center

Watertown, Massichusett: 02172

\section{CORQIERCIAL TITANIUM ALLOYS}

Many commercial titanium alloys employ aluminum and vanadium as major alloying elements. In the investigation of the phase transformations which occur during the heat treatment of these alloys, the prescilce of two or more phases complicates the interpretation of the mechanical and physical property data. The major strengthening mechanisms can often be related to the compositions of the alpha and beta phases in equilibriun at the solution temperature. Standards made up with various amounts of aluminum and vanadium were analyzed chemically and on an electron microprobe. A calibration curve was thereby developed for the titaniun rich corner of the ternary diagram. Application of this calibration curve was demonstrated on the most popular commercial titallum alloy, Ti-6Al-4V. Various solution-treated conditions in the alpha plus hetil field were investigated. The compositions of the alpha plus beta phises were determined and compared to the published litcrature which had becn developed before the probe was generally available. 


\section{STUDIES OF THE FE-C-B PHASE DIAGRAM BY AUTORADIOGRAPHY \\ Thomas B. Cameron and John E. Morral \\ Department of Metal7urgy and \\ Institute of Materials Science, U-136 \\ University of Connecticut \\ Storrs, CT 06268}

The iron rich corner of the $\mathrm{Fe}-\mathrm{C}-\mathrm{B}$ phase diagram is being investigated in the first step of a study probing the mechanism behind boron hardenability in steel. The major problems encountered in this type of study are first, obtaining accurate measurements of soluble boron concentrations, on the order of $30 \mathrm{ppm}$ or less; and second, maintaining high purity samples since boron will react with other elements, notably nitrogen, in the ppm range. For these reasons a novel approach is being used in the phase diagram study. Boron concentrations are being measured by neutron autoradiography along the carbon gradient of a carburized Fe-B alloy. The autoradiography technique allows measuring boron concentrations of $5 \pm 1 \mathrm{ppm}$ and the use of somewhat massive samples prevents contamination during processing. Isotherma 1 sections of the austenite - borocarbide solvus are obtainable by this technique. 
USE OF SEGREGATION PHENOMENA IN SOLID SOLUTIONS AS A METHOD FOR DETERMINING SOLIDIFICATION DIAGRAMS. APPLICATION TO SOME Sc $\mathrm{O}_{3}-\mathrm{In}_{2} \mathrm{O}_{3}$ SYSTEMS T. M. Badie

Laboratoire des Ultra-Refractaires Centre National de la Recherche Scientifique France

Controlled freezing offers opportunities for determining liquidus and solidus surfaces or curves of multicomponent or binary systems, respectively.

We have tried to make the best use of its rarely exploited possibilities in studying the systems $\mathrm{Sc}_{2} \mathrm{O}_{3}-\mathrm{Ln}_{2} \mathrm{O}_{3}, \mathrm{Ln}=\mathrm{La}, \mathrm{Nd}, \mathrm{Sm}, \mathrm{Gd}$, Dy, Ho, Er, Tm, Yb, Lu and $Y$.

In this study, the results obtained by high temperature $\mathrm{X}$-ray diffractometry and direct thermal analysis in a solar furnace are compared with those obtained by segregation analysis in solid solutions.

Segregation phenomena which are connected with the freezing of the liquid out of equilibrium, are studied by $\mathrm{X}$-ray diffractometry and electron microprobe at room temperature. The products are obtained by normal freezing from liquid mixtures in a solar furnace. The moving rate of the liquid-solid interface was $10 \mathrm{~mm} / \mathrm{s}$ and $510^{-3} \mathrm{~mm} / \mathrm{s}$. The analysis of those phenomena brought about a better knowledge of the nature of the solidification diagram as well as the localization of the invariant points.

The results obtained in the systems $\mathrm{Sc}_{2} \mathrm{O}_{3}-\mathrm{Ho}_{2} \mathrm{O}_{3}$ and $\mathrm{Sc}_{2} \mathrm{O}_{3}-\mathrm{Dy}_{2} \mathrm{O}_{3}$ are examples. In the systems $\mathrm{Sc}_{2} \mathrm{O}_{3}-\mathrm{Ln}_{2} \mathrm{O}_{3} ; \mathrm{Ln}=\mathrm{Ho}$, Er, $\mathrm{Yb}$, the set of experimental information on solidification diagrams is compared with calculations based on two experimental results from the systems' liquidus. Based on the calculated data of mixtures in these systems, the solidification diagrams of neighbouring systems $\left(\mathrm{L}_{\mathrm{n}}=\mathrm{Y}, \mathrm{Tm}, \mathrm{Lu}\right)$ are predicted. 
c) The solid solubility range (SSR), for those compounds that are incongruentmelting type and superconductors, exists only on the A-rich side of the stoichiometric composition (i.e., never on the B-rich side). In contradistinction, the compounds of congruent-melting type and not superconducting have their SSR extended on both sides of the stoichiometric composition.

These correlations can all be reconciled in terms of the "A-chain integrity" which is a manifestation of the basic electronic properties in these compounds. Subsequentiy a new dimension in the interpretation and use of phase equilibrium diagrams is offered. 


\section{PHASE EQUILIBRIUM DIAGRAMS IN TERMS OF ELECTRONIC STRUCTURE \\ Frederick E. Wang \\ Materials Division \\ Naval Surface Weapons Center \\ White Oak, Silver Spring, Md. 20910}

Heretofore, interpretation and use of the phase equilibrium diagrams are invariably limited to the knowledge of both the macroscopic and microscopic arrangements of atoms within the system. However, atomic arrangement in a given solid state is only half of the story; the other half is electronic arrangements. Since a phase equilibrium diagram is a manifestation of all the thermodynamic properties involved, it must contain information concerning electronic arrangements as well as atomic arrangements. This contention is dramatically demonstrated in the correlation of the electronic properties of the $A_{3} B(B-W)$ type compounds and their phase equilibrium diagrams. Based on the $23 \mathrm{~A}_{3} \mathrm{~B}$ compounds for which the phase equilibrium diagram as well as the superconducting critical temperature $\left(T_{C}\right)$ are known, the correlation falls into three major categories:

a) The $A_{3} B$ compounds which are formed from congruent-melting type are not superconductors while those formed from incongruent-melting type are. For example:

$$
\begin{array}{ll}
\mathrm{Nb}_{3} \mathrm{Ir}, \mathrm{Cr}_{3} \mathrm{Si}, \mathrm{V}_{3} \mathrm{Pd}- & \begin{array}{l}
\text { congruent melting type } \\
\text { non-superconducting }
\end{array} \\
\mathrm{Nb}_{3} \mathrm{Ga}, \mathrm{V}_{3} \mathrm{Ga}, \mathrm{Mo}_{3} \mathrm{Os}- & \begin{array}{l}
\text { incongruent melting type } \\
\text { superconductors }
\end{array}
\end{array}
$$

b) Among the compounds which are superconducting, their individual superconducting critical temperature $\left(T_{C}\right)$ is directly proportional to their solid solubility range (SSR) at room temperature as observed in the phase diagrams. 
USE OF HIGH ENERGY ION BEAMS IN PHASE DIAGRAM OETERMINATION

\author{
J. E. Smugeresky \\ Metallurgy and Electroplating Division 8312 \\ S. M. Myers \\ Ion-Solid Interactions Oivision 5111 \\ Sandia Laboratories \\ Livermore, CA 94550
}

Phase boundaries can now be investigated by using a new approach which utilizes high energy ion beams. The technique uses ion implantation and ion backscattering analysis combined with diffusion annealing treatments. Ion-implantation of solute elements into the matrix is used to create a super-saturated solid solution in the first $\simeq 0.1 \mu \mathrm{m}$ of the sample. After isothermal annealing the composition versus depth profile is monitored nondestructively via $2 \mathrm{MeV}$ He backscattering. Using these profiles and the appropriate boundary conditions for the diffusion equation, the phase boundaries can be obtained. The advantage of this technique lies in the ability to monitor very low solubilities like iron in beryllium as well as extending data to $600 \mathrm{~K}$ or almost $300 \mathrm{~K}$ lower than has been measured by diffusion couples. Application of this technique to both binary and ternary systems will be described. 
squeezed. This capsule bursting method was found by the authors to be useful in the study of phase equilibria of systems in which the reaction rate of hydration was rapid.

In RCI solutions, equilibrium temperatures in the system $\mathrm{MgO}-\mathrm{Mg}(\mathrm{OH})_{2}$ obtained are generally lower than that in pure water. For example, equilibrium temperatures at $1000 \mathrm{~kg} / \mathrm{cm}^{2}$ were $517^{\circ} \mathrm{C}$ in 5 mol \% LiCl solution, $559^{\circ} \mathrm{C}$ in 5 mol \% NaCl solution and $537^{\circ} \mathrm{C}$ in $\mathrm{KCI}$ solution. On the other hand it was $595^{\circ} \mathrm{C}$ in pure water.

The three equilibrium curves in RCl solutions were nearly parallel and steeper than that in pure water. It seems that the equilibrium curves in 5 mol \% $\mathrm{NaCl}$ solution crossed that in pure water below $200 \mathrm{~kg} / \mathrm{cm}^{2}$.

From these results, the capsule bursting method is seen to be a good method for the study of phase equilibria under hydrothermal conditions whenever the reaction rate of hydration is rapid. 
Phase Equilibria in the System $\mathrm{MgO}-\mathrm{RCl}$ ( $\mathrm{R}=\mathrm{Li}$, Na, and $\mathrm{K}$ ) Solution under Hydrothermal Conditions by Means of A Capsule Bursting Method

Shigeyuki Sōmiya, Kazuo Nakamura, Shin-ichi Hirano and Shinroku Saito

Research Laboratory of Engineering Materials

Tokyo Institute of Technology

Ookayama, Meguro, Tokyo, 152, Japan

Brucite, $\mathrm{Mg}(\mathrm{OH})_{2}$, is one of the raw materials to produce basic bricks. Brucite is obtained from sea water by precipitation or as natural rock. Brucite has been known to occur in nature in hydrothermal veins. It is well known that the hydrothermal solutions often contain alkali chlorides. Though a considerable amount of research has been carried out for phase equilibria in the system $\mathrm{MgO}-\mathrm{Mg}(\mathrm{OH})_{2}$ in pure water, the literature that can be found on the phase equilibria in the system $\mathrm{Mg}(\mathrm{OH})_{2}-\mathrm{MgO}$ in alkali chloride solution, is scarce.

The purpose of the present work is to clear up the effect of the alkali chlorides such as $\mathrm{LiCl}, \mathrm{NaCl}$, and $\mathrm{KCl}$ on the phase equilibria curve of the system $\mathrm{MgO}-\mathrm{Mg}(\mathrm{OH})_{2}$ up to $1500 \mathrm{~kg} / \mathrm{cm}^{2}$ by means of a capsule bursting method.

In order to study equilibrium curves, a gold capsule including the desired quantity of $\mathrm{MgO}$ powder and $5 \mathrm{~mol} \% \mathrm{RCl}$ solution was sealed by an electric arc, and two capsules, $3 \mathrm{~mm}$ in outside diameter and 35-50 mm in length, were inserted into one test-tube of Roy-Tuttle type hydrothermal vessel. The quantity of $\mathrm{H}_{2} \mathrm{O}$ in the capsule was from 0.6 to 0.8 in molar ratio to $\mathrm{MgO}$ converted to $\mathrm{Mg}(\mathrm{OH}) 2^{\text {. }}$ After treatment under high temperature and high pressure, the pressure was released quickly and then the vessel was quenched in cold water. This is called the "Capsule Bursting Method."

If the set point of temperature and pressure was on the high temperature side of the equilibrium curve, the capsule would be burst by unreacted solution. In contrast, if it was on the low temperature side, water inside the capsule was completely consumed to form $\mathrm{Mg}(\mathrm{OH})_{2}$. Therefore the capsule would not be burst but 
MPSII - 8

INTERRELATIONS BETWEEN PHASE DIAGRAMS AND HYDRIDING PROPERTIES FOR AIIOYS BASED ON THE INTERMETAIIIC COMPOUND FETI

by

G. D. Sandrock*, J. J. Reilly**, and J. R. Johnson**

\section{ABSTRACT}

Hydriding alloys based on the intermetallic compound FeTi have potential for the safe and convenient storage of hydrogen, both for mobile and stationary applications. In spite of its simple formula, the hydriding behavior of Feti is quite complex and a strong function of alloy microstructure. The alloy microstructure, in turn, depends on composition, not only deviations from stoichiometry but also various inpurities. In this paper we discuss some of the interrelations among composition, microstructure, and hydriding behavior that can be related to phase diagram information. In particular, we will discuss the Fe-Ti, Fe-Ti-O, and Fe-Ti-Mn phase diagrams and their relationships to hydriding properties. The use of hydriding data to infer metal-hydrogen phase diagrams will also be briefly ¿iscussed.

*The author is with The International Nickel Company, Inc., Paul D. Merica Research Laboratory, Sterling Forest, Suffern, NY 10901 **The authors are with Brookhaven National Laboratory, Department of Applied Science, Upton, NY 11973 
1. Goldstein, J.I. and Ogilvie, R.E., Trans TMS-AIME, 1965, vo1. 233, p. 2083 .

2. Goldstein, J.I. and Ogilvie, R.E. in X-ray Optics and Microanalysis, ed by R. Castaing, P. Deschamps, and J. Philibert, Hermann, Paris (1966), p. 594 .

3. Widge, S., Master's Thesis, Lehigh University (1976).

4. Goldstein, J.I., Hewins, R., and Romig, A.D. Jr., Proc. 7th Lunar Science Conference, to be published.

5. Cliff, G. and Lorimer, G.W., Proc. 5th Euro. Cong. on Electron Microsco., 1972 , p. 140. 
Experimental Determination of Phase Diagrams

with the Electron Microprobe and Scanning Transmission Electron Microscope

A.D. Romig, Jr. and J.I. Goldstein

Department of Metallurgy and Materials Science

Lehigh University, Bethlehem, PA, 18015

Within the past dozen years the electron microprobe (EMP) has proven itself a valuable tool in the determination of phase diagrams (solid phase regions). A literature survey indicates that since the first application of this technique, to the determination of the Fe-Ni phase diagram, in 1965 ( 1 ), at least 14 binary, 18 ternary, and several higher order metallic systems have been analyzed with the electron microprobe.

The most powerful aspect of this technique is that one can determine the location and orientation of tie lines even when the bulk phases are not in equilibrium (2) (ie, concentration gradients across a continuous phase). This advantage is best realized when one is considering a system where true bulk equilibrium cannot be attained, either because diffusion rates are so slow that the bulk equilibrium condition cannot be reached in a reasonable time period, such as $\mathrm{Fe}-\mathrm{Ni}-\mathrm{Co}$ (3), or where the phase diagram is to contain a metastable phase where heat treatments long enough to produce homogeneous phases are also of sufficient length to cause the metastable phase to decompose, such as $\mathrm{Fe}-\mathrm{Ni}-\mathrm{C}(4)$.

An important set of factors, unique to the determination of interface. compositions with the electron microprobe and which affect the accuracy of the measurements are: (1) spatial resolution; (2) $x$-ray absorption; and (3) $x-r a y$ flouresence. These affects are mainly attributable to the finite size of the $x$-ray excitation volume. Even under optimum conditions it is not possible to generate $x$-rays from a volume with a diameter much less than 1 um. Typically, a trace is made across the boundary at $1 \mathrm{Hm}$ intervals, and the interface composition determined by extrapolation to the interface position. This is a reasonable procedure, unless the concentration gradient is too steep. To improve the resolution of interface composition discontinuities, a smaller excitation volume is desirable. Errors attributable to extrapolated interface compositions could be minimized and steeper gradients could be measured.

The newly developed scanning transmission electron microscope (STEM) will allow $x$-ray excitation from volumes less than $0.10 \mu m$ in radius. The technique requires thin foils which are transparent to the incident electron beam (typically $100 \mathrm{kv}$ ) (5). The use of thin foils and high excitation voltages eliminates the flourescence and absorption problems present in microprobe analysis, thus permitting the use of a relatively simple matrix correction technique.

The STEM methods have just recently been developed to the point where phase diagram determination is possible. Research results on the Fe-Ni-Co system using this technique will be presented. 
In perturbed angular correlation experiments the nucleus is prepared in the second excited state $\left(\mathrm{I}_{2}\right)$. This can be done, for example, by using radioactive ${ }^{57} \mathrm{Co}$ which decays to the $I_{2}$ level of ${ }^{57} \mathrm{Fe}$. As the nucleus decays to its ground state, it emits two gammas in coincidence. The coincidence rate varies sinusoidally with time with a period given by $T=\frac{1}{v}=h / \Delta E_{1}$.

All three techniques, then, sense the splitting in one or more nuclear levels produced by interaction with the hyperfine field present in the material. Since the hyperfine field itself depends upon crystal structure, chemical composition, and magnetic ordering of the material, it is possible to use the hyperfine interation as a phase label. Several specific examples of this use will be discussed, including Mossbauer studies and NMR of Ti-Fe and $\mathrm{Ti}-\mathrm{Fe}-\mathrm{H}$ alloy systems, NMR studies of $\mathrm{AuIn}_{2}-\mathrm{AuAl}_{2}-\mathrm{AuGa}_{2}$ pseudobinary alloys and PAC studies of Ni-Hf alloys.

*Also consultant, Alloy Physics Section, Institute for Materials Research, National Bureau of Standards.

1. e.g. Hyperfine Interactions, ed. by A. J. Freeman and R. B. Franke1, (Academic Press, New York, 1967).

2. I. D. Weisman, L. J. Swartzendruber, and L. H. Bennett, Nuclear Resonances in Metals: Nuclear Magnetic Resonance and Mossbauer Effect, chapter VI-2, in Techniques of Metals Research, ed. by R. F. Bunshah (John Wiley \& Sons, 1973).

3. G. C. Carter, D. J. Kahan and L. H. Bennett, Metallic Shifts in NMR, Progress in Materials Science 20, 1 (1976).

4. M. Frauenfelder and R. M. Steffen, in Alpha-, Beta- and Gamma-Ray Spectroscopy, Vol. 2, ed. by K. Seigbahn (North Holland Pub. Co., Amsterdam, 1966), p. 997. 
HYPERFINE FIELDS: Techniques for Meosurement

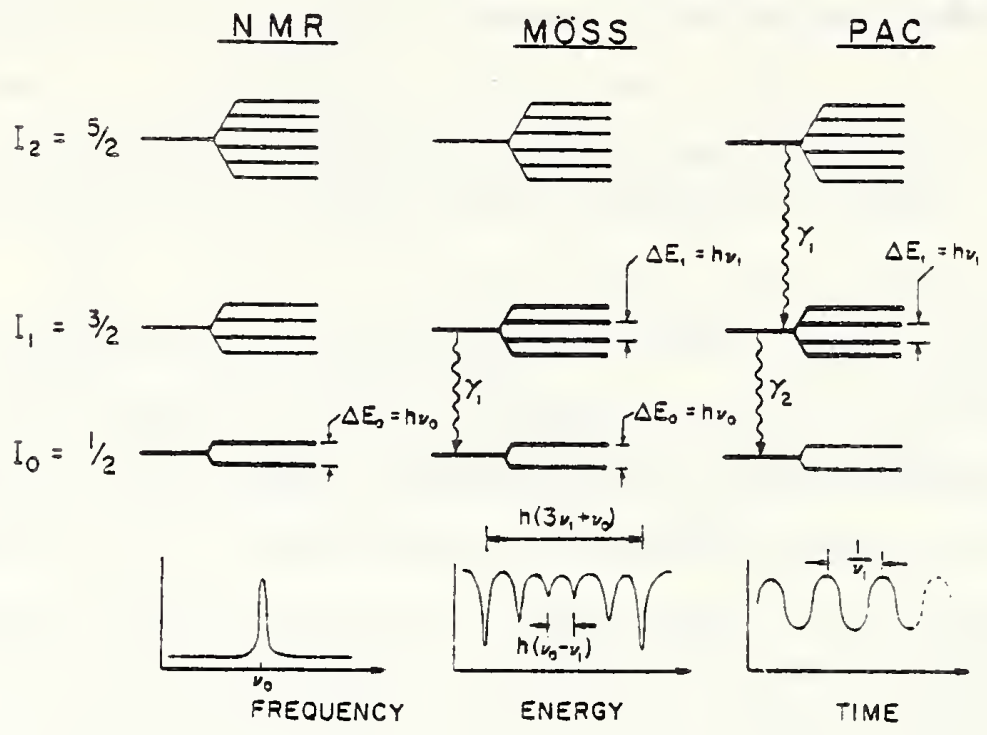

The nucleus has three energy levels of interest - a ground state (spin $I_{0}$ ) and two excited states (spins $I_{1}$ and $I_{2}$ ). All of these levels are split by the hyperfine field, assumed here to be a static magnetic field.

In MMR one looks only at the ground state (indicated by the heavy lines). and observes the level splitting, $\Delta E_{0}$, by observing transitions between the split levels caused by external application of a radio-frequency field, $v$. A resonant absorption of RF energy is observed when the RF frequency satisfies the condition $\Delta E_{0}=h v_{0}$. Since only the ground state is involved, no nuclear radiations are emitted.

In the Mossbauer effect, the ground state and the first excited state are involved. Nuclei in the ground state are excited to $I_{1}$ by the absorption of gamma radiation. Then $I_{1}$ decays back to the gound state with the emission of a second gamma ray. The transitions observed here are between a split sublevel of $I_{1}$ and a split sublevel of $I_{0}$. Since several gamma ray energies can cause the excitation, absorption can occur at each of these. The absorption spectrum, then, has resonances whose positions depend up on the hyperfine splitting of both states $I_{0}$ and $I_{1}$. 
MPSI I - 6

Nuclear Hyperfine Techniques and the Determination of Phase Diagrams

\author{
R. C. Reno* \\ Department of Physics \\ University of Maryland Baltimore County \\ Baltimore, MD 21228 \\ and
}

L. J. Swartzendruber, G. C. Carter and L. H. Bennett

Institute for Materials Research

National Bureau of Standards

Washington, DC 20234

Within any material there exist internal electric and magnetic fields which are produced by the positively charged atomic nuclei and the negatively charged core and valence electrons. The fields depend upon the arrangement of these consituents (e.g., spatial ordering of the ion cores) as well as interactions between the constituents (e.g., chemical bonding and electron exchange effects). A particularly important class of internal fields is that present at the positions of the atomic nuclei. These fields interact with the nuclei and shift the discrete energy levels which describe possible nuclear excitations. The fine structure of each atomic nucleus is therefore altered (slightly) and these hyperfine changes are then described in terms of hyperfine fields acting on unperturbed nuclei ${ }^{1}$.

The hyperfine field is, therefore, a subclass of all internal fields present in materials but it has particular significance because the interaction between this field and the nucleus can be measured by several techniques. This review will discuss three well-established techniques for measuring the hyperfine interaction - nuclear magnetic resonance (NMR) ${ }^{2,3}$, the Mossbauer effect (ME) ${ }^{2}$ and the perturbed angular correlation of gamma rays $(P A C)^{4}$. It will discuss how the hyperfine interaction is influenced by the chemical, magnetic and structural properties of the material involved and will illustrate how each of the above techniques can be used to provide information useful in constructing phase diagrams.

All three of the above hyperfine techniques detect a change in the nuclear energy levels of the atom at the site studied by observing transitions between levels. A comparison of all three techniques is made with the aid of the following schematic nuclear energy level diagram for ${ }^{57} \mathrm{Fe}$ nuclei. 
APPLICATION OF THE SCANNING ELECTRON MICROSCOPE (SEM)

TO THE STUDY OF HIGH TEMPERATURE OXIDE PHASE EQUILIBRIA

\author{
L. P. Cook and D. B. Minor \\ Institute for Materials Research \\ National Bureau of Standards \\ Washington, D.C. 20234
}

The use of the electron microprobe $x$-ray analyzer in phase equilibrium studies has been demonstrated both for ceramic and metallurgical systems. The energy dispersive $x$-ray analyzer (EDX) - equipped scanning electron microscope (SEM), a more recently developed member of the family of electron microbeam instruments, offers many of the advantages of the electron microprobe and has other features making it a uniquely useful tool in the study of phase equilibria. This instrument has particular potential for certain aspects of oxide research.

The characterization of powdered oxide starting materials is not a trivial problem, particularly if grain size is of the order of a micron. Techniques for mounting oxide powders so as to eliminate specimen charging are reviewed. For bulk $x$-ray analysis using an EDX system, careful attention must be paid to powder aggregation, grain size, surface geometry and instrumental operating conditions. Examples of $x-r a y$ analysis of finely homogenized powdered starting materials prepared at closely spaced compositional intervals are given. If suitable care is exercised this technique could conceivably be used to sample miliigram or smaller quantities of powder as a check on the effectiveness of the homogenization process used. The effect of parameters such as grain shape, size, size range and porosity (of compacted powders) on experiments can be monitored.

For the examination of the products of high temperature experiments, the SEM is especially useful. Quench experiments can be examined in total without special sample preparation other than carbon coating, and after SEM examination the usual $x$-ray diffraction and optical examinations can be made. Sintering effects due to grain boundary melting and recrystallization can in some instances be distinguished from effects due to a small amount of equilibrium melt present along grain boundaries and in interstices. This type of phenomenon is ordinarily observable with only great difficulty, if at all, in the conventional light microscope using the immersion technique. Evidence for liquid immiscibility can be observed, and the presence of minute amounts of crystalline phases in quenched melts can be detected on fractured surfaces. Crystal morphology can in some instances be used to distinguish equilibrium from nonequilibrium (quench) crystal growth. Equilibrium phases of variable composition. can be quantitatively characterized by their chemistry. 
To our knowledge, reliable measurements in the Li-Al-Mg system have been carried out only in the $\mathrm{Mg}$-rich $\operatorname{cormer}^{8}$ at $\mathrm{T}=648 \mathrm{~K}$. The calculated portion of the phase diagram is in reasonably good agreement with the experimental results.

Despite inherent Iimitations in such computations, they remain important in ultimately deducing phase relations. The present calculations should be considered as a good approximation to the phase diagram. These results can be refined by incorporating, in a thermodynamically self-consistent way, very few experimental data at key compositions. A reliable phase diagram can thus be computed with a minimum number of measurements.

\section{References}

1. P. A. Nelson et al., USAEC Report ANL-8109, 1974.

2. I. Raufman and H. Nesor, "Treatise on Solid State Chemistry," N. B. Hannay, Ed., Plenum Press, New York 5 , 179-232, 1975.

3. S. P. Yatsenko and E. A. Saltykova, Russ. J. Chem. Phys. 48, 1402 (1974).

4. M. I. Saboungi and M. Blander, J. Electrochem. Soc. (in press).

5. R. M. Myles, F. C. Mrazek, J. A. Smaga and J. I. Settle in "Proceedings of the Symposium and Workshop on Advanced Battery Research and Design," March, 1976, ANL-76-8, P. B-50.

6. M. I. Saboungi and M. Blander, J. Electrocher. Soc. 122, 1631 (1975).

7. R. Hultgren, P. D. Desai, D. T. Hawkins, M. Gleiser and K. K. Kelley, "Selected Values of Thermodynamic Properties of Binary Alloys," American Society for Metals, Metals Park, Onio (1973).

8. J. A. Rowland, Jr., C. E. Armantrout and D. F. Walsh, Trans. AIM 333 (1955). 


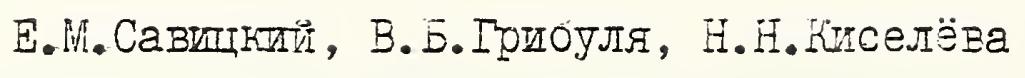

Кнбернетическое пропнозирование образования хиниески

соединенй В недсследованных системах

/ Тезисы доклада /

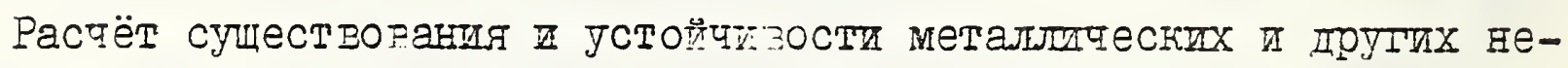
органических б̆аз из "первых понципов" остаётся пока неразрешённой проблемой. С пругой сторонн, появление п супествование мазаз опрепеляется інотыи бакторами / размеры и свойства атомов т состав-

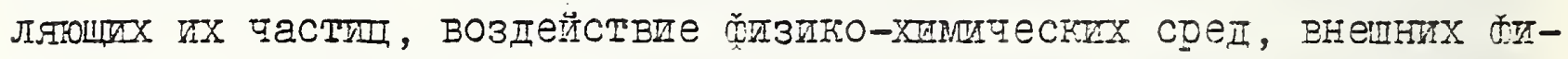
зпчески полей, состава, тенператури, павления, ктнетипи /. Велиपина этих параметров перевенна и индивидуальна пля конкретнех саз.

Учёт одновременно больпого количества банторов под силу кибернетически устройствам при условин задания логико-математической спстеме анализа взапмопействия әтих фағторов. ПІо сушеству мы име-

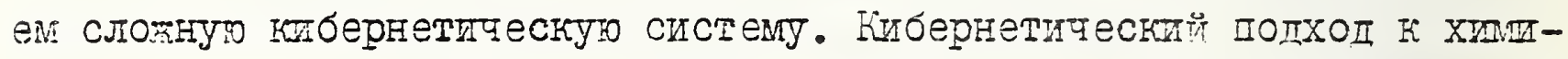

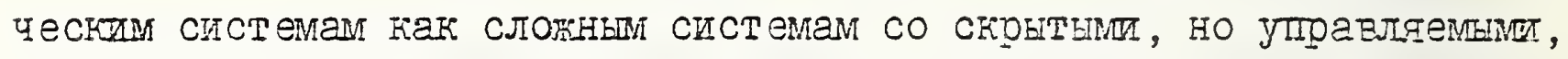
Связям позволяет постронть обучаюшеся машинные програмпі, способнне пропнозировать поведение п свойства хнических объектов.

Стремление получить прогноз Пз"первыХ прннциов" попсказивает пспользованше в качестве исходных шанных фундаментальных хараптеристик атомов хпмгесктх әлементов - атомного номера, распретеления электронов по энергетически состояниям в атоме П пругих. Но в зависпмости от задачи исследования мопут быть исповьзованы раз-

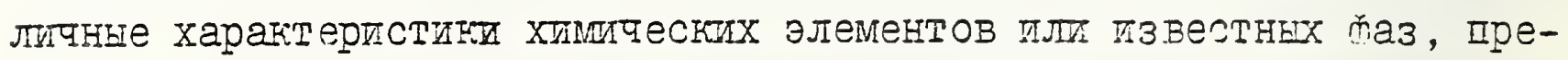

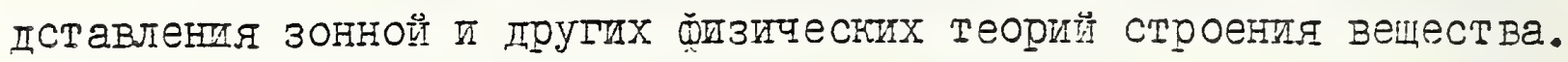

IІервые исследования в этой области были начаты нали в I966 I. /If. На пвотиных спстемах была показана возможность Пропноза суціестрования неорганицеских соэдиненй определённого состава: AB, A $F$

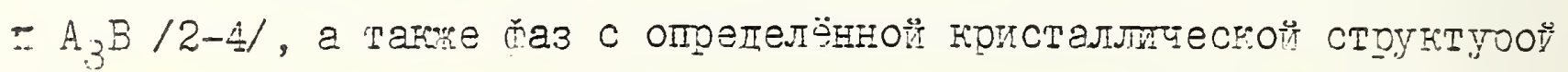

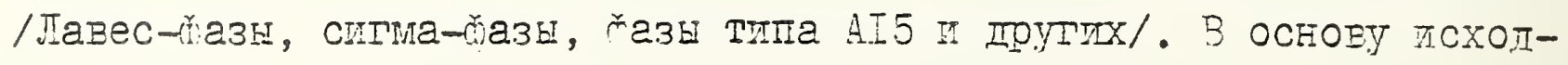

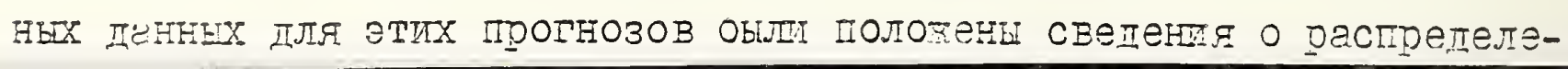




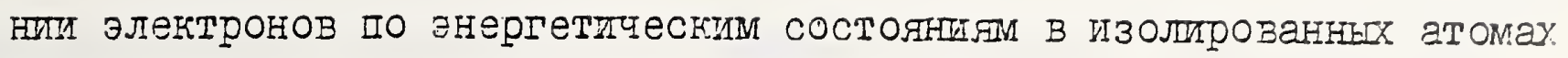
Мнотие из прогнозироганных соелиненй сеітас уже спнтезтрованы. По напим подсчётам достоғерность прогноза не ните 90\%. IЛя некоторых составов прогнозировались типн кристаллохилиесклі реактй образовандя соетшнениі /5/, типы присталлических структур /6/, а тан

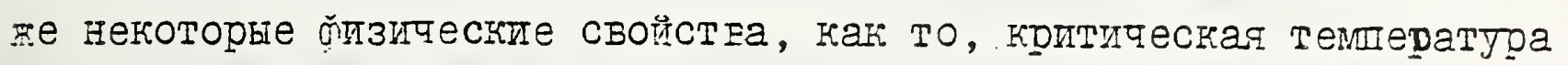
перехода в сверхпроводянее состояние /7/ и температура плавления $18 /$.

Учптывая перспективность настоянего направления, нататы тссле-

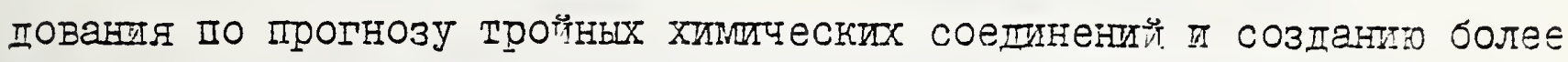
мошной кибернетпеской спстелы. В первуп очередь прогнозировались наиболее представит ельные глассы соединенши, представляғше практический пнтерес / $\mathrm{ABO}_{3}, \mathrm{AB}_{2} \mathrm{O}_{4}, \mathrm{AB}_{4}, \mathrm{~A}_{2} \mathrm{~B}_{2} \mathrm{O}_{7}, \mathrm{AB}_{2} \mathrm{~S}_{4} /, 9 /$, а тагте напболее распространённне типн кристалличесих структур / перовскиты, шпинели, пирохлоры /.В настоянее время ведется работа по накоплению опнта прогноза тройных неорганических соединенш й проверке схопимости прогноза с экспериментальнылд панными.

Полученные прогнозы значительно расшияят ооласть попска неор-

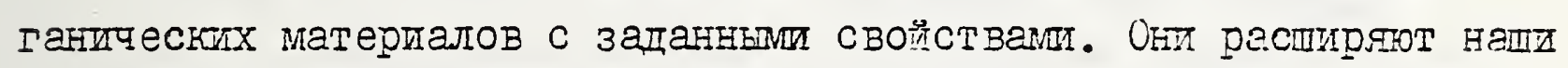
возмовности теоретическопо расчёта пиаграмм состояния и новех ю̆аз I показынают относттельность суцествунци препставлендй мах состояния как инструменте познания фииино-хпми еспх спстем. Они требуют такте уточнения понятия химтеского соепнения, услоБтй его образования, стехиометричности, равновесного состоянাЯ, Кинетических панних и оолее широкой формулировки термопинамтие еского правила паз с учётом воздействий разлшных п̆изиеских полей, вакуума, писперсности и т.п.

\section{爪итература}

I. … Савпций, 10.В.Девингталь, В.В.Гоибуля, Докл. АН СССР, I968, T.I78, $\mathrm{HFI}, 79-8 I$. 
174

T FSI - 20

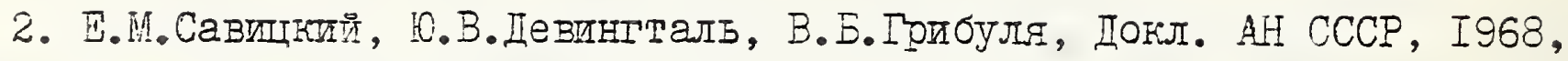
T.I83, N55. IIIO-III2.

3. Е.и.Савиншй, В.Б.Грибуля, изз. АН СССР. Неорган. матер., I97I, T.7, 157, IO97-IIO4.

4. E.M.Savitskii and V.B.Gribulya, J. Phys. Chem. Solids, I972, $\nabla .33, I 853-I 860$.

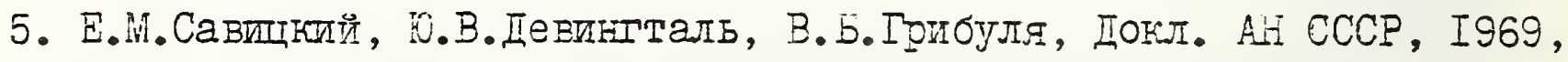
T.I85, 163, 56I-563.

6. E.М.Савипнти, В.Б̈.Гр⿰буля, Iокл。AH CCCP, 1975, т.220, 155, I066I069.

7. Е.М.Савипитй, О.В.Дерпнтталь, В.Б.Грибуля, в сб. "Сверхпоовопяшие сплавы и соединентя", М., "Наука", I972, 7-20.

8. Е.М.Савинили, В.Б.Грибуля, в сб. "Структура ти свойства жаропроपншх металлических матеркалов", М., "Ниука", I973, 3-I0.

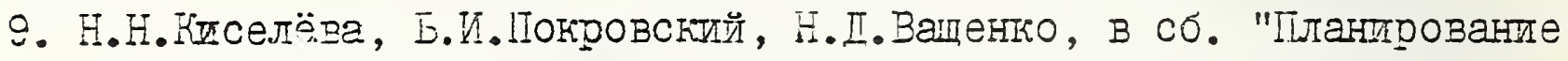
и автоматизагия эксперпмента в научных исследованиях", М., "Сов радио", I974, 308-3I5.

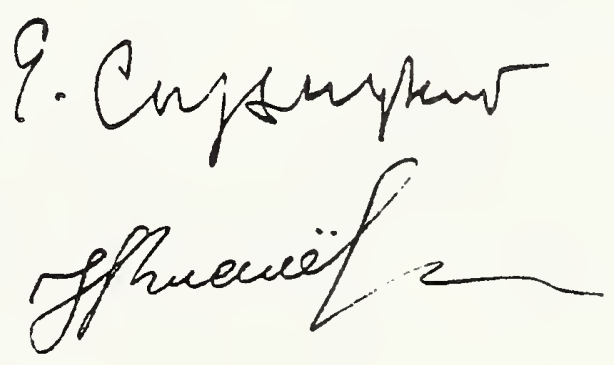


An english transiation prepared by D. B. Butrymowicz, Diffusion Data Center, NBS

A Ziteral translation is given since the exact words intempreted in different disciplines (e.g. Chemistry versus Physics) can lead to different "engiish" and thas different physical model interpretations.

Cybernetic Prediction of the Formation

of Chemical Compounds in Uninvestigated Systems

by

E. M. Savitskii, V. B. Gribulya, N. N. Kiseleva

Baikov Institute of Metallurgy

Academy of Science of the USSR

Moscow

Calculations of the existence and stability of the metallic as well as other inorganic phases on the basis of "first principles" remains an unresolved problem. On the other hand, the occurrence and existence of phases is determined by many factors (size and properties of atoms as well as their constituent particles, interactions of physical media, effects of external physical fields, composition, temperature, pressure, kinetics). The magnitude of these parameters is variable and unique for each specific phase.

One can take into account simultaneously a large number of these factors in view of the capabilities of cybernetic devices under the conditions of assigning mathematical-logic system of analysis of the interactions between these factors. In fact we deal with a complex cybernetic system. The cybernetic approach to chemical systems as to complex systems with latent, however guiding, links (or ties) enables one to develop self-educating computer programs which would be capable of predicting the behavior as well as properties of chemical systems.

The attempt to obtain prediction from "first principles" suggests the use of the fundamental characteristics of atoms of the atoms as the starting dataatomic number, distribution of electrons in accordance with energy states in the atom, as well as others. However depending on the problem under consideration, different characteristics of chemical elements from the known phases can be utilized, which are the concepts of the zone as well as the other physical theories for the structure of matter.

Our first research in this area began in 1966 (1). Using binary systems we were able to show the possibility of predicting the existence of inorganic compounds of definite composition; $A B, A_{2} B, A_{3} B / 2-4 /$, as well as the phases with definite crystal structure (Laves-phases, sigma-phases, Al5-type phases et al). As the primary data for these predictions, information on the distribution of electrons in accordance with the energy states in isolated atoms were taken. Many of the compounds which were predicted have been now synthesized. According to our calculations, the reliability of our predictions is no less than 90\%. For certain compounds, types of crystal-chemical reactions for the formation of the compounds (5), crystal-structure type (6), as well as certain physical properties, such as critical temperature of transition to the superconducting state (7), and melting point (8) were predicted. 
Taking into account the future perspective of this inquiry, we have startad investigations into the predictability of ternary-chemical systems as veil as the creation of a larger cybernetic system. We first of all made predictions on the most representative classes of the compounds of practical interest $\left(\mathrm{ABO}_{3}, \mathrm{AB}_{2} \mathrm{O}_{4}, \mathrm{ABO}_{4}, \mathrm{~A}_{2} \mathrm{~B}_{2} \mathrm{O}_{7}, \mathrm{AB}_{2} \mathrm{~S}_{4}\right)(9)$, as well as the most widespread types of crystal steuctures (perkovisites, spinels, periciase). At present we are conducting the work and aquiring experience with the prediction. of ternary inorganic compounds and verification of the accuracy of prediction with known experimental data.

The obtained predictions provide for a significant expansion of the areas of search for inorganic materials with specific desireable properties. They extend our capabilities of theoretical calculations of phase diagrams and new phases as well as shows the correlation between existing concepts of phase diagrams as an instrument of understanding physi-chemical systems. They require also a more specific understanding of chemical compounds, conditions for their formation, stoichiometry, equilibrium state, kinetic data, and wider (broader) fornulation of the thermodynamic phase rules which would take into account the interactions of various physical fields, vacuum, dispersity of the system, etc.

\section{References}

1. E. M. Savitskii, Tu. V. Devingtal and V. B. Gribulya, "Recognition of Binary Phase Diagrams of Metallurgical Systems with the assistance of an Electronic Calculating Machine", Dokl. Acad. Nauk SSSR: 178, 1, 79-81, 1968

2. E. M. Savitskii, Yu. V. Devingtal and V. B. Gribulya, "Solubility Ranges of $A_{3} B$ type Intermetalic Compounds with the assistance of an Electronic Calculating Machine", Dokl. Acad. Nauk SSSR: 183, 5, 1110-1112, 1968.

3. E. M. Savitskii and V. B. Gribulya, "Computer-Based predictions concerning Inorganic Compounds in Binary Systens", Inorg. Matis.: 7, 973-980, 1971; translated from Izv. Akad. Nauk SSSR, Neorganicheskie MateriaIy: 7, 7, 1097-1104, 1971.

4. E. Y. Savieskii and V. B. Gribulya, "Prediction of Rare Earth Metal Compounds by means of Computers", J. Phys. Chem. So1.: 33, 1853-1860, 1972.

5. E. M. Savitskii, Yu. V. Devingtal and V. B. Gribulya, "Recognition of Fonmation [Peritectic] type reactions and estimating the width of Homogeneous Metallic Phases with the assistance of an Electronic Calculating Machine", Dokl. Acad. Nauk SSSR: $185,3,561-563,1969$.

6. E. M. Savitskii and V. B. Gribulya, "Solubility Ranges of Binary Sigma-Phases with the assistance of an Electronic Calculating Machine", Dokl. Acad. Nauk SSSR: 220, 5, 1066-1069, 1975 .

7. E. M. Savitskii, Yu. V. Devingtal and V. B. Gribulya in "Superconducting Alloys and Compounds", pp. 7-20, Nauka, Moscow, 1972.

8. E. M. Savitskii and V. B. Gribulya in "Structures and Properties of Eeat-Resistant Metallurgical Materials", pp. 3-10, Nauka, Moscow, 1973.

9: N. N. Kiseleva, B. I. Pokrovskii and N. B. Vashchenko in "Planning and Automating Experinents in Scientific Investigations", 308-315, Sovradio, Moscow, 1974. 
THE DETERMINATION AND REPRESENTATION OF METASTABLE PHASE DIAGRAM FEATURES AND SOME KINETIC CHARACTERISTICS OF ALLOYS

Bill C. Giessen

Institute of Chemical Analysis, Applications and Forensic Science and Department of Chemistry

Northeastern University, Boston, Mass. 02115

The current strong interest in non-equilibrium alloys, especially amorphous metals, has focussed attention on the possibility of systematically presenting metastable equilibria in phase diagrams and even including kinetic features, primarily in order to depict their composition dependence.

The non-equilibrium phases of prime interest are the following (we use the term "phases" here for constitutional entities and not necessarily in the Gibbsian sense):

1. Metastable extensions of terminal or intermediate solid solutions;

2. Metastable intermediate phases;

3. Amorphous alloys.

These phases have been dealt with in detail in many recent papers, e.g., References 1-4; alloy constitutional aspects are emphasized in references 1 , 3 , 5. Especially in reference 5 , the constitutional requirements of metastable phase formation have been discussed intensively and the kinetic aspects are treated in terms of solidification theory.

Because most metastable metallic phases studied to date either have two components or two groups of closely related components, and because they are principally prepared from the melt, we focus here on binary systems; we also disregard pressure effects. We treat three types of phase diagram-related plots involving nonequilibrium phases:

1. $x-T$ phase diagram representations and related diagrams; 
2. Free energy diagrams;

3. Diagrams involving kinetic parameters.

1. $x-T$ Diagrams

a. X-T diagrams showing metastable phases, and the equilibria involving them, especially metastable melting reactions. This representation should be as complete as possible, including all metastable phases that could energetically form from the liquid in constrained equilibrium upon supercooling of the latter to $0 \mathrm{~K}$.

b. $x-T_{0}$ diagrams containing $T_{0}$, the cross-over temperatures of the free energy curves of the respective phases at composition $x$. These curves are of considerable practical importance as, for liquid-solid transitions, they define the composition limits within which metastable phases or metastable extensions of equilibrium phases can be retained by supercooling of the melt to a given temperature if equilibrium phase formation is prevented and glass formation does not intervene.

c. $x-T_{C}^{A}$ plots, showing the composition dependence of the temperatures of phase transitions involving a property $A$ of metastable phases, such as magnetic or superconducting transitions.

d. $x-\Delta T_{s}$ plots, giving the supercooling temperatures $\Delta T_{S}$ required for the formation of a given metastable phase. '

\section{Free Energy Diagrams}

G-T-x diagrams (three dimensional for binary systems) and their $G-T$ ( $x=$ constant) and $G-x(T=$ constant $)$ sections. Diagrams of this type can incorporate nonequilibrium phases having free energies exceeding those of phases that can be included in $x-T$ diagrams; knowledge of these phases over at least a certain free energy range is a requirement for a complete description of a given alloy system 
in terms of fundamental concepts, as they should correctly predict not only equilibrium phases but also more energetic phases.

\section{Diagrams Involving Kinetic Parameters}

$a, \quad x-T_{g}$ and $x-T_{C}$ plots of $T_{g}$, the glass transition and $T_{C}$, the crystallization temperature, vs, alloy composition. ${ }^{6}$ As $T_{g}$ and $T_{c}$ depend on the heating rate, $\dot{T}_{3}$ three dimensional representations $x-T_{g}-\dot{T}$ and $x-T_{c}-\dot{T}$ are required. At present, two dimensional $\dot{T}-T_{C}$ plots (which yield the activation energies of crystallization) exist for some selected compositions $x$, and $x-T_{g}$ and $x-T_{C}$ data taken at fixed $\dot{T}$ are available for some systems.

b. T-T-T (time-temperature-transformation) plots at fixed composition, both for nonequilibrium phase formation ${ }^{7}$ and decomposition. ${ }^{8}$ The former are especially useful for an interpretation of the occurrence of amorphous metals in terms of operational parameters such as the c00ling rate; the latter describe their thermal stability below $T_{c}$. Relations of the reduced glass transition temperature to the cooling rate also exist.

These diagrams and the techniques used in their determination will be discussed. Their purpose is to present thermal and other parameters for the total range of condensed phases amenable to experimental or theoretical study.

1. B.C. Giessen and R. H, Willens, in: Phase Diagrams; Materials Science and Technology, Vol. III., A.M. Alper, Ed., Academic Press, N.Y., p. 103 (1970).

2. B,C. Giessen, in Proc. Second Internat. Conf. on Rapidly Quenched Metals, M.I.T., 1975, N.J. Grant and B.C. Giessen, Eds., Section I, M.I.T. Press, Cambridge, Mass. 1976, p. 119.

3. A.K. Sinha, B.C. Giessen and D.E. Polk, in Treatise on Solid State Chemistry, N.B. Hannay, Ed., Vol. III, Plenum Press, New York, P.1. (1976).

4. H. Jones, Rep. Prog. Phys. 36, 1425 (1973). 
5. J.C. Baker and J,W. Cahn, in Solidification, American Society of Metals, Metals Park, Ohio (1971), p. 23.

6. B.G. Lewis and H.A. Davies, Proc. Second Internat. Conf. on Rapidly Quenched Metals, M.I.T., 1975, N.J. Grant and B.C. Giessen, Eds., Section II, Mater. Sci. Eng. 23, 179 (1976).

7. H.A. Davies, J. Aucote and J.B. Hu11, Scripta Met. $\underline{8},(1974) 1179$.

8. T. Masumoto and R. Maddin, Mater. Sci. Eng. 19, (1975) 1. 
Theses Report

An Analitical Method of Construction and Representation of Diagrams of Equilibrium of Multicomponent Systems

o. S. Ivanov, A. I. Udovsky and A. M. Gaydukov
A. A. Baykov Institute of Metallurgy Acaderny of Sciences Moscow, U.S.S.R.

A method of construction of phase bcuncaries of diagreas of equilibzium of multicomponent systems is proposed, procseding from the known experimental diagrams of equilibrium of twoco=ponent and otker subsysters and limits zumber of additional s=:oriments for alioys of multicomponent systens in question. An anzlitical recuri of surface of one/t::chhase phuse boundery for muiticopgcnent system in question is presented in tro perts. The first part is determined by comptec anelitical expressions ion the correspondine inown fhase joundaries as a whole ( as a whole alo-5 all curves for twoconponent slijsystens ), and as not by s=perate points of binary subsystems, as it is realised by tise aristing analitical methods. The second pert is conputed irzespecivive of the first one by the metiod of tis lesst siucres, procescis: frow the exjerimentai iste for more then bisary alioys. Tis givoposed zettod aliows to construct anditicslly exooth phase soun-

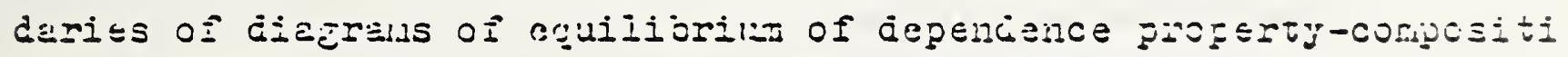
on (within tise limits of a dafinits ficse fisld ), frestickliy, of slij coppiex siaje for a systez riti the sritrary nuber of cor

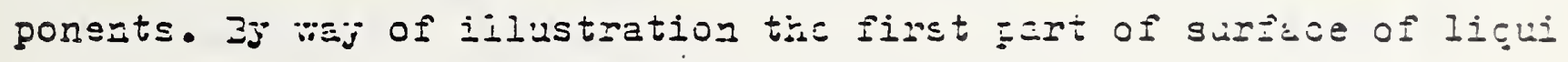
dus in tise system U_UC-IJT computed with the heip of a computer is

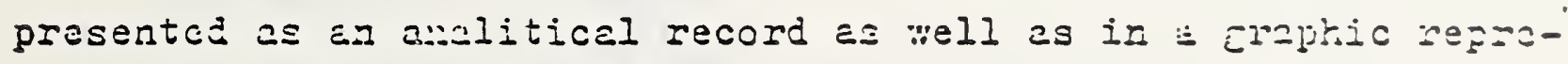
sentetior for a fluil

The froogosed instiod is developed conformably to construsticn

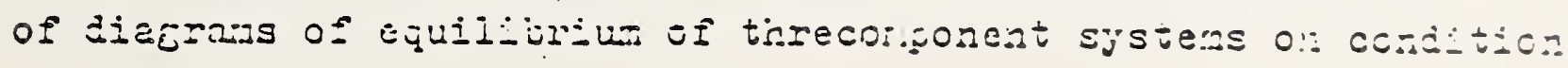


that all the bindry siesjaters are eutectic. To our aind, practicil Iy, it can be spread to any types of diazrang of equilibrium of multicomponent systems.

On these erounds a prokranne of actions is proposed:I) for an analitical generalization and representation of the whole accumulated experinontal material on the diagrans of equilibrium for double, threefold and more complex systens, usually graphic represented, 2)kesping of these data in a computer's menory, 3) their delivery from a computer in different forms (analitical, tablelike, Jranic),4)an analitical calculationfroceedings erom these data and a liwited number of experiaental diata of unknown diagaars of equilibrium of wore complex systems, 5)comparison and coordjnation with the help of a computer of experimental data on therncdynamic parameterg for the excess enthalpy and entropy of elioye as well as for the difference of the enthalpy and entropy between dif forent phases of pure componenta and the thermodynamic calculation on the basis of these parameters of the unknown diagrans of equilibrium of multicomponent systems, 7) the use of diagrams of equiIibrium ald computers for the calcul.ution of the thermodynanic and physical paranetersof the metallic pilases in order to use them later on in the gichtun-mechanical caludlations of the unknom diagramsof equilibrium, thermodynamic and pirysical properties of alloy: of multicomponent systens.

Step by step progranne of zeaiization of this complex task is proposed.

5. $10.76=$

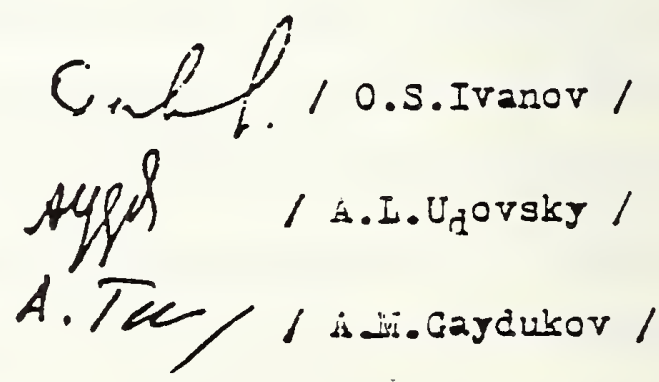


The author of this abstract is unable to attend the workshop; his paper witl not be presented. A full paper will be published in the workshop preceedings.

THE CAICULATION OF NULTICOMPONENT ALIOY PHASE DIAGRAMS AT THE NATIONAI PHYSICAL LABORATORY, UK

$$
\text { I G Chart }
$$

National Physical Laboratory Teddington, Middlesex, England

Members of the Division of Chemical Standards, National Physical Laboratory, are currently engaged in the calculation of ternary and quatemary phase diagrams of relevance to superalloys and related materials, from the thermodynamic data for the binary systems involved. Computer methods involving the uinimization of Gibbs energy are utilized. At present we are in a position to calculate isothermal sections in over 100 different temary systems. In order to extend this range an extensive programme of critical assessment of thermodynamic data for binary systems, mainly involving transition metal-boron and transition metal-silicon systems is being undertaken. The full scope of this work will be described, and recent examples of calculated ternary diagrams included. 
The author of this abstract will not present this paper by poster. A full paper will be published in the workshop proceedings.

\section{SYNTHESIS OF BINARY METALLIC SYSTEMS \\ I. ISMORPHOUS SYSTEMS \\ II. SIMPLE EUTECTIC SYSTEMS}

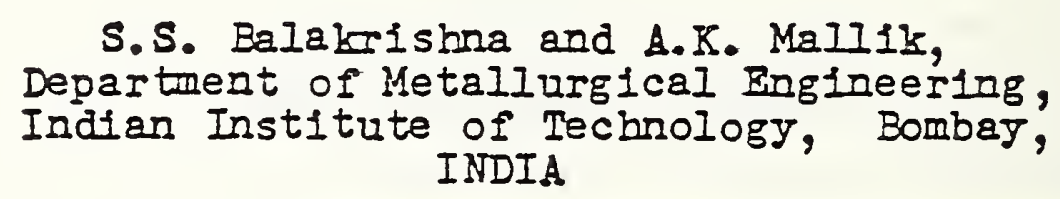

I. The isomorphous binary metallic systems of Ag-Pd, Cb- TI, Mo- W, Mo-V, V-W and CD-W have been calculated from the available information of heats of fusion, heats of vaporization, molar volumes, heat capacities, melting temperatures, etc. of the pure components with various theoretical models of ideal, regular, and quasi-chemical using computing techniques without recourse to extensive experimentation. The equations for the phase boundaries for these models are:

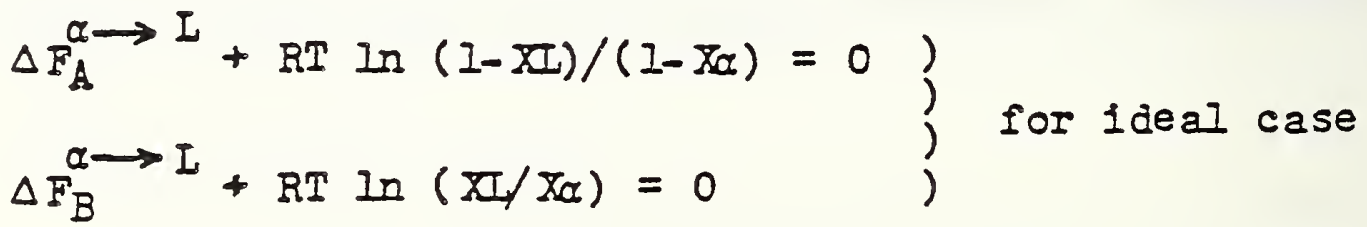

$$
\begin{aligned}
& \left.\Delta F_{A}^{\alpha \rightarrow I}+\operatorname{RT} \text { In }(I-\overline{X I}) /(I-\overline{X \alpha})=\overline{X \alpha}^{2} B-X^{2} I\right) \\
& \left.\Delta F_{B}^{\alpha \rightarrow I}+R T I n(X I / X \alpha)=\left(I-X_{C}\right)^{2} B-(I-X I)^{2} L\right) \text { solution case } \\
& \Delta F_{A}^{\alpha \rightarrow I}+R T I n(I-X I) /(I-Z \alpha)=R T \frac{Z}{2} \lambda_{\alpha} Z\left[\alpha ^ { 2 } \left[I-2 \lambda_{\alpha} Z_{\alpha}+\right.\right. \\
& 6 \lambda_{\alpha}\left(\frac{I}{4}+\frac{5}{3} \lambda_{\alpha}\right) \quad 3 \alpha^{2} J-R T \frac{Z}{2} \lambda_{I} \quad Z I^{2}\left[I-2 \lambda_{I} \quad Z I+\right. \\
& 6 \lambda_{I}\left(\frac{I}{4}+\frac{5}{3} \lambda_{I}\right) x^{2} J
\end{aligned}
$$




$$
\begin{aligned}
& \Delta F_{B}^{\alpha \rightarrow I}+R T \text { In }\left(X I / T_{\alpha}\right)=R T \frac{Z}{2}\left[\left(I n\left(\lambda_{\alpha}+I\right)-2 \lambda_{\alpha} Z_{\alpha C}\right.\right. \\
& \left.+\lambda_{\alpha}\left(1+3 \lambda_{\alpha}\right) Z \alpha^{2}-4 \lambda_{\alpha}^{2}\left(1+\frac{10}{3} \lambda_{\alpha}\right) Z_{\alpha}^{3}+6 \lambda_{\alpha}^{2}\left(\frac{I}{4}+\frac{5}{3} \lambda_{\alpha}\right) Z_{\alpha}^{4}\right) \\
& -\left(I n\left(\lambda_{I}+I\right)-2 \lambda_{I} I I+\lambda_{I}\left(I+3 \lambda_{I}\right) \pi I^{2}-4 \lambda_{I}^{2}\left(I+\frac{10}{3} \lambda_{I}\right) \pi I^{3}\right. \\
& \left.+6 \lambda_{I}^{2}\left(\frac{I}{4}+\frac{5}{3} \lambda_{I}\right) \pi^{4}\right) J \text { for quasi-chemical modeI. }
\end{aligned}
$$

II. The simple eutectic binary metallic systems of $\mathrm{Ag}-\mathrm{SI}$, Sn-AI, Au-Si, Be-Si, Bi-Cl have been calculated from the available thermodynamic data of heats of fusion, heats of vaporization, molar volumes, heat capacities, melting temperatures, etc. of the pure components with various theoretical models of ideal, regular and quasi-chemical using computing techniques without recourse to extensive experimentation. The equations for phase boundaries for these models are:

$$
\begin{aligned}
& \left.\Delta F_{A}^{S \rightarrow I}+R T I n(I-X A I)=0,\right) \\
& \Delta \mathrm{F}_{\mathrm{B}}^{\mathrm{S}} \rightarrow \mathrm{I}+\mathrm{RT} \text { In } X B I=0 \quad \text { f for ideaI case } \\
& \left.\Delta F_{A}^{S \longrightarrow I}+\operatorname{RT} \operatorname{In}(I-X A I)=-I(X A I)^{2},\right) \\
& \left.\Delta F \xi I+R T I n(X B I)=-I(I-X B I)^{2}\right) \text { case } \\
& \text { and } \Delta F_{A}^{S \rightarrow I}+R T I n(I-X A I)=-R T \frac{Z}{2} \lambda_{I}(X A I)^{2}\left[I-2 \lambda_{I}(X A I)\right. \\
& +6 \lambda_{I}\left(\frac{1}{4}+\frac{5}{3} \lambda_{I}\right)(X A I)^{2} J
\end{aligned}
$$




$$
\begin{aligned}
& \Delta F_{B}^{S \rightarrow I}+R T I n(X S I)=R T \frac{Z}{2} E\left(I n\left(\lambda_{I}+I\right)-2 \lambda_{I}(X B I)\right. \\
& +\lambda_{I}\left(I+3 \lambda_{I}\right)(X B I)^{2}-4 \lambda_{I}^{2}\left(I+\frac{10}{3} \lambda_{I}\right)(X B I)^{3} \\
& \left.+6 \lambda_{I}^{2}\left(\frac{I}{4}+\frac{5}{3} \lambda_{I}\right)(X B I)^{4}\right)+\left(I n\left(\lambda_{S}+I\right)-2 \lambda_{S}+\lambda_{S}\left(I+3 \lambda_{S}\right)\right. \\
& \left.-4 \lambda_{S}^{2}\left(I+\frac{10}{3} \lambda_{S}\right)+6 \lambda_{S}^{2}\left(\frac{I}{4}+\frac{5}{3} \lambda_{S}\right)\right) J \text { for quasi-chemicaI modeI. }
\end{aligned}
$$

The phase diagrams in ideal cases with or without $C_{p}$ data remain same in all the systems considered.

All the theoretical models are compared wh the experimentally observed diagrams from ASM Handbook. 
The author of this abstract will not present this paper by poster. A full paper will be published in the workshop proceedings.

\author{
Quantitative Fits to Phase Lines and High Temperature \\ Thermodynamic Data for Systems Forming \\ Semiconductor Compounds
}

Robert F. Brebrick
Metallurgy and Materials Science Program
Marquette Univeristy, Milwaukee, WI 53233

We have been interested in phase diagrams of binary systems involving compound or elemental semiconductors. These are relatively simple compared to the diagrams for some metallic systems and consequently a more detailed investigation of the process of theoretically constructing these phase diagrams is not unmanageable. For a congruently-inelting, narrow homogeneity- range compound the composition dependence of the compound's Gibbs free energy of formation can usually be neglected, an approximation often implicitly made in thermochemistry. The general thermodynamic equations connecting the solidus and liquidus lines of the compound are then separable. A liquidus equation can be obtained which is general as far as the liquid phase is concerned and therefore be used with any model.

Certain properties of the compound enter this liquidus equation as input parameters. These are the idealized composition (usually the stoichiometric composition), the melting temperature and the heat of fusion, and the temperature dependence of the enthalpy and entropy of formation of the compound form its pure liquid elements. In the derivation of this equation the properties of the liquid and compound are seen to be linked through the requirement that the congruent melting involves a zero change in Gibbs free energy. This furnishes two equations which hold at the melting point and which connect the enthalpy of formation and heat of fusion with the heat-of-mixing of the liquid at the stoichiometric composition on the one hand, and the entropies of formation and fusion with the entropy of mixing of the liquid on the other. For brievity we refer to these equations as the auxiliary relations. If the experimental liquidus lines.for the compound can be satisfactorily duplicated with some model of the liquid phase then the second half of the problem, the calculation of the solidus lines, can be attacked using one of the known thermodynamic models for a defect semiconductor compound. Alternatively, provided certain other data are available, such as the partial pressure of one element along the three-phase curve for the compound, a calculation or theoretical fit of the solidus lines can be directly attempted without first establishing an appropriate liquid phase model.

The latter approach has been followed for the compounds PbTe and $\mathrm{SnTe}^{2}$. Aside from confirming the validity of the defect model used and establishing values for some of the intrinsic, high temperature properties of the compounds, the results potentially furnish the starting point for a calculation of the homogeneity range for all $\mathrm{Pb} / \mathrm{Sn}$ ratios in the $\mathrm{PbTe}-\mathrm{SnTe}$
pseudobinary. 
The former approach of calculating the liquidus lines has been followed for some III-V systems ${ }^{3}$ in which the compound solidus Iines are not well established but appear to be so close to the stoichiometric composition as to make their previous determinations by Hall measurements significantly biased by accidentally present, unknown impurities. An extension and refinement of previous efforts in this area is interesting not only in its own right but also as a potential starting point in the construction or reliable interpolation of the liquidus surfaces in ternary and quatenary systems constructed from these binaries. Considerable technological effort is presently concerned with crystal growth of ternary and quatenary semiconductor compounds. A summary of some central features of our approach and results follows for the calculation of the liquidus lines.

A quantitative measure-of-fit $\sigma(T)$ is defined as

$$
\sigma^{2}(T)=\sum_{i=1}^{N}\left(T_{j, c a l^{-T}} j, o b s\right)^{2} / N
$$

where $T_{j}$,obs is an observed liquidus temperature and $T_{j}$, cal is one calculated for the observed composition using some model for the liquid phase (which usually contains adjustable parameters). A critical value of $\sigma, \sigma_{\text {crit }}$, is chosen as characterizing the accuracy of the experimental data. All fits with $\sigma \leq \sigma_{\text {crit }}$ are judged equally.valid. This latter choice proves significant since when the liquidus points are fit alone one usually finds that $\sigma<\sigma_{\text {crit }}$ for a significantly wide, highly-correlated range in the adjustable parameters. As a result, only certain properties of the liquid phase are well established and these at only some temperature within the range of experimental temperatures used ${ }^{4}$. A similar behavior usually appears in the determination of the second law enthalpy and entropy for some constant pressure process from an experimental determination of the Gibbs free energy change as a function of temperature ${ }^{5}$. When the enthalpy and entropy of compound formation at the melting point are known, the auxiliary relations can be used. These appear generally to be quite restrictive. The auxillary relations can be satisfied and the liquidus lines fit ${ }^{3}$ to within critical value of $10^{\circ} \mathrm{C}$ for InSb, $8^{\circ} \mathrm{C}$ for $\mathrm{GaSb}, 16^{\circ} \mathrm{C}$ for InAs and $10^{\circ} \mathrm{C}$ for GaAs. The liquid phase model is defined in terms of temperature independent heats and excess entropies of mixing given by

$$
\begin{aligned}
& \Delta H_{M}^{L}=W x(1-x)\{1+a(x-1 / 2)\} \\
& \Delta S_{M}^{L, e}=V_{x}(1-x)\{1+c(x-1 / 2)\}
\end{aligned}
$$

where $W, a, V$, and $c$ are constants. The values of $W$ and $V$ are fixed by the auxiliary relations. Satisfactory fits are obtained for a range of values along a line in the c-a plane. Treating the III-V compound - Group V eutectic temperature as accurate to within $\pm 2{ }^{\circ} \mathrm{C}$ (except for GaAs) generates a 2nd line in the a-c plane and effectively eliminates the range of $a-c$ values to a single point. The liquid parameters thus established, 
the remaining high temperature data are found to be fit in a quantitatively satisfactory manner. The simpler variants of the model in which $a, V$ and $c$ are zero (strictly regular solution) or in which a and $c$ are zero

(quasiregular solution) can fit the liquidus points satisfactorily but not if the auxiliary relations are applied and if the other thermodynamic data are to be fit well also. This liquid model is essentially the same as that used by Kaufmann and Nesor to fit many complex metallic systems and is essentially a truncated version of the series representation used by Lupis. Qualitatively it appears to be applicable to many metallic liquids.

Unfortunately it proves inadequate for the more ionic II-VI and IV-VI melts and an important problem is the identification of a liquid solution model or models that is adequate for these systems.

Because the model defined by Eqs. (2) and (3) is of wide, if limited, applicability, its critical point behavior is of interest. For the simpler quasi-regular version $(a=c=0)$ symmetrical normal, or inverted miscibility gaps can appear 4 . For the model defined by Eqs. (2) and (3) an additional flexibility appears in that the critical composition can be made to fall anywhere in the composition range and normal and inverted miscibility gaps can occur in the same system, $i . e$. for appropriately fixed values of $W, a$, $V$, and $c$. Near the critical point the width of a normal miscibility gap goes as $\left(T / T_{c}-1\right)^{1 / 2}$.

1. R. F. Brebrick, Met. Trans. A (in press).

2. R. F. Brebrick, Abstracts of Papers Presented at 1976 Electronic Materials Conference, J. Electronic Materials (to be published).

3. R. F. Brebrick, Quantitative Fits to the Liquidus Lines and High Temperature Thermodynamic Data for InSb, GaSb, InAs, and GaAs, submitted to Met. Trans.

4. R. F. Brebrick and R. J. Panlener, J. Electrochemical Soc., 121, 932 (1974).

5. R. F. Brebrick, High Temperature Science, 8,11 (1976). 


\section{TUESDAY, II JANUARY, 1977$$
3: 30 P M-6: 00 P M
$$

PAPERS GIVEN BY POSTER TOPIC II

FORMAT AND DISTRIBUTION

OF PHASE DIAGRAM DATA 


\section{TABLFS OF COHTE!ITS AMIN CIMM!LATIVE SIIO,JECT I"HFY \\ FOR "PHASE MIATRAMS DF METALLIT. SYSTE!'?," \\ 11. W. AREEY, EMITOR, YOI!IIPFS? - I?}

Tranglateit and Comiler hy

Coulson !1. Scheuermann

$\operatorname{liA} \Omega A$

Lewis Resparch Center

Clevelant, nhio 141,135

\section{ARSTRACT}

Phase diarram information is an important eactor in the thsirr and development of alloys. Phase tiarram information is rnasonaliy accessihle for binary systems. Informatinn for hirhnp orter systems, hovever, is not ns reatily acrosaible. The most corinrehensive source of nhase tiarram information for hinary and hisher order systems is the comnilation and annlial silno!ement:c editcd hy II. Y. Areey amit produced hy the llig? Acartemy of Sciences. They are, holnover, sompuhat difficult and elumbrosome to use by those who cannot read the Russian lanruare hecallse thoir Tables of Contents are in Russian and hecause they th not waun a cumulative index.

This translation is designed th aid in the utilization ne thr Ageev compilations. it is comnoser of two sections. Thn first section rives the Tahles of Contents for volumes I throurh I? (1959 - 1376) with the phase diarrams irentified hy elenical symbol.

The second section of this translation is a cumulative indro of phase diagrams included in the Ngeney comnilatinns, volumes 1 through 19 ( 1959 throurh 1776). The ohase tiarpargs aro listopt in alphabetical order by chemical symbol. Throughnut fection 2, the following conventinn is llsed. The yolume is riven hy ponan numerals. Pares are designated hy Arahir numerals. For examole, the notation 'v|l-2n5' refers to volume 7, nage ?n5. 1ihere tata for one system extends to following pases, only the first nate is piven.

It is hoped that this muhlication will farilitate usp of thr Mrspu compilations and the enopmols amount of nhasp tiorram infopmation which they contain. 


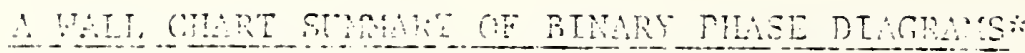

J. E. Selle

ICtals and Ceramics Division, Oak Ridge National Laboratory Oak Ridge, Tennessee 37830

A large six color waIl chart is described which gives pertinent information on binary phase diagrams such as: the general type of diagram, degree of solubility, number of eutectics, lowest melting eutectic, number of intermetallic compounds, etc. Detailed information is given on the data presented on the chart, its format, comparison of various binary systems with presentation on the chart, and some typical uses of a chart of this type.

AResearch sponsored by the Energy Research and Development Administration under contract with the Union Carbide Corporation.

toperated by Union Carbide Corporation for the Energy Research and Development Administration. 
Standards for Publication of Phase Equilibrium Data

\author{
Eric R. Kreidler \\ LIGHTING RESEARCH AND \\ TECHNICAL SERV ICES OPERATION \\ Lamp Materials Research Lab 非1361 \\ General Electric Co. \\ Cleveland, Ohio
}

A paper on phase equilibria typically receives a review before publication and may not be critically evaluated again until it is included in a compilation. Since most phase diagrams will eventually be published in handbooks or compilations such as Phase Diagrams for Ceramists, it is important that the initial review process be critical and constructive. It is suggested that a set of published standards for phase equilibrium papers would assure uniform treatment of data and would help both journal reviewers and compilers to properly assess the value of individual papers. A brief survey of the literature quickly reveals the wide variation in quality. Papers range from speculations based on a few haphazard experiments to thorough studies based on hundreds of experiments and using complementary experimental techniques. The purpose of standards should not be to preclude publication of incomplete or exploratory work, but to assure that such works are based upon sound data. Sandards should be used to prevent publication of erroneous diagrams, and if properly written and used can improve the general quality of work done on phase equilibria.

The establishment of standards is the responsibility of the concerned scientific community. A committee of phase equilibrium experts representing the disciplines metallurgy, ceramics, mineralogy, semiconductor technology, geochemistry, etc. could accomplish the task. The purpose of this presentation is not to formulate standards but to point out some of the problems which are frequently encountered in phase equilibrium studies. The areas to be considered are; tests of equilibrium, accuracy of results, failure to provide documented data in support of diagrams, diagrams which violate the phase rule, misuse of terminology, and inappropriate experimental techniques. 
FORMATING AND DISTRIBUTING EVALUATED REFERENCE DATA

BY THE OFFICE OF STANDARD REFERENCE DATA

AT THE NATIONAL BURERU OF STANDARDS

S. P. Fivozinsky and G. B. Sherwood Office of Standard Reference Data National Bureau of Standards Washington, D.C. 20234

The Office of Standard Reference Data at the National Bureau of Standards manages a complex of data evaluation centers located in university, industrial, and other Government laboratories as well as within NBS. The centers are engaged in the compilation and critical evaluation of numerical data on physical and chemical properties retrieved from the world scientific literature. This system of centers, the Jational Standard Reference Data System (NSRDS), is a means of coordinating on a national scale the production and dissemination of critically evaluated reference data in the physical sciences. The primary focus of the NSRDS is on well-defined physical and chemical properties of well-characterized materials or systems.

The Office of Standard Reference Data, as coordinator of the system:

- establishes needed data centers in technical areas which fall within the scope of the program

- maintains close contact with other data compilation activities both in the U.S. and abroad to encourage exchange of data and avoid needless duplication of effort

- identifies, by contacts with users, areas where needs for 
evaluated reference data are increasing or decreasing, and formating procedures which will make the outputs of the system as useful as possible

- distributes evaluated reference data tinrough a variety of output channels

The output channels include:

- Joumal of Physical and Chemical Reference Data a quarterly joumal containing data compilations and critical data reviews, published for the National Bureau of Standards by the American Institute of Physics and the American Chemical Society

- NSRDS-NBS Series

a publication series distributed by the superintendent of Documents, U.S. Government Printing office

- appropriate publications of technical societies and commercial publishers. Handbook publications are an important element of this category

- magnetic tape data files - sold through the National Technical Information Service

The outputs of several NSRDS centers are directly or indirectly related to phase diagram applications in metallurgy and ceramics; examples include alloy data, data on diffusion in metallic systems, properties of substances at high pressures; properties of superconducting materials, and thermodynamic data of minerals. Some recent publications on these subjects are: 
1. Butrymowicz, Daniel B., Manning, John R., Read, Michael E., "Diffusion in Copper and Copper Alloys, Part IV. Diffusion in Systems Involving Elements of Group VIII," J. Phys. Chem. Ref. Data, 5 (1) 103-200 (1976).

2. Chang, Y. Austin, "Phase Diagrams and Thermodynamic Properties of Ternary Copper-Silver Systems," J. Phys. Chem. Ref. Data (in process).

3. Donnay, J.D.H. and Ondik, Helen M., Crystal Data Determinative Tables, Third Edition, Vol. 1, Organic Compounds, Vol. 2, Inorganic Compounds, Swarthmore, PA, Joint Committee on Powder Diffraction Standards, Vol. 1 (1972), Vol. 2 (1973).

4. Hultgren, R. and Desai, P. D., Selected Thermodynamic Values and Phase Diagrams for Copoer and Some of Its Binary Alloys, New York, International Copper Research Association, Inc. (1973).

5. Roberts, B. W., "Survey of Superconductive Materials and Critical Evaluation of Selected Properties," J. Phys. Chem. Ref. Data, 5(3) 281-821 (1976).

6. Stull, D. R. and Prophet, H., JANAF Thermochemical Tables, Second Edition, NSRDS-NBS 37, U.S. GPO (1971)

Reprint No. 50, "JANAF Thermochemical Tables, 1974

Supplement," J. Phys. Chem. Ref. Data, 3(2) 311-480 (1974). Reprint No. 60, "JANAF Thermochemical Tables, 1975

Supplement," J. Phys. Chem. Ref. Data, 4(1) 1-175 (1975).

Examples of outputs, formats, and dissemination mechanisms will

be displayed along with more general information on the National Standard Reference Data System, and the activities of the office of Standard Reference Data. 
TUESDAY, II JA INUARY, 1977

$$
3: 30 P M-6: 00 P M
$$

DEMONSTRATIONS DURING THE

POSTER SESSION 
DEMONSTRATIONS DURING THE POSTER SESSION

IN THE EMPLOYEE'S LOUNGE

TWO DEMONSTRATIONS IN CONUUNCTION WITH POSTERS

T PSI-11 APPLICATION OF DATA BANK METHODS TO CALCULATION OF THE

THERMOCHEMISTRY AND PHASE DIAGRAM OF METAL AND CERAMIC SYSTEMS

MTDATA ON-LINE THERMOCHEMICAL

CALCULATIONS

LARRY KAUFMAN, MANLABS, INC, CAMBRIDGE, MASSACHUSETTS

T PSI-16 FACILITY FOR THE ANALYSIS OF CHEMICAL THERMODYNAMICS - A COMPUTERIZED CANADIAN THERMODYNAMIC DATA BANK

AN ON-LINE DEMONSTRATION

A. D. PELTON, DEPT, DE GÉNIE METALLURGiQUe, ÉCOLE POLYTECHNIQUE, UNIVERSITE DE MONTREAL, CANADA 
WEDNESDAY, 12 JANUARY, 1977

$$
9: 00 \text { AM - 12:30 PM }
$$

\author{
USER NEEDS FOR \\ PHASE DIAGRAM INFORMATION
}

PANEL II ON

PRIMARY PRODUCTION

AND

PANEL II I ON

MATERIALS PROCESSING 


\section{PANEL I I \\ PRIMARY PRODUCTION}

Moderator:

J. F. Elliott

Department of Materials Science and Engineering

M. I. T.

Cambridge, MA

Panel Members: $\quad$ P. Amman

Ledgemont Laboratory

Kennecott Copper Corporation

Lexington, MA

H. Larson

American Smelting and Refining Company

South Plainfield, NY

R. D. Pehlke

Metallurgy Department

University of Michigan

Ann Arbor, MI

Information on phase equilibria is often of great importance in the design, operation and control of processes employed in the primary production of metals. Several case studies of specific processing systems in the industry are presented to show the nature of information that is needed and how the information is utilized. Examples are employed to show where such information has, and has not, been available. 


\title{
COMMENTS RELATED TO THE PANEL II TOPIC
}

This contribution is from an audience participant, not a panel member. A paper on this COMMENT will appear in the proceedings.

\section{USER NEEDS FOR PHASE DIAGRAMS}

by

\author{
Dr. Paul J. Fopiano \\ Army Materials \& Mechanics Research Center \\ Watertown, Massachusetts 02172
}

In multicomponent systems where two ore more phases have important effects on the properties of the alloy, it is rare that the phase compositions are known. Sometimes these compositions can be ignored with impurity but other times this is not the case. In the latter category, the determination of a single tie line only may be required or, because of the prevalence of several alloys using the same alloying elements, a more thorough investigation of phase compositions is justified. In few of these cases, however, is the construction of a phase diagram carried out and widely disseminated. As a result, much otherwise useful data is lost before it can become a useful part of a databank. Examples of one of each type of application are included to indicate the normal limits to which we go to satisfy a specific need. It might be added that without the advent of the probe microanalyzer, little of this work would have been carried out.

\section{TYPICAL EXAMPLES OF PHASE COMPOSITION}

Determinations in Commercial Alloys

Titanium-Aluminum-Vanadium Alloys

In the investigation of the phase transformations which occur during the heat treatment of commercial titanium alloys, the presence of two or more phases complicates the interpretation of the mechanical and physical property data. The major strengthening mechanisms can often be related to the compositions of the alpha and beta phases in equilibrium at the solution temperature. Many titanium alloys of commercial interest employ aluminum and vanadium as major alloying elements.

Several standards were made up with various amounts of aluminum and vanadium. The nominal compositions are given in Table 1. Chemical analyses of these alloys were also determined. A probe analysis of these standards yield for our experimental conditions the calibration curve in Figure 1. The least square slope of these lines is given analytically as:

$$
\begin{aligned}
& w / 0 V=\frac{I_{V}-629}{486} \\
& w / 0 A 1=\frac{I_{A 1}+27}{1048}
\end{aligned}
$$

where $\mathrm{w} / \mathrm{oV}, \mathrm{w} / \mathrm{oAl}=$ weight percent vanadium and aluminum. 
COMMENTS PANEL II TOPIC P. J. FOPIano

Table 1. NOMINAL COMPOSITIONS OF STANDARD ALLOYS IN WEIGHT PERCENT

\begin{tabular}{|c|r|r|}
\hline Specimen & A1 & $V$ \\
\hline 76 & 2 & 2 \\
77 & 2 & 4 \\
78 & 2 & 8 \\
81 & 4 & 2 \\
82 & 4 & 4 \\
83 & 4 & 8 \\
84 & 8 & 2 \\
85 & 8 & 4 \\
86 & 8 & 8 \\
43 & 12 & 0 \\
44 & 0 & 12 \\
\hline
\end{tabular}

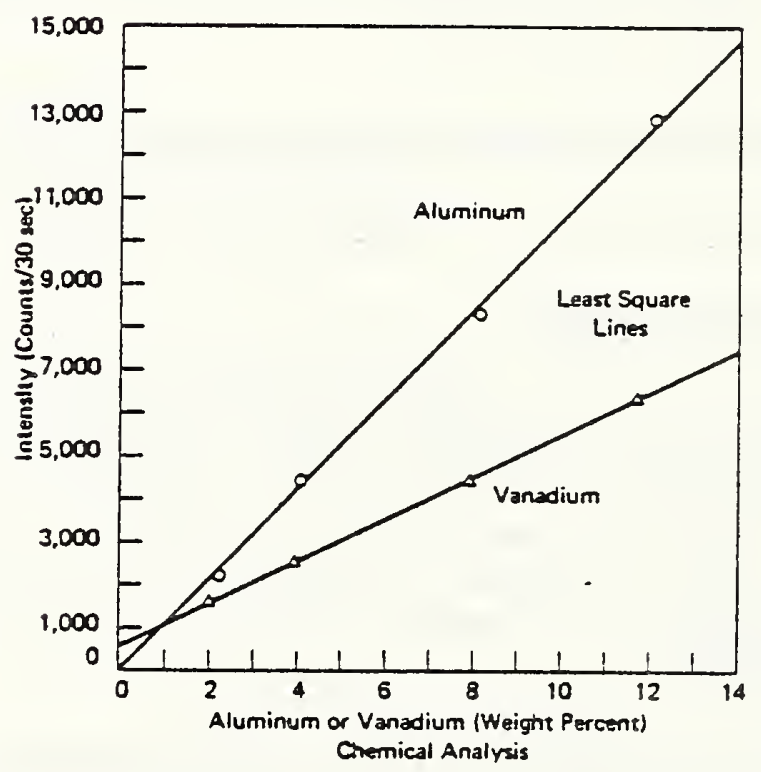

FIGURE 1. Mean Number of Counts (per $30 \mathrm{sec}$.) Versus Chemical Analysis of Aluminum and Vanadium Standards

$$
\begin{aligned}
& I_{V}=\text { counts (vanadium) } / 30 \text { seconds } \\
& I_{A 1}=\text { counts }(\text { aluminum }) / 30 \text { seconds }
\end{aligned}
$$

Utilization of this data for the most popular commercial alloy of titanium, $\mathrm{Ti}-6 \mathrm{Al}-4 \mathrm{~V}$ is illustrated in the following discussion. Five solution-treated conditions (all in the alpha beta field) were investigated (Figure 2); i.e., 
COMMENTS PANEL II TOPIC P. J. FOPIano

Table 2. NUMBER OF COUNTS (per $30 \mathrm{sec)}$ ) AND CORRESPONDING COEFFICIENT OF VARIATION FOR THE ALPHA AND BETA PHASES FOR SEVERAL SOLUTION TREATMENT CONDITIONS

\begin{tabular}{|c|c|c|c|}
\hline $\begin{array}{l}\text { Sample Designation } \\
\text { (and Solution Temp) }\end{array}$ & $\begin{array}{l}\text { Phase } \\
(\alpha \text { or } \beta)\end{array}$ & \multicolumn{2}{|c|}{$\begin{array}{l}\text { Counts } / 30 \text { Seconds } \\
\text { (Coeff. of Variation) }\end{array}$} \\
\hline \multirow[b]{2}{*}{$\begin{array}{c}P-1 \\
(1750 \mathrm{~F})\end{array}$} & & $\mathrm{AT}$ & $V$ \\
\hline & & $\begin{array}{l}7301 \\
(2.5) \\
6052 \\
(2.6)\end{array}$ & $\begin{array}{l}1307 \\
(2.9) \\
2519 \\
(4.3)\end{array}$ \\
\hline $\begin{array}{c}P-2 \\
(1700 \mathrm{~F})\end{array}$ & $\begin{array}{l}\alpha \\
\beta\end{array}$ & $\begin{array}{l}7849 \\
(1.5) \\
6150 \\
(1.1)\end{array}$ & $\begin{array}{l}1475 \\
(2.0) \\
3040 \\
(2.3)\end{array}$ \\
\hline $\begin{array}{c}P-3 \\
(1650 \mathrm{~F})\end{array}$ & $\begin{array}{l}\alpha \\
B\end{array}$ & $\begin{array}{l}7078 \\
(4.2) \\
5779 \\
(1.6)\end{array}$ & $\begin{array}{l}1593 \\
(2.2) \\
3686 \\
(3.7)\end{array}$ \\
\hline $\begin{array}{c}P-4 \\
(1600 \mathrm{~F})\end{array}$ & $\begin{array}{l}\alpha \\
\beta\end{array}$ & $\begin{array}{l}7664 \\
(1.4) \\
5570 \\
(2.2)\end{array}$ & $\begin{array}{l}1709 \\
(2.5) \\
4062 \\
(2.3)\end{array}$ \\
\hline $\begin{array}{c}P-5 \\
(1550 \mathrm{~F})\end{array}$ & $\begin{array}{l}\alpha \\
\beta\end{array}$ & $\begin{array}{l}7398 \\
(1.3) \\
4723 \\
(2.8)\end{array}$ & $\begin{array}{l}1747 \\
(4.7) \\
4551 \\
(3.7)\end{array}$ \\
\hline
\end{tabular}

$1750,1700,1650,1600,1550 \mathrm{~F}$ with designations $\mathrm{P}-1$ through $\mathrm{P}-5$ respectively. In order to get large enough fields to examine with the probe microanalyzer, it was necessary to heat all specimens to $1850 \mathrm{~F}$ for one hour furnace cool to the solution temperature (Figure $3-1550 \mathrm{~F}$ ) and hold for the times indicated in Figure 2.

Probe analysis data of both the alpha and beta phases are presented in Table 2. The measured compositions of the alpha and beta phases are shown in Table 3 ( $\mathrm{P}-1$ through $\mathrm{P}-5)$. Estimated compositions from published literature is also shown in Table 3 for specimens solution treated at 1562, 1652, and $1742 \mathrm{~F}$. An approximate retrofit of our data to published work on the Ti-6Al-4V alloy is shown in Figure 4. The published work was done before the probe was generally available and was typical of a type of publication then popular. In no sense, however, could it be considered a complete phase diagram even for the titanium-rich corner. 


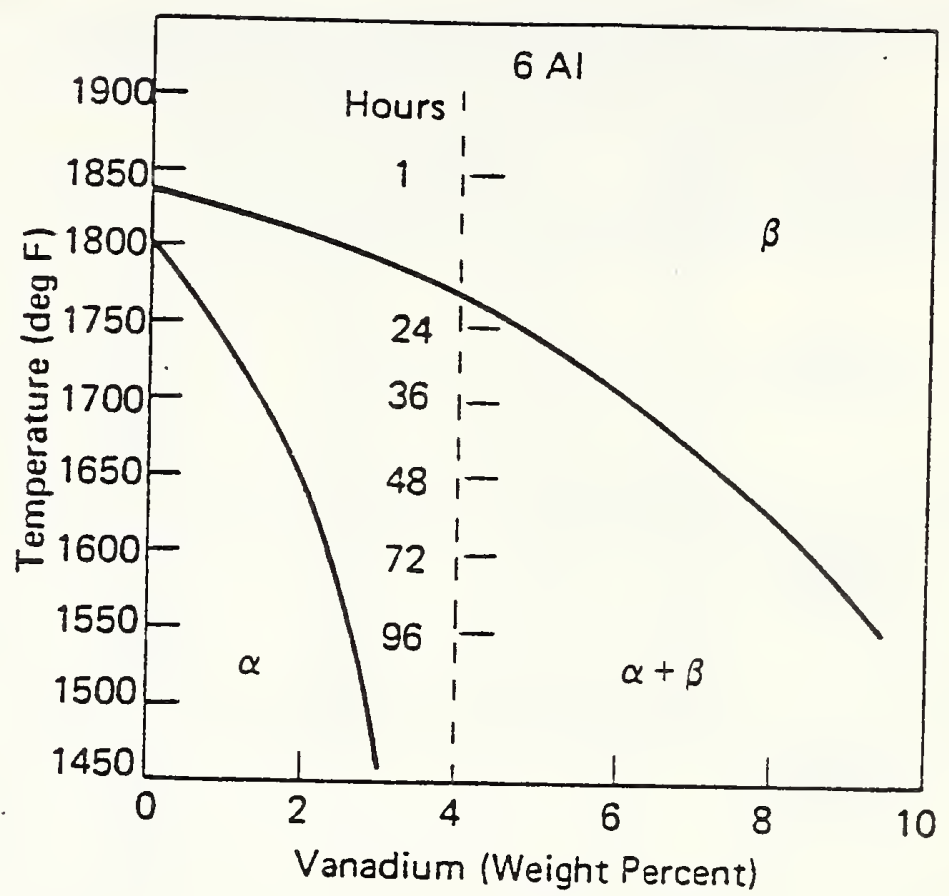

FIGURE 2. Schematic Representation of the 6 Al Section of Titaniun Corner of Ti-Al-V Ternary
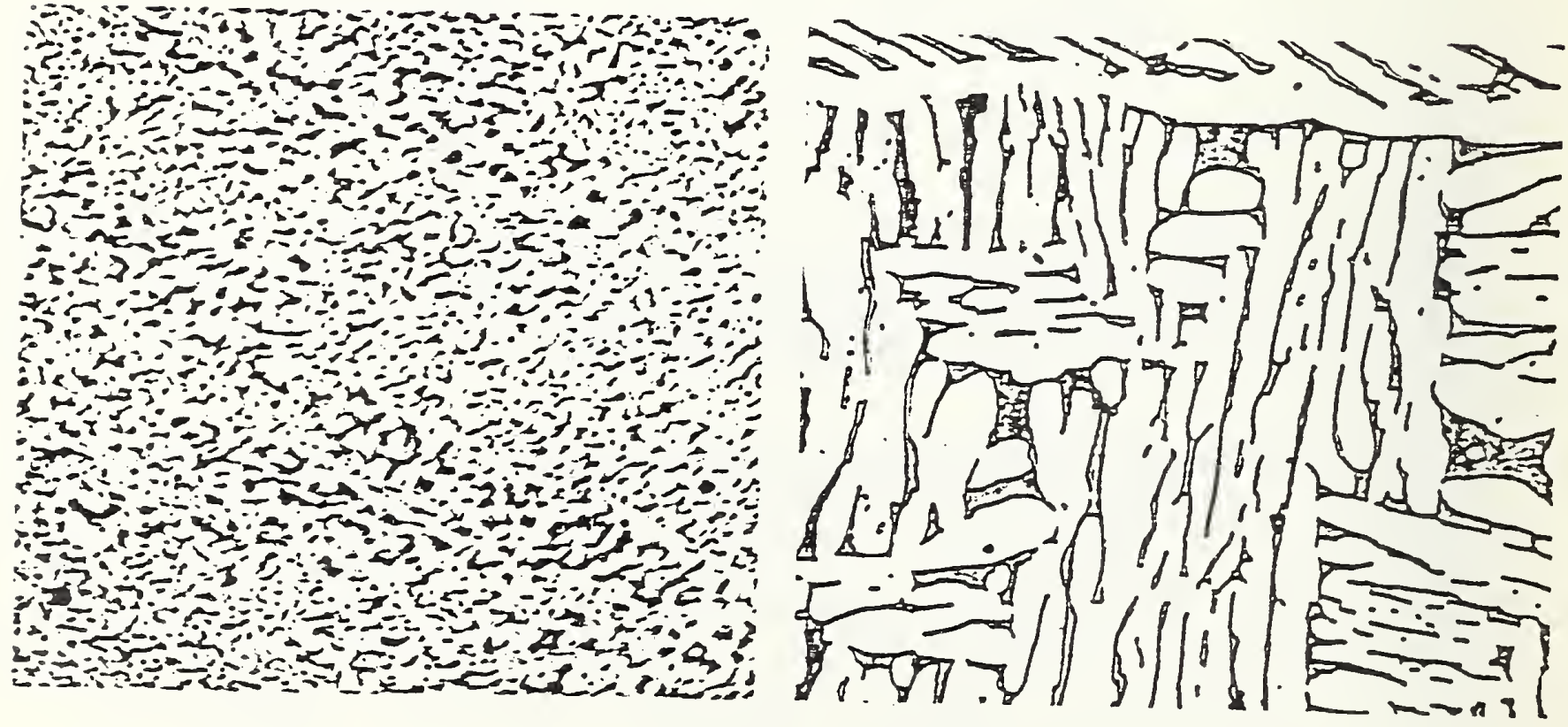

FIGURE 3. Solution-treated Ti-6Al-4V Alloy. Mag. 500X 
Table 3. EFFECT OF SOLUTION TEMPERATURE ON THE COMPOSITIONS OF THE ALPHA AIIO BETA PHASES IN Ti-6AT-4V

\begin{tabular}{|l|l|l|l|l|c|}
\hline \multirow{2}{*}{$\begin{array}{c}\text { Solution Treatment } \\
\text { Temperature } \\
\text { (deg } F)\end{array}$} & \multicolumn{4}{|c|}{ Weight Percent } & \multirow{2}{*}{ Vol \% $\varepsilon$} \\
\cline { 2 - 5 } & \multicolumn{2}{|c|}{ Alpha } & \multicolumn{2}{|c|}{ Beta } & \\
\hline & $A 1$ & $V$ & $A 1$ & $V$ & \\
$1550(P-5)$ & 7.08 & 2.30 & 4.53 & 8.07 & \\
1562 & 8 & $2-1 / 2$ & 2 & 8 & 25 \\
$1600(P-4)$ & 7.34 & 2.22 & 5.34 & 7.06 & \\
$1650(P-3)$ & 6.78 & 1.98 & 5.54 & 6.26 & \\
1652 & 9 & $2-1 / 2$ & 2 & $6-1 / 2$ & 38 \\
$1700(P-2)$ & 7.52 & 1.74 & 5.89 & 4.96 & \\
$1750(P-1)$ & 6.99 & 1.40 & 5.80 & 3.89 & \\
1742 & 10 & 2 & 4 & 5 & 64 \\
\hline
\end{tabular}

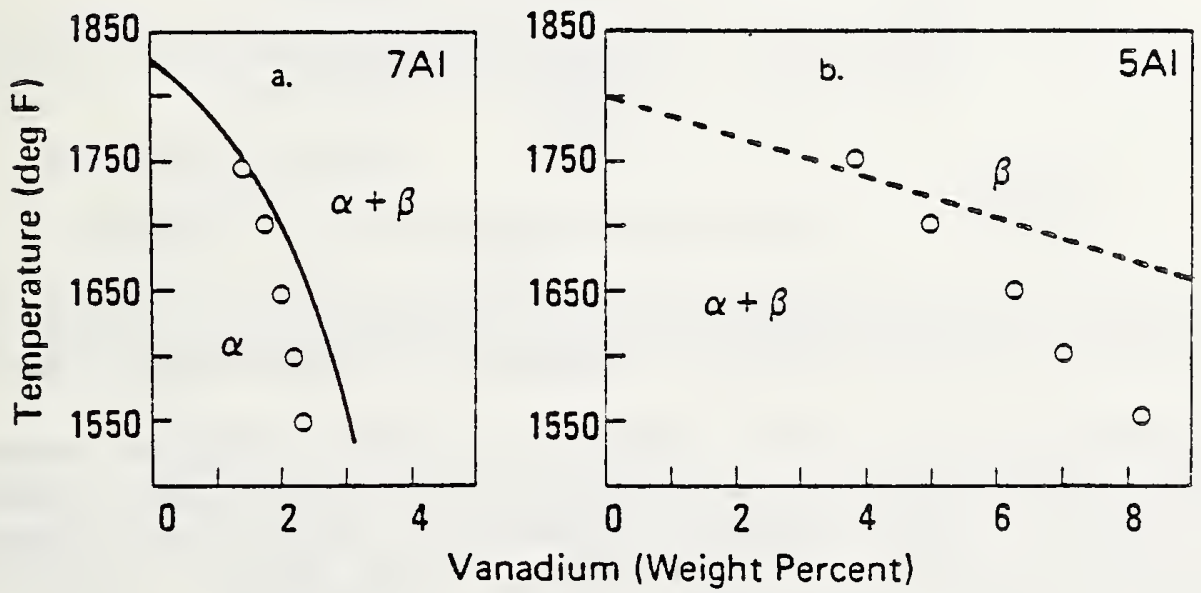

FIGURE 4. Correlation of Probe Data with Published Isothermal Sections (Ref. 5)

\section{$43 \times x$ Steel}

Even though the $43 X X$ steels have been utilized for many years, no phase diagram was available in the literature when the investigation on "Partially Austenitized 43XX Steel" was initiated. A "pseudo" iron-carbon phase diagram was then determined by microstructural analysis. A copy of this "pseudo" 
iron-carbon phase diagram for 4300 steels is shown in Figure 5 . This is an example where even a very nudimentary phase diagram data was helpful and necessary to develop an optimum compositional and temperature requirements for a new application of a very old alloy.

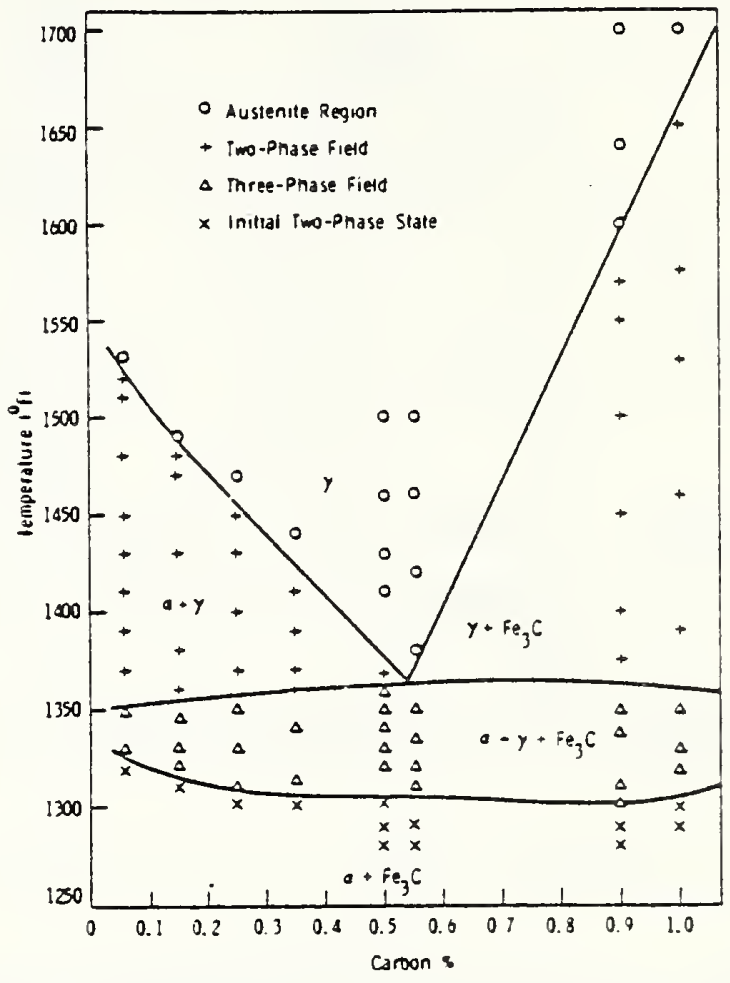

FIGIIRE 5. Constitution Diagram for 43XX Steels

\section{Partitioning of Impurity Elements in Iron-Carbon Alloys}

The addition of even small amounts of certain impurity elements to ironcarbon alloys can result in a severe loss in ductility when tempered at $500 \mathrm{C}$. The partitioning of these elements between the ferrite and the carbide phases was felt critical to better understanding of the problem. Electron probe. microanalysis, carbide extraction, and $x$-ray diffraction techniques were employed to this end. Figure 6 shows some of the data and Figure 7 shows the iron-rich end of the binary phase diagram for one of the impurity elements, antimony. Again, the phase diagram was gemain to the better understanding of the problem.

Heat Treatment of a Modified Tool Steel

In the heat treatment of a modified tool steel where the carbon level is lowered considerably, a much higher hardening temperature than normal was required to eliminate the low temperature ferrite phase which was considered 


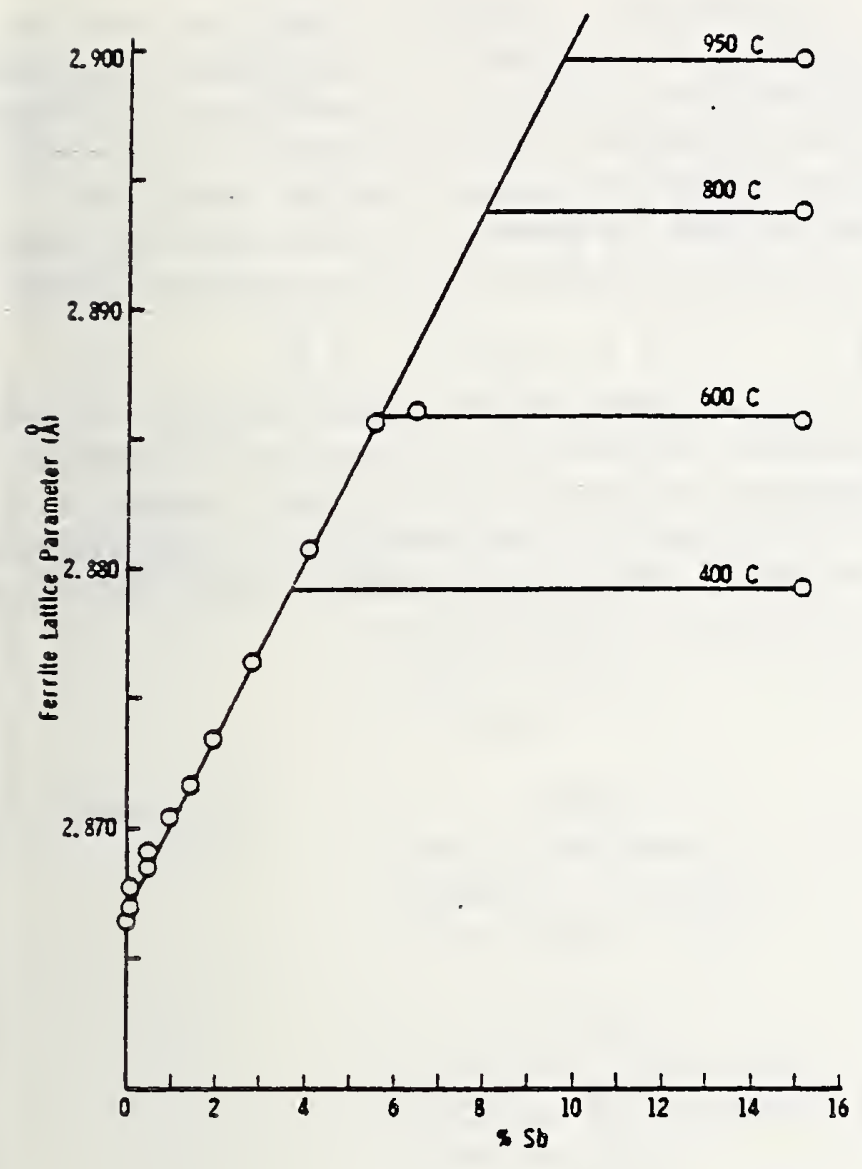

a. Fe-Sb binary alloys.

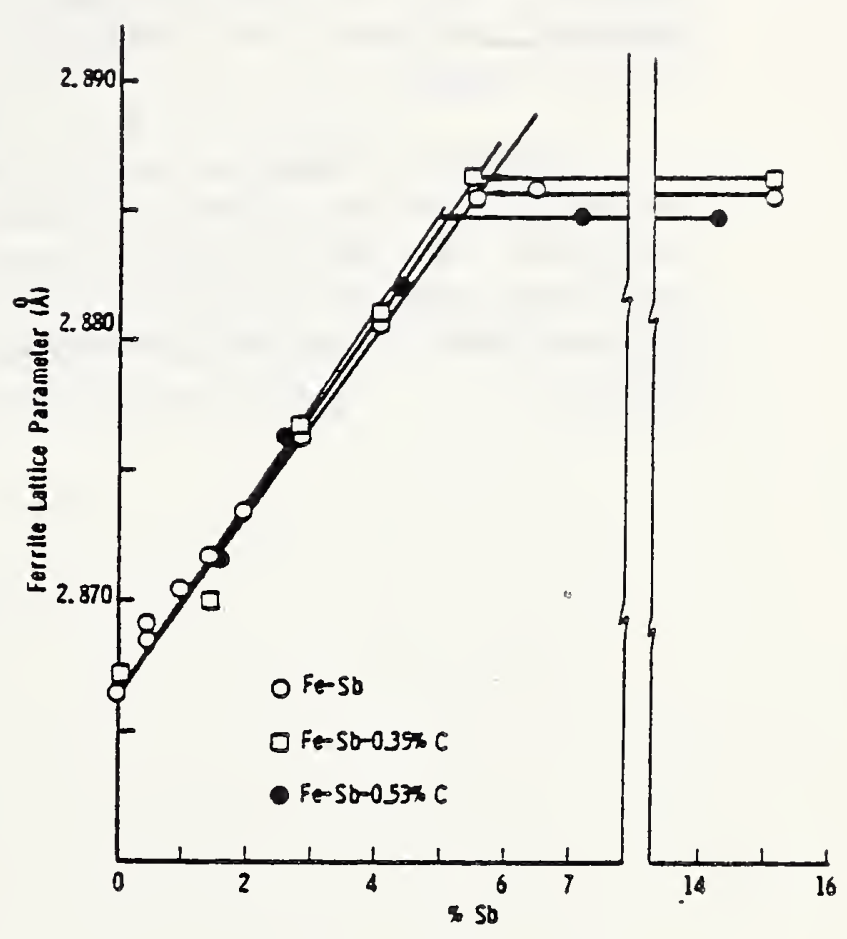

b. Fe-Sb and Fe-Sb-C alloys.

FIGURE 6. Ferrite Lattice Parameter as a Function of Antimony Concentration Alloys were Annealed at $600 \mathrm{C}$ Unless Otherwise Indicated

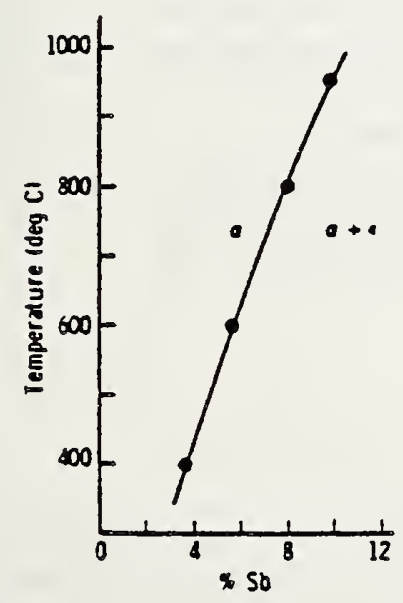

FIGURE 7. The Iron-Rich End of the Iron-Antimony Binary Phase Diagram Based Upon Present Results, Showing the a-Solvus 
undesirable for the application. It turned out, however, that the ferrite could be reduced only to an irreduceable limit before the hardening temperature became so high as to create a distortion problem. A qualitative probe analysis indicated no significant alloy transfer to the ferrite for normal hardening times and the relatively low amount of delta ferrite could be ignored. This is a very simple example but, in general, phase amounts and compositions would be invaluable in the investigation of the general class of tool steels.

The above examples are typical of the needs of the metallurgist in his investigations of alloys for the important information contained in phase diagrams. Any help that the metallurgist can get in this area whether it be a data bank of available (readily retrievable) information or approximate computational diagrams (generally for multicomponent systems) would be welcome. 


\section{PANEL I I I \\ MATERIALS PROCESSI II G}

Moderator:

Wm. Rostoker

Department of Materials Engineering University of Illinois

Chicago, IL

Panel Members: E. R. Kreidler

Lamp Business Division

General Electric

Cleveland, $\mathrm{OH}$

R. MC NaIIy

Ceramics Research

Corning Glass Works

Corning, NY

L. Mondolfo

Consultant

Clinton, NY

S. Prochazka

Ceramics Branch

Physical Chemistry Laboratory

General Electric

Schenectady, NY

G. R. Speich

Research Laboratory

U. S. SteeI

Monroeville, PA

The members of this panel have provided abstracts of their introcuctony statements (pp $162-168$ ). 


\title{
PANEL DISCUSSION - MATERIALS PROCESSING
}

\author{
Eric R. Kreidler \\ LIGHTING RESEARCH AND \\ TECHNICAL SERV ICES OPERATION \\ Lamp Materials Research Lab \#1361 \\ General Electric Company \\ Cleveland, Ohio
}

The kinds of phase equilibrium data useful in the sythesis of luminescent materials (phosphors) and thermionic emission materials will be discussed. Although specific and perhaps unusual examples are used, similar questions and needs arise in the preparation of many electronically active materials.

Most phosphors consist of a dilute solution of optically active ions (activators) in an optically inactive host material. The green luminescent material, zinc orthosilicate $\left(\mathrm{Zn}_{2} \mathrm{Mn}_{\mathrm{N}} \mathrm{SiO}_{4}\right)_{3}$ in which $\sim 1.0$ atomic percent of the zinc ions are replaced by $\mathrm{Mnn}^{4}$ activator ions, is a typical example. The optical properties of phosphors are determined by the nature and concentration of activators and by the nature of the host material. In synthesizing phosphors, phase equilibrium data are often used to determine expected solubility limits of activators and to establish sythesis conditions over which the host material is stable. Examples will be given of these uses. Some phosphors require processing in special oxidizing or reducing atmospheres to obtain the activator ions in the desired oxidation state. Although phase equilibrium data, useful for specifying these atmospheres, seldom exist, the practical advantages of having such data will be indicated.

Thermionic emission materials are used to coat the cathodes in discharge lamps. Their purpose is to enhance electron emission by lowering the energy barrier to emission (i.e. the work function). Confusion often exists about the identity and relative importance of the phases present in these mixtures. An example of how phase equilibrium studies were used to eliminate such confusion will be presented. 
Equilibrium Diagrams in Non Ferrous Alloys

\author{
by L. F. Mondolfo \\ Consultant \\ RD \# 1, Clinton, NY 13323
}

Equilibrium diagrams are the plot of the structure of the alloys; trying to work without them is the same as taking a trip through unknown country without a map. It can be done, but the chances of taking a wrong turn and having to backtrack are $100 \%$.

A few examples will show what can be done with equilibrium diagrams in the non-ferrous industry. In the continuous casting of brasses, when changing from a $80 \% \mathrm{Cu}, 20 \% \mathrm{Zn}$ to a $70 / 30$, the pouring temperature has to be 10 ered some $50^{\circ} \mathrm{C}$, but the speed of descent and the amount of cooling water used remain the same. When changing from a $70 / 30$ to a $60 / 40$, only a few degrees lowering of the pouring temperature is required, but if both the speed of descent and the amount of cooling water are not reduced, one ends either with a split ingot or a spill-out. As can be seen in the equilibrium diagram, both the $80 / 20$ and $70 / 30$ in the solid state are composed mainly of ductile $\alpha$ phase, whereas the $60 / 40$ is mainly $\beta$ phase, less ductile (and more sensitive to impurities), which must be cooled more slowly.

In the welding of high strength AlznMg alloys the amount of copper present has a decided effect. In Cu-free alloys there is a strong tendency for cracking in the weld zone, in Cu-bearing alloys there is less cracking and concentrated in the zone near the weld. From the AlCuMgzn diagram it can be seen that the Cu-free alloys are within the solid solubility limits and contain little or no eutectic to feed the shrinkage at the end of solidification. Shrinkage cracks are formed. The Cu-bearing alloys contain a low melting eutectic that feeds the shrinkage and elimiates shrinkage cracks. However in the zone adjacent to the weld, extensive eutectic melting takes place and cracking concentrates in this deteriorated zone.

Similar examples are the $\mathrm{Mg}$ base alloys that contain $\mathrm{Al}$ and $\mathrm{Zn}$. They are in the solid solution range and therefore have very poor castability. A look at the MgSi diagram suggests a possible remedy: the addition of $0.25-0.50 \% \mathrm{Si}$ to the alloys provides a large amount of eutectic, which gives an excellent castability. 
In the zone refining of Al the binary diagrams predict that $\mathrm{Cu}, \mathrm{Mg}, \mathrm{Si}$, Zn, whose eutectic composition is far from the solid solubility limit, can be moved to the end fairly rapidly and easily, whereas $\mathrm{Mn}$, which has a eutectic composition very close to the solubility limit, will move extremely slowly. Cr, Ti, V, Zr, which undergo peritectic reactions with Al, will move backwards to the starting end. Experimental results confirm the predictions.

The addition of $\mathrm{Mg}$ to $\mathrm{Zn}$ die casting alloys to neutralize $\mathrm{Pb}$; the choice of the heat treatment temperature of AICuMg alloys, as function of the Si content; Mn additions to AlMg alloys to improve corrosion resistance; additions of Co or Mn to AlSi alloys to correct for Fe; the Cr content of CuNi alloys that makes them heat treatable; additions of $\mathrm{Al}$ to $\mathrm{MnCu}$ alloys for high damping capacity are all examples of the use of equilibrium diagrams in non-ferrous alloys, that cannot be discussed for lack of time.

However there are serious difficulties in the use of equilibrium diagrams. For example there are some 20 different diagrams published. for the Alzn system, all presented by reliable investigators. Obviously only one can be correct, and not necessarily one of the 20 !

Another serious problem is that most alloys contain more than 2 elements, and often may contain as many as 8-10 elements. Reliance on binary diagrams may be grossly misleading, but the multicomponent diagrams are not available and, if available, difficult to read or interpret.

In recent years there has been relatively little work on the determination of equilibrium diagrams; most structural work has been concentrated on the intermetallic compounds, usually the ones in the middle of the diagram, where seldom one finds useful commercial alloys. The fault for this to some extent resides in the Universities. When somebody decreed that determination of an equilibrium diagram was not a fit subject for a PhD thesis, one of the major sources of useful diagrams dried up. Research on intermetallic compounds on the other hand survived: by bringing in thermodynamic and crystallographic relationships, fancy theoretical papers can be prepared with much less experimental work and effort and ingenuity needed for the accurate determination of a multicomponent diagram. 
The aluminum and magnesium industries, which where born in an era when metallurgy was becoming a science, are in a favorite position: many more diagrams are available for Al or Mg alloys than for older metals. However even in these industries there is need for more diagrams. The Concorde airplane uses a large amount of AlCuFeMgNiSi alloys yet the AlCuFeNi diagram, which is vital for the understanding of the alloys, is very poorly investigated and far from established. Those people who have the money to fly the Concorde should ask themselves "How does it feel to fly a plane whose equilibrium diagram is not known?" 
Phase Equilibria in the Development

of High Temperature Structural

Ceramics

\author{
Savante Prochazka \\ General Electric Research and Development \\ P. 0 . Box 8 \\ Schenectady, New York 12345
}

Oxidation resistance, low thermal expansion and low creep rates are first-approach criteria for the development of high-temperature engineering ceramics (temperatures $1300^{\circ} \mathrm{C}$ and above). Prime candidates are covalently bonded compounds, $\mathrm{SiC}, \mathrm{Si}_{3} \mathrm{~N}_{4}, \mathrm{Si}-\mathrm{Al}-\mathrm{O}-\mathrm{N}$ solid solutions and perhaps AlN, some transition metal borides and materials based on combinations of these compounds. Single phase ceramics are believed to offer the highest temperature capability, but the presence of some other specific phases is usually required for fabrication purposes and for microstructural control and control of related properties. All consolidation processes developed for these materials involve chemical reactions, additions and thermal treatments. Information on phase equilibria is essential for understanding fabrication processes, which are usually established empirically, and the behavior of the materials at high temperature and their interactions with the environments.

The types of chemical processes and equilibria which need to be understood in this field of ceramics may be grouped into the following categories.

A. Pure compound in equilibrium with its decomposition products:

$$
\begin{aligned}
\text { ex. } & \mathrm{SiC}_{(\mathrm{s})} \rightarrow \mathrm{C}_{(\mathrm{s})}+\mathrm{Si}_{(g)}+\mathrm{Si}_{2} \mathrm{C}_{(\mathrm{g})}+\mathrm{SiC}_{2}(\mathrm{~g})+\ldots \\
\mathrm{Si}_{3} \mathrm{~N}_{4} & \rightarrow \mathrm{N}_{2(\mathrm{~g})}+\mathrm{Si}_{(\mathrm{g})}+\mathrm{SiN}_{(\mathrm{g})}+\mathrm{Si}_{2} \mathrm{~N}_{(\mathrm{g})}+\ldots
\end{aligned}
$$


B. Stability of polymorphs and the effect of some species on phase transitions between polymorphs:

ex. $\beta-\operatorname{SiC} \rightarrow \alpha-\operatorname{SiC}$

effect of $\mathrm{N}_{2}, \mathrm{O}_{2}$, metals (Si) etc.

$\alpha-\mathrm{Si}_{3} \mathrm{~N}_{4} \rightarrow \mathrm{BSi}_{3} \mathrm{~N}_{4}$

effect of $\mathrm{O}_{2}$, metals (Si) etc.

C. Limits of nonstoichiometry in pure compounds.

D. Solubility limits in pure compounds of species used to promote sintering.

ex. $\mathrm{B}, \mathrm{Be}, \mathrm{Al}, \mathrm{La}$, in SiC

E. Phase relations, composition ranges and esp. solidus and liquidus temperatures in systems of interest:

$$
\begin{aligned}
\text { ex. } & \text { Si }-A I-N-O \\
& \text { Si }-M g-N-O \\
& \text { Si }-C-B \\
& S i-A I-C-N
\end{aligned}
$$

F. Phase relations in oxidation products:

$$
\text { ex. } \mathrm{Si}_{3} \mathrm{~N}_{4}+\mathrm{MgO} \rightarrow \mathrm{SiO}_{2}+\mathrm{Mg}_{2} \mathrm{SiO}_{4} \rightarrow 2 \mathrm{MgSiO}_{3}
$$

G. Interaction of the parent material and its oxidation products in the environment of combustion products containing $\mathrm{CO}, \mathrm{SO}_{2}, \mathrm{Na}_{2} \mathrm{O}, \mathrm{V}_{2} \mathrm{O}_{5}$ etc.

H. Interaction of nickel and cobalt based refractory alloys with the base material.

h of the information does not exist; its generation will be slow and will pire unconventional techniques. 
Application of Phase Diagrams in Processing of Low-Carbon Low-Alloy Steel

\author{
Gilbert Speich \\ tnited States Steel Research Laboratories \\ Monroeville, Pennisylvaria
}

Applications of phase diagrams in the processing of low-carbon low-alloy steels are generally concerned with the effect of rather small amounts of alloying elements on phase equilibria. There are principally two classes of alloying elements; minor alloying elements, such as $\mathrm{Cb}(\mathrm{Nb}), \mathrm{V}, \mathrm{B}, \mathrm{O}$, $A I, S$, and $N$, which are present in amounts of less than 0.1 percent; and major alloying elements, such as Si, Cr, Mn, Mo, and Ni, which are present in amounts between 0.2 and 2 percent. In the case of minor alloying elements, information on solubility products of various carbice, nitride, sulfide, boride, or oxide phases is important. For instance, in the case of $\mathrm{Cb}$ or $\mathrm{V}$, precipitation of $\mathrm{CbC}$ or $\mathrm{ViJ}(\mathrm{C})$ is an important strengthening mechanism and also serves to pin austenite grain boundaries and inhibit recrystallization. Therefore, information on the solubility product of $\mathrm{CbC}$ or $\mathrm{VN}(\mathrm{C})$ is important to specify $\mathrm{Cb}$ and $\mathrm{V}$ levels where precipitation can occur at or during cooling from hot-rolling temperatures. Another example is $S$, which is present as MnS in most plate steels. The ductility and toughness of plate steels is primarily controlled by the shape and amount of Mins inclusions. Ductility or toughness can be increased by decreasing the sulfur content or by adding rare-earth additions for shape control. Therefore, information on the Mins solubility product or on solubility products involving rare-earth oxysulfides is important.

In the case of major alloying elements, phase equilibria are of interest because of the possibility of using this information to predict their effect on austenite start and finish temperatures, on hardenability, or on martensite start and finish temperatures. However, because of the complexity of these phenomena in steels containing several alloying elements, and because of the large body of empirical information already available, the effect of these elements is still analyzed by use of empirical formulae. 
COMMENTS RELATED TO THE PANEL III TOPIC

This contribution is from an audience participant, not a panel

member. A paper on this COMMENT will appear in the proceedings.

Phase Diagram Information for Processing of Superconductors*

\author{
David Dew-Hughes \\ Brookhaven National Laboratory \\ Upton, New York 11973
}

The bronze process, in which filaments of niobium are drawn. down in a Cu-Sn bronze matrix and reacted to form the A-15 compound $\mathrm{Nb}_{3} \mathrm{Sn}$ is now an established route for high current density superconductor. The ease with which $\mathrm{Nb}_{3} \mathrm{Sn}, \mathrm{V}_{3} \mathrm{Ga}$ and $\mathrm{V}_{3} \mathrm{Si}$ can be produced by this technique has prompted attempts to similarly form the potentially superior $\mathrm{A}-15$ compounds $\mathrm{Nb}_{3} \mathrm{Al}, \mathrm{Nb}_{3} \mathrm{Ga}$ and $\mathrm{Nb}_{3} \mathrm{Ge}$. These efforts to date have been unsuccessful.

The superconducting properties of A-15 compounds are maximized in well-ordered, stoichiometric samples. The A-15 phase field in the Nb-Al, Nb-Ga and Nb-Ge systems does not include the stoichiometric composition. The presence of a stable $\sigma$ or c-related compound pushes the range of homogeneity of the A-15 compound to the Nb-rich side of the 3:I composition. A ternary A-15 compound forms close stoichiometry in the Nb-AI-Ge system, presumably because of a

*This work was performed under the auspices of the U.S. Energy Research and Development Administration. 
miscibility gap between $\mathrm{Nb}_{2} \mathrm{Al}$ and $\mathrm{Nb}_{5} \mathrm{Ge}_{3} \cdot \mathrm{A}$ similar situation also exists in the No-Al-si system. The existence of this miscibility gap may be related to the eutectic in the Al-Ge and Al-Si systems. If so, are there other ternary systems based on No which show a eutectic and a stoichiometric ternary A-15 compound? Phase diagram studies on No-based ternaries are needed to resolve this point.

In the bronze process, the presence of copper suppresses the formation of Sn-rich, Ga-rich or Si-rich phases in the production of $\mathrm{Nb}_{3} \mathrm{Sn}, \mathrm{V}_{3} \mathrm{Ga}$ and $\mathrm{V}_{3} \mathrm{Si}$ respectively. In attempts to make $\mathrm{Nb}_{3} \mathrm{Al}$, $\mathrm{Nb}_{3} \mathrm{Ga}$ and $\mathrm{Nb}_{3} \mathrm{Ge}$ by this process, the compounds $\mathrm{Nb}_{2} \mathrm{Al}, \mathrm{Nb}_{3} \mathrm{Ga}$ and $\mathrm{Nb}_{3} \mathrm{Ge}_{2}$ are preferentially formed. Is it possible, by adding a suitable fourth element, or by using some element other than copper as a matrix, to successfully produce the A-15 compounds? Phase diagram data on ternary and quaternary systems based on Nb and $\mathrm{Cu}$ are needed here, together with a better understanding of the factors which govern relative phase stability. 


$$
\begin{aligned}
& \text { WEDNESDAY, } 12 \text { JANUARY, } 1977 \\
& 2: 00 \text { PM - 3:30PM }
\end{aligned}
$$

USER NEEDS FOR

PHASE DIAGRAM INFORMATION

(CONTINUED)

PANEL IV

PRODUCT APPLICATIONS 


\section{PANEL I V}

PRODUCT APPLICATIONS

Moderator:

F. L. VerSnyder

Materials Engineering and Research

Pratt and Whitney Aircraft, U. T. C.

E. Hartford, CT

Panel Members:

C. Greskovich
Research and Development Center

General Electric Company

Schenectady, NY

R. I. Jaffee

Fossil Fuel \& Advance Systems Division

Electric Power Research Institute

Palo Alto, CA

B. H. Kear

Materials Engineering and Research Lab.

Pratt and Whitney Aircraft, U. T. C.

Middletown, CT

A. I. MIavsky

Senior Vice President of Technology

Tyco Laboratories, Inc.

Wal tham, MA

P. Slick

Bell Telephone Laboratories

Allentown, PA

The end use of materials in sophisticated applications is often influenced by an understanding of the subtle effects of phase equilibria. Thus, the panel is composed of members from industry so as to focus attention on phase diagrams from the viewpoint of the use of materials. The backgrounds of the panel members represent involvement with a broad spectrum of materials. The topic areas will include glasses, ceramics, electronic materials, aerospace (high temperature) materials, energy (nuclear) materials, as well as eutectics and others. Each of the panel members will give a brief informal presentation of production application where information on phase equilibria was of crucial importance to the success of a materials application or where such information will be a prerequisite for future success. Subsequently, the audience will be invited to participate from the floor. 


\title{
COMMENTS RELATED TO THE PANEL IV TOPIC
}

This contribution is from an audience participant, not a panel

member. A paper on this COMMENT will appear in the proceedings.

\section{THE APPLICATION OF THE PHASE DIAGRAM}

TO THERMA L ENERGY STORAGE TECHNOLOGY

\author{
Dr. J. E. Davison \\ University of Dayton Research Institute \\ Dayton, Ohio 45469 \\ and \\ Mr. Jerry E. Beam \\ United States Air Force Aeropropulsion Laboratory \\ Wright-Patterson Air Force Base, Ohio 45433
}

ABSTRACT: The application of phase diagramsto thermal energy storage is discussed. The properties of pure components, their melting points and enthalpies of fusion, are reviewed as a selection criteria for these applications. The performance of elemental components, inorganic oxides, and inorganic fluorides are compared. The application of information available in the temperature-constitution phase diagram to determine the type of liquid-solid transformation, the temperature and composition of the transformation, and a determination of the enthalpy of the transformation is presented. Specific needs for the development of phase diagrams for a thermal energy storage technology base will be presented.

(1) Aran archis 
THE NEEDS FOR PHASE EQUILIBRIA DATA IN THE DEVELOPMENT OF MAGNETOHYDRODYNAMICS

\section{R. A. Howald and I. El jezer}

Chemistry Department, Montana State University

Bozeman, Montana 59715

A major research program on thermodynamic properties and phase equilibria involving inorganic substances is needed for study of the uses of coal in magnetohydrodynamic power production.

Liquid or gaseous slag constituents, sulfur compounds and other inorganic materials dissolve protective oxide layers on alloys and have deteriorating effects on ceramic materials used in MHD channels and other components of the MHD power plant. These materials also affect the electrical conductivity of gases in the MHD energy converters and affect the emission of pollutants. A comprehensive study of the high temperature equitibria of the materials involved under the conditions of operation of MHD power generation is necessary. These include broad ranges of temperature, pressure and oxidation potential, i.e. 1000-2500 K, 1-20 bars excess oxygen, excess carbon, various moisture contents, etc. The number of constituents is large and the effects on the equipment and the effluent gases, liquids and solids are numerous and complex. The constituents include ions (e.g. $\mathrm{K}^{+}, \mathrm{OH}^{-}, \mathrm{e}^{-}, \mathrm{Na}^{+}, \mathrm{H}_{3} \mathrm{O}^{+}, \mathrm{SO}_{4}^{-}$, etc.) and related neutral species, gaseous and liquid coal slag components (e.g. $\mathrm{K}_{2} \mathrm{O}, \mathrm{MgO}$, $\mathrm{SiO}_{2}, \mathrm{AT}_{2} \mathrm{O}_{3}, \mathrm{FeO}$, etc.), sutphur compounds (e.g. $\mathrm{K}_{2} \mathrm{SO}_{4}, \mathrm{~K}_{2} \mathrm{~S}, \mathrm{SO}_{2}$, etc), refractory materials (e.g. $\mathrm{ZrO}_{2}, \mathrm{LaCrO}_{3}, \mathrm{Al}_{2} \mathrm{O}_{3}, \mathrm{SiO}_{2}$, etc.) along with the standard combustion gases. 
Since the addition of potassium seed compounds $\left(\mathrm{K}_{2} \mathrm{SO}_{4}, \mathrm{~K}_{2} \mathrm{CO}_{3}\right.$, etc. $)$ is necessary to achieve the necessary electrical conductivity in open cycle MHD the interactions between potassium oxide and various refractory oxides are particularly important. Coal slag has actually been used in operating MHD channels as a continually replaced protective coating over the electrodes. Thus the vapor pressures of potassium oxide over typical slag compositions are important. For economic reasons it will be necessary to recover and recycle most of the seed compound, presumably as $\mathrm{K}_{2} \mathrm{SO}_{4}$. In this connection additional phase equilibria data on solubilities of various oxides in liquid potassium sulfate are needed.

Similar data on cesium compounds are important in the engineering design of closed cycle MHD systems.

Large high temperature heat exchangers constitute one of the major capital expenses for MHD. Thus phase relations involved in the preparation and useful lifetime of high temperature ceramics should be known in detail.

To sum up, information on the phase relations of contacting phases, solid, liquid and gas, in a variety of MHD systems is vital both to establish the extent of interaction and to locate temperature and pressure regimes in which deleterious reactions will and will not occur.

Much of the above information is needed for gas turbine engine development as well as for MHD. 
WEDNESDAY, 12 JANUARY, 1977

$$
4: 00 P M-4: 30 P M
$$

SUMMARY OF THE WORKSHOP

$$
\text { BY }
$$

$J, F$, ELLIOTT

DEPT, OF MATERIALS SCIENCE AND ENGINEERING $M, I, T$,

CAMBRIDGE, MA 
Ageev, N. V., 46

Ageeva, D. L., 46

Aldinger, E., 51

Amman, P., 2C1(P)

Ansara, I., 51,110

Badie, T. M., 103

Bailey, D. M., '160

Balakrishna, S. S., 185

Bale, C. W., 165

Beam, J. E., 221 (C)

Bennett, L. H., 42, 69, 92, 112

Bilimoria, Y., 162

Blander, M., 169

Boreni, R., 67

Boyle, M. L., 130

Brebrick, R. F., 188

Brewer, L., 114 (P)

Brown, J. J., Jr., 72

Cameron, T. B., 104

Carter, F. L., 135

Carter, G. C., 42, 69, 92

Chang, L. L. Y., 56

Chang, Y. A., 60, 137

Chart, T. G., 184

Choudary, U. V., 69, 137

Cleek, G. W. 38,56

Cook, I. P., 38, 65, 91

Davison, J. E., 221 (P)

de Fontaine, D., 144 (P), 155, 157

Dew-Hughes, D., 218 (C)

Dreshfield, R. L., 114 (P) 115

Ehrenreich, H., 112

Eliezer, I., 140, 142, 222

Elliott, J.F.s 201 (P), 224

Evans, B. L. , 58

Fine, H. A., 84

Fisher, J. R., 146

Fivozinsky, S. P., 195

Flukiger, R., 85

Fopiano, P. J., 105, 202 (C)

Gaydukov, A. M., 182

Gaye, H., 144

Giessen, B. C., 114 (P), 118, 178

Glasser, F. P., 86

Goldstein, J. I., 95

Greskovich, C., 220(P)

Gribulya, V. B., 173, 176
Haas, J. L., JI., 146

Hasebe, M., 148

Henfg, E.-Th., 54, 152

Hilsenrath, J., 110

Howald, R. A., 140, 142, 222

Hsu, C. C., 171

Ivanov, 0. S., 182

Jackson, M. R., 88

Jaffee, R. I., 220 (P)

Johnson, J. R., 97

Jorda, J.-I., 85

Kagan, E. K., 74, 79

Kahan, D. J., 42, 69

Kaufman, L., 114 (P) , 153, 199

Kear, B. H., 220 (P)

Khanna, K. M., 107

Kikuchi, R., 155, 157

Kirsch, R. A., 110

Kiseleva, N. N., 173, 176

Kleppa, O. J., 114 (P)

Kolesnikova, T. P., 46

Kriedler, E. R., 94, $210(\mathrm{P}), 211$

Kubaschewski, 0., 160

Larson, H., 201 (P)

Ifvingston, J. D., 123

Lukas, H. L., 54, 152

Lupis, C. H. P., 144

Mallik, A. K., 185

McCormick, S., 162

McKinstry, H., 110

McNally, R., 210(P)

Merrill, L., 48

Mighel1, A., 67

Minor, D. B., 91

Miodownik, P. A., 164

Mlav sky, A. I., 220 (P)

Molino, B. B., 110

Mondolfo, L., $270(P), 212(P)$

Morral, J. E., 104

Myers, S. M:, 100

Nakamura, K., 98

Navrotsky, A., 114 (P), 119

Negas, T., 38, 56

Neumann, J. 3., 60

Nish1zawa, T., 148

Ond 1 k, H., 67 
Pearson, W. B., 125

Peilke, R. D., 201 (P)

Pelton, A. D., 165, 199

Petrova, I. A., 46

Petzow, G., 54

Prince, A., 122

Prochazka, S., 210(P), 215 (P)

Rairden, J. R., 88

Reilly, J. J., 97

Reno, R. C., 92

Rhines, F. N., 52

Romig, A. D., Jr., 95

Rosof, B. H., 167

Rostoker, W., 210 (P)

Roth, R. S., 38. 65

Saboungi, M.-I., 169, 171

Sandrock, G. D., 97

Savitskii, E. M., 173, 176

Scheuermann, C. M., 192

Selle, J. E., 193

Sherrood, G. B., 195

Shina, V. K., 108

slick, P., $220(\mathrm{P})$

Smith, J. F., 160

Smugeresky, J. E., 100
Sömiya, S., 98

Spear, K. E., 135

Speich, G. R., $210($ P) , 217 (P)

stalick, J., 67

Swartzendruber, L. J., 92, 110

Tarby, S. K., 130

Thompson, W. T., 165

Thumond, C. D., 39

Udovsky, A. I., 182

Tan Tyne, C. J., 130

Verkade, M. E., 58

VerSnyder, F. L., 220 (P)

Vo1, A. E., 74,79

Wachtman, J. W., 38

Wang, F. E., 101

Watson, R. E., 112

White, H. J., Jr., 124

White, W. B., 631

Zimerman, B., 152 


\section{Information Program for Phase Diagram Data Center Representatives}

An added day, Thursday 13 Jan 1977, was scheduled for informal interactions among data center representatives. To keep the group small enough that informal discussions were likely to result, all foreign center representatives were invited, but only a limited number of US center representatives. The program listed below, was highly successful, with ten data center particlpating, from France, Germany, the USSR, Canada, the U.K., and Japan (see listing below). Details of current data activities and future evaluation plans were described by each of these centers, laying the groundwork for future collaboration. Already some overlap of efforts in evaluations on the multicomponent systems of Be-based alloys has been avoided in this manner, and availability of ternary phase diagram bibliographies (U.K.) and unevaluated phase diagram Iiterature (USSR) has been clarified, facilitating tremendously, a major undertaking of a ternary phase diagram critical compendium (Germany).

\section{PROGRAM THURSDAY 13 JAN}

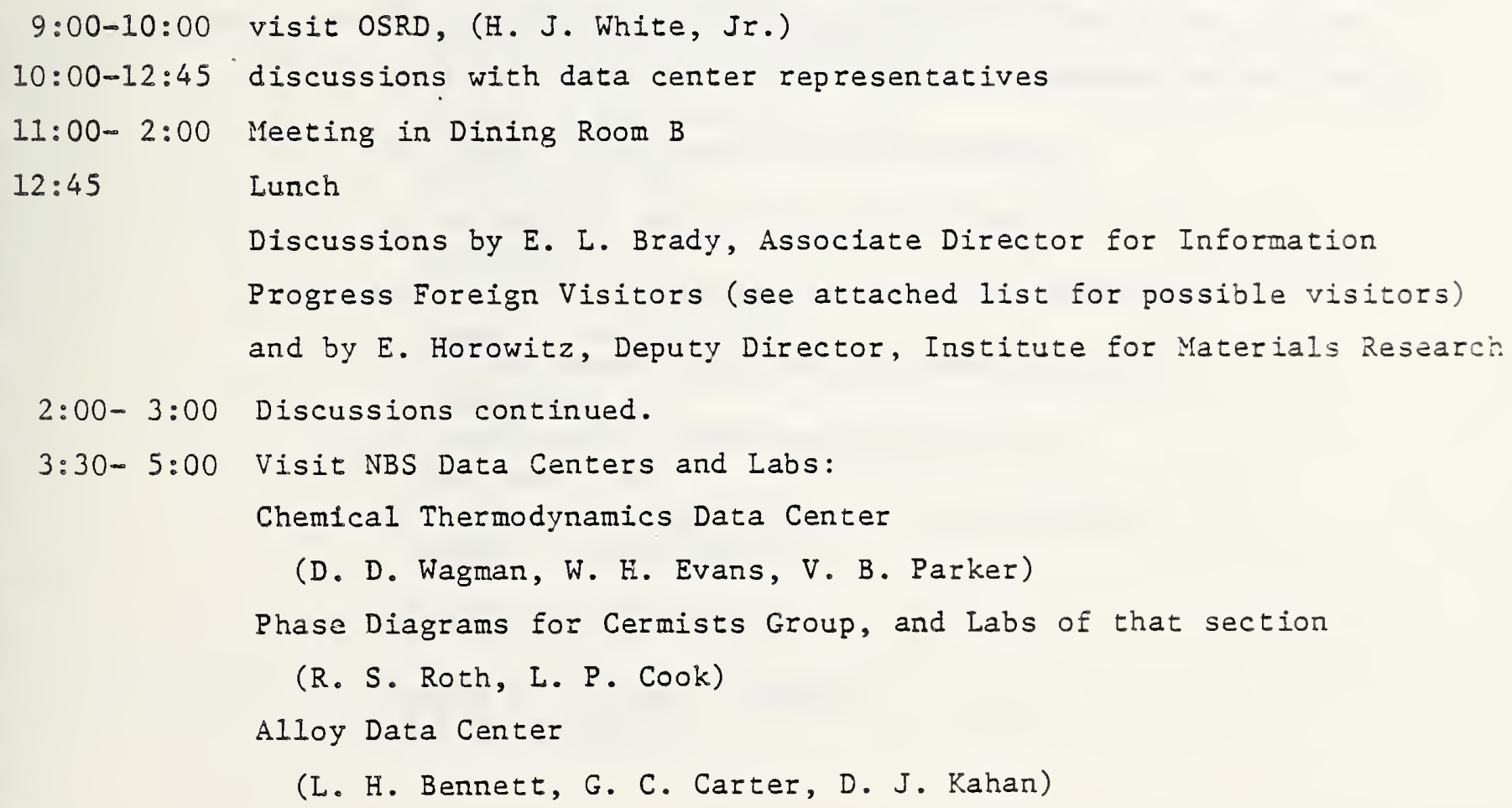




\section{Workshop Participants of Program, $13 \mathrm{Jan} 77$}

I. Ansara, Phase Diagram Data Center, Grenoble, France

Y. A. Chang, Ternary alloy evaluation group, U. Wisconsin

E. -Th. Henig and G. Petzow, Initiating a major ternary phase diagram evaluation program, Max-Planck Inst., Stuttgart, Germany

J. H. Westbrook, Director, Data Center and, Chaiman, CODATA Advisory panel, G. E. Schenectady

A. D. Pelton and W. T. Thompson, compilation and prediction of phase diagrams U. Montreal and MCGill U., Canada

A. D. Prince, compilation of ternary and higher order phase diagrams, Hirst Res. Cotr., G.E., U.K.

S. Sömiya, critical evaluation of ceramic phase diagrams, Tokyo Inst. of Tech., Japan

T. Kolesnikova, Institute for Scientific Information, USSR Academy of Sciences, Moscow, USSR

J. F. Smith, Ames Laboratory, representing 0. Kubaschewski, Thermodynamic Data Center, Aachen, Germany 
6. WORKSHOP ORGANIZING COMMITTEE

Members from NBS

L. H. Bennet, chairman

G. T. Armstrong, C. J. Bechtoldt, D. B. Butrymowicz, G. C. Carter, L. P. Cook, J. R. Cuthill, P. R. deBruyn, D. J. Kahan,

M. B. McNeil, R. I. Parker, R. M.

Waterstrat, H. J. White

Members from other Organizations

N. Ault, Norton Co., Worcester, MA

J. Elliott, M.I.T., Cambridge, MA

S. G. Epstein, Aluminum Association, New York, NY

I. Kaufman, Manlabs, Cambridge, MA

R. Laudise, Bell Telephone Laboratories, Nurray Hill, NJ

J. D. Ilvingston, General Electric, Schenectady, $\mathrm{N} Y$

E. S. Osborne, Carnegie Geophysical Lab. Washington, DC

E. C. Van Reuth, Defense Advanced Res. Projects Agency, Arlingtor, VA

Schrade F. Radtke, Intl. Lead-Zinc Research Organization, New York, NY

R. Reynik, National Science Foundation, Washington, DC

E. Salkovitz, Office of Navill Research, Arlington, VA

L. M. Schetky, Intemational Copper Research Assoc., New York, NY

C. Scheuermann, NASA Lewis Research Center, Cleveland, $\mathrm{OH}$

M. Semchyshen, Climax Molybdenum Corp. Ann Arbor, MI

J. Swisher, Energy Research \& Development Admin., Washington, DC

ARRANGEMENTS COMMTTEE

Ronald B. Johnson, Chairman

Sara R. Torrence 


$$
-
$$


NBS-114A (REV. 7-73)

\begin{tabular}{|c|c|c|c|}
\hline $\begin{array}{l}\text { U.S. DEPT. OF COMM. } \\
\text { BIBLIOGRAPHIC DATA } \\
\text { SHEET }\end{array}$ & 1. PUBLICATION OR REPORT NO. & $\begin{array}{l}\text { 2. Gov't Accession } \\
\text { No. }\end{array}$ & 3. Recipient's Accession No. \\
\hline \multirow{2}{*}{\multicolumn{3}{|c|}{$\begin{array}{l}\text { 4. TITLE AND SUBTITLE } \\
\text { Workshop on Applications of Phase Diagrams in Metallurgy } \\
\text { and Ceramics }\end{array}$}} & 5. Publication Date \\
\hline & & & 6. Performing Organization Code \\
\hline \multicolumn{3}{|c|}{$\begin{array}{l}\text { 7. AUTHOR(S) } \\
\text { L. H. Bennett and G. C. Carter }\end{array}$} & 8. Performing Organ. Report No. \\
\hline \multirow{2}{*}{\multicolumn{3}{|c|}{$\begin{array}{l}\text { 9. PERFORMING ORGANIZATION NAME AND ADDRESS } \\
\text { NATIONAL BUREAU OF STANDARDS } \\
\text { DEPARTMENT OF COMMERCE } \\
\text { WASHINGTON, D.C. } 20234\end{array}$}} & 10. Project/Task/Work Unit No. \\
\hline & & & 11. Contract/Grant No. \\
\hline \multirow{2}{*}{\multicolumn{3}{|c|}{$\begin{array}{l}\text { 12. Sponsoring Organization Name and Complete Address (Street, City, State, ZIP) } \\
\text { National Science Foundation, Defense Advanced Research Project } \\
\text { Agency, Office of Naval Research, National Aeronautics \& Space } \\
\text { Administration, Energy Research and Development Administration, } \\
\text { and U. S. Army Research Office }\end{array}$}} & $\begin{array}{l}\text { 13. Type of Report \& Period } \\
\text { Covered } \\
\text { Final }\end{array}$ \\
\hline & & & 14. Sponsoring Agency Code \\
\hline
\end{tabular}

16. ABSTRACT (A 200-word or less factual summary of most significant information. If document includes a significant bibliography or literature survey, mention it here.)

A workshop was held at the National Bureau of Standards, Gaithersburg, Md., January 10-12, 1977, to assess the current national and international status of phase diagram determinations and evaluations for alloys, ceramics and semiconductors; to determine the needs and priorities, especially technological, for phase diagram determinations and evaluations; and to estimate the resources being used and potentlally avallable for phase diagram evaluation. A one-day meeting was held following the workshop for the international data center representatives from France, Germany, Canada, the U.K., Japan, the USSR, and the USA, in a further attempt to assess currently on-going phase diagram data evaluation activities and to stimulate interaction and cooperation between these centers.

This report includes highlights of the workshop, description of a new poster board design used in the poster sessions, lists of attendees and demonstrations, the program, and descriptions of the presentations.

17. KEY WORDS (six to twelve entries; alphabetical order; capitalize only the first letter of the first key word unless a proper name; separated by semicolons) Computer predictions; Critical eyaluations; Data compllations; Industrial needs; Phase diagrams; Theory of phase diagrams; Thermodynamics.

18. AVAILABILITY X Unlimited

For Official Distribution. Do Not Release to NTIS

Order From Sup. of Doc., U.S. Government Printing Office Washington, D.C. 20402, SD Cat. No. C13

Order From National Technical Information Service (NTIS) Springfield, virginia 22151

\begin{tabular}{|l|l|}
\hline $\begin{array}{l}\text { 19. SECURITY CLASS } \\
\text { (THIS REPURT) }\end{array}$ & 21. NO. OF PAGES \\
UNCL ASSIFIED & 22. Price \\
\hline $\begin{array}{l}\text { 20. SECURITY CLASS } \\
\text { (THIS PAGE) } \\
\text { UNCLASSIFIED }\end{array}$ & \\
\hline
\end{tabular}



